\title{
Minimally invasive techniques in foregut surgery : natural orifice surgery for gastroesophageal reflux disease, esophageal high-grade dysplasia and superficial adenocarcinoma
}

Citation for published version (APA):

Witteman, B. P. L. (2013). Minimally invasive techniques in foregut surgery : natural orifice surgery for gastroesophageal reflux disease, esophageal high-grade dysplasia and superficial adenocarcinoma. [Doctoral Thesis, Maastricht University]. Datawyse / Universitaire Pers Maastricht. https://doi.org/10.26481/dis.20131121bw

Document status and date:

Published: 01/01/2013

DOI:

10.26481/dis.20131121bw

Document Version:

Publisher's PDF, also known as Version of record

Please check the document version of this publication:

- A submitted manuscript is the version of the article upon submission and before peer-review. There can be important differences between the submitted version and the official published version of record. People interested in the research are advised to contact the author for the final version of the publication, or visit the $\mathrm{DOI}$ to the publisher's website.

- The final author version and the galley proof are versions of the publication after peer review.

- The final published version features the final layout of the paper including the volume, issue and page numbers.

Link to publication

\footnotetext{
General rights rights.

- You may freely distribute the URL identifying the publication in the public portal. please follow below link for the End User Agreement:

www.umlib.nl/taverne-license

Take down policy

If you believe that this document breaches copyright please contact us at:

repository@maastrichtuniversity.nl

providing details and we will investigate your claim.
}

Copyright and moral rights for the publications made accessible in the public portal are retained by the authors and/or other copyright owners and it is a condition of accessing publications that users recognise and abide by the legal requirements associated with these

- Users may download and print one copy of any publication from the public portal for the purpose of private study or research.

- You may not further distribute the material or use it for any profit-making activity or commercial gain

If the publication is distributed under the terms of Article $25 \mathrm{fa}$ of the Dutch Copyright Act, indicated by the "Taverne" license above,

Download date: 26 Apr. 2023 


\section{Minimally Invasive Techniques in Foregut Surgery}

Natural Orifice Surgery for Gastroesophageal Reflux Disease, Esophageal High-Grade Dysplasia and Superficial Adenocarcinoma 


\section{Colofon}

ISBN 9789461592620

Cover design \& illustrations: Dana Hamers, Randal McKenzie

Press: Datawyse | Universitaire Pers Maastricht

De publicatie van dit proefschrift werd financieel ondersteund door: Chipsoft BV, Covidien Nederland BV, Erbe Nederland BV, FitForMe BV, Johnson \& Johnson Medical BV, Hodes Medische Speciaalzaken BV, Hoogland Medical BV, Krijnen Medical Innovations BV, Medicor BV, Profileringsfonds Academisch ziekenhuis Maastricht, Stichting Pelerin, Olympus Nederland BV, Richard Wolf BV, Stichting Rijnstate Vriendenfonds, Sigma Medical BV, Takeda Nederland BV, The Surgical Company BV.

Niets uit deze uitgave mag worden verveelvoudigd, opgeslagen in een geautomatiseerd gegevensbestand of openbaar gemaakt worden in enige vorm of op enige wijze, hetzij elektronisch, mechanisch of door fotokopieën, opname, of op enige andere manier, zonder voorafgaande schriftelijke toestemming van de auteur. Copyright @ 2013 B.P.L. Witteman, Maastricht 


\section{Minimally Invasive Techniques in Foregut Surgery}

Natural Orifice Surgery for Gastroesophageal Reflux Disease, Esophageal High-Grade Dysplasia and Superficial Adenocarcinoma

\section{PROEFSCHRIFT}

ter verkrijging van de graad van doctor

aan de Universiteit Maastricht, op gezag van de Rector Magnificus,

Prof. dr. L.L.G. Soete

volgens het besluit van het College van Decanen,

in het openbaar te verdedigen

op donderdag 21 november 2013 om 14.00 uur

door

Bart Pieter Laurens Witteman

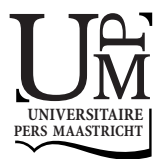




\section{Promotor}

Prof. dr. L.P.S. Stassen

\section{Copromotoren}

Dr. N.D. Bouvy

Dr. J.M. Conchillo

\section{Beoordelingscommissie}

Prof. dr. C.G.M.J. Baeten (voorzitter)

Prof. dr. M.A. Cuesta

Prof. dr. A.A.M. Masclee

Dr. C. Rosman

Dr. E.J. Spillenaar Bilgen 
Aan mijn ouders 



\section{Contents}

Chapter 1 General introduction, aim and outline of thesis 9

Chapter 2 Review of surgical and endoscopic techniques for treatment 21 of gastroesophageal reflux disease

Chapter 3 Transoral incisionless fundoplication for treatment of gastroesophageal reflux disease in clinical practice

Chapter 4 Randomized controlled trial of transoral incisionless fundoplication versus proton pump inhibitors for treatment of gastroesophageal reflux disease

Chapter 5 Revisional laparoscopic antireflux surgery after unsuccessful endoscopic fundoplication

Chapter 6 Minimally invasive esophagectomy

Chapter 7 Transoral endoscopic esophagectomy: Management of high grade dysplasia and superficial esophageal cancer with organ preservation

Chapter 8 General discussion and future perspectives

Appendices List of abbreviations

Summary

Samenvatting

List of publications and presentations

Dankwoord 



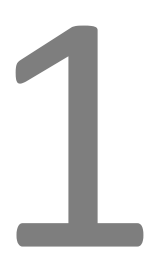

General introduction, aim and outline of thesis 
Chapter 1 


\section{GENERAL INTRODUCTION}

Minimally invasive surgery continues to evolve. The laparoscopic approach in abdominal surgery was introduced in the 1980's and caused a true surgical revolution. From then, abdominal surgery could be performed through only several small incisions in the abdominal wall, while visualization was provided by a video camera and television monitors. Although there was skepticism initially, the benefits of laparoscopy, as opposed to open surgery, have now become broadly acknowledged and confirmed in well-designed clinical trials. Today, laparoscopic surgery has become the standard approach for most intra-abdominal operations and as a result, the interest in minimally invasive surgical techniques has grown.

At the beginning of this century an even less invasive surgical approach has been introduced. Natural Orifice Surgery (NOS) is a new and exiting technique, whereby diagnostic and therapeutic procedures can be performed through a natural orifice with the avoidance of abdominal wall incisions., ${ }^{12}$ NOS refers to the entire field of surgical procedures performed through natural orifices and includes Natural Orifice Transluminal Endoscopic Surgery (NOTES). The 'T' in NOTES of 'Transluminal' represents NOS-procedures in which the abdominal cavity is entered through internal incisions in hollow organs.

Potential benefits of NOS to patients include the avoidance of all incisionrelated complications, such as wound infection, incisional hernias and scars. This is advantage is especially true for the increasing obese population. The minimally invasive technique may eventual proof to be associated with less pain, less immunosupression, lower anesthesia requirements, a faster recovery and thereby a shorter hospital stay. At the contrary the new technique will entail new potential risks, associated with lack of experience with new devices and procedures. Challenges will also include the reliable closure of internal incisions in case of transluminal approaches and the surgeon will need to get familiar with the orientation with a flexible, instead of a rigid laparoscope. Furthermore, it will be critical to prevent infections when accessing the peritoneal cavity through the stomach, rectum or vagina.

Experts in the field recognize the potential of NOS and are eagerly awaiting clinical trials to assess whether this emerging technology has real potential and may lead, after laparoscopy, to another surgical revolution. Implementation of NOS in routine clinical care should however be based on safety, efficacy and significant benefits over existing procedures. To provide a safe implementation of NOS in clinical practice, it would be argumentative to begin with the evaluation of the endoluminal instead of transluminal surgery, in order to avoid the complex and hazardous closure of visceral incisions. 


\section{Gastroesophageal reflux disease}

To some extent gastroesophageal reflux is a physiologic process and entails the ability to release abundant gas from the upper gastrointestinal tract. Gastroesophageal reflux disease (GERD) is a condition that develops when the reflux of the stomach contents causes troublesome symptoms and/or complications.3, 4 GERD has a comprehensive prevalence of up to $20 \%$ of the Western adult population. Typical symptoms include heartburn, regurgitation, belching and dysphagia. Esophageal complications of GERD are associated with mucosal injury and include esophagitis, stricture formation, Barrett's esophagus and esophageal cancer. ${ }^{5}$ The so-called 'atypical symptoms' of GERD are related to volume reflux and cause extra-esophageal complications of the disease, such as laryngitis, cough, asthma, and dental erosions.

Therapeutic options for GERD have been lifestyle changes, acid suppressive medication and laparoscopic surgery. Lifestyle changes include weight loss, smoking cessation and limiting meal size and alcohol consumption. Beside these lifestyle modifications, medical treatment with proton pump inhibitors (PPIs) is recommended for initial GERD-management and is effective in reduction of the distal esophageal acid exposure. ${ }^{6}$ Alkalization of the gastric contents improves reflux symptoms and allows esophagitis to heal. However, with PPIs the disease is not cured and the "volume reflux" is unaltered. Grounds for searching alternative therapies are based in insufficient symptom control, high medication costs and potential long-term health risks associated with the chronic use of PPIs.

In general, surgery is reserved for patients with esophageal or extraesophageal complications of reflux disease, while treatment with acid suppressive medications fails. ${ }^{7}$ In antireflux surgery (ARS) a defective reflux barrier is reconstructed and thereby the exposure of the distal esophagus to the gastric contents is diminished. Next to acidic reflux, also volume reflux is controlled and GERD is actually cured. Surgery has been shown equally effective in controlling GERDsymptoms compared to PPIs and obtains normalization of 24-hour $\mathrm{pH}$ monitoring in over $85 \%$ of patients. ARS has also been proven cost-effective over life-long proton pump inhibition. ${ }^{8}$

In spite of the excellent data on surgical GERD treatment, many clinicians are reluctant to refer for surgery, due to the invasiveness, concerns on durability and mostly, because of the feared fundoplication-related side effects, such as dysphagia and gas-bloating. To address these concerns NOS has taken its entry in the area of GERD-management. The ideal natural orifice approach would be non-invasive and easy to learn, to perform and to reproduce. It should be durable and eliminate all symptoms of GERD, without inducing the side effects of a surgical fundoplication. ${ }^{9}$ To date, the ideal NOS-procedure to cure GERD has not yet been established. Several procedures with different mechanisms of action have been developed of which many failed and have been abandoned. The endoluminal fundoplication techniques 
are most similar to the anatomic reconstruction of the gastroesophageal junction seen after surgery and therefore seem to have most potential.10-39

Transoral incisionless fundoplication (TIF) was introduced in 2006 and is currently under evaluation. It is performed with the use of the EsophyX $\mathrm{X}^{\mathrm{TM}}$-device and was designed to resemble elements of the surgical fundoplication. The technique enables the reduction of small hiatal hernia and the creation of a fullthickness partial fundoplication at the level of the gastroesophageal junction, entirely endoscopically.

In the event that GERD-induced esophagitis has resulted in Barrett's metaplasia at time of diagnosis, management involves three major components: treatment of the associated GERD, endoscopic surveillance to detect dysplasia and subsequently the treatment of the dysplasia. The normal esophagus is comprised of squamous mucosa unto the rugal folds of the stomach. Acid and bile exposure of the distal esophagus in GERD can lead to injury of the esophageal mucosa leading to esophagitis, metaplasia and subsequently to dysplasia and cancer.

Barrett's esophagus refers to esophageal metaplasia and was first described by the British surgeon Norman Barrett in 1950.40 The adaptation to chronic reflux causes the normal squamous epithelium lining to be replaced by columnar cells (columnarization) with subsequently acquisition of goblet cells (intestinalization) leading to intestinal metaplasia (Barrett's esophagus). Barrett's esophagus is diagnosed by both endoscopic and histological findings. First, a columnar-lined segment must be visible on endoscopy and second; biopsies of the segment must show goblet cells within cardiac mucosa. Because of the increased risk on the development of dysplasia and cancer in Barrett's metaplasia, it is considered a premalignant condition. ${ }^{41,42}$

The prevalence of GERD-induced esophageal adenocarcinoma has alarmingly risen, with a 6-fold increase from 3,8 to 22,3 cases per million between 1975 and 2001 in the United States. ${ }^{43}, 44$ When invasive esophageal malignancy is detected, esophageal resection with gastric conduit interposition is the standard treatment. The same applies to patients with high-grade dysplasia (HGD) in Barrett's esophagus, because an invasive component is found in $40 \%$ of patients at histological assessments after resection. ${ }^{45-47}$

Traditional open esophagectomy with gastric conduit substitution has been associated with significant morbidity and mortality rates. Minimally invasive esophagectomy was introduced in an attempt to lower these rates. Despite a significant reduction in mortality with the minimally invasive approach, esophagectomy is still an invasive procedure with substantial morbidity rates. ${ }^{48-50}$ As a result, there has been a driving force to move towards organ preservation in patients with HGD and intramucosal cancer in which lymph node involvement is unlikely. ${ }^{51-53}$

Endoscopic approaches, such as endoscopic mucosal resection and radiofrequency ablation have been introduced to remove the damaged parts of the esophageal inner lining. A significant limitation of the current techniques is the omitted, 
incomplete or inconsistent histological assessment of the entire affected luminal surface area. Therefore a lifelong surveillance and subsequent interventions for undetected synchronous or metachronous lesions is inevitable. ${ }^{54}, 55$ While endoscopic submucosal dissection, a considerable "more surgical" approach, provides larger specimens, this technique is highly operator dependent, limited by existing technology and has a high risk of perforation. ${ }^{56-58}$ Finally, with all techniques aimed at esophageal preservation there is a risk for stricture formation, particularly when resection involves the complete circumference, if ablation depth travels into the submucosal layer or if the defect is over $3 \mathrm{~cm}$ in length. ${ }^{59-61} \mathrm{In}$ an attempt to overcome these limitations, we designed a new natural orifice surgical approach, focused on obtaining an intact sleeve of the mucosa-submucosa complex over the entire length of the diseased esophagus. The technique is aimed to provide a less invasive substitute for esophagectomy in patients with HGD and T1a-stage esophageal cancer.

\section{AIM AND OUTLINE OF THE THESIS}

The general aim of this thesis was to review, describe, develop and research the natural orifice approach in foregut surgery for treatment of gastroesophageal reflux disease and related esophageal complications, such as esophageal high-grade dysplasia and esophageal adenocarcinoma.

In chapter 2 the history of antireflux surgery and present state of minimally invasive techniques in foregut surgery, including the laparoscopic and the endoluminal approach, are described after a review of literature.

The TIF-procedure was introduced after years of extensive pre-clinical research and designed to mimic antireflux surgery by means of a natural orifice approach. One of the first clinical TIF-procedures was performed at the Maastricht University Medical Center (MUMC) and after the first successful cases, a pilot cohort study to evaluate the feasibility, safety and effectiveness of the technique was initiated. Outcomes in a cohort of 38 chronic GERD-patients, who were referred for surgical GERD management were analyzed after a three-year follow-up and described in chapter 3 .

While the cohort study was recruiting, we prepared a randomized controlled clinical trial. Initially, the trial was intended to be sham-controlled, but this studydesign was viewed unethical by our Ethics Committee, due to the risks of general anesthesia combined with the risks of device introduction. The second best option for the randomized controlled trial was to compare the TIF-technique to the standard of care. As said, medical treatment with PPIs is recommended for initial management of GERD, while surgery is reserved in case of failure of drug therapy. If proven effective, TIF-procedure is thought to position in the spectrum of GERDmanagement in between pharmaceutical and surgical therapy with overlap to both sides. In a randomized controlled trial, we compared TIF to PPI-treatment in pa- 
tients, who were responsive to PPIs, but desired a more definitive solution for their GERD. In chapter 4 the results of the randomized controlled clinical trial are reported.

In the early experience, the TIF-procedure had various outcomes and in some early series, a substantial failure rate has been reported. In case of treatment failure, subsequent revisional laparoscopic antireflux surgery (rLARS) would be the obvious next step in an attempt to control reflux in these patients. However, revisional surgery could technically be more challenging, as a result of the altered anatomical situation around the gastroesophageal junction after endoscopic fundoplication and may lead to an increased rate of complications and/or suboptimal outcomes. In chapter $\mathbf{5}$ we focus on rLARS after unsuccessful endoscopic fundoplication and the results in terms of feasibility, safety and efficacy in subjective and objective reflux control are reported.

Esophagectomy is the primary therapy for resectable distal esophageal carcinoma without distant dissemination. Minimally invasive esophagectomy (MIE) is described in chapter 6. After a review of literature, the outcomes of MIE as opposed to open surgery, are reported and two laparoscopic approaches, each indicated for different stages of disease, are described in detail. Laparoscopic transhiatal inversion esophagectomy (LIE) with gastric substitution can be employed for treatment of end stage benign disease, early malignancy and the combined laparoscopic-thoracoscopic (two-cavity) approach with en bloc lymphadenectomy is indicated for treatment of resectable advanced locoregional disease. The chapter is intended to act as an introduction to chapter 7. Based on the principles of LIE, we designed a new NOS-technique, called transoral endoscopic esophagectomy (TEE) for treatment of HGD and superficial esophageal carcinoma. We report technical feasibility, procedural complications and determination of resection adequacy after ten TEE-procedures in a porcine model.

Finally, the main findings of this thesis and future perspectives are discussed in chapter 8. 


\section{REFERENCES}

1. ASGE/SAGES Working Group on Natural Orifice Translumenal Endoscopic Surgery White Paper October 2005. Gastrointest Endosc 2006;63:199-203.

2. Baron TH. Natural orifice transluminal endoscopic surgery. Br J Surg 2007;94:1-2.

3. Kahrilas PJ, Shaheen NJ, Vaezi MF. American Gastroenterological Association Institute technical review on the management of gastroesophageal reflux disease. Gastroenterology 2008;135:13921413,1413 e1-5.

4. Vakil N, van Zanten SV, Kahrilas P, Dent J, Jones R. The Montreal definition and classification of gastroesophageal reflux disease: a global evidence-based consensus. Am J Gastroenterol 2006;101:1900-20; quiz 1943.

5. Kahrilas PJ. Clinical practice. Gastroesophageal reflux disease. N Engl J Med 2008;359:1700-7.

6. Tamhankar AP, Peters JH, Portale G, Hsieh CC, Hagen JA, Bremner CG, DeMeester TR. Omeprazole does not reduce gastroesophageal reflux: new insights using multichannel intraluminal impedance technology. J Gastrointest Surg 2004;8:890-7; discussion 897-8.

7. Eubanks TR, Omelanczuk P, Richards C, Pohl D, Pellegrini CA. Outcomes of laparoscopic antireflux procedures. Am J Surg 2000;179:391-5.

8. Viljakka M, Nevalainen J, Isolauri J. Lifetime costs of surgical versus medical treatment of severe gastro-oesophageal reflux disease in Finland. Scand J Gastroenterol 1997;32:766-72.

9. Nieponice A, Jobe BA. Endoscopic fundoplication: real or fantasy? J Gastrointest Surg;15:1295-8.

10. von Renteln D, Schiefke I, Fuchs KH, Raczynski S, Philipper M, Breithaupt W, Caca K, Neuhaus H. Endoscopic full-thickness plication for the treatment of GERD by application of multiple Plicator implants: a multicenter study (with video). Gastrointest Endosc 2008;68:833-44.

11. Rothstein RI, Filipi CJ. Endoscopic suturing for gastroesophageal reflux disease: clinical outcome with the Bard EndoCinch. Gastrointestinal Endosc Clin N Am 2003;13:89-101.

12. Schiefke I, Zabel-Langhennig A, Neumann S, Feisthammel J, Moessner J, Caca K. Long term failure of endoscopic gastroplication (EndoCinch). Gut 2005;54:752-758.

13. Arts J, Lerut T, Rutgeerts P, Sifrim D, Janssens J, Tack J. A one-year follow-up study of endoluminal gastroplication (Endocinch) in GERD patients refractory to proton pump inhibitor therapy. Dig Dis Sci 2005;50:351-356.

14. Mahmood Z, McMahon BP, Arfin Q, Byrne PJ, Reynolds JV, Murphy EM, Weir DG. Endocinch therapy for gastro-oesophageal reflux disease: a one year prospective follow up. Gut 2003;52:34-39.

15. Domagk D, Menzel J, Seidel M, Ullerich H, Pohle T, Heinecke A, Domschke W, Kucharzik T. Endoluminal gastroplasty (EndoCinch) versus endoscopic polymer implantation (Enteryx) for treatment of gastroesophageal reflux disease: 6-month results of a prospective, randomized trial. Am J Gastroenterol 2006;101:422-30.

16. Swain P, Park PO, Mills T. Bard EndoCinch: the device, the technique, and pre-clinical studies. Gastrointest Endosc Clin N Am 2003;13:75-88.

17. Montgomery M, Hakanson B, Ljungqvist O, Ahlman B, Thorell A. Twelve months' follow-up after treatment with the EndoCinch endoscopic technique for gastro-oesophageal reflux disease: a randomized, placebo-controlled study. Scand J Gastroenterol 2006;41:1382-9.

18. Chuttani R, Kozarek R, Critchlow J, Lo S, Pleskow D, Brandwein S, Lembo T. A novel endoscopic full-thickness plicator for treatment of GERD: an animal model study. Gastrointest Endosc 2002;56:116-22.

19. Chuttani R. Endoscopic full-thickness plication: the device, technique, pre-clinical and early clinical experience. Gastrointest Endosc Clin N Am 2003;13:109-16, ix-X.

20. Chuttani R, Sud R, Sachdev G, Puri R, Kozarek R, Haber G, Pleskow D, Zaman M, Lembo A. A novel endoscopic full-thickness plicator for the treatment of GERD: A pilot study. Gastrointest Endosc 2003;58:770-6.

21. Pleskow D, Rothstein R, Lo S, Hawes R, Kozarek R, Haber G, Gostout C, Lembo A. Endoscopic fullthickness plication for the treatment of GERD: a multicenter trial. Gastrointest Endosc 2004;59:163-71. 
22. Pleskow D, Rothstein R, Lo S, Hawes R, Kozarek R, Haber G, Gostout C, Lembo A. Endoscopic fullthickness plication for the treatment of GERD: 12-month follow-up for the North American openlabel trial. Gastrointest Endosc 2005;61:643-649.

23. Rothstein R, Filipi C, Caca K, Pruitt R, Mergener K, Torquati A, Haber G, Chen Y, Chang K, Wong D, Deviere J, Pleskow D, Lightdale C, Ades A, Kozarek R, Richards W, Lembo A. Endoscopic fullthickness plication for the treatment of gastroesophageal reflux disease: a randomized, shamcontrolled trial. Gastroenterology 2006;131:704-712.

24. Caca K, Schiefke I, Fuchs K-H, Von Renteln D, Radczynski S, Philipper M, Breithaupt W, Neuhaus H. Endoscopic full-thickness plication for the treatment of GERD: 6 month data of the German multicenter serial implant trial. American Journal of Gastroenterology 2007;102:S127.

25. Pleskow D, Rothstein R, Kozarek R, Haber G, Gostout C, Lembo A. Endoscopic full-thickness plication for the treatment of GERD: long-term multicenter results. Surg Endosc 2007;21:439-44.

26. Rothstein RI, Filipi C, Caca K, Pruitt R, Mergener K, Torquati A, Haber G, Chang K, Wong D, Deviere J, Pleskow D, Lightdale C, Ades A, Kozarek R, Richards W, Lembo A. Endoscopic full-thickness plication for the treatment of GERD: 12 month follow-up in the sham-controlled trial. American Journal of Gastroenterology 2007;102:S152.

27. von Renteln D, Brey U, Riecken B, Caca K. Endoscopic full-thickness plication with two serially placed implants improves esophagitis, GERD symptoms and reduces PPI use and esophageal acid exposure. American Journal of Gastroenterology 2007;102:S127.

28. Pleskow D, Rothstein R, Kozarek R, Haber G, Gostout C, Lo S, Hawes R, Lembo A. Endoscopic fullthickness plication for the treatment of GERD: Five-year long-term multicenter results. Surg Endosc 2008;22:326-32.

29. von Renteln D, Brey U, Riecken B, Caca K. Endoscopic full-thickness plication (Plicator) with two serially placed implants improves esophagitis and reduces PPI use and esophageal acid exposure. Endoscopy 2008;40:173-8.

30. Cadiere GB, Rajan A, Rqibate M, Germay O, Dapri G, Himpens J, Gawlicka AK. Endoluminal fundoplication (ELF) - evolution of EsophyX ${ }^{\mathrm{TM}}$, a new surgical device for transoral surgery. Minim Invasive Ther Allied Technol 2006;15:348-355.

31. Cadiere GB, Buset M, Muls V, Rajan A, Rosch T, Eckardt AJ, Weerts J, Bastens B, Costamagna G, Marchese M, Louis H, Mana F, Sermon F, Gawlicka AK, Daniel MA, Deviere J. Antireflux Transoral Incisionless Fundoplication Using EsophyX: 12-Month Results of a Prospective Multicenter Study. World J Surg 2008.

32. Cadiere GB, Rajan A, Germay O, Himpens J. Endoluminal fundoplication by a transoral device for the treatment of GERD: A feasibility study. Surg Endosc 2008;22:333-42.

33. Dapri G, Rajan A, Himpens J, Cadiere GB. Transoral incisionless fundoplication: results at 2 years. Gastrointest Endosc 2008;67:AB138.

34. Jobe BA, O'Rourke RW, McMahon BP, Gravesen F, Lorenzo C, Hunter JG, Bronner M, Kraemer SJ. Transoral endoscopic fundoplication in the treatment of gastroesophageal reflux disease: the anatomic and physiologic basis for reconstruction of the esophagogastric junction using a novel device. Ann Surg 2008;248:69-76.

35. Demyttenaere SV, Bergman S, Pham T, Anderson J, Dettorre R, Melvin WS, Mikami DJ. Transoral incisionless fundoplication for gastroesophageal reflux disease in an unselected patient population. Surg Endosc 2009.

36. Testoni PA, Vailati C. Transoral incisionless fundoplication with EsophyX(R) for treatment of gastro-oesphageal reflux disease. Dig Liver Dis;44:631-5.

37. Bell RC, Cadiere GB. Transoral rotational esophagogastric fundoplication: technical, anatomical, and safety considerations. Surg Endosc;25:2387-99.

38. Bell RC, Freeman KD. Clinical and pH-metric outcomes of transoral esophagogastric fundoplication for the treatment of gastroesophageal reflux disease. Surg Endosc;25:1975-84.

39. Hoppo T, Immanuel A, Schuchert M, Dubrava Z, Smith A, Nottle P, Watson DI, Jobe BA. Transoral incisionless fundoplication 2.0 procedure using EsophyX for gastroesophageal reflux disease. J Gastrointest Surg;14:1895-901.

40. Barrett NR. Chronic peptic ulcer of the oesophagus and 'oesophagitis'. Br J Surg 1950;38:175-82. 
41. Chang EY, Morris CD, Seltman AK, O'Rourke RW, Chan BK, Hunter JG, Jobe BA. The effect of antireflux surgery on esophageal carcinogenesis in patients with barrett esophagus: a systematic review. Ann Surg 2007;246:11-21.

42. Parrilla P, Martinez de Haro LF, Ortiz A, Munitiz V, Molina J, Bermejo J, Canteras M. Long-term results of a randomized prospective study comparing medical and surgical treatment of Barrett's esophagus. Ann Surg 2003;237:291-8.

43. Shaheen NJ, Crosby MA, Bozymski EM, Sandler RS. Is there publication bias in the reporting of cancer risk in Barrett's esophagus? Gastroenterology 2000;119:333-8.

44. Pohl H, Welch HG. The role of overdiagnosis and reclassification in the marked increase of esophageal adenocarcinoma incidence. J Natl Cancer Inst 2005;97:142-6.

45. Konda VJ, Ross AS, Ferguson MK, Hart JA, Lin S, Naylor K, Noffsinger A, Posner MC, Dye C, Cislo B, Stearns L, Waxman I. Is the risk of concomitant invasive esophageal cancer in high-grade dysplasia in Barrett's esophagus overestimated? Clin Gastroenterol Hepatol 2008;6:159-64.

46. Collard JM. High-grade dysplasia in Barrett's esophagus. The case for esophagectomy. Chest Surg Clin N Am 2002;12:77-92.

47. Reed MF, Tolis G, Jr., Edil BH, Allan JS, Donahue DM, Gaissert HA, Moncure AC, Wain JC, Wright CD, Mathisen DJ. Surgical treatment of esophageal high-grade dysplasia. Ann Thorac Surg 2005;79:1110-5; discussion 1110-5.

48. Thomas P, Doddoli C, Neville P, Pons J, Lienne P, Giudicelli R, Giovannini M, Seitz JF, Fuentes P. Esophageal cancer resection in the elderly. Eur J Cardiothorac Surg 1996;10:941-6.

49. Ell C, May A, Pech O, Gossner L, Guenter E, Behrens A, Nachbar L, Huijsmans J, Vieth M, Stolte M. Curative endoscopic resection of early esophageal adenocarcinomas (Barrett's cancer). Gastrointest Endosc 2007;65:3-10.

50. Holscher AH, Bollschweiler E, Schneider PM, Siewert JR. Early adenocarcinoma in Barrett's oesophagus. Br J Surg 1997;84:1470-3.

51. Oh DS, Hagen JA, Chandrasoma PT, Dunst CM, Demeester SR, Alavi M, Bremner CG, Lipham J, Rizzetto C, Cote R, Demeester TR. Clinical biology and surgical therapy of intramucosal adenocarcinoma of the esophagus. J Am Coll Surg 2006;203:152-61.

52. Rice TW, Zuccaro G, Jr., Adelstein DJ, Rybicki LA, Blackstone EH, Goldblum JR. Esophageal carcinoma: depth of tumor invasion is predictive of regional lymph node status. Ann Thorac Surg 1998;65:787-92.

53. Rice TW, Blackstone EH, Adelstein DJ, Zuccaro G, Jr., Vargo JJ, Goldblum JR, Murthy SC, DeCamp MM, Rybicki LA. Role of clinically determined depth of tumor invasion in the treatment of esophageal carcinoma. J Thorac Cardiovasc Surg 2003;125:1091-102.

54. Farrell JJ, Lauwers GY, Brugge WR. Endoscopic mucosal resection using a cap-fitted endoscope improves tissue resection and pathology interpretation: an animal study. Gastric Cancer 2006;9:38.

55. Ahmadi A, Draganov P. Endoscopic mucosal resection in the upper gastrointestinal tract. World J Gastroenterol 2008;14:1984-9.

56. Kakushima N, Yahagi N, Fujishiro M, Kodashima S, Nakamura M, Omata M. Efficacy and safety of endoscopic submucosal dissection for tumors of the esophagogastric junction. Endoscopy 2006;38:170-4.

57. Yoshinaga S, Gotoda T, Kusano C, Oda I, Nakamura K, Takayanagi R. Clinical impact of endoscopic submucosal dissection for superficial adenocarcinoma located at the esophagogastric junction. Gastrointest Endosc 2008;67:202-9.

58. Oyama T, Tomori A, Hotta K, Morita S, Kominato K, Tanaka M, Miyata Y. Endoscopic submucosal dissection of early esophageal cancer. Clin Gastroenterol Hepatol 2005;3:S67-70.

59. Kamler JP, Borsatto R, Binmoeller KF. Circumferential endoscopic mucosal resection in the swine esophagus assisted by a cap attachment. Gastrointest Endosc 2002;55:923-8.

60. Katada C, Muto M, Manabe T, Boku N, Ohtsu A, Yoshida S. Esophageal stenosis after endoscopic mucosal resection of superficial esophageal lesions. Gastrointest Endosc 2003;57:165-9. 
61. Conio M, Sorbi D, Batts KP, Gostout CJ. Endoscopic circumferential esophageal mucosectomy in a porcine model: an assessment of technical feasibility, safety, and outcome. Endoscopy 2001;33:791-4. 



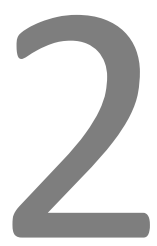

Review of surgical and endoscopic techniques for treatment of gastroesophageal reflux disease 


\section{ABSTRACT}

Gastroesophageal reflux disease (GERD) is defined as a condition that develops when the reflux of stomach contents causes troublesome symptoms and/or complications. Therapeutic options have been lifestyle changes, antisecretory medication and surgery. Medical management with proton pump inhibition was shown highly effective in controlling distal esophageal acid exposure, however, the disease is not cured and patients require a lifelong commitment to drug-therapy. Grounds for searching alternatives are based in inadequate symptom control, high medication costs and potential risks or side effects. The alternative to medical treatment has been surgery. Laparoscopic Nissen fundoplication was shown largely effective and has become the "gold standard". Recently, the partial posterior (Toupet) fundoplication has gained popularity as it is associated with less side effects compared to the complete fundoplication while providing equal reflux control. New in this field are the endoscopic techniques, introduced as a less invasive alternative to laparoscopic antireflux operations. Attempts have been made to develop safe, effective, and durable endoscopic procedures to treat GERD. Techniques include radiofrequency ablation, injection therapy, and suturing/stapling techniques. Of these, the latter are most similar to the anatomic restructuring of the gastroesophageal junction provided by surgical fundoplication. While early attempts at endoluminal suturing have been disappointing, significant advances in instrumentation, a more complete understanding of the gastroesophageal junction anatomy, and improvements in the technical skills of the endoscopic surgeon have been realized. As a result, techniques now being tested, such as the endoluminal fundoplication, may prove to be more effective and durable than previous endoscopic antireflux procedures.

Published as:

Laparoscopic antireflux procedures. Witteman BPL and Jobe BA. On invitation of UpToDate, Waltham, MA, 2013

The laparoscopic approach to paraesophageal hernia repair. Nason KS, Levy R, Witteman BPL, Luketich JD. J Gastrointest Surg. 2012 Feb;16(2):417-26.

Will skepticism stop the evolution of endoscopic GERD treatment? Witteman BPL, Bouvy ND, Koek GH. Eur J Gastroenterol Hepatol. 2009 Oct; 21(10):1222-4

Endoscopic therapies for treatment of reflux disease. Nason KS, Schuchert MJ, Witteman BPL, Jobe BA. The Semin Thorac Cardiovasc Surg. 2008; 20(4):320-5 


\section{INTRODUCTION}

Gastroesophageal reflux disease (GERD) has a prevalence of 10-20\% in Western Europe and North America and is defined in the Montreal consensus as a condition that develops when the reflux of stomach contents causes troublesome symptoms and/or complications. ${ }^{1}$ Typical symptoms include heartburn, regurgitation, belching and dysphagia. Esophageal complications of GERD are associated with mucosal injury and include esophagitis, stricture formation, Barrett's esophagus and esophageal cancer. The so-called 'atypical symptoms' are related to extraesophageal complications of the disease, such as laryngitis, cough, asthma and dental erosions.

Therapeutic options for GERD have been lifestyle modifications, antisecretory medication and surgery. Lifestyle modification can improve GERD symptoms by means of dietary changes, sleeping with the upper body raised and weight loss.

To date, medical management with proton pump inhibitor (PPI) therapy is the initial choice and was shown highly effective in controlling gastric acid secretion. Among GERD patients $70-80 \%$ is asymptomatic on PPIs during their whole life or at least for a long period of time. ${ }^{2}$ However, with PPIs the disease is not cured and patients require a lifelong commitment to the drugs. Grounds for searching alternatives are based in inadequate symptom control, high medication costs and potential risks or side effects. Recent studies have raised concerns about the long-term health problems associated with chronic PPI use, including an increased risk of enteric infections, pneumonia and osteoporosis in women caused by a decreased calcium absorption. . $^{3-7}$

The alternative to drug treatment has been antireflux surgery (ARS). ARS restores the barrier to reflux and eliminates the exposure of the esophagus to gastroduodenal contents. Over the past two decades, laparoscopic Nissen fundoplication (LNF) was shown largely effective and has become the "gold standard" to which all other antireflux procedures are now compared. Unfortunately, the suggestion has been made that laparoscopic antireflux procedures may be less durable than originally anticipated, particularly when performed by low-volume surgeons. ${ }^{8}$ But more importantly, it remains an invasive procedure with bothersome side effects, such as dysphagia, gas bloating and excessive flatulence, that can highly impact a patient's quality of life. ${ }^{9}$ Surgery has therefore produced reluctance among primary physicians and gastroenterologists to refer patients for surgical GERD management. ${ }^{10,11}$ In view of the downsides of current treatment-modalities, a less invasive endoscopic therapy is appealing. It is likely that many patients would prefer an endoscopic procedure, if safe and effective, to the alternative of lifelong antireflux medications or to more invasive surgery.

In this chapter the abnormal anatomy of the gastroesophageal junction (GEJ) in patients with GERD is described, the data regarding antireflux surgery and endoscopic therapies are reviewed and, finally, the pitfalls and problems encoun- 
tered in performing and researching endoscopic antireflux procedures are discussed.

\section{PATHOPHYSIOLOGY}

Patients with GERD experience excessive exposure of the esophagus to gastroduodenal secretions. This may be the result of inadequate esophageal clearance secondary to disordered or inadequate esophageal motility (including increased transient Lower Esophageal Sphincter Relaxations, tLESR's), impaired barrier function at the gastroesophageal junction and/or poor gastric emptying. ${ }^{12}$ The surgical perspective on the pathophysiology underlying the disease is centered on failure of the antireflux barrier at the gastroesophageal junction, which is an anatomically and physiologically complex entity, vulnerable to several potential mechanisms of reflux. Anatomical components of the gastroesophageal junction that play a role in the pathophysiology of reflux disease include:

- The intrinsic sphincter (the high pressure zone of the lower esophageal sphincter)

- Gastroesophageal valve (formed by the clasp fiber complex and musculomucosal fold in the angle of His)

- $\quad$ The extrinsic sphincter (formed by the crural diaphragm)

- Anatomic location of the gastroesophageal junction (hiatal hernia)

Proper function of the gastroesophageal junction as a barrier to reflux depends on the high-pressure zone of the lower esophageal sphincter (LES), the closing mechanism of the gastroesophageal valve $(\mathrm{GEV})$, and the normal geometry of the gastroesophageal junction in relation to the hiatus in the diaphram. ${ }^{13}$ While this geometry has been well described, a complete understanding of both the normal and pathologic anatomy is critical for surgeons judging the success of any antireflux procedure. ${ }^{14-17}$ The appearance of the GEV in patients with reflux disease has been well characterized by Hill and colleagues as a predictor of the presence and severity of GERD. ${ }^{18}$ In the normal gastroesophageal anatomy, the intraluminal extension of the acute angle of His is a 180 degree fold of musculomucosa that opposes the lesser curve until deglutition, whereupon receptive relaxation occurs, allowing food to pass through the gastroesophageal junction into the stomach but preventing the reflux of ingested contents. The collar sling musculature of the gastric cardia is critically important in maintaining the geometry of the flap valve (figure 2.1). In patients with gastroesophageal reflux, especially in those with a hiatal hernia, the collar sling musculature has become stretched and attenuated. This abnormal musculature allows the perimeter of the gastric cardia to increase, thereby blunting the angle of His and producing a funnel shaped gastroesophageal junction. The 
intraluminal extension of the angle of His is diminished or absent and the flap valve is no longer present.

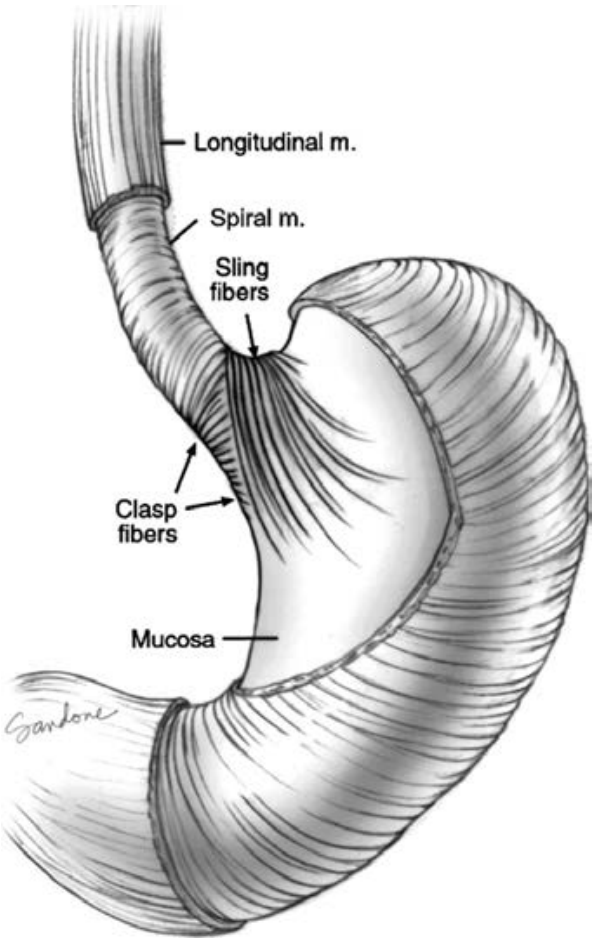

Figure 2.1 Schematic appearance of the muscular layers of the distal esophagus and proximal stomach. The sling and clasp fibers constitute the collar sling fibers, which become attenuated and stretched over time in the formation of a hiatal hernia, increasing the diameter of the cardia and resulting in loss of the acute angle of His.

Endoscopically, one can use the visual appearance of the GEV to predict the presence or absence of reflux as well as judge the adequacy of a reparative procedure, whether it is open, laparoscopic or endoscopic. Hill and colleagues published a grading system in 1996 that is predictive of the presence or absence of reflux and describes the visible goal of antireflux surgery, which is to restore the GEV to appear endoscopically as a grade I valve. A grade I valve is a prominent fold of tissue along the lesser curvature that is closely apposed to the endoscope, in normal subjects. Also considered normal is the grade II valve, which possesses a prominent fold but the apposition to the endoscope is less consistent, with periods of opening and rapid closing around the endoscope. In contrast, reflux patients typically have grade III (nonprominent fold without tight apposition to the endoscope) or grade IV (absent fold and gaping lumen with visualization of the squamous epithelium) valves when evaluated endoscopically (figure 2.2). ${ }^{16} \mathrm{~A}$ fundamental aspect of reflux barrier reconstruction at the gastroesophageal junction, inherent in all forms of antireflux surgery regardless of approach, is the envelopment of the distal esophagus by the proximal stomach. This single act results in the recreation of the acute angle of His and recalibration of the collar-sling musculature. When viewed endoscopically, there is an intragastric valve that resembles native anatomy. With in- 
creases in intragastric and abdominal pressure, the valve (with enveloped esophagus) is compressed, thereby resisting the retrograde movement of gastric contents.
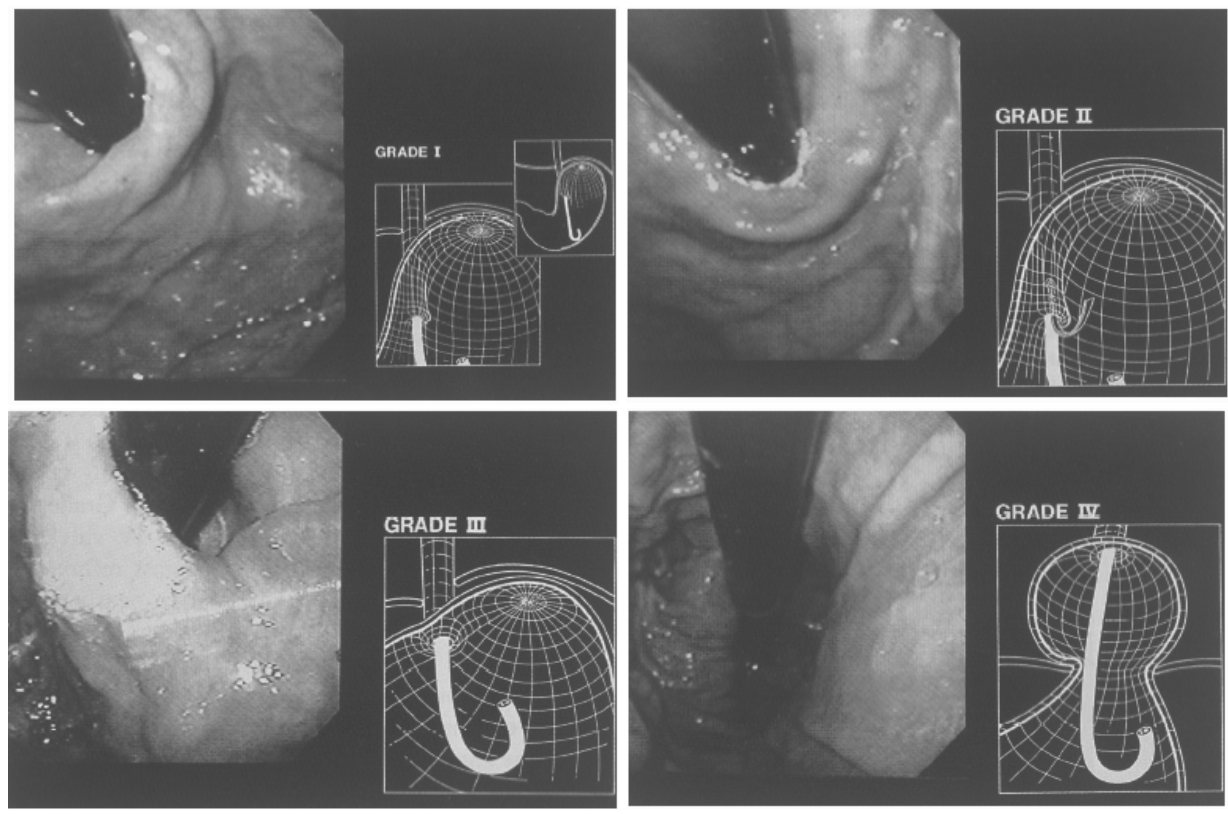

Figure 2.2 Hill grading system of the gastroesophageal valve, predictive of the presence of reflux.

Grade I valve: prominent fold of tissue along the lesser curvature closely apposed to endoscope. Grade II valve: prominent fold, apposition to endoscope less consistent. Grade III valve: nonprominent fold without tight apposition to the endoscope. Grade IV: absent fold and gaping lumen with visualization of the squamous epithelium.

\section{ANTIREFLUX SURGERY}

In 1948, Allison described a technique to treat GERD by hernia reduction followed by approximation of the crura and hereby he described the first surgical antireflux procedure. Unfortunately, this procedure alone did not result in adequate reflux control.19, 20 Surgical fundoplication was first described by Rudolph Nissen in 1956, after he accidently had found this maneuver to prevent esophagitis in a patient with a fundic wrap, created in order to shield a gastric anastomosis after cardia resection. ${ }^{21}$ Several modifications and different techniques based on Nissens' discovery have been described since. Current surgical techniques can basically be divided into two groups: complete (360 degree) and partial (less than 360 degree) fundoplications. Regardless the technique, ARS should be focused on safety, reducing surgery related side effects and performing the most durable repair to prevent gastric refluxate from entering the esophagus. In general ARS should be offered to chronic GERD patients who are intolerant of PPIs or refractory, with persistent 
esophageal or extra-esophageal symptoms or complications despite acid suppression therapy. ${ }^{22}$ Patient selection for surgery should be based on objective evidence of GERD. Preoperative work-up includes upper gastrointestinal (GI) endoscopy to evaluate the presence of hiatal hernia, esophagitis or columnar metaplasia or, in case of normal findings, pathologic esophageal acid exposure with $\mathrm{pH}$-monitoring and/or non-acidic reflux by impedance measurements. Before surgery is advised, primary motility disorders such as achalasia should be ruled out by manometry testing. Patients who are most likely to benefit from ARS are those with typical GERD symptoms, a certain response to PPIs and abnormal pH-impedance testing. ${ }^{23}$

\section{Laparoscopic antireflux surgery}

Laparoscopic antireflux surgery (LARS) was first described in 1991 by Geagea and Dallemagne. ${ }^{24,} 25$ The laparoscopic technique resembles the open surgical procedure, but is less invasive. A substantial learning curve for the laparoscopic approach has been reported and for less experienced surgeons supervision should be sought in at least the first 15-20 cases. ${ }^{26-28}$ Absolute contraindications for LARS are the inability to undergo general anesthesia or laparoscopy and uncorrectable coagulopathy. The approach can be challenging after previous upper abdominal surgery and in morbid obesity. In obese patients exposure of the hiatus may be difficult due to a large left liver lobe and the high intra-abdominal pressure. Overall, morbidly obese patients are bad responders to LARS and therefore for these patients bariatric surgery is a better option. Roux-en-Y gastric bypass is highly effective for treatment of GERD and obesity with the associated co-morbidities. ${ }^{29} \mathrm{~A}$ large number of studies have been conducted to compare open to laparoscopic fundoplication. ${ }^{30-37}$ In a meta-analysis of randomized trials published between 1990 and 2007, a faster convalescence and return to productive activity after the laparoscopic approach, with a reduced risk of complications and equal treatment outcomes, compared to the open approach was concluded. The reintervention rate, however, was significantly higher for patients treated laparoscopically. Most common cause of treatment failure with the need for re-operation was wrap herniation. After re-operation complication rates were reported up to $37 \%$ versus $14 \%$ after primary operations. ${ }^{38-40}$ Dysphagia, one of the most common side effects of ARS, has been suggested to occur more frequently after the laparoscopic approach compared to the open approach, in $12 \%$ versus $8 \%$, respectively. ${ }^{41} \mathrm{~A}$ more recent report on the ten-year outcomes of a randomized clinical trial in 148 patients concluded the opposite concerning re-interventions. A higher risk for reintervention was found in the open group, mainly unrelated to reflux recurrence, but due to the risk on incisionial hernia and with this study a level 1 support for the laparoscopic approach as the procedure of choice arised. ${ }^{42}$ 


\section{Laparoscopic complete fundoplication}

The Society of American Gastrointestinal Endoscopic Surgeons (SAGES) has recommended LNF as the first choice surgical procedure for ARS. ${ }^{43}$ The technique includes reduction of hiatal hernia and trans-hiatal mobilization of the esophagus to take the gastroesophageal junction back in the abdominal cavity. By closure of the crura the extrinsic sphincter is restored. Subsequently, the gastric fundus is mobilized in order to create tension free 360 degree fundic wrap around the esophagus (figure 2.3). A bougie can be used during the procedure for wrap calibration. The fundoplication results in the recreation of the distal high pressure zone at the LES, the restoration of the angle of His and the GEV and also reduces tLESR's. ${ }^{44-47}$

\section{Surgical technique of laparoscopic Nissen fundoplication}

Under general anesthesia with endotracheal intubation, the patient is positioned in supine position with the legs spread and strapped to the table, to allow the surgeon to stand in between. A vacuum beanbag mattress may be used to prevent intra-operative sliding of the patient. The operation table is placed in 30 degree reversed Trendelenburg position. The assistant positions at the patient's left and the scrub nurse at the right side. Skin preparation from the nipple-line to the pubic symphysis is performed. Video monitors are placed above the patients' head and trocars are inserted. An angled (30-45 degree) laparoscope is advised to allow alternative views at the operation field. A liver retractor is of key importance in this procedure to allow view on the operation field by lifting the left liver lobe. It can be handheld or fixed into an articulated mechanical arm on the operation table. The gastroesophageal junction is mobilized by dissection of the crura using ultrasonic scissors. The pars flacida of the lesser omentum is opened while preserving the hepatic branch of the vagal nerve and an eventual aberrant left hepatic artery that is present in about fifteen percent of patients. The phrenoesophageal membrane is incised anteriorly to the esophagus from the left to the right crus. The esophagus is then dissected posteriorly, which can be performed bluntly, to allow access to the crura and the mediastinal part of the esophagus. Intrathoracic dissection is used to reduce an eventual hiatal hernia and to provide sufficient $(>3 \mathrm{~cm})$ intra-abdominal esophageal length. Care is taken to preserve the vagal nerves and the parietal pleura. A loop can be used for retraction of the esophagus. In order to establish a tension free fundoplication, the gastric fundus can be mobilized by division of the gastrosplenic ligament and two to three short gastric vessels, while the stomach is retracted caudally and to the right side of the patient by the assistant. Dissection is continued until the posterior part of the gastrosplenic ligament and the gastrophrenic ligament are divided up to the left crus. A cruraplasty is performed to narrow the diaphragmatic opening by placing non-resorbable sutures at 
the posterior side of the hiatus, until the empty esophagus is reached. Teflon pledgets may be used in case of a fragile crura.

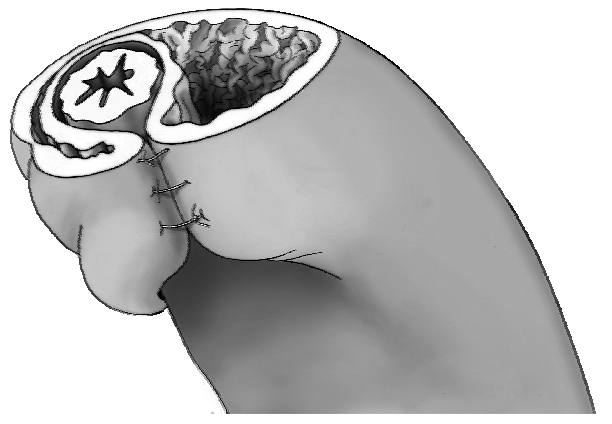

Figure 2.3 In the 360 degree Nissen fundoplication the gastroesophageal valve is restored by a $2 \mathrm{~cm}$ wrap, secured with three interrupted nonresorbable sutures.

In order to create the 360 degree posterior fundoplication, the esophagus is pulled ventrally by the assistant using the loop. An atraumatic grasper is passed posterior to the esophagus to grab the fundus and pass it to the right side of the esophagus. As it should be a tension-free wrap, the fundus should stay in this position while the grasper is released. Some surgeons use a 50-60 French bougie for calibration. The wrap should be placed around the esophagus at z-line level (1-2 cm above the anatomic junction) and should be about $2 \mathrm{~cm}$ in length. Three non-resorbable sutures are used to secure the wrap. The wrap can be secured to the anterior muscular wall of the esophagus in the most distal stitch. Trocars are removed under vision and checked for hemostasis and wounds are closed.

\section{Laparoscopic partial fundoplication}

Partial fundoplications have commonly been employed after Heller myotomy and advocated as a tailored approach in patients with an esophageal motility disorders at risk for postoperative dysphagia. ${ }^{48}$ However, the available evidence suggests that the outcome in patients with motility disorders is not influenced by the type of fundoplication. ${ }^{49-50}$ Some expert groups have recommended partial fundoplication as a better alternative to the 360 degree Nissen fundoplication, mainly because of reduction of side effects like dysphagia and gas-bloating due to the overcompetence of the created antireflux barrier. Over the years many different types of partial fundoplications have been described. In general there are two types of partial fundoplications, which will be discussed here: the posterior (or "Toupettype") and the anterior (or "Dor-type") partial fundoplication. The technique for laparoscopic partial fundoplication is for the most part similar to the technique for LNF. The difference between the approaches relates to the creation of the wrap. In Toupets partial fundoplication a posterior fundoplication is created by suturing a 270 degree fundic wrap on the esophagus. The repair can be securely fixed to the right and left crura to take the tension off of the esophageal sutures. In the Dor- 
type anterior fundoplication the fundus is first sutured to the left crus and the left side of the esophagus, then the greater curvature is brought anteriorly and sutured to the right crus with interrupted sutures.

A meta-analysis of total versus partial fundoplication was published in 2009.51 The available literature from 1975 until 2007 was assessed, which resulted in the selection of eleven reports of randomized controlled trials. Four trials compared open approaches and seven trials compared the laparoscopic approaches. Complete fundoplication resulted in significantly higher incidence of postoperative dysphagia, gas-bloating, flatulence and the need for re-operation compared to partial fundoplication, with a similar control of acid reflux, heartburn and esophagitis. The authors however warranted caution in interpretation of the data due to the poor quality of the included trials.

\section{Laparoscopic complete versus partial posterior fundoplication}

Two retrospective studies suggested inferior long-term reflux control after laparoscopic partial posterior fundoplication, but Mardani et al. showed in a randomized controlled trial that both techniques maintain a high level of reflux control even after 20 years of follow up. ${ }^{52-54}$ A systematic review published in 2010 compared posterior total fundoplication (Nissen) to posterior partial fundoplication (Toupet) and only included laparoscopic approaches in the analysis. Seven eligible randomized controlled trials published between 1960 and 2009 were assessed. A similar control of reflux with a significant decrease of surgery related side effects, like dysphagia and gas-related symptoms, and a decreased re-operation rate was found after Toupet-fundoplication. The authors recommended the laparoscopic posterior partial fundoplication as the first choice antireflux operation. ${ }^{55}$

\section{Laparoscopic complete versus partial anterior fundoplication}

Anterior fundoplication has been compared to complete Nissen fundoplication in several randomized controlled trials. ${ }^{56-60}$ Follow-up duration varied between 6 months and 10 years. Anterior fundoplication resulted in significantly less postoperative dysphagia compared to LNF, but reflux control was shown to be inferior for the 90 degree, as well as the 180 degree anterior fundoplication. The 90 and 180 degree approaches were compared in a re-analysis of original data of four randomized controlled trials comparing anterior fundoplication to LNF. ${ }^{61}$ Two trials evaluated 90 degree anterior fundoplication and two trails the anterior 180 degree fundoplication. The authors concluded that reflux control of the 180 degree variant was superior to the 90 degree anterior fundoplication. 


\section{Outcomes and complications of laparoscopic antireflux surgery}

Multiple studies have been conducted to evaluate efficacy of LARS in GERD treatment. LARS results in resolution of typical symptoms in $90 \%$ in short-time followup and in $67 \%$ after long-term ( $>5$ years) follow-up. Also atypical symptoms and objective outcome measures such as LES-pressure, acid exposure of the distal esophagus and Barrett's esophagus improved significantly. ${ }^{43}$ Mortality after LARS is rare and fortunately limited to some case reports. Complications can be categorized in early and late complications. Early complications are related to the procedure and include general anesthesia-related complications, hemorrhage (injury of liver or short gastric vessels), vagal nerve injury, gastric, esophageal or visceral injury (0-4\%), which can lead to conversion to open surgery $(0-24 \%)$ and pneumothorax $(0-1.5 \%)$, especially in cases with large hiatal hernia, in which extensive mediastinal dissection is necessary. Late complications include port-site hernia (0.17-9\%), gas-bloating syndrome and postoperative dysphagia (1.8-10.8\%). Dysphagia is difficult to treat and may require several endoscopic pneumodilations (0$25 \%$ ) or even revisional surgery. The majority of redo-operations however, are performed in case of recurrent reflux due to anatomical failure of the fundoplication. An anatomical failure rate of $2.8 \%$ has been reported and is most commonly caused by wrap herniation (61\%). ${ }^{62}$ Less common causes are slipped wrap (13\%) and wrap disruption (6\%).

\section{Revisional laparoscopic surgery after unsuccessful primary antireflux surgery}

Revisional surgery is safe and effective in experienced hands and can be managed laparoscopically in $80-90 \% .63,64$ In a systematic review of 81 studies, recurrent reflux and dysphagia were the most common indications for revisional surgery. Compared to primary procedures, revisional surgery was associated with longer operative times, higher conversion rates in the laparoscopic approach $(8.7 \%)$, increased complication rate $(21.4 \%$ intra-operative and $15.6 \%$ post-operative) and a mortality rate of $0.9 \%$. Symptomatic outcomes of laparoscopic revisional surgery were comparable to those from open revisional surgery, but the laparoscopic approach was more successful in objective outcomes $(85.8 \%$ versus $78 \%) .{ }^{65}$

\section{Other technical aspects and modifications}

\section{Short gastric vessel division}

Laparoscopic Nissen fundoplication is mostly described with the division of the short gastric vessels (technique described by Donahue and Blombeck) in order to establish a tension-free fundoplication. LNF without division of the short gastric vessels, the so-called Nissen-Rossetti-technique, is a well-accepted variant. Five 
randomized controlled trials showed that when the fundus can easily be wrapped around the distal esophagus without tension, no division of the short gastric vessels is necessary. The division increases the operation time, operation risks and would also lead to increased postoperative flatulence and gas-bloating, while equal outcomes in symptoms and quality of life were reported.66-70 These results were recently confirmed after a follow-up period of more than 10 years. ${ }^{71}$

\section{Esophageal bougie for wrap calibration}

Is has been suggested that the use of an esophageal bougie during creation of the fundal wrap would minimize postoperative dysphagia. Two randomized studies on this topic have been performed. In one study 336 patients were randomized between LNF with or without the use of a bougie for wrap calibration. ${ }^{72}$ A significant lower incidence of dysphagia was found in the bougie-group after almost one-year follow-up at the cost of one esophageal injury (1.2\%) caused by bougie introduction. The other study reported no differences in the incidence of dysphagia between two groups, with or without bougie introduction, after a one-year follow-up in 82 patients. ${ }^{73}$

\section{Robotic assisted procedures}

A meta-analysis of robotic-assisted versus conventional laparoscopic Nissen fundoplication in over 200 patients showed that clinical results (re-operation, complications, hospital stay) were comparable but the robotic procedure was associated with longer procedure time and costs. ${ }^{74}$ Whether there is an advantage of the robotic assisted procedure in ergonomics and workload for the surgeon was not reported.

\section{ENDOSCOPIC TREATMENT OF GASTROESOPHAGEAL REFLUX DISEASE}

Several efforts have been made to develop techniques and devices that enable to treat GERD endoscopically. These devices employ one of three techniques to reinforce or recreate the gastroesophageal barrier:

- Radiofrequency ablation

- Injection therapy

- Suture-plication (sutures or staples)

Unfortunately, the first-generation devices have been unable to replicate the dramatic improvement in objective measures of GERD achievable by laparoscopic fundoplication. ${ }^{43,75-77}$ Of these three techniques, suture plication is most similar to the anatomic reconstruction of the gastroesophageal junction seen after surgical fundoplication and, as such, holds the most promise for achieving effective and 
ideally, durable, symptomatic relief. Because esophageal mobilization and crural closure are not possible with endoscopic approaches, the selection of patients with little or no hiatal hernia is very important as the effectiveness of the repair is entirely dependent on the "ink-welling" of the distal esophagus into the proximal stomach with some axial tightening. An endoscopic valve grading system with 10 valve criteria has been proposed to determine the adequacy of a specific surgical repair type. ${ }^{78}$ There are significant differences in the endoscopic appearance of the valve, depending on whether it was repaired via a properly performed Nissen fundoplication, Nissen with Collis gastroplasty, Toupet, Dor, or Hill repair. These differences may become very important when developing endoscopic methods for antireflux surgery as they can guide the endoscopist in creating a technically effective repair and enhance our understanding of approach.

\section{Patient selection for endoscopic antireflux therapies}

While several devices have received FDA approval for use in patients with GERD, the lack of long-term safety and efficacy data has led many, including the American Gastroenterological Association, to recommend that endoscopic therapies should be approached cautiously by both patients and practitioners. ${ }^{79}$ It is therefore critical that surgeons proceed with extreme care in selecting the appropriate patients for endoscopic antireflux procedures. Similar to laparoscopic approaches, the ideal patient for endoscopic antireflux procedure would be one who has clearly documented, symptomatic gastroesophageal reflux that is well controlled with medical therapy. ${ }^{80}$ It is important to stress that the presence of a large hiatal hernia, while entirely acceptable for a laparoscopic approach, should be a contraindication for endoluminal therapy. Additionally, extreme caution should be exercised when considering an endoscopic antireflux procedure in patients who have refractory symptoms despite maximum PPI-therapy, esophageal stricture, esophageal dysmotility, or Barrett's esophagus. Finally, the presence of severe liver disease, portal hypertension with esophageal or gastric varices, or other coagulation disorders would be a contraindication to endoluminal therapy.

\section{Endoscopic plicator techniques}

Because a major component of the barrier loss at the gastroesophageal junction results from the effacement of the valve mechanism, endoscopic procedures that reconstruct this valve mechanism will likely have the greatest possibility for longterm success. Ideally, endoscopic reconstruction should produce a gastroesophageal flap valve that is indistinguishable from that produced using open or laparoscopic techniques. Three types of plicator (or suturing) techniques for endoscopic antireflux surgery have been developed and are presented in detail below. 


\section{Endocinch}

The Bard EndoCinch Endoscopic Suturing System ${ }^{\mathrm{TM}}$ (Bard Endoscopic Technologies, Billerica, MA, a subsidiary of C. R. Bard, Inc., Murray Hill, NJ) received FDA approval for the treatment of gastroesophageal reflux in March of 2000. Using endoscopic techniques, the device places sutures at the LES, which are tied together to create a circumferential pleat or plication. Early results from this procedure were encouraging, with significant improvements in symptoms, including heartburn severity, frequency and regurgitation at 3 and 6-month follow-up. Objective measures of reflux, including total number of episodes and percent time $\mathrm{pH}<4$ were also improved but not normalized. The most frequent complaint after the procedure was pharyngitis in $31 \%$ of patients, with major complications of gastric bleeding and suture perforation occurring in $2 \%$ and $1 \%$, respectively. ${ }^{81}$ This and similar publications established the early efficacy and safety of the procedure; long-term results, however, have demonstrated treatment failure in up to $80 \%$ of patients in several reports. ${ }^{82}$ Treatment failure is typically defined as persistent symptoms similar to preoperative complaints or medication use at greater than $50 \%$ of the preoperative dose. The primary reason for treatment failure is assumed to be related to loss of the mucosa-based sutures within months after placement.

\section{NDO plicator}

The NDO Surgical Endoscopic Plication System ${ }^{\mathrm{TM}}$ (NDO Surgical, Inc., Mansfield, MA) received FDA approval for use in the treatment of chronic, medicationresponsive GERD in 2004. This device is passed transorally and is used to create a full-thickness, serosa-to-serosa plication of the anterior gastric cardia using a suture-based implant near the gastroesophageal junction. The safety and efficacy of the NDO plicator has been demonstrated in multiple short- and mid-term studies. ${ }^{83-85}$ A randomized, sham-controlled trial in 2006 reported a significant improvement in validated symptom assessment in 78 patients treated with endoscopic full-thickness plication of the anterior cardia compared with 81 patients undergoing a sham procedure. By intention-to-treat analysis at 3 months, $56 \%$ of patients undergoing plication had achieved $\geq 50 \%$ improvement in GERD healthrelated quality of life (HRQL) score compared with only $18.5 \%$ in the sham group $(p<0.001)$. Proton pump inhibitor (PPI) use was discontinued in $50 \%$ versus $24 \%$ $(p=0.002)$ and median percent time $\mathrm{pH}<4$ was reduced from $10 \%$ to $7 \%$ in the treatment group with no change in the sham group. Endoscopy at 3 months in 50 patients revealed intact plications in $98 \%$. Half of the patients undergoing plication complained of postoperative symptoms including pain, nausea, vomiting or dysphagia. Importantly, physical and mental quality-of-life (short-form-36) mean scores were significantly better for the plication group compared with the sham group. ${ }^{85}$ Recently, long-term (5-year) follow-up of the original multicenter feasibility study testing the safety and feasibility of the NDO plicator was published. ${ }^{86}$ In 
this report, 33 of the original 64 subjects were available for reassessment by symptom questionnaire at 60-month follow-up, including the GERD-HRQL, gastrointestinal symptom rating scale (GSRS), and SF-36 questionnaires. Before treatment, 91\% of the 33 patients were using PPIs; 60 months after plication, 40\% were using PPI daily. Median GERD-HRQL scores were also significantly improved from 19 preplication to 10 at 60 months post plication $(p<0.001) ; 50 \%$ of subjects had a $\geq 50 \%$ improvement in GERD-HRQL score compared with the preoperative score. The authors concluded that the plicator procedure safely reduced GERD symptoms up to 60 months after the procedure with long-term durability and no obvious adverse effects. Important limitations of the study and the device are noted, including the exclusion of patients with hiatal hernia or erosive esophagitis as well as the lack of information regarding efficacy of the plicator in patients with breakthrough GERD not fully responsive to PPI therapy or patients with laryngopharyngeal reflux. The company that makes the plicator has gone out of business and the device is no longer available for clinical use.

\section{Transoral incisionless fundoplication}

The transoral incisionless fundoplication (TIF), performed with the Esophy $\mathrm{X}^{\mathrm{TM}}$ device was approved by the FDA in September of 2007 for the treatment of symptomatic chronic GERD in patients requiring and responding to antireflux medications and is currently under investigation (figure 2.4).

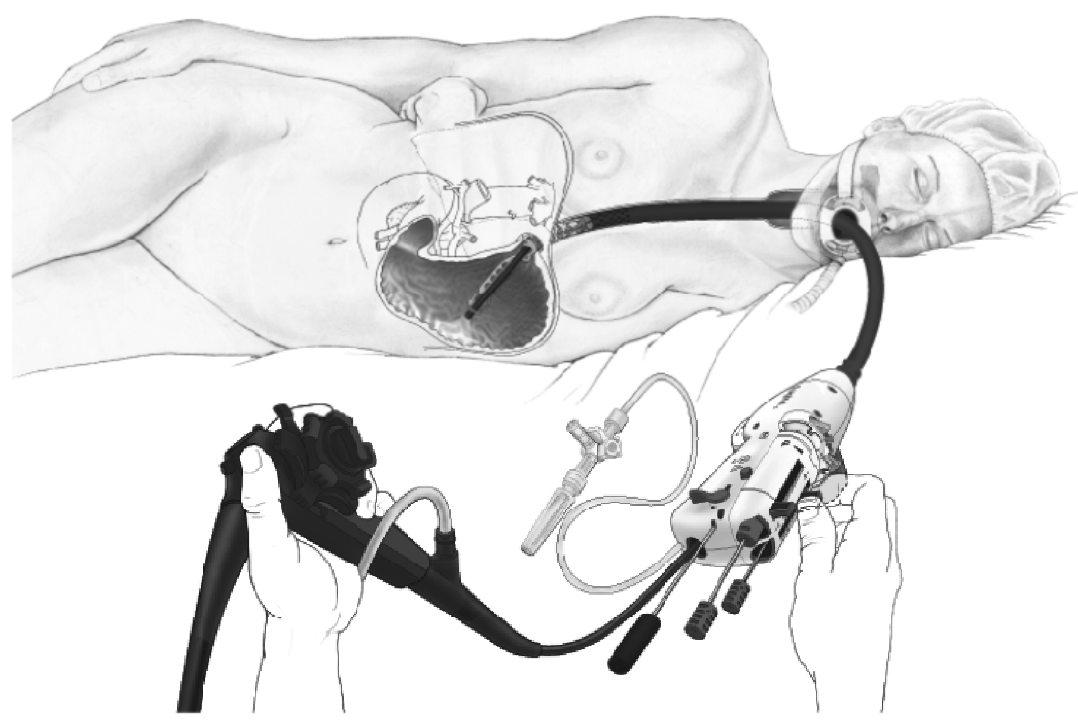

Figure 2.4 Transoral incisionless fundoplication. A full-thickness fundoplication is created endoscopically with the use of the Esophy $\mathrm{X}^{\mathrm{TM}}$ device under monitor visualization with a regular flexible endoscope. 
Similar to the NDO plicator ${ }^{\mathrm{TM}}$, the Esophy $\mathrm{X}^{\mathrm{TM}}$-device provides a full-thickness, serosa-to-serosa, or serosa to muscularis (depending on the approach: TIF1 or TIF2procedure) plication of the gastroesophageal junction. Unlike the NDO plicator, this device will also allow reduction of a hiatal hernia up to $2 \mathrm{~cm}$ and is designed to recreate the gastroesophageal valve (ideally to a Hill type I) by restoring the intraluminal extension of the angle of His and restoring intra-abdominal length.

\section{Technique of transoral incisionless fundoplication}

Under general anesthesia with (nasal) endotracheal intubation, the patient is positioned in left lateral decubitus position. A vacuum beanbag mattress and stays are used to prevent intra-operative sliding. Arms and legs are padded to prevent compression nerve injury. The surgeon performs the procedure while the endoscopist provides visualization by the use of a flexible endoscope. A bite-block is inserted in the patient's mouth. Before device insertion a pre-procedure endoscopy is performed to examine the esophagus for pathology or stricture. The Z-line is identified and the distance to the incisors is measured. With the endoscope orientation in retroflexed view, the GEV is inspected and "Hill-graded". Subsequently, the Esophy $\mathrm{X}^{\mathrm{TM}}$-device is lubricated and inserted over the endoscope, used as a guidewire With the use of vacuum suction holes in the device, small hernias are reduced by advancing the device towards the stomach while it is secured to the esophageal wall. The invaginator vacuum can also be used to stabilize the device in relation to the esophagus further in the procedure. When the device is advanced below the GEJ and checked for accurate position, the endoscope is retracted to allow the tissue mold to close and introduced again to provide visualization throughout the procedure in retroflexed view (figure 2.5ab). The tissue mold contains a helical retractor, which is engaged to retract $5 \mathrm{~cm}$ of tissue into the mold, aided by a 'massage' or 'shoe-horn' maneuver for axial rotation in order to envelope the esophagus in the stomach and to create circumferential tightening (figure 2.5c). With the use of stylets, polypropylene H-shaped serosal fasteners (SerosaFuse ${ }^{\mathrm{TM}}$ ) are advanced through the device and deployed to create and secure a full-thickness plication at the level of the GEJ (figure 2.5d, 2.6). With sequential deployment of multiple fastener-sets under visual control a 270 degree omega shaped partial fundoplication is created (figure 2.5e). To finish the procedure the endoscope is retracted into the device and cautiously removed from the patient with the tissue mold in opened position. Postprocedure endoscopy is performed to assess for hemostasis and the geometric appearance of the restored gastro-esophageal valve (figure 2.7). 

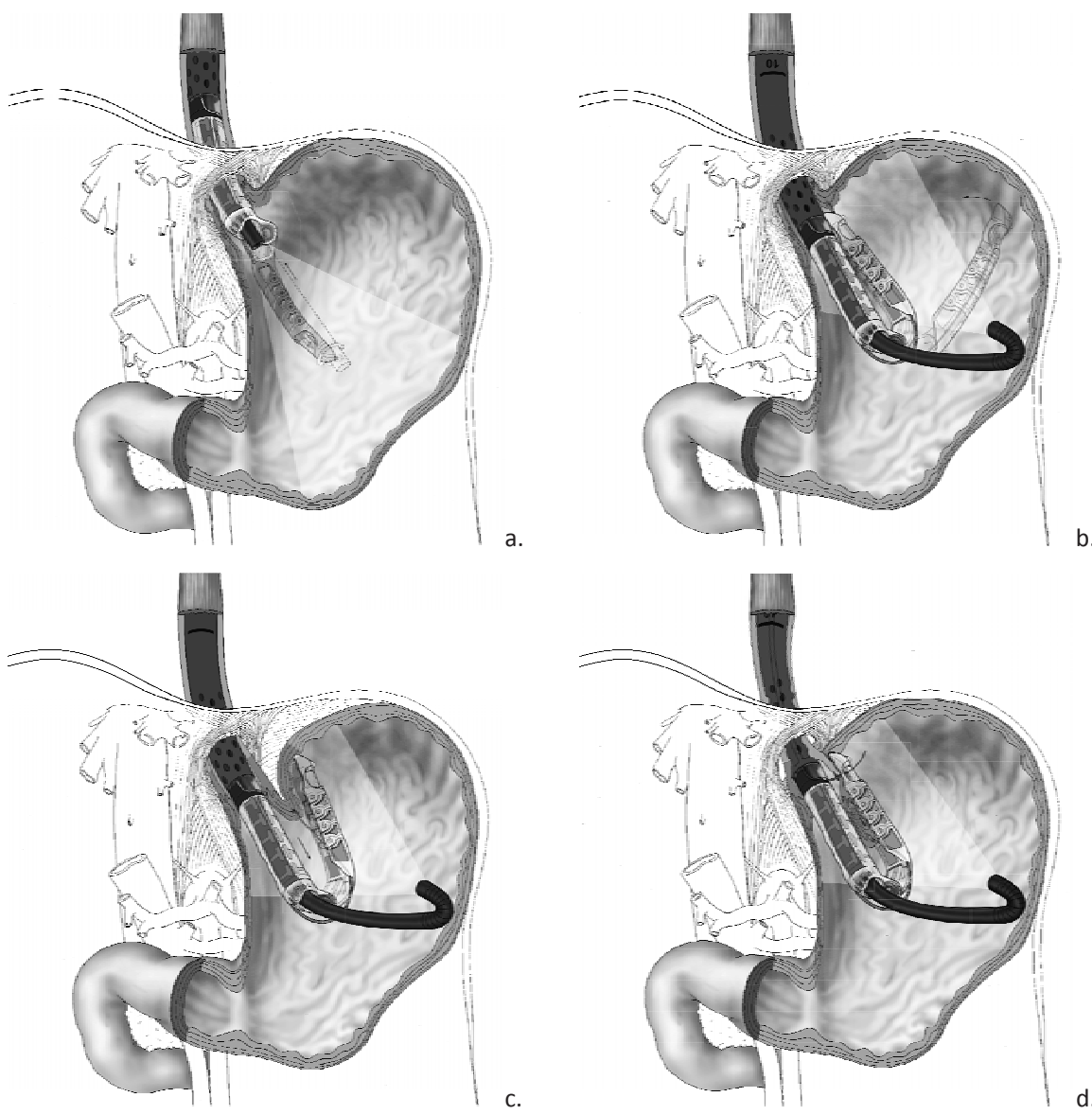

.

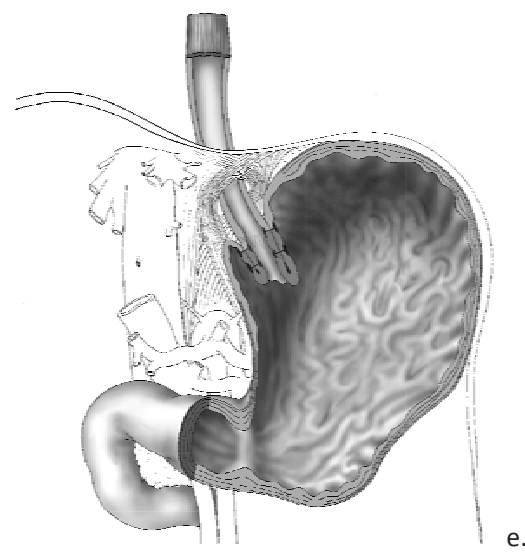

Figure 2.5 TIF procedure.

a. The endoscope is retracted to allow the tissue mold to close. Vacuum suction holes enable small hiatal hernia reduction.

b. The device is advanced and hiatal hernia reduced. Visualization is provided with the endoscope in retroflexed view.

c. The helical retractor is engaged to retract tissue into the mold.

d. Polypropylene $\mathrm{H}$-shaped fasteners are advanced by stylets.

e. After sequential deployment of fastener-sets a full-thickness fundoplication is created at the level of the gastroesophageal junction. 


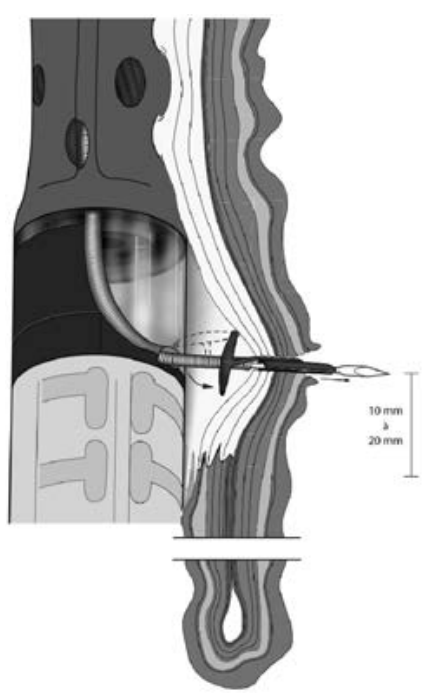

a.

Figure 2.6 Polypropylene $\mathrm{H}$-shaped serosal fasteners are used to secure the full-thickness fundoplication at the level of the gastroesophageal junction.

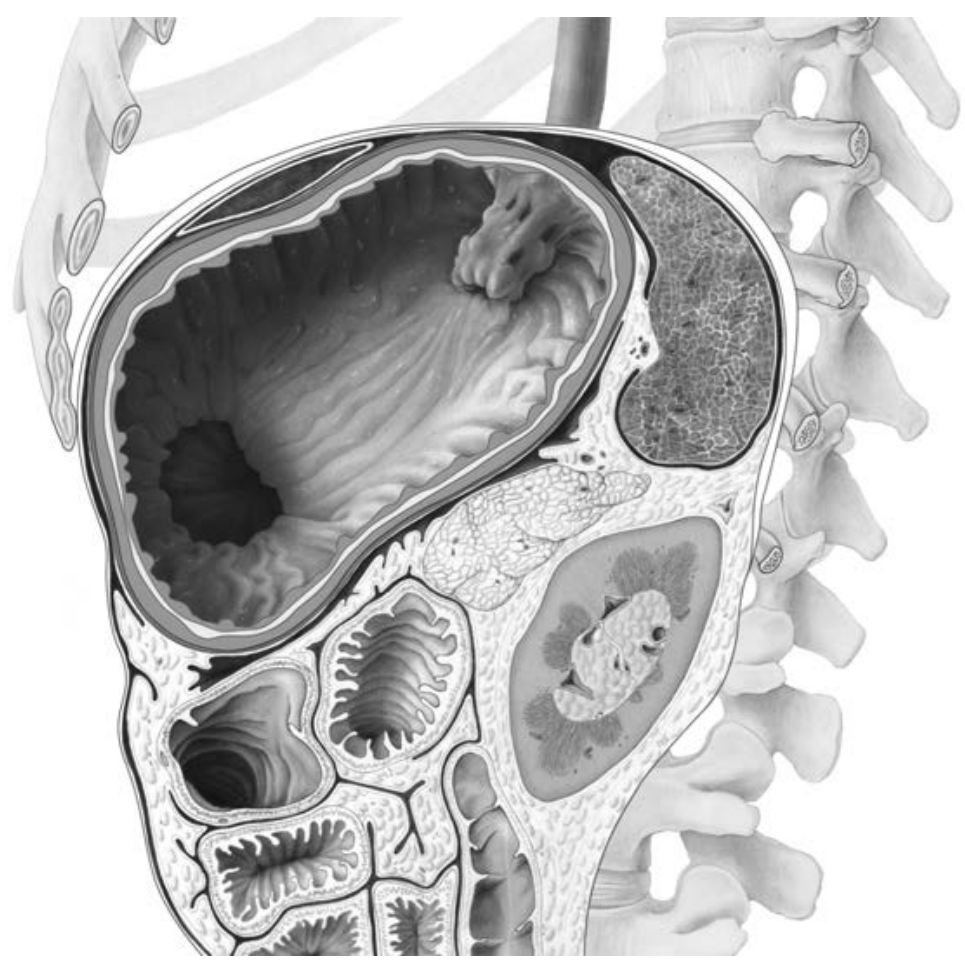

Figure 2.7 Transoral incisionless fundoplication: three-dimensional image of the reconstructed gastroesophageal valve. 
The TIF1 procedure was validated in a multicenter study of 86 patients with a 12month follow-up. ${ }^{87}$ Esophageal $\mathrm{pH}$ was normalized at 12 months in $37 \%$ of patients and significantly reduced in $61 \%$. PPI use was eliminated in $85 \%$ of patients. Clinically significant reduction in heartburn allowing cessation of PPIs occurred in 45 patients (56\%) and was considered "cured"; of these 45 patients, $80 \%$ had normalization or significant reduction in esophageal acid exposure. When evaluated endoscopically, a Hill type I valve was visualized in 24 patients (33\%). Objective measures, such as esophageal pH normalization, esophagitis and cardia circumference, were significantly better in the post-TIF1 Hill type I valves compared with the type II or type III/IV valves. Symptomatic improvement was not different between these three groups. Two patients suffered proximal esophageal perforations during device insertion, one patient had significant gastric bleeding requiring transfusion and prolonged hospital stay and $\sim 25 \%$ of patients complained of musculoskeletal, abdominal or pharyngolaryngeal pain lasting $<1$ month. This multicenter study established the safety, feasibility and potential effectiveness of this approach and led to FDA approval for use in chronic GERD. However, the inability to obtain a durable Hill type I valve in $\sim 70 \%$ of the patients has prompted development of a second protocol for transoral incisionless fundoplication (TIF2). The TIF2 protocol places the serosal $\mathrm{H}$-fasteners 3 to $5 \mathrm{~cm}$ proximal to the gastroesophageal junction rather than only at the gastroesophageal junction (figure 2.8).
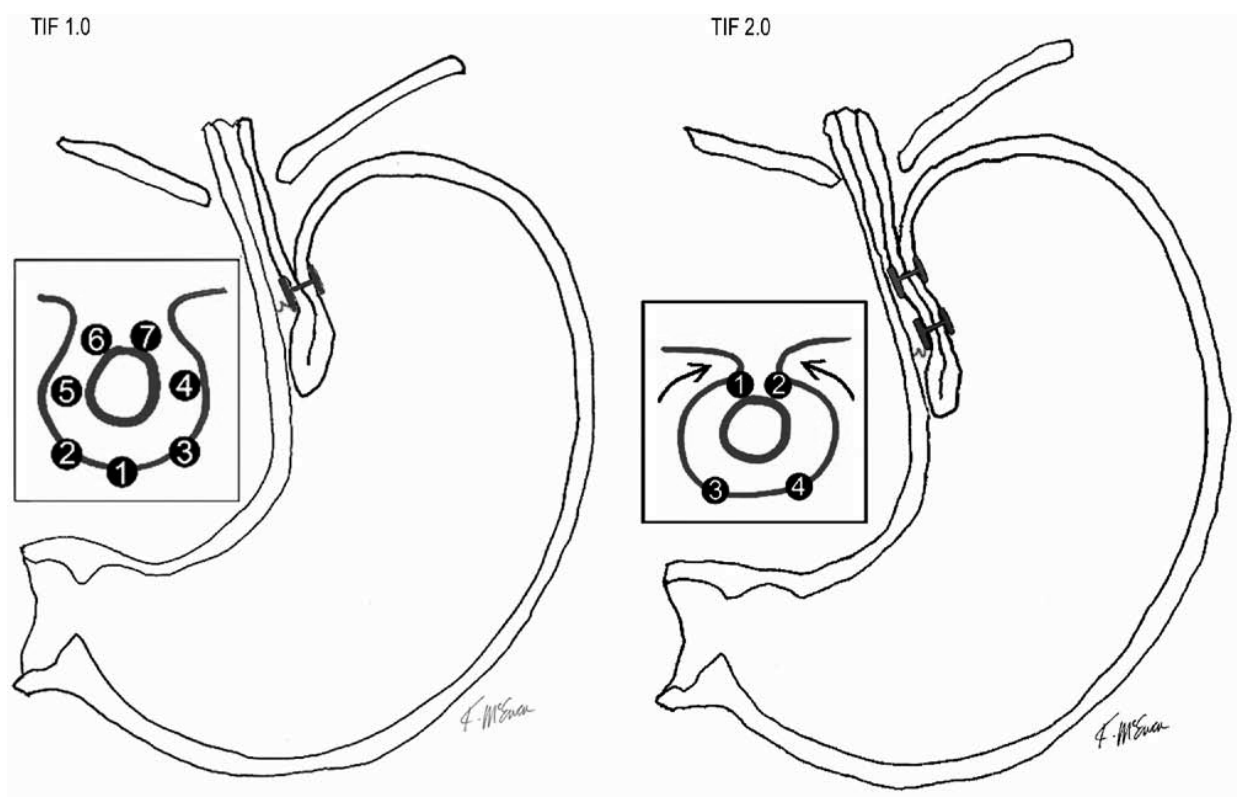

Figure 2.8 TIF procedure schematics. The TIF1 procedure is created at the level of the GEJ and results in a proximal gastric-gastric fundoplication. The TIF2 procedure combines circumferential tightening (arrows) with fundoplication created around the intra-abdominal esophagus. 
This results in a restoration of the extension of the angle of His into the proximal stomach. With this repair, a nipple valve is created that includes esophageal muscle to gastric serosal fusion and strongly resembles the appearance of a standard Nissen fundoplication, both by endoscopy (figure 2.9) and on barium esophagram (figure 2.10).
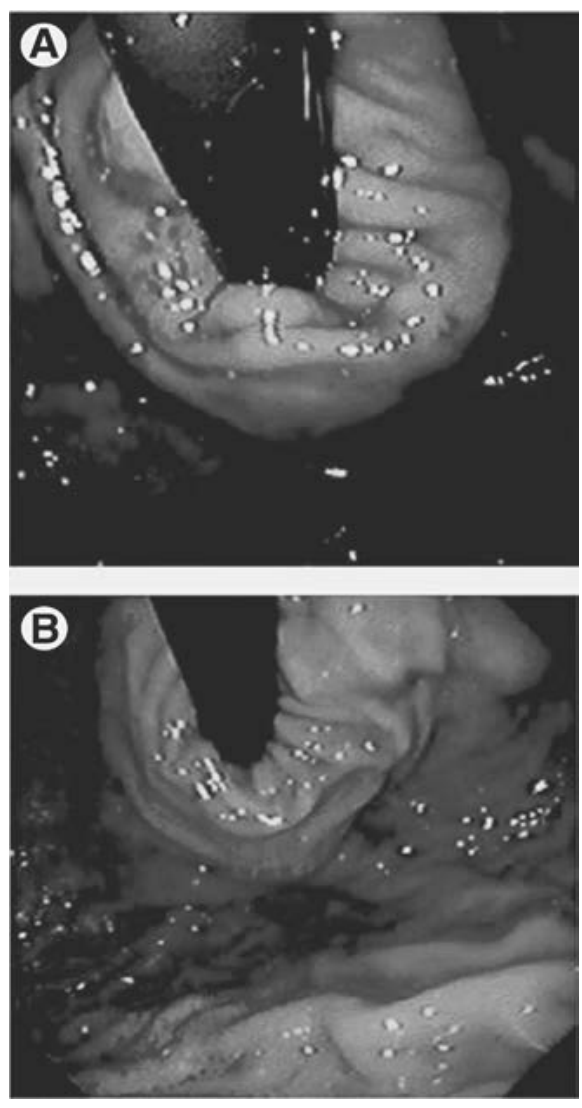

Figure 2.9

(A) Retroflexed endoscopic view immediate post-operative after esophago-gastric transoral incisionless fundoplication (TIF2).

(B) Same repair at 2 weeks. Endoscopic findings include a nipple valve with an anterior and posterior groove, tight adherence to the endoscope and a "stacked coils" appearance, similar to a Nissen fundoplication.
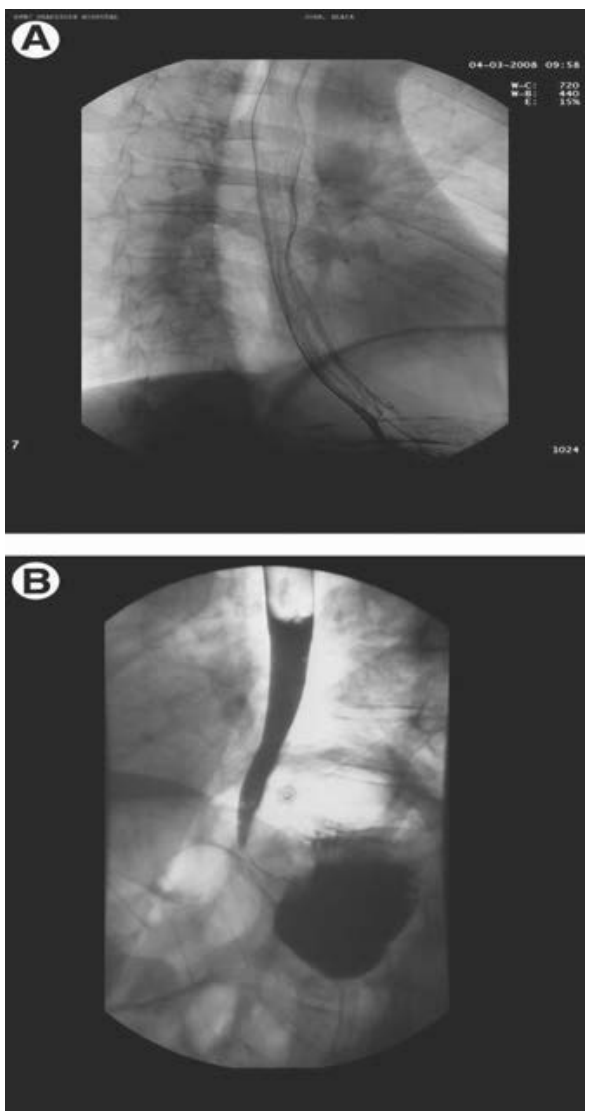

Figure 2.10

Barium swallow with antero-posterior (A) and lateral (B) views of the gastroesophageal junction and fundoplication after endoluminal fundoplication. The radiologist reported "the study was performed with water soluble contrast material followed by ingestion of barium. The fundoplication is intact and in its expected sub diaphragmatic location with the expected degree of narrowing of the intra-abdominal esophagus. There is no evidence of leak or obstruction and no reflux." 
In a canine model, the TIF2 approach was shown to be safe, feasible and well tolerated. ${ }^{88}$ In addition, compared with sham or TIF1, TIF2 significantly improved DeMeester scores (pre-TIF2=15, post-TIF2 at 2 weeks=5), LES total, intraabdominal length and LES pressure. LES relaxation was normal post-procedure for both TIF1 and TIF2. Evaluation of the TIF2-procedure in patients is currently underway. Formal assessment of objective measures of GERD, including normalization of esophageal $\mathrm{pH}$, validated symptomatic assessment and the need for postprocedure PPIs will provide the best information regarding the utility of this approach.

\section{RECRUITEMENT OF PATIENTS FOR CLINICAL ENDOSCOPIC FUNDOPLICATION TRIALS}

A German group reported the results of a study in which the patient-recruitmentprocess for the TIF-procedure was analyzed. ${ }^{89}$ Their recruitment sources were 50 referring private practices, 23 hospitals and 3 advertisements in major newspapers. Assessment of the recruitment process showed that almost $90 \%$ of potential candidates were recruited through public media. Eventually, out of these potential candidates, no more then $10 \%$ were successfully recruited for the trial. Strict patient selection criteria and skepticism in the gastroenterological community were found to be the most important recruitment barriers.

The strict selection criteria used, were similar to those in previous studies within the field of endoscopic GERD treatment. Exclusion criteria were insufficient response to PPI's, lack of PPI use, atypical symptoms and large hiatal hernia. Patients who are refractory to PPIs or have atypical symptoms are known for an increased risk of failure after surgical fundoplication. ${ }^{90}$ Furthermore, current endoscopic techniques can not compete with surgery concerning larger hiatal hernia reduction, which can not be acquired without extra gastroesophageal dissection. Accordingly, the strict selection criteria seem to be appropriate in the early evaluation of endoscopic fundoplication in order to avoid complications and poor outcomes. This highly selected group of patients appeared not to be easily recruited through newspaper advertisements and therefore, future trials will depend on expert referrals.

First generation endoscopic GERD treatments have been unsuccessful and therefore skepticism overweighs enthusiasm in the gastroenterological community. In the German study, questionnaires were sent to referring physicians, which showed that $70 \%$ did not believe a new endoscopic method would be superior to previous techniques and as a result, referrals were scarce.

While recruiting for trials using TIF, this phenomenon was also experienced by our research group. It is, however, to consider that the mechanisms of action of early techniques that failed were rather different compared to those currently tested. Skepticism in the gastroenterological community will only turn to enthusi- 
asm when scientific proof of safety and efficacy has been established in welldesigned trials. In order to perform these trials and select patients who are expected to benefit from endoscopic fundoplication, a close collaboration with referring physicians seems to be of key importance.

\section{CONCLUSIONS}

Quality of life is an important consideration in the treatment of any chronic medical condition and is particularly important for patients with GERD. While laparoscopic antireflux procedures are extremely effective in eliminating GERD symptoms, the associated invasiveness, side effects like dysphagia, gas-bloating and hyperflatulence, as well as the potential for peri-operative morbidity have resulted in surgical referral trends that are limited to patients with the most complicated GERD. Although posterior partial (Toupet) fundoplication has been associated with a reduction of side effects, it has become apparent that less invasive therapeutic options need to be available to the vast majority of GERD patients, who are otherwise relegated to medical therapy. This is particularly true for patients who have elements of volume reflux and regurgitation in their symptom complex. Endoscopic therapies offer an alternative to lifelong antireflux medications and, as such, are undergoing intensive research and development. While several endoscopic techniques have been developed, suture plication is the only approach that addresses the geometric abnormalities of the GEV. Careful reconstruction of the gastroesophageal valve, including restoration of the angle of His and reshaping of the cardia, are critical for successful amelioration of both symptoms and exposure of the esophagus to gastroduodenal secretions. Of the FDA-approved suture plication devices, both the NDO plicator ${ }^{\mathrm{TM}}$ and Esophy $\mathrm{X}^{\mathrm{TM}}$ device appear to have similar therapeutic efficacy compared with medical therapy in highly selected cohorts. However, the anatomic result of the EsophyX ${ }^{\mathrm{TM}}$ TIF2 closely resembles the endoscopic appearance of a Nissen fundoplication and therefore, may ultimately prove to be more efficacious than the NDO plicator. Because the early endoscopic techniques have been unable to replicate the substantial improvement in objective measures of GERD achievable by laparoscopic fundoplication, skepticism towards endoscopic antireflux procedures has grown and studying this topic has therefore become challenging. Further studies, including randomized (sham) controlled trials are however necessary to determine whether endoscopic plication of the gastroesophageal valve will provide patients with safe, durable and efficacious relief of GERD. 


\section{REFERENCES}

1. Vakil N, van Zanten SV, Kahrilas P, Dent J, Jones R. The Montreal definition and classification of gastroesophageal reflux disease: a global evidence-based consensus. Am J Gastroenterol 2006;101:1900-20; quiz 1943.

2. Klinkenberg-Knol EC, Nelis F, Dent J, Snel P, Mitchell B, Prichard P, Lloyd D, Havu N, Frame MH, Roman J, Walan A. Long-term omeprazole treatment in resistant gastroesophageal reflux disease: efficacy, safety, and influence on gastric mucosa. Gastroenterology 2000;118:661-9.

3. O'Connell MB, Madden DM, Murray AM, Heaney RP, Kerzner LJ. Effects of proton pump inhibitors on calcium carbonate absorption in women: a randomized crossover trial. Am J Med 2005;118:778-81.

4. Nealis TB, Howden CW. Is There a Dark Side to Long-term Proton Pump Inhibitor Therapy? Am J Ther 2008;15:536-42.

5. Cote GA, Howden CW. Potential adverse effects of proton pump inhibitors. Curr Gastroenterol Rep 2008;10:208-14.

6. Proton pump inhibitors and risk of fractures: a meta-analysis of 11 international studies Yu EW, Bauer SR, Bain PA, Bauer DC.Am J Med. 2011 Jun;124(6):519-26. doi: 10.1016/j.amjmed.2011.01.007

7. Weng MY, Lane NE: Medication-induced osteoporosis. Curr Osteoporos Rep 5:139-145, 2007

8. Flum DR, Koepsell T, Heagerty $\mathrm{P}$, et al: The nationwide frequency of major adverse outcomes in antireflux surgery and the role of surgeon experience, 1992-1997. J Am Coll Surg 195:611-618, 2002

9. Bammer T, Hinder RA, Klaus A, Klingler PJ. Five- to eight-year outcome of the first laparoscopic Nissen fundoplications. J Gastrointest Surg 2001;5:42-8

10. Gee DW, Andreoli MT, Rattner DW: Measuring the effectiveness of laparoscopic antireflux surgery: long term results. Arch Surg 143:482-487, 2008

11. Dassinger MS, Torquati A, Houston HL, et al: Laparoscopic fundoplication: 5-year follow-up. Am Surg 70:691-694; discussion 694-695, 2004

12. Stein HJ, DeMeester TR: Outpatient physiologic testing and surgical management of foregut motility disorders. Curr Probl Surg 29:413-555, 1992

13. Sloan S, Rademaker AW, Kahrilas PJ: Determinants of gastroesophageal junction incompetence: hiatal hernia, lower esophageal sphincter, or both? Ann Intern Med 117:977-982, 1992

14. Adler RH, Firme CN, Lanigan JM: A valve mechanism to prevent gastroesophageal reflux and esophagitis. Surgery 44:63-76, 1958

15. Ellis FH Jr, Lyons WS, Olsen AM: The gastroesophageal sphinctermechanism: a review. Proc Staff Meet Mayo Clin 31:605-614, 1956

16. Hill LD, Kozarek RA: The gastroesophageal flap valve. J Clin Gastroenterol 28:194-197, 1999

17. Liebermann-Meffert D, Allgower M, Schmid P, et al: Muscular equivalent of the lower esophageal sphincter. Gastroenterology 76:31-38, 1979

18. Hill LD, Kozarek RA, Kraemer SJ, et al: The gastroesophageal flap valve: in vitro and in vivo observations. Gastrointest Endosc 44:541-547, 1996

19. Allison PR. Peptic ulcer of the oesophagus. Thorax. 1948;3(1):20-42.

20. Allison PR. Hiatus hernia: (a 20-year retrospective survey). Ann Surg. 1973;178(3):273-6.

21. Nissen R. [A simple operation for control of reflux esophagitis.]. Schweiz Med Wochenschr. 1956;86(Suppl 20):590-2.

22. Kahrilas PJ, Shaheen NJ, Vaezi MF. American Gastroenterological Association Institute technical review on the management of gastroesophageal reflux disease. Gastroenterology. 2008;135(4): 1392-1413, 1413 e1-5.

23. Campos GM, Peters JH, DeMeester TR, et al. Multivariate analysis of factors predicting outcome after laparoscopic Nissen fundoplication. J Gastrointest Surg. 1999;3(3):292-300.

24. Geagea T. Laparoscopic Nissen's fundoplication: preliminary report on ten cases. Surg Endosc. 1991;5(4):170-3. 
25. Dallemagne B, Weerts JM, Jehaes C, Markiewicz S, Lombard R. Laparoscopic Nissen fundoplication: preliminary report. Surg Laparosc Endosc. 1991;1(3):138-43.

26. Deschamps C, Allen MS, Trastek VF, Johnson JO, Pairolero PC. Early experience and learning curve associated with laparoscopic Nissen fundoplication. J Thorac Cardiovasc Surg. 1998;115(2):281-4; discussion 284-5.

27. Soper NJ, Dunnegan D. Anatomic fundoplication failure after laparoscopic antireflux surgery. Ann Surg. 1999;229(5):669-76; discussion 676-7.

28. Watson DI, Baigrie RJ, Jamieson GG. A learning curve for laparoscopic fundoplication. Definable, avoidable, or a waste of time? Ann Surg. 1996;224(2):198-203.

29. Reavis KM. Management of the obese patient with gastroesophageal reflux disease. Thorac Surg Clin;21(4):489-98.

30. Nilsson G, Larsson S, Johnsson F. Randomized clinical trial of laparoscopic versus open fundoplication: blind evaluation of recovery and discharge period. Br J Surg. 2000;87(7):873-8.

31. Laine S, Rantala A, Gullichsen R, Ovaska J. Laparoscopic vs conventional Nissen fundoplication. A prospective randomized study. Surg Endosc. 1997;11(5):441-4.

32. Salminen P, Sala E, Koskenvuo J, Karvonen J, Ovaska J. Reflux laryngitis: a feasible indication for laparoscopic antireflux surgery? Surg Laparosc Endosc Percutan Tech. 2007;17(2):73-8.

33. Hakanson BS, Thor KB, Thorell A, Ljungqvist O. Open vs laparoscopic partial posterior fundoplication : A prospective randomized trial. Surg Endosc. 2007:289-298.

34. Heikkinen TJ, Haukipuro K, Bringman S, Ramel S, Sorasto A, Hulkko A. Comparison of laparoscopic and open Nissen fundoplication 2 years after operation. A prospective randomized trial. Surg Endosc. 2000;14(11):1019-23.

35. Chrysos E, Tsiaoussis J, Athanasakis E, Zoras O, Vassilakis JS, Xynos E. Laparoscopic vs open approach for Nissen fundoplication. A comparative study. Surg Endosc. 2002;16(12):1679-84.

36. Ackroyd R, Watson DI, Majeed AW, Troy G, Treacy PJ, Stoddard CJ. Randomized clinical trial of laparoscopic versus open fundoplication for gastro-oesophageal reflux disease. Br J Surg. 2004;91(8):975-82.

37. Bais JE, Bartelsman JF, Bonjer HJ, et al. Laparoscopic or conventional Nissen fundoplication for gastro-oesophageal reflux disease: randomised clinical trial. The Netherlands Antireflux Surgery Study Group. Lancet. 2000;355(9199):170-4.

38. Peters MJ, Mukhtar A, Yunus RM, et al. Meta-analysis of randomized clinical trials comparing open and laparoscopic anti-reflux surgery. Am J Gastroenterol. 2009;104(6):1548-61; quiz 1547, 1562.

39. Haider M, Iqbal A, Salinas V, Karu A, Mittal SK, Filipi CJ. Surgical repair of recurrent hiatal hernia. Hernia. 2006;10(1):13-9.

40. Viljakka MT, Luostarinen ME, Isolauri JO. Complications of open and laparoscopic antireflux surgery: 32-year audit at a teaching hospital. J Am Coll

41. Bais JE, Bartelsman JF, Bonjer HJ, et al. Laparoscopic or conventional Nissen fundoplication for gastro-oesophageal reflux disease: randomised clinical trial. The Netherlands Antireflux Surgery Study Group. Lancet. 2000;355(9199):170-174.

42. Broeders JA, Rijnhart-de Jong HG, Draaisma WA, Bredenoord AJ, Smout AJ, Gooszen HG. Ten-year outcome of laparoscopic and conventional nissen fundoplication: randomized clinical trial. Ann Surg. 2009;250(5):698-706.

43. Stefanidis D, Hope WW, Kohn GP, Reardon PR, Richardson WS, Fanelli RD. Guidelines for surgical treatment of gastroesophageal reflux disease. Surg Endosc;24(11):2647-69.

44. Attwood SE, Lundell L, Ell C, et al. Standardization of surgical technique in antireflux surgery: the LOTUS Trial experience. World J Surg. 2008;32(6):995-8.

45. DeMeester TR, Bonavina L, Albertucci M. Nissen fundoplication for gastroesophageal reflux disease. Evaluation of primary repair in 100 consecutive patients. Ann Surg. 1986;204(1):9-20.

46. Hunter JG, Trus TL, Branum GD, Waring JP, Wood WC. A physiologic approach to laparoscopic fundoplication for gastroesophageal reflux disease. Ann Surg. 1996;223(6):673-85; discussion 685-7.

47. Donahue PE, Samelson S, Nyhus LM, Bombeck CT. The floppy Nissen fundoplication. Effective longterm control of pathologic reflux. Arch Surg. 1985;120(6):663-8. 
48. Stein HJ, Bremner RM, Jamieson J, DeMeester TR. Effect of Nissen fundoplication on esophageal motor function. Arch Surg. 1992;127(7):788-91.

49. Strate U, Emmermann A, Fibbe C, Layer P, Zornig C. Laparoscopic fundoplication: Nissen versus Toupet two-year outcome of a prospective randomized study of 200 patients regarding preoperative esophageal motility. Surg Endosc. 2008;22(1):21-30.

50. Booth MI, Stratford J, Jones L, Dehn TC. Randomized clinical trial of laparoscopic total (Nissen) versus posterior partial (Toupet) fundoplication for gastro-oesophageal reflux disease based on preoperative oesophageal manometry. Br J Surg. 2008;95(1):57-63.

51. Varin O, Velstra B, De Sutter S, Ceelen W. Total vs partial fundoplication in the treatment of gastroesophageal reflux disease: a meta-analysis. Arch Surg. 2009;144(3):273-8.

52. Jobe BA, Wallace J, Hansen PD, Swanstrom LL. Evaluation of laparoscopic Toupet fundoplication as a primary repair for all patients with medically resistant gastroesophageal reflux. Surg Endosc. 1997;11(11):1080-3.

53. Patti MG, Robinson T, Galvani C, Gorodner MV, Fisichella PM, Way LW. Total fundoplication is superior to partial fundoplication even when esophageal peristalsis is weak. J Am Coll Surg. 2004;198(6):863-9; discussion 869-70.

54. Mardani J, Lundell L, Engstrom C. Total or posterior partial fundoplication in the treatment of GERD: results of a randomized trial after 2 decades of follow-up. Ann Surg;253(5):875-8.

55. Broeders JA, Mauritz FA, Ahmed Ali U, et al. Systematic review and meta-analysis of laparoscopic Nissen (posterior total) versus Toupet (posterior partial) fundoplication for gastro-oesophageal reflux disease. Br J Surg;97(9):1318-30.

56. Baigrie RJ, Cullis SN, Ndhluni AJ, Cariem A. Randomized double-blind trial of laparoscopic Nissen fundoplication versus anterior partial fundoplication. Br J Surg. 2005;92(7):819-23.

57. Watson DI, Jamieson GG, Lally C, et al. Multicenter, prospective, double-blind, randomized trial of laparoscopic nissen vs anterior 90 degrees partial fundoplication. Arch Surg. 2004;139(11):11607.

58. Spence GM, Watson DI, Jamiesion GG, Lally CJ, Devitt PG. Single center prospective randomized trial of laparoscopic Nissen versus anterior 90 degrees fundoplication. J Gastrointest Surg. 2006;10(5):698-705.

59. Ludemann R, Watson DI, Jamieson GG, Game PA, Devitt PG. Five-year follow-up of a randomized clinical trial of laparoscopic total versus anterior 180 degrees fundoplication. Br J Surg. 2005;92(2):240-3.

60. Nijjar RS, Watson DI, Jamieson GG, et al. Five-year follow-up of a multicenter, double-blind randomized clinical trial of laparoscopic Nissen vs anterior 90 degrees partial fundoplication. Arch Surg;145(6):552-7.

61. Broeders JA, Roks DJ, Jamieson GG, Devitt PG, Baigrie RJ, Watson DI. Five-year outcome after laparoscopic anterior partial versus Nissen fundoplication: four randomized trials. Ann Surg;255(4): 637-42.

62. Smith CD, McClusky DA, Rajad MA, Lederman AB, Hunter JG. When fundoplication fails: redo? Ann Surg. 2005;241(6):861-9; discussion 869-71.

63. Iqbal A, Awad Z, Simkins J, et al. Repair of 104 failed anti-reflux operations. Ann Surg. 2006;244(1):42-51.

64. Coelho JC, Goncalves CG, Claus CM, Andrigueto PC, Ribeiro MN. Late laparoscopic reoperation of failed antireflux procedures. Surg Laparosc Endosc Percutan Tech. 2004;14(3):113-7.

65. Furnee EJ, Draaisma WA, Broeders IA, Gooszen HG. Surgical reintervention after failed antireflux surgery: a systematic review of the literature. J Gastrointest Surg. 2009;13(8):1539-49.

66. Yang H, Watson DI, Lally CJ, Devitt PG, Game PA, Jamieson GG. Randomized trial of division versus nondivision of the short gastric vessels during laparoscopic Nissen fundoplication: 10-year outcomes. Ann Surg. 2008;247(1):38-42.

67. O'Boyle CJ, Watson DI, Jamieson GG, Myers JC, Game PA, Devitt PG. Division of short gastric vessels at laparoscopic nissen fundoplication: a prospective double-blind randomized trial with 5-year follow-up. Ann Surg. 2002;235(2):165-70. 
68. Blomqvist A, Dalenback J, Hagedorn C, Lonroth H, Hyltander A, Lundell L. Impact of complete gastric fundus mobilization on outcome after laparoscopic total fundoplication. J Gastrointest Surg. 2000;4(5):493-500.

69. Engstrom C, Blomqvist A, Dalenback J, Lonroth H, Ruth M, Lundell L. Mechanical consequences of short gastric vessel division at the time of laparoscopic total fundoplication. J Gastrointest Surg. 2004;8(4):442-7.

70. Chrysos E, Tzortzinis A, Tsiaoussis J, Athanasakis H, Vasssilakis J, Xynos E. Prospective randomized trial comparing Nissen to Nissen-Rossetti technique for laparoscopic fundoplication. Am J Surg. 2001;182(3):215-21.

71. Engstrom C, Jamieson GG, Devitt PG, Watson DI. Meta-analysis of two randomized controlled trials to identify long-term symptoms after division of the short gastric vessels during Nissen fundoplication. Br J Surg;98(8):1063-7.

72. Patterson EJ, Herron DM, Hansen PD, Ramzi N, Standage BA, Swanstrom LL. Effect of an esophageal bougie on the incidence of dysphagia following nissen fundoplication: a prospective, blinded, randomized clinical trial. Arch Surg. 2000;135(9):1055-61; discussion 1061-2.

73. Somasekar K, Morris-Stiff G, Al-Madfai H, Barton K, Hassn A. Is a bougie required for the performance of the fundal wrap during laparoscopic Nissen fundoplication? Surg Endosc;24(2):390-4.

74. Markar SR, Karthikesalingam AP, Hagen ME, Talamini M, Horgan S, Wagner OJ. Robotic vs. laparoscopic Nissen fundoplication for gastro-oesophageal reflux disease: systematic review and metaanalysis. Int J Med Robot;6(2):125-31.

75. Jafri SM, Arora G, Triadafilopoulos G. What is left of the endoscopic antireflux devices? Curr Opin Gastroenterol. 2009 Jul;25(4):352-7. Review.

76. Torquati A, Richards WO: Endoluminal GERD treatments: critical appraisal of current literature with evidence-based medicine instruments. Surg Endosc 21:697-706, 2007

77. Cicala M, Gabbrielli A, Emerenziani S, et al: Effect of endoscopic augmentation of the lower esophageal sphincter (Gatekeeper reflux repairsystem) on intraesophageal dynamic characteristics of acid reflux. Gut54:183-186, 2005

78. Jobe BA, Kahrilas PJ, Vernon AH, et al: Endoscopic appraisal of the gastroesophageal valve after antireflux surgery. Am J Gastroenterol 99:233-243, 2004

79. Falk GW, Fennerty MB, Rothstein RI: AGA Institute medical position statement on the use of endoscopic therapy for gastroesophageal refluxdisease. Gastroenterology 131:1313-1314, 2006

80. DeVault KR, Castell DO: Updated guidelines for the diagnosis andtreatment of gastroesophageal reflux disease. Am J Gastroenterol 100:190-200, 2005

81. Filipi CJ, Lehman GA, Rothstein RI, et al: Transoral, flexible endoscopic suturing for treatment of GERD: a multicenter trial. Gastrointest Endosc 53:416-422, 2001

82. Schiefke I, Zabel-Langhennig A, Neumann S, et al: Long-term failure of endoscopic gastroplication (EndoCinch). Gut 54:752-758, 2005

83. Pleskow D, Rothstein R, Lo S, et al: Endoscopic full-thickness plication for the treatment of GERD: a multicenter trial. Gastrointest Endosc 59:163-171, 2004

84. Pleskow D, Rothstein R, Lo S, et al: Endoscopic full-thickness plication for the treatment of GERD: 12-month follow-up for the North American open-label trial. Gastrointest Endosc 61:643-649, 2005

85. Rothstein R, Filipi C, Caca K, et al: Endoscopic full-thickness plication for the treatment of gastroesophageal reflux disease: a randomized, sham-controlled trial. Gastroenterology 131:704-712, 2006

86. Pleskow D, Rothstein R, Kozarek R, et al: Endoscopic full-thickness plication for the treatment of GERD: five-year long-term multicenter results. Surg Endosc 22:326-332, 2008

87. Cadiere GB, Buset M, Muls V, et al: Antireflux transoral incisionless fundoplication using esophyX: 12-month results of a prospective multicenter study. World J Surg 32:1676-88, 2008

88. Jobe BA, O’Rourke RW, McMahon BP, et al: Transoral endoscopic fundoplication in the treatment of gastroesophageal reflux disease: the anatomic and physiologic basis for reconstruction of the esophagogastric junction using a novel device. Ann Surg 248:69-76, 2008 
89 Eckardt AJ, Pinnow G, Pohl H, Wiedenmann B, Rosch T. Antireflux 'barriers": problems with patient recruitment for a new endoscopic antireflux procedure. Eur J Gastroenterol Hepatol 2009;21:1110-8

90. Morgenthal CB, Lin E, Shane MD, Hunter JG, Smith CD. Who will fail laparoscopic Nissen fundoplication? Preoperative prediction of long-term outcomes. Surg Endosc 2007;21:1978-84. 



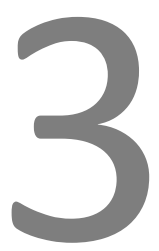

Transoral incisionless fundoplication for treatment of gastroesophageal reflux disease in clinical practice 


\section{ABSTRACT}

\section{Background}

Transoral incisionless fundoplication (TIF) is a recently introduced endoluminal technique for the treatment of gastroesophageal reflux disease (GERD). The objective of this study was to determine outcomes in chronic GERD patients who were referred for surgical treatment.

\section{Methods}

A cohort of 38 patients underwent TIF in a tertiary care setting. Pre-, and postprocedure assessment included GERD-related quality of life questionnaires, proton pump inhibitor (PPI) usage, 24-h pH-measurements, upper gastrointestinal endoscopy, esophageal manometry and registration of adverse events. Duration of follow-up was 36 months.

\section{Results}

Gastroesophageal valves were constructed of $4 \mathrm{~cm}$ (range 4-6) in length and 220 degrees (range 180-240) in circumference. One serious adverse event occurred, consisting of intraluminal bleeding at a fastener site. Hiatal hernia was completely reduced in $56 \%$ and esophagitis was cured in $47 \%$ of patients. Post-procedure esophageal acid exposure did not significantly improve ( $p>0.05)$. At 36 months (range 29-41) follow-up 14 patients (37\%) had undergone revisional laparoscopic fundoplication. Quality of life scores of the remaining cohort showed significant improvement $(\mathrm{p}<0.0001)$ and daily use of antisecretory medication was discontinued by $74 \%$.

\section{Conclusion}

Endoluminal fundoplication improved quality of life and reduced the need for PPIs in only a subgroup of patients at three years follow-up. The amount of patients requiring additional medication and revisional surgery was high.

Published as:

Transoral incisionless fundoplication for treatment of gastroesophageal reflux disease in clinical practice. Witteman BPL, Strijkers R, De Vries EE, Toemen L, Conchillo JM, Hameeteman W, Dagnelie PC, Koek GH, , Bouvy ND. Surg Endosc. 2012 Nov; 26(11): 3307-15.

Presented as:

Transoral incisionless fundoplication for treatment of gastroesophageal reflux disease in clinical practice. Three years follow-up in 38 chronic GERD patients. Witteman BPL, De Vries EE, Strijkers R, Dagnelie PC, Koek GH, Conchillo JM, Bouvy ND. Annual meeting of The Dutch Society of Gastroenterology and Gastrointestinal Surgery, 2010, Veldhoven. 


\section{INTRODUCTION}

Gastroesophageal reflux disease (GERD) is defined as a condition that develops when the reflux of stomach contents causes troublesome symptoms and/or complications and has a prevalence of $10-20 \%$ in Western Europe and North America. ${ }^{1}$ The goals of clinical management of gastroesophageal disease (GERD) are prompt symptom relief, long-term symptom control and maintenance of esophageal healing. 2,3 The current algorithm for the effective treatment of GERD consists of antisecretory medication at all patient care levels. ${ }^{4}$ Antireflux surgery is reserved for "refractory" patients who do not respond symptomatically to a double dose of proton pump inhibitors (PPIs) and those who experience PPI intolerance, complications or are unwilling to stay on continuous medication lifelong.4-12

In view of the invasiveness of surgery, a less invasive endoscopic procedure for treatment of GERD would be appealing. Several procedures, based on different mechanisms of action, have been developed. ${ }^{13-16}$ Many endoscopic techniques and devices, however, did not withstand the test of randomized controlled trials and many have been withdrawn from the market. One of the latest endoscopic techniques for treatment of GERD is transoral incisionless fundoplication (TIF), which is currently under evaluation. ${ }^{17,18}$ The purpose of this study was to review and report the safety and effectiveness of first-generation technique (TIF1) in 38 chronic GERD patients, who were referred for surgical therapy in our center, a 720-bed tertiary care University Hospital.

\section{METHODS}

\section{Patient characteristics}

TIF1 was offered to patients who were referred for surgical GERD management, because they required high doses of PPIs but were either refractory, unsatisfied or unwilling to have a lifelong commitment to medication. Inclusion criteria for the procedure were chronic GERD ( $>6$ months), age of 18-75 years, body mass index (BMI) $<36 \mathrm{~kg} / \mathrm{m}^{2}$, and normal or hypotonic lower esophageal sphincter (LES) pressure $(<30 \mathrm{mmHg}$ ). The presence of gastroesophageal reflux was confirmed by either pathological 24-h esophageal $\mathrm{pH}$ monitoring or, in case of the intolerance to the ambulatory 24-h pH-system catheter, upper GI barium radiography in both recumbent and Trendelenberg position following standard protocols. Patients were excluded if they had large hiatal hernia $(>5 \mathrm{~cm})$, esophagitis grade $C$ or $D$ in the Los Angeles classification or Barrett's esophagus, hypertonic LES pressure (>30 mm Hg) or motility disorders. ${ }^{19}$ These criteria were chosen as we assumed that patients who met these criteria would respond well to the new endoluminal fundoplication. Patients underwent follow-up assessment to evaluate treatment effectiveness. Resumption of PPIs or revisional standard laparoscopic Nissen fun- 
doplication was offered in case of treatment failure based on relapse of symptoms. Data were collected in a prospective fashion with additional retrospective chart reviews. The research protocol was approved by the Maastricht Medical Ethics Committee (MEC 09-4-046.2/pl).

\section{Procedure details}

TIF1 procedure was performed using the EsophyX-1 $1^{\mathrm{TM}}$-device (EndoGastric Solutions, Inc., Redmond, WA, USA) under general anesthesia following the TIF1 protocol. ${ }^{20-22}$ The device was inserted transorally into the esophagus with the patient in left lateral position. Hiatal hernia, if present, was reduced by pushing the squamocolumnar junction to its natural position below the diaphragm using the built-in vacuum invaginator. The gastroesophageal valve (GEV) was restored with a partial fundoplication using a series of sequential retractions of tissue and placement of multiple polypropylene "serosa-fuse ${ }^{\mathrm{TM}}$ " fasteners circumferentially around the gastroesophageal junction (GEJ).

\section{Safety assessment}

The incidence of serious and non-serious adverse events was recorded. Serious adverse events were defined as complications necessitating hospitalization and medical or surgical intervention. Non-serious adverse events represented expected side effects and symptoms.

\section{Effectiveness assessment}

GERD-related quality of life was assessed by the GERD health-related quality-of-life (GERD-HRQL) questionnaire. ${ }^{23-25}$ The questionnaire was developed and validated to measure changes of typical GERD symptoms such as heartburn, in response to surgical or medical treatment. In the present study, an extended version of the questionnaire was used to assess regurgitation. A visual analogue scale ranged from 0 (no symptom) to 5 (worst symptom) and scores of $\leq 2$ were indicative of rare or absent symptoms. ${ }^{23,26}$ The heartburn and regurgitation scores were calculated by summing the responses to six questions referring to each symptom, and the scores $\leq 12$ with each score $\leq 2$ were indicative of symptom elimination. Total GERD-HRQL scores $\leq 30$ with each score $\leq 2$ were considered normal. Patients' satisfaction was evaluated as either satisfied, neutral, or dissatisfied. ${ }^{23}$ Quality of life was evaluated at baseline while on antisecretory medication and at 6 and 36 months while off medication. Patients were asked to stop their PPIs at 14 days after the procedure. In case of persisting or recurrent symptoms, PPIs were resumed on demand and recorded. "Daily" usage of PPIs corresponded to full-, or half-dose taken for more than $50 \%$ of the preceding follow-up period, "occasional" 
to half-dose (or less) taken for $<50 \%$ of the preceding follow-up period, and "none" to no medication taken within the specified period.

At 3 months post-procedure, all patients underwent follow-up testing $(\mathrm{pH}$ metry and upper GI endoscopy). Esophageal acid exposure was measured while off PPIs at screening and at 3 months postprocedure using the Orion II Ambulatory 24-h pH System (Medical Measurement Systems, Enschede, The Netherlands). Normal esophageal acid exposure was defined by $\mathrm{pH}<4$ for $\leq 4.2 \%$ of the total monitoring time. A reduction in esophageal acid exposure to $\leq 4.2 \%$ of time or by at least $30 \%$ compared to baseline was considered clinically significant. ${ }^{20}$

Hiatal hernia and esophagitis were assessed by upper GI endoscopy. ${ }^{27,} 28$ The displacement of the squamocolumnar junction proximal to the diaphragmatic hiatus by at least $1 \mathrm{~cm}$ was determinant of sliding hiatal hernia and measured endoscopically using standard protocols. ${ }^{29}, 30$ The procedure was intended to reduce small and medium size hiatal hernia (1-5 cm). Because hiatal hernia size correlates with the presence and severity of esophagitis, its $50 \%$ reduction was considered clinically significant. ${ }^{31}$ Esophagitis was assessed following the Los Angeles classification scale and its reduction by one grade was considered clinically significant. ${ }^{19}$ During upper GI endoscopy, the anatomic aspects of the restored GEV's were assessed by measuring their body length, defined as the length in $\mathrm{cm}$ from the apex of the fundus to the valve lip, and circumference between the two most distant fasteners, as well as by estimating adherence to the endoscope (tight, moderate or loose) and Hill grade. ${ }^{32,33}$ The design of the study has been illustrated in the study timeline (figure 3.1).

\section{Statistical analysis}

Data were analyzed using SPSS $®$ software version 16.0 (SPSS, Inc., Chicago, IL, USA). Continuous variables, such as age, procedure duration, GERD-HRQL scores, percentage of time at $\mathrm{pH}<4$, hiatal hernia size and valve measurements, were summarized by median and range to better represent the location of the population main trend because of the generally-skewed data distribution. Categorical variables, such as adverse events, PPI usage, satisfaction level, Hill grade, adherence and esophagitis, were summarized as counts and percentages. $p$-values for changes at follow-ups compared to baseline within groups were calculated using the Wilcoxon signed-rank test.

Predictors of clinical effectiveness were evaluated through correlation analysis between GERD-HRQL scores and anatomic and pathophysiologic variables. At 36 months follow-up, categorical variables were compared between groups using the Fischer's exact test and continues variables using Mann-Whitney $U$ test. Two tailed $p$-values of $<0.05$ were considered statistically significant. Backward stepwise regression models were used to select independent predictors of failure. 


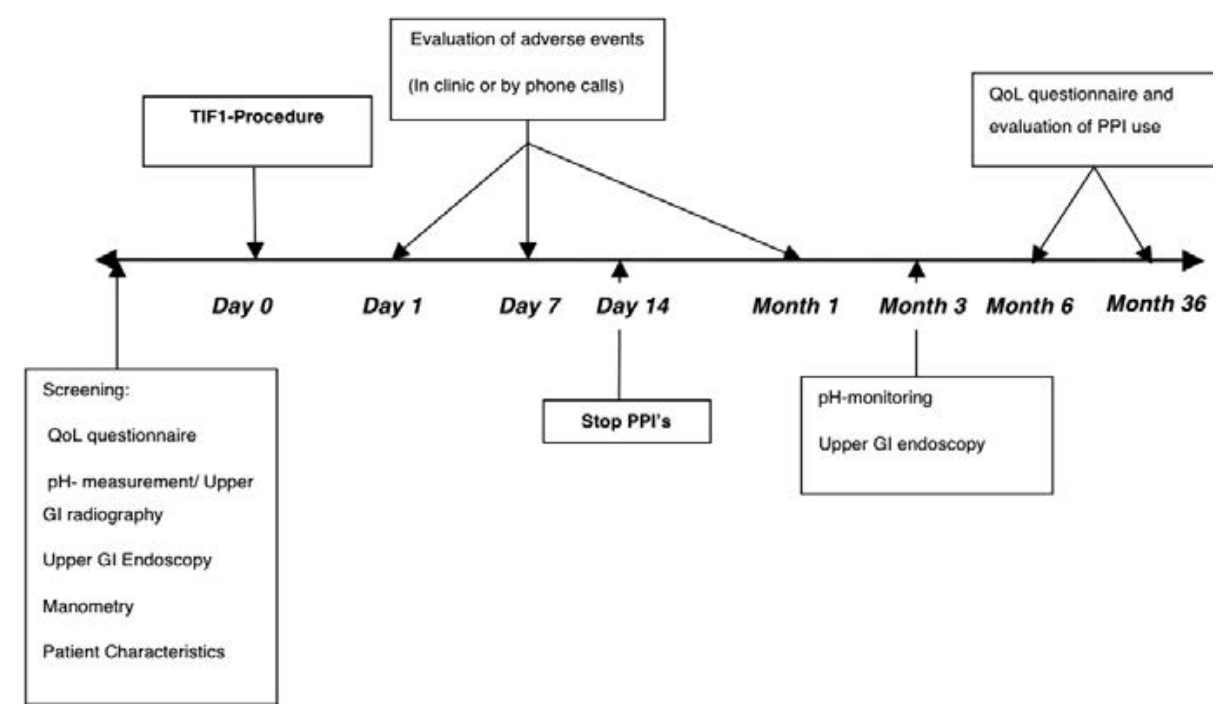

Figure 3.1 Study timeline: TIF1 cohort study.

\section{RESULTS}

\section{Patient characteristics}

A total of 38 patients underwent TIF1-procedure between June 2006 and June 2007. The majority of patients were Caucasian males between 40 and 50 years and overweight (median BMI $26.3 \mathrm{~kg} / \mathrm{m}^{2}$, range 20-36). Patients suffered from GERD for median 6 years (range 1-25) and all were treated with antisecretory medication for median 3 years (range 1-24). Smoking was reported by $34 \%$ of patients, and $29 \%$ of patients were former smokers. Alcohol was consumed by $57 \%$ of patients at a frequency of either one drink a day (34\%) or 2-4 drinks a day (23\%). PPIs were used daily by 37 (97\%) patients, mostly at a double dose and $\mathrm{H}_{2}$ blockers were used daily by one patient. Most patients (69\%) had small-sized $(1-2 \mathrm{~cm}$, $\mathrm{n}=25$ ) and some medium-sized (3-5 cm, $\mathrm{n}=11$ ) hiatal hernia, and $39 \%$ of patients had esophagitis (table 3.1). The Quality of life screening assessment was conducted while patients were taking antisecretory medication and revealed pathologic GERD-HRQL scores in 37 (97\%) patients. Satisfaction index at screening showed $13(34 \%)$ patients were satisfied, 13 (34\%) were neutral and 12 (32\%) were dissatisfied with their health condition while using PPIs. 
Table 3.1 Patient characteristics at screening. Values are medians (ranges) or counts (\%).

\begin{tabular}{ll}
\hline No. patients & 38 \\
Female/male & $11(29 \%) / 27(71 \%)$ \\
Age $(\mathrm{y})$ & $46(22-79)$ \\
BMI (kg/m²) & $26.3(20.1-36.0)$ \\
GERD duration (y) & $6(1-25)$ \\
No. On antisecretory medication & $38(100 \%)$ \\
Duration of PPI use (y) & $3(1-24)$ \\
Hiatal hernia & $36(95 \%)$ \\
Small (1-2 cm) & $25(69 \%)$ \\
Medium (3-5 cm) & $11(31 \%)$ \\
Esophagitis & $15(39 \%)$ \\
Grade A & $7(47 \%)$ \\
Grade B & $8(53 \%)$ \\
LES resting pressure (mmHg) & $14(3-27)$ \\
\hline
\end{tabular}

\section{Procedure details}

Median duration of the procedures was 65 minutes (range 35-142), and 16 (range 10-21) fasteners were used to reconstruct the GEV. Most valves measured $4 \mathrm{~cm}$ (range 4-6) in length, 220 degree (range 180-240) in circumference, were centrally balanced (81\%) and tight (78\%). Hiatal hernia, present in 36 patients, was directly post procedure reduced to $\leq 1 \mathrm{~cm}$ in all patients. Hospitalization stay was one day for most (37 of 38) patients. All were instructed to consume a liquid diet during the first two weeks and a soft diet during the following four weeks.

\section{Safety assessment}

One serious adverse event occurred and consisted of post-operative bleeding. The night after the procedure, one patient experienced hematemaesis and melena. The patient was male, and his hemoglobin dropped from 9.5 to $7.0 \mathrm{mmol} / \mathrm{l}$. Endoscopy was repeated and did not show an active bleeding focus. The patient was closely monitored and remained hemodynamically stable as well as his hemoglobin levels. Discharge followed on the third post-operative day and no further drawbacks were reported at follow-up visits. In another patient, a mucosal lesion occurred in the esophagus with the introduction of the device. Post-operative upper GI radiography did not show signs of a full-thickness perforation and the event had no further consequences. Other adverse events were mild and resolved spontaneously in the majority of patients within the first week (table 3.2). Epigastric pain was most commonly reported by 37 (97\%) patients, further left shoulder pain (29\%) and 
pharynx irritation (16\%). Dysphagia and gas-bloating was reported by four (11\%) patients and lasted up to one week.

Table 3.2 Adverse events reported after TIF1 grouped in order of occurrence and by their duration. Values represent a percentage of patients experiencing each adverse event at one day, one week and one month after the procedure.

\begin{tabular}{llll}
\hline & Day 1 & Week 1 & Month 1 \\
\hline Epigastric pain & $37(97 \%)$ & $11(29 \%)$ & $1(3 \%)$ \\
Left shoulder pain & $11(29 \%)$ & $6(16 \%)$ & $3(8 \%)$ \\
Pharynx irritation & $6(16 \%)$ & $0(0 \%)$ & $0(0 \%)$ \\
Dysphagia & $4(11 \%)$ & $1(3 \%)$ & $0(0 \%)$ \\
Fever & $4(11 \%)$ & $2(5 \%)$ & $0(0 \%)$ \\
Gas-bloating & $4(11 \%)$ & $2(5 \%)$ & $0(0 \%)$ \\
Nausea & $4(11 \%)$ & $0(0 \%)$ & $0(0 \%)$ \\
Hematemesis & $3(8 \%)$ & $0(0 \%)$ & $0(0 \%)$ \\
Vomiting & $2(5 \%)$ & $0(0 \%)$ & $0(0 \%)$ \\
Mucosal tear & $1(3 \%)$ & $1(3 \%)$ & $0(0 \%)$ \\
Pneumonia & $0(0 \%)$ & $2(5 \%)$ & $0(0 \%)$ \\
\hline
\end{tabular}

\section{Clinical effectiveness}

At a follow-up period of 6 months (range 3-15) over $80 \%$ of patients had normal GERD-HRQL, heartburn and regurgitation scores (table 3.3). Seventy-percent of patients were satisfied with their health condition, $27 \%$ neutral and 3\% dissatisfied. Daily use of antisecretory medication was discontinued by 31 (82\%) patients (table 3.4) and reduced in dosage by six of the remaining seven patients. Postprocedure esophageal acid exposure while off medication was decreased but did not show significant improvement (table 3.5). Hiatal hernia was completely reduced in $56 \%$ of patients and reduced in size in $75 \%$ of patients (table 3.6 ) compared to baseline. The reduction rate of both small and medium hiatal hernia was equally successful and occurred in $72 \%$ and $73 \%$ of patients, respectively. Complete reduction was higher for small hiatal hernia than for medium hiatal hernia size (60\% vs. $45 \%)$. At 3 months, esophagitis was not changed significantly and was present in $34 \%$ of patients at post-procedure endoscopic evaluation. Among patients who had esophagitis at baseline, 47\% experienced complete healing and $6 \%$ experienced its reduction by one grade, however, four patients experienced worsening in their scores from endoscopically-negative at baseline to grade $\mathrm{A}$ $(n=1)$ or grade $B(n=3)$.

At 36 months follow-up, 14 (37\%) patients had undergone revisional laparoscopic Nissen fundoplication, because their GERD symptoms were not satisfactory managed. In the revisional surgery, the TIF fundoplication was taken down laparoscopically by dissecting though the serosa-to-serosa fusion layer until anatomy was restored to the pre-TIF situation. Laparoscopic Nissen fundoplication was feasible in all of these patients. 
Table 3.3 GERD Health-Related Quality of Life (HRQL), heartburn and regurgitation scores.

\begin{tabular}{|c|c|c|c|}
\hline & $\begin{array}{l}\text { Median } \\
\text { (range) }\end{array}$ & $\begin{array}{l}\text { Median \%improvement versus } \\
\text { baseline On PPIs }\end{array}$ & $\begin{array}{l}\text { N (\%) with normal } \\
\text { GERD-scores }^{\text {a }}\end{array}$ \\
\hline \multicolumn{4}{|l|}{ GERD-HRQL-score: } \\
\hline Pre TIF1 On PPIs & $33(7-69)$ & & \\
\hline Post TIF1 Off PPIs 6 months $(n=38)$ & $4(0-51)$ & $87 \%(p<0.0001)$ & $31(82 \%)$ \\
\hline Post TIF1 Off PPIs 36 months ( $n=19)$ & $5(0-29)$ & $83 \%(p<0.0001)$ & $9(47 \%)$ \\
\hline \multicolumn{4}{|l|}{ Heartburn score } \\
\hline Pre TIF1 On PPIs & $17(5-30)$ & & \\
\hline Post TIF1 Off PPIs 6 months $(n=38)$ & $3(0-20)$ & $84 \%(p<0.0001)$ & $31(82 \%)$ \\
\hline Post TIF1 Off PPIs 36 months ( $n=19)$ & $0(0-5)$ & $100 \%(p<0.0001)$ & $13(86 \%)$ \\
\hline \multicolumn{4}{|l|}{ Regurgitation score: } \\
\hline Pre TIF1 On PPIs & $14(0-29)$ & & \\
\hline Post TIF1 Off PPIs 6 months $(n=38)$ & $0(0-20)$ & $83 \%(p<0.0001)$ & $34(89 \%)$ \\
\hline Post TIF1 Off PPIs 36 months ( $n=19)$ & $1(0-5)$ & $90 \%(p<0.0001)$ & $13(86 \%)$ \\
\hline
\end{tabular}

${ }^{a}$ GERD-HRQL scores were normal if $\leq 30$ and each individual score was $\leq 2$; heartburn and regurgitation scores were normal if $\leq 12$ and each individual score was $\leq 2$.

In the remaining cohort of 24 patients, four were lost to follow-up and one patient was deceased two years after TIF1-procedure of non-GERD-related cause (ischemic heart disease). In this group of 19 patients, 47\% had normal GERD-HRQL-scores and $86 \%$ had normal heartburn and regurgitation scores (table 3.3). Seventy percent of patients were satisfied, $27 \%$ were neutral and $3 \%$ were dissatisfied with their health condition. Daily use of antisecretory medication was discontinued by 8 (42\%) patients and used occasional in 32\% (table 3.4).

Table 3.4 Usage of PPIs before, 6 months after TIF1 and 36 months after TIF1. Values represent counts (\%).

\begin{tabular}{lrlr}
\hline & Daily & Occasional & None \\
\hline Baseline & $37(97 \%)$ & $0(0 \%)$ & $1(3 \%)$ \\
Post-TIF1 6 months $(n=38)$ & $7(18 \%)$ & $6(16 \%)$ & $25(66 \%)$ \\
Post-TIF1 36 months $(n=19)$ & $5(26 \%)$ & $6(32 \%)$ & $8(42 \%)$ \\
\hline
\end{tabular}

Table 3.5 Esophageal pH monitoring while off PPIs pre-TIF-procedure and at 3 months follow-up. Values are medians (ranges).

\begin{tabular}{llll}
\hline & $\begin{array}{l}\text { Baseline off PPIs } \\
(\mathbf{n}=\mathbf{3 6})\end{array}$ & $\begin{array}{l}\text { Post-TIF1 off PPIs } \\
(\mathbf{n}=33)\end{array}$ & $\begin{array}{l}\text { Median \% improvement } \\
\text { vs. baseline }^{\text {a }}\end{array}$ \\
\hline Percentage time $\mathrm{pH}<4$ & $7.4(0.8-54.2)$ & $5.5(0.6-18.7)$ & $22 \%$ \\
DeMeester score & $21(3-143)$ & $17(2-63)$ & $20 \%$ \\
No. reflux episodes per 24h & $60(14-515)$ & $50(6-131)$ & $23 \%$ \\
No. long (> 5 min) episodes per 24h & $2(0-13)$ & $2(0-10)$ & $-10 \%$ \\
Longest reflux episode (min) & $10(1-88)$ & $8(1-45)$ & $17 \%$ \\
Patients (\%) with normal pH ${ }^{\text {b }}$ & $9(25 \%)$ & $14(42 \%)$ & - \\
\hline
\end{tabular}

${ }^{a}$ Median \% improvement at 3 months was not significant $(p>0.05)$ in all cases.

${ }^{\mathrm{b}}$ Normal esophageal $\mathrm{pH}$ was defined by $\mathrm{pH}<4$ for less than or equal to $4.2 \%$ of 24 -h monitoring time. 
Table 3.6 Endoscopic examination of gastroesophageal valves before and 3 months after TIF1.

\begin{tabular}{|c|c|c|}
\hline & Baseline $(n=38)$ & 3 months Post-TIF1 $(n=38)$ \\
\hline \multicolumn{3}{|l|}{ Hill grade } \\
\hline n (\%): Grade I & $3(8 \%)$ & $21(55 \%)$ \\
\hline Grade II & $11(29 \%)$ & $7(18 \%)$ \\
\hline Grade III & $12(32 \%)$ & $10(26 \%)$ \\
\hline Grade IV & $12(32 \%)$ & $0(0 \%)$ \\
\hline Reduced vs. pre-TIF & - & $35 / 38(92 \%)$ \\
\hline \multicolumn{3}{|l|}{ Hiatal hernia } \\
\hline Present & $36(95 \%)$ & $16(42 \%)$ \\
\hline $\mathrm{n}(\%): \quad 1-2 \mathrm{~cm}$ & 25 (69\%) & $13(81 \%)$ \\
\hline $3-5 \mathrm{~cm}$ & $11(31 \%)$ & $3(19 \%)$ \\
\hline Reduced $>50 \%$ & - & $27 / 36(75 \%)$ \\
\hline $\mathrm{n}(\%): \quad 1-2 \mathrm{~cm}$ & - & $18 / 25(72 \%)$ \\
\hline $3-5 \mathrm{~cm}$ & & $8 / 11(73 \%)$ \\
\hline Eliminated & - & $20 / 36(56 \%)$ \\
\hline $\mathrm{n}(\%): \quad 1-2 \mathrm{~cm}$ & - & $15 / 25(60 \%)$ \\
\hline $3-5 \mathrm{~cm}$ & - & $5 / 11(45 \%)$ \\
\hline$>5 \mathrm{~cm}$ & - & $0 / 1(0 \%)$ \\
\hline Worsend & - & $0 / 0(0 \%)$ \\
\hline \multicolumn{3}{|l|}{ Esophagitis } \\
\hline Present & $15(39 \%)$ & $13(34 \%)$ \\
\hline $\mathrm{n}(\%):$ Grade A & $7(47 \%)$ & $6(46 \%)$ \\
\hline Grade B & $8(53 \%)$ & $7(54 \%)$ \\
\hline Grade $C+D$ & $0(0 \%)$ & $0(0 \%)$ \\
\hline Reduced & & $8 / 15(53 \%)$ \\
\hline n (\%): Grade A & - & $4 / 7(57 \%)$ \\
\hline Grade B & - & $3 / 8(38 \%)$ \\
\hline Grade $C+D$ & - & $0 / 0(0 \%)$ \\
\hline Eliminated & - & $7 / 15(47 \%)$ \\
\hline $\mathrm{n}(\%)$ : Grade A & - & $4 / 7(57 \%)$ \\
\hline Grade B & - & $3 / 8(38 \%)$ \\
\hline Grade $C+D$ & - & $0 / 0(0 \%)$ \\
\hline Worsend & & $4(20 \%)$ \\
\hline n (\%): None to Grade A & & $1(25 \%)$ \\
\hline None to Grade B & & $3(75 \%)$ \\
\hline
\end{tabular}

Backward stepwise regression analysis, used to identify patient characteristics that could predict treatment outcomes, showed the presence of esophagitis at screening as the only statistically significant predictor of treatment failure and the demand for revisional laparoscopic fundoplication (table 3.7). 
Table 3.7 Patient characteristics in relation to the need for revisional laparoscopic fundoplication.

\begin{tabular}{llll}
\hline No. patients & 24 & 14 & p-value \\
Female/male & $18 / 6$ & $9 / 5$ & 0.48 \\
Age (y) & $45(22-79)$ & $51(25-65)$ & 0.56 \\
BMI (kg m-2) & $27(21-36)$ & $26(20-33)$ & 0.62 \\
GERD duration (y) & $5.8(1-24)$ & $5.8(1-25)$ & 0.62 \\
Duration of PPI use (y) & $3.5(0.7-24)$ & $2.0(0.7-15)$ & 0.48 \\
Small hiatal hernia (0-2 cm) & $79 \%$ & $64 \%$ & 0.45 \\
Medium hiatal hernia (3-5 cm) & $21 \%$ & $36 \%$ & 0.45 \\
Esophagitis & $6 / 24(25 \%)$ & $9 / 14(64 \%)$ & 0.04 \\
LES resting pressure (mmHg) & $15(3-27)$ & $12(4-23)$ & 0.16 \\
3 months post TIF1 pH-metry & & & \\
Total percentage time $<4$ & $5.5 \%(0.6-19)$ & $4.2 \%(0.7-14.5)$ & 0.91 \\
\hline
\end{tabular}

\section{DISCUSSION}

Medical management of GERD with proton pump inhibitors is effective for $70-80 \%$ of GERD patients, however, the disease is not cured, resulting in a life long commitment to drug therapy. ${ }^{34}$ Refractory patients seek alternative treatment as well as patients who are unwilling to take lifelong medication, due to the medication costs or suggested side effects, such as osteoporosis and increased risks on enteric and pulmonary infections. ${ }^{35,36}$ Surgery has been the alternative to drug treatment. The 360 degree laparoscopic Nissen fundoplication is the current "gold standard" and also partial surgical fundoplication techniques have been shown to be effective for long-term GERD control as well. ${ }^{37}$

The invasiveness and side effects, such as dysphagia and gas-bloating syndrome are downsides of current surgical options and therefore, an effective less invasive endoscopic alternative is appealing. ${ }^{38}$ The ideal endoscopic antireflux procedure should be safe, easy to perform, effective, durable and minimally invasive and have the ability to be performed under conscious sedation. ${ }^{39}$ Several endoscopic techniques, based on different mechanisms of action have been tested; tissue remodeling by radiofrequency delivery, injection of bulking agents, creation of esophageal mucosal tissue pleats by suturing and full-thickness fundoplication. ${ }^{13-16}$ Most of these techniques and devices were not able to control GERD and have been withdrawn from the market.

The TIF procedure was, in contrast to most early endoscopic antireflux procedures, designed to resemble parts of the surgical fundoplication. The goal is to increase the competence of the antireflux barrier by constructing a full-thickness partial fundoplication by the deployment of transmurally placed polypropylene tissue fasteners in conjunction with circumferential tightening of the distal esophagus. Serosa-to-serosa fusion results in the recreation of a 200-300 degree GEV that can be tailored to the individual patient. ${ }^{20,22}$ The most important difference 
compared to the surgical approach is the inability of extragastric dissection to reduce (larger) hiatal hernia and to perform cruraplasty.

In the present study, TIF1-procedure was relatively safe among the 38 patients. We experienced post-operative bleeding in one patient. Another adverse event was an esophageal mucosal tear. After experiencing this event we started to use olive oil as lubricant for device introduction, which has been successful preventing this complication further on in our series. The post-operative dysphagia experienced by $11 \%$ was mild and resolved within seven days without intervention and could result from edema at the GEJ. Early gas-bloating and nausea, present in $11 \%$ of patients could be caused by insufflation of the stomach during the procedure, anesthesia or manipulations of tissue at the GEJ that possibly caused vagal irritation. These mild adverse events were also reported by others as well as postoperative bleeding, however also two full-thickness esophageal perforations upon device insertion in one series have been reported.

TIF1-technique resulted in a reduction of hiatal hernia and restoring Hill grade I GEVs in $75 \%$ of patients, based on endoscopic appearance at the end of the procedure. Complete reduction was higher for small $(1-2 \mathrm{~cm})$ hiatal hernia than for medium $(3-5 \mathrm{~cm})$ hiatal hernia size and for this reason we excluded medium hernia size in further studies using this technique. At six months follow-up, TIF1 had a promising control of symptoms and quality of life improved in over $80 \%$ of patients, with cessation of daily GERD medication. Post-procedure $\mathrm{pH}$ measurements, however, did not show a significant reduction of distal esophageal acid exposure among the 38 patients. After three years, symptoms were not satisfactorily managed among $37 \%$ to such a degree that they underwent revisional surgery. Because symptoms worsened over time for these patients after a relatively symptom-free period, durability of the restored GEV using the polypropylene tissue fasteners could be of concern. The "pull-through" of the H-fasteners through the esophageal wall has been suggested as the primary mechanism of failure with this technique. ${ }^{40}$ Another explanation of these initial encouraging outcomes could be the placebo effect. In the experience with other endoscopic therapies for GERD, this effect could be as high as $25-50 \%{ }^{41,42}$

In the remaining cohort of patients, who completed the three year follow-up, symptoms were still significantly improved and daily use of antisecretory medication was discontinued by $74 \%$. Although it remains unclear whether symptoms will increase over time in this group as well, we tried to identify patient characteristics that could predict treatment outcome by the use of backward stepwise regression analysis of our data. Patient characteristics that we recorded in this study were sex, age, BMI, GERD-duration, hiatal hernia size, presence of esophagitis at sreening, LES-resting pressure and $\mathrm{pH}$-measurements. The presence of esophagitis at screening was the only statistically significant predictor of treatment failure with the need for revisional surgery. It is possible that the durability may be worse in these patients, because the diseased tissue in the distal esophagus could possi- 
bly cause early slippage of the polypropylene H-fasteners and cause failure of the restored GEV. Although we know from literature that symptom severity is not directly related to pathological findings, another possible explanation of failure in this group could be that patients with more progressed disease needed revisional surgery earlier compared to patients without esophagitis, after having undergone insufficient treatment.

Early reports on this technique had various outcomes. A feasibility study claimed long-term safety and durability after TIF and showed sustained improvement of symptoms after a two-year follow-up period in 14 patients. Cessation of PPI therapy was sustained in more than 70 percent of patients. ${ }^{43}$ In a company sponsored multicenter study of 84 patients, complete symptom elimination was achieved in $75 \%$ of patients after one year and $85 \%$ were off medication. Lower esophageal acid exposure was however reduced in $61 \%$ and normalized in only $37 \%$. The authors concluded that the procedure was safe and effective for improving subjective, as well as objective outcome measures. ${ }^{20}$

Other reports showed less favorable outcomes. In an Italian study, which included 20 patients for the TIF procedure, four patients needed laparoscopic fundoplication within the first year. Quality of life was improved in 15 patients at one year follow-up, but esophageal acid exposure worsened in $66.7 \%$ of patients versus pre-procedure. ${ }^{45}$ According to the literature and to this study, effectiveness in GERD management of endoscopic fundoplication does not compare to the excellent results of laparoscopic antireflux surgery by far. ${ }^{45}$

So, will there be a future for endoluminal fundoplication? TIF-procedure has undergone technical modifications into the so-called "TIF2-technique" based on a study in canines, which showed superior results in lower esophageal sphincter pressure and length compared to the TIF1-technique and tridimensional vector volume measurements that resembled the Nissen fundoplication. ${ }^{22}$ The Esophy $\mathrm{X}^{\mathrm{TM}}$ device has also been modified. The shaft of the second generation device is less flexible, which enables the surgeon to apply more torque to the fundoplication and wrap the stomach around the esophagus and is theoretically more consistent with a surgical fundoplication. Furthermore, we have to consider a learning curve and that more clinical experience with the technique may improve outcomes. Perhaps there will be a group of selected GERD patients who could benefit from the procedure, even if results will never be as good as those from surgery? For instance, patients who are at high risk for surgery due to their co-morbidities may benefit from the procedure. It is also to be considered that the present study and other early studies with this new technique, attracts patients who are not satisfied or refractory to PPI-treatment. All patients enrolled in this study were referred for surgical fundoplication by their gastroenterologists. Perhaps the TIF-procedure turns out to be much better suitable as initial GERD treatment in selected patients, who also would respond well to PPI treatment. The endoscopic procedure may be an alternative to PPIs as opposed to an alternative to surgical treatment. This 
would be difficult to investigate, because it may not be easy to enroll patients who are satisfied with their PPI treatment for a study with the new technique.

In the present study, one of the largest, single-center experiences with transoral incisionless fundoplication has been described with the longest follow-up period published. Pre-, and post-procedure, subjective as well as objective outcome measures were tested. There are several limitations to this study. We used a non-randomized design and there is possible selection bias with the mixed population at inclusion. Another limitation is that we defined failure as the patients' request for revisional surgical fundoplication based on recurrent symptoms only, without repeating objective measurements in these patients (such as $\mathrm{pH}$ measurements and endoscopy) at time of failure.

The TIF1-procedure was relatively safe and the feared side effects from antireflux surgery; dysphagia and gas-bloating resolved within one week postprocedure in this group. Only a subgroup of patients experienced improved quality of life and reduced the need for PPIs at three years follow-up, and an unacceptably high amount of patients required additional medication or revisional laparoscopic fundoplication. Esophagitis at screening was a predictor for treatment failure of endoscopic fundoplication. Although the endoluminal technique seems attractive because it is minimally invasive and side-effects are mild, according to this study it is not ready for routine GERD treatment. Additional studies are needed to indentify predictors of success and failure more clearly, to explore the technical modifications and to compare endoluminal fundoplication to conventional treatment modalities for GERD in a randomized study design. 


\section{REFERENCES}

1. Vakil N, van Zanten SV, Kahrilas P, Dent J, Jones R. The Montreal definition and classification of gastroesophageal reflux disease: a global evidence-based consensus. Am J Gastroenterol 2006;101:1900-20; quiz 1943.

2. Jones R, Bytzer P. Review article: acid suppression in the management of gastro-oesophageal reflux disease--an appraisal of treatment options in primary care. Aliment Pharmacol Ther 2001;15:765-72.

3. Spicak J. Treatment of gastroesophageal reflux disease: endoscopic aspects. Dig Dis 2007;25:183187.

4. Tytgat GN, McColl K, Tack J, Holtmann G, Hunt RH, Malfertheiner P, Hungin AP, Batchelor HK. New algorithm for the treatment of gastro-oesophageal reflux disease. Aliment Pharmacol Ther 2008;27:249-256.

5. Garcia Rodriguez LA, Ruigomez A, Panes J. Use of acid-suppressing drugs and the risk of bacterial gastroenteritis. Clin Gastroenterol Hepatol 2007;5:1418-23.

6. Lundell L. Surgery of gastroesophageal reflux disease: a competitive or complementary procedure? Dig Dis 2004;22:161-170.

7. de Vries DR, van Herwaarden MA, Smout AJ, Samsom M. Gastroesophageal pressure gradients in gastroesophageal reflux disease: relations with hiatal hernia, body mass index, and esophageal acid exposure. Am J Gastroenterol 2008;103:1349-54.

8. Hirano I, Richter JE. ACG practice guidelines: esophageal reflux testing. Am J Gastroenterol 2007;102:668-685.

9. Fass R. Proton-pump inhibitor therapy in patients with gastro-oesophageal reflux disease: putative mechanisms of failure. Drugs 2007;67:1521-30.

10. Fass R, Shapiro M, Dekel R, Sewell J. Systematic review: proton-pump inhibitor failure in gastrooesophageal reflux disease--where next? Aliment Pharmacol Ther 2005;22:79-94.

11. Carlsson R, Dent J, Watts R, Riley S, Sheikh R, Hatlebakk J, Haug K, de Groot G, van Oudvorst A, Dalvag A, Junghard O, Wiklund I. Gastro-oesophageal reflux disease in primary care: an international study of different treatment strategies with omeprazole. International GORD Study Group. Eur J Gastroenterol Hepatol 1998;10:119-24.

12. Tutuian R, Vela MF, Hill EG, Mainie I, Agrawal A, Castell DO. Characteristics of symptomatic reflux episodes on acid suppressive therapy. Am J Gastroenterol 2008;103:1090-6.

13. Schwartz MP, Wellink H, Gooszen HG, Conchillo JM, Samsom M, Smout AJ. Endoscopic gastroplication for the treatment of gastro-oesophageal reflux disease: a randomised, sham-controlled trial. Gut 2007;56:20-8.

14. Corley DA, Katz P, Wo JM, Stefan A, Patti M, Rothstein R, Edmundowicz S, Kline M, Mason R, Wolfe MM. Improvement of gastroesophageal reflux symptoms after radiofrequency energy: a randomized, sham-controlled trial. Gastroenterology 2003;125:668-676.

15. Deviere J, Costamagna G, Neuhaus H, Voderholzer W, Louis H, Tringali A, Marchese M, Fiedler T, Darb-Esfahani P, Schumacher B. Nonresorbable copolymer implantation for gastroesophageal reflux disease: a randomized sham-controlled multicenter trial. Gastroenterology 2005;128:532540 .

16. Rothstein R, Filipi C, Caca K, Pruitt R, Mergener K, Torquati A, Haber G, Chen Y, Chang K, Wong D, Deviere J, Pleskow D, Lightdale C, Ades A, Kozarek R, Richards W, Lembo A. Endoscopic fullthickness plication for the treatment of gastroesophageal reflux disease: a randomized, shamcontrolled trial. Gastroenterology 2006;131:704-712.

17. Cadiere GB, Rajan A, Rqibate M, Germay O, Dapri G, Himpens J, Gawlicka AK. Endoluminal fundoplication (ELF) - evolution of EsophyXTM, a new surgical device for transoral surgery. Minim Invasive Ther Allied Technol 2006;15:348-355.

18. Cadiere GB, Buset M, Muls V, et al: Antireflux transoral incisionless fundoplication using esophyX: 12-month results of a prospective multicenter study. World J Surg 32:1676-88, 2008 
19. Lundell LR, Dent J, Bennett JR, Blum AL, Armstrong D, Galmiche JP, Johnson F, Hongo M, Richter JE, Spechler SJ, Tytgat GN, Wallin L. Endoscopic assessment of oesophagitis: clinical and functional correlates and further validation of the Los Angeles classification. Gut 1999;45:172-180.

20. Cadiere GB, Buset M, Muls V, Rajan A, Rosch T, Eckardt AJ, Weerts J, Bastens B, Costamagna G, Marchese M, Louis H, Mana F, Sermon F, Gawlicka AK, Daniel MA, Deviere J. Antireflux Transoral Incisionless Fundoplication Using EsophyX: 12-Month Results of a Prospective Multicenter Study. World J Surg 2008.

21. Cadiere GB, Rajan A, Germay O, Himpens J. Endoluminal fundoplication by a transoral device for the treatment of GERD: A feasibility study. Surg Endosc 2008;22:333-42.

22. Jobe BA, O’Rourke RW, McMahon BP, Gravesen F, Lorenzo C, Hunter JG, Bronner M, Kraemer SJM. Transoral endoscopic fundoplication in the treatment of gastroesophageal reflux disease: the anatomic and physiologic basis for reconstruction of the esophagogastric junction using a novel device. Ann Surg 2008;248:69-76.

23. Velanovich V. The development of the GERD-HRQL symptom severity instrument. Dis Esophagus 2007;20:130-134.

24. Velanovich V, Karmy-Jones R. Measuring gastroesophageal reflux disease: relationship between the Health-Related Quality of Life score and physiologic parameters. Am Surg 1998;64:649-53.

25. Velanovich V, Vallance SR, Gusz JR, Tapia FV, Harkabus MA. Quality of life scale for gastroesophageal reflux disease. J Am Coll Surg 1996;183:217-224.

26. Hunter JG, Trus TL, Branum GD, Waring JP, Wood WC. A physiologic approach to laparoscopic fundoplication for gastroesophageal reflux disease. Ann Surg 1996;223:673-685.

27. Linke GR, Borovicka J, Schneider P, Zerz A, Warschkow R, Lange J, Muller-Stich BP. Is a barium swallow complementary to endoscopy essential in the preoperative assessment of laparoscopic antireflux and hiatal hernia surgery? Surg Endosc 2007.

28. Moss SF, Kidd M, Modlin IM. The status of the hiatus: the role of hernia in gastroesophageal reflux disease. J Clin Gastroenterol 2007;41:S144-S153.

29. Boyce HW, Jr. Hiatal hernia and peptic diseases of the esophagus, 1987:401-418.

30. Wolf BS. Sliding hiatal hernia: the need for redefinition. Am J Roentgenol Radium Ther Nucl Med 1973;117:231-47.

31. Jones MP, Sloan SS, Rabine JC, Ebert CC, Huang CF, Kahrilas PJ. Hiatal hernia size is the dominant determinant of esophagitis presence and severity in gastroesophageal reflux disease. Am J Gastroenterol 2001;96:1711-1717.

32. Jobe BA, Kahrilas PJ, Vernon AH, Sandone C, Gopal DV, Swanstrom LL, Aye RW, Hill LD. Endoscopic appraisal of the gastroesophageal valve after antireflux surgery. Am J Gastroenterol 2004;99:233243.

33. Hill LD, Kozarek RA, Kraemer SJ, Aye RW, Mercer CD, Low DE, Pope CE, 2nd. The gastroesophageal flap valve: in vitro and in vivo observations. Gastrointest Endosc 1996;44:541-547.

34. Klinkenberg-Knol EC, Nelis F, Dent J, Snel P, Mitchell B, Prichard P, Lloyd D, Havu N, Frame MH, Roman J, Walan A. Long-term omeprazole treatment in resistant gastroesophageal reflux disease: efficacy, safety, and influence on gastric mucosa. Gastroenterology 2000;118:661-9.

35. O'Connell MB, Madden DM, Murray AM, Heaney RP, Kerzner LJ. Effects of proton pump inhibitors on calcium carbonate absorption in women: a randomized crossover trial. Am J Med 2005;118:778-81.

36. Cote GA, Howden CW. Potential adverse effects of proton pump inhibitors. Curr Gastroenterol Rep 2008;10:208-14.

37. Broeders JA, Rijnhart-de Jong HG, Draaisma WA, Bredenoord AJ, Smout AJ, Gooszen HG. Ten-year outcome of laparoscopic and conventional nissen fundoplication: randomized clinical trial. Ann Surg. 2009;250(5):698-706

38. Bammer T, Hinder RA, Klaus A, Klingler PJ. Five- to eight-year outcome of the first laparoscopic Nissen fundoplications. J Gastrointest Surg 2001;5:42-8.

39. Falk GW, Fennerty MB, Rothstein RI. AGA Institute Technical Review on the Use of Endoscopic Therapy for Gastroesophageal Reflux Disease. Gastroenterology 2006;131:1315-36.

40. Nieponice A, Jobe BA. Endoscopic fundoplication: real or fantasy? J Gastrointest Surg;15:1295-8. 
41. Hogan WJ. Clinical trials evaluating endoscopic GERD treatments. Is it time for a moratorium on the clinical use of these procedures? Am J Gastroenterol 2006;101:437-439.

42. Pearl JP, Marks JM. Endolumenal therapies for gastroesophageal reflux disease: are they dead? Surg Endosc 2007;21:1-4.

43. Cadiere GB, Van Sante N, Graves JE, Gawlicka AK, Rajan A. Two-year results of a feasibility study on antireflux transoral incisionless fundoplication using EsophyX. Surg Endosc 2009;23:957-64.

44. Repici A, Fumagalli U, Malesci A, Barbera R, Gambaro C, Rosati R. Endoluminal fundoplication (ELF) for GERD using EsophyX: a 12-month follow-up in a single-center experience. J Gastrointest Surg;14:1-6.

45. Peters MJ, Mukhtar A, Yunus RM, Khan S, Pappalardo J, Memon B, Memon MA. Meta-analysis of randomized clinical trials comparing open and laparoscopic anti-reflux surgery. Am J Gastroenterol 2009;104:1548-61; quiz 1547, 1562. 



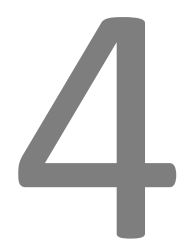

Randomized controlled trial of transoral incisionless fundoplication versus proton pump inhibitors for treatment of gastroesophageal reflux disease 


\section{ABSTRACT}

\section{Background}

Although proton pump inhibitors (PPIs) are effective in controlling gastroesophageal reflux disease (GERD), the disease is not cured. The objective of this study was to compare effectiveness of transoral incisionless fundoplication (TIF) to PPIs. The study population consisted of GERD patients controlled with PPIs, who opted for an endoscopic intervention over lifelong drug-dependence.

\section{Methods}

Patients were randomized for TIF2-procedure or continuation of PPI-therapy. $\mathrm{ASA}>2$, BMI $>35$, hiatal hernia $>2 \mathrm{~cm}$ and esophageal motility disorders were exclusion criteria. Follow-up assessments included quality of life, PPI-usage, 24-h pHimpedance measurements, manometry and upper gastrointestinal endoscopy. Crossover for the PPI-group was allowed after 6 months follow-up.

\section{Results}

60 patients (TIF $n=40$, PPI $n=20$, mean BMI 26 and 37 male) were included. At 6 months quality of life was more improved in the TIF-group compared to the PPIgroup $(p<0.001)$, with a similar decrease in distal esophageal acid exposure $(p=0.229)$. Normalization of $\mathrm{pH}$ for TIF-group and PPI-group was $50 \%$ and $63 \%$, respectively. All patients allocated for PPI treatment opted for crossover and underwent TIF2-procedure. At 12 months post-TIF, quality of life was still increased compared to baseline $(p<0.05)$, but statistically significant improvement in distal esophageal acid exposure was not achieved $(p=0.171)$. Normalization of $\mathrm{pH}$ measurements was accomplished at 12 months in only $29 \%$ in conjunction with valve decadence.

\section{Conclusion}

In a selected group of patients, TIF resulted in an improved quality of life, with a similar decrease in distal esophageal acid exposure compared to PPI-treatment at 6 months follow-up. The initial objective reflux control was not sustained at 12 months due to a lack of durability of TIF.

Published as:

Randomized controlled trial of transoral incisionless fundoplication versus proton pump inhibitors for treatment of gastroesophageal reflux disease. Witteman BPL, Conchillo JM, Rinsma NF, Betzel B, Peeters A, Koek GH, Stassen LPS, Bouvy ND (submitted)

Presented as:

Randomized controlled trial of transoral incisionless fundoplication versus proton pump inhibitors for treatment of gastroesophageal reflux disease. Witteman BPL, Conchillo JM, Rinsma NF, Betzel B, Peeters A, Koek GH, Stassen LPS, Bouvy ND, Annual meeting of The Dutch Society of Gastroenterology and Gastrointestinal Surgery, Veldhoven 2013 and Digestive Disease Week 2013, Orlando, Florida, USA 


\section{INTRODUCTION}

The need for a long-term treatment of gastroesophageal reflux disease (GERD) has become increasingly apparent in the past two decades as a result of a growing incidence and prevalence of this chronic disease. Typical GERD symptoms include heartburn, regurgitation, belching, and dysphagia, while the so-called atypical symptoms are chronic nausea, hoarseness, chest pain, laryngospasm, globus sensation, cough, wheezing and dental erosions. The likelihood of developing GERD increases with the severity of the anatomical change and dysfunction of the gastroesophageal junction (GEJ) which represents the primary defense against reflux of gastric content into the esophagus. ${ }^{1-6}$ Although proton pump inhibitors (PPIs) are effective in controlling symptoms, such as heartburn and the healing of reflux esophagitis, the disease is not cured and patients will often have a lifelong commitment to drug therapy. ${ }^{7-12}$ Studies have demonstrated that up to $50 \%$ of patients treated with PPIs continue to have abnormal acid reflux and up to 35\% experience a relapse of symptoms after a 3-year follow-up requiring titration with increasing doses of PPIs and later referral for surgery. ${ }^{13-15}$

The merits of early surgery in GERD-patients have been demonstrated in several randomized controlled trials. ${ }^{15-18}$ Antireflux surgery has been shown to be more effective than pharmacological antisecretory therapies in terms of patient satisfaction, clinical outcome and healthcare cost reduction in the long-term management of chronic GERD. ${ }^{19-22}$ Hence, operative restoration of the GEJ competence at the anatomic, mechanic and physiologic levels, is critical in GERD treatment. Disadvantages of surgery are the invasiveness and feared fundoplication-related gastrointestinal side effects, that frequently compromise the otherwise excellent post surgical results. ${ }^{21,23}$ Persistent dysphagia, inability to belch and vomit, as well as gas-bloating and flatulence are common and difficult to treat. 19, 24-27 To minimize the risk of chronic complications, a variety of factors need to be taken into account, including technical aspects of the operation. ${ }^{26,28}$ Restoration of the anatomy, mechanics and physiology of the GEJ, with "tailoring" of the valve to the individual patient needs, seems crucial for an adequate repair that should allow air to be vented from the stomach, without jeopardizing the efficacy of the antireflux barrier. ${ }^{29}$

The field of endoscopic fundoplication has gained popularity over the last few years and in an attempt to create a minimally invasive procedure that mimics antireflux surgery with fewer side effects, transoral incisionless fundoplication (TIF) was developed. ${ }^{30}$ The technique was designed to construct a partial fundoplication at the GEJ, restoring the angle of His, and reducing small hiatal hernia, by means of natural orifice surgery, using the Esophy $\mathrm{X}^{\mathrm{TM}}$-device. ${ }^{31}$ The device was cleared by the U.S. FDA for treatment of symptomatic chronic GERD in 2007, after it was demonstrated safe and effective in a company sponsored multi-center study. ${ }^{31,} 32$ Several initial reports on TIF were encouraging and showed effective- 
ness in reducing typical and atypical GERD symptoms, eliminating daily PPI dependence, as well as in normalizing esophageal $\mathrm{pH}$. At the contrary, other early experiences showed substantial failures rates. ${ }^{32-36}$ The available data on the TIFtechnique is of limited quality and was extracted from uncontrolled studies with generally a short follow-up duration. TIF is expected to position in between pharmaceutical and surgical treatment in the spectrum of GERD management, with overlap to both sides. Previous studies included patients, who were referred for surgical management as they were refractory to PPI-treatment, with more "progressed" GERD and would otherwise probably have undergone conventional laparoscopic antireflux surgery. Because important components of antireflux surgery, such as extra-gastric mobilization of the stomach and esophagus, allowing hernia reduction and crural closure, are not achievable with TIF, the procedure would only be suitable for few selected surgical candidates. We hypothesized the procedure would be more suitable to patients who are well controlled with medication, but opt for more definitive GERD therapy. Particularly patients who have elements of volume reflux and regurgitation in their symptom complex may benefit from an anatomical repair. If proven effective, endoscopic fundoplication would be a valuable alternative to PPI treatment and might also be cost effective if PPI cessation is maintained.

We compared TIF to PPI treatment in a randomized controlled trial. The objective of this trial was to evaluate the relative merits, safety and effectiveness of TIF-procedure in treating GERD patients, who were well controlled on daily PPI therapy. The study tested the hypothesis that TIF would be as effective as PPI treatment in controlling GERD symptoms, esophageal acid exposure and esophagitis, but would be more effective in controlling reflux and thereby improve the quality of life. Further objectives were the evaluation of effectiveness of the TIFprocedure in restoring the anatomy, biomechanics, geometry and physiology of the antireflux barrier.

\section{PATIENTS AND METHODS}

\section{Study design}

The trial was designed as a two-centre study, performed at two University hospitals, in Europe and The United States of America. Patients were 2:1 randomized to either the TIF (intervention-group) or continuation on PPI-therapy (controlgroup). Power analysis determined a sample size requirement of 120 patients. The randomization was conducted by an independent statistician using randomization software (SAS Institute, Cary, North Carolina, USA). Allocation assignments were deposited in consecutively numbered, opaque, sealed envelops. The study coordinator opened envelopes at time of inclusion after signed informed consent was obtained. No effort to blind patients or study staff to treatment assignment was 
made after randomization. Date of TIF-procedure was considered the enrollment day for the TIF-group and randomization-day was the enrollment day for the PPI group. Cross-over from PPI to TIF-group was allowed after the 6-month follow-up assessment was completed. All patients who had undergone TIF were then followed as one cohort. The research protocol was approved by the Maastricht Medical Ethics Committee (METC 07-2-051, NL17303.068.07) and was registered NCT0085759 (clinicaltrials.gov).

\section{Study population}

The study population consisted of GERD patients controlled with PPI therapy, but who opted for an intervention over lifelong dependence on pharmaceutical therapy. Patients were referred to gastroenterologists for GERD analysis and were selected to participate in the trial when meeting the study criteria. 18-75 years of age, hiatal hernia $\leq 2 \mathrm{~cm}$, proven reflux while off PPIs, on daily PPIs for $\geq 1$ year, recurrence of GERD symptoms after cessation of PPIs (GERD-HRQL score difference of $>10$ between on and off PPIs), normal or reduced LES resting pressure (5$40 \mathrm{mmHg}$ ) at manometry and signed informed consent were inclusion criteria. Patients with BMI $\geq 35$, hiatal hernia $>2 \mathrm{~cm}$, esophagitis grade D, Barrett's esophagus, esophageal stricture or ulcer, motility disorders, previously splenectomy, gastric paralysis, pregnancy (in females), immunosuppression, ASA $>2$, portal hypertension or a previous antireflux procedure were excluded from participation. These criteria were chosen in such a way, that patients who met these criteria were assumed to respond well to endoscopic fundoplication and were based on experiences with surgical fundoplication. Demographics, the duration of GERD, frequency and dose of PPIs-usage at the time of inclusion were recorded. At baseline, GERD-related quality of life was assessed with the use of a validated qualityof-life questionnaire (GERD-HRQL) while patients were using PPIs and again after a cessation-period of 14 days. ${ }^{37,38}$ The questionnaire was developed to assess typical and atypical GERD symptoms. The presence of pathologic esophageal acid exposure was confirmed by 24-h pH-metry (AG Attikon, Switserland). Normal pH was considered $\mathrm{pH}<4$ for $<4.2 \%$ of a 24 -h monitoring period. Other baseline evaluations included 24-h multichannel intraluminal impedance (Ohmega Medical Measurement Systems, Enschede, The Netherlands), high resolution manometry (Unisensor AG, Attikon, Switzerland) and upper GI endoscopy. ${ }^{39-46}$ By endoscopy, hiatal hernia size, esophagitis (Los Angeles classification scale, confirmed with biopsy) and geometrical aspects (valve length, circumference, adherence and Hillgrade) were assessed. ${ }^{47,48}$ 


\section{Endpoints}

Primary outcome measures were GERD-related symptoms, assessed by the GERDHealth-Related Quality-of-Life questionnaire (HRQL). Treatment success was defined by a significantly $(p<0.05)$ higher number of patients with $\geq 50 \%$ improvement in scores in the TIF-group vs. PPI-group at 6 months. Secondary outcome measures were esophageal acid exposure, number of reflux episodes, PPI usage, appearance of the GEV and healing of reflux esophagitis.

\section{Trial interventions}

\section{PPI (control-group)}

Patients randomized to the PPI-group were treated according to a PPI management scheme. If GERD symptoms were well controlled on their previous dose of PPIs for at least a month, the regimen was reduced a step and if poorly controlled, increased by one step according to the PPI-algorithm, which provides a treatment plan consistent with good clinical practice. ${ }^{16}$ The usage of all GERD medications was recorded in a medication-diary.

\section{TIF (intervention-group)}

Immediately before the procedure, each patient underwent endoscopic examination of the esophagus and stomach. The device was inserted transorally through a bite-block with the patient in left lateral decubitus. Hiatal hernia, if present was reduced by returning the squamocolumnar junction to its natural position below the diaphragm using the built-in vacuum invaginator. TIF2-procedure was performed by a team of two experienced physicians (surgeon and gastroenterologist) under continuous endoscopic visualization using the EsophyX-2 ${ }^{\mathrm{TM}}$ device with polypropylene SerosaFuse ${ }^{\mathrm{TM}}$ fasteners (EndoGastric Solutions, Inc., Redmond, WA, USA). According to the standard TIF2-protocol, gastroesophageal valves were constructed by full-thickness esophagogastric plications, secured by placement of multiple polypropylene fasteners. ${ }^{49}, 50$ Patients were discharged from the hospital the next day after a complete physical examination and instructed to consume a liquid diet during the first two weeks and a soft diet during the following four weeks. Following TIF2-procedure, PPI usage was continued for 14 days to allow healing of the mucosa around the fasteners and then stopped. In the event of the recurrence of symptoms, the PPI management scheme was also employed for the TIF-group. Revisional standard laparoscopic fundoplication was offered in case of treatment failure based on relapse of symptoms, unresponsive to PPI treatment, in conjunction with anatomical failure at endoscopy and/or pathologic $\mathrm{pH}$ measurements. 


\section{Follow-up assessment}

The follow-up assessment was conducted after 1 week, 1, 3, 6 and 12 months following inclusion to record PPI usage and adverse events. At 6 months follow-up all patients underwent the same assessment tests as performed at baseline. Patients in the PPI-group underwent all tests while using PPIs and the TIF-group (if PPIs were resumed) discontinued any PPI usage for 14 days before the 6-month followup assessment. At 12 months after TIF2 the follow-up assessment was repeated for the entire group, including the eventual cross-overs from the PPI-group.

\section{Safety}

The incidence of serious and non-serious adverse events was recorded. Serious adverse events were defined as complications necessitating prolonged hospitalization and additional medical or surgical intervention. Non-serious adverse events represented expected side effects and symptoms. Gastrointestinal side effects, such as epigastric pain, flatulence, bloating, diarrhea, dysphagia, the ability to vomit and belch, were assessed using Gastrointestinal Symptom Rating Scale (GSRS) questionnaire. ${ }^{51}$

\section{Data handling and record-keeping}

Case Report Forms (CRFs) were completed for each subject enrolled into the trial and stored in a binder in a secured room. CRFs also contained the signed informed consent and source documents of clinical data and patients were identified by their enrollment number only. Next to the CRFs, an electronic database capture system (Microsoft Excell@ 97-2004) was used to collect, organize and report the study data. Data in the CRFs were entered by the study coordinators. Investigators and monitors only had the privilege to read data. Trial monitors verified the accuracy of this transcription against the source documents.

\section{Statistical analysis}

According to the intention-to-treat principle, all enrolled subjects were included in the primary effectiveness analysis. Missing data imputation was done by lastvalue-carried-forward techniques and for baseline by overall mean-imputation. Metric variables with normal distribution (tested by Shapiro-Wilk statistic) were univariately presented by their means and standard deviations and if not normally distributed the mean and range were used. Categorical variables were presented by frequencies and percentages. The primary outcome parameter was calculated as a $\geq 50 \%$ difference in the GERD questionnaire scores between baseline and at 6 months postoperatively. Differences between randomized TIF and PPI-groups 
were first analyzed in a 2 by 2 cross-tabulation table and odds-ratio plus $95 \%$ Confidence Intervals (C.I.) were calculated. Subsequently, logistic regression analysis was performed controlling for baseline values and 8 other relevant, possibly confounding variables (gender, age, BMI, baseline hernia, Hill grade, esophagitis grade, LES resting pressure and duration of GERD symptoms). Secondary outcome parameters were analyzed by repeated measures ANOVA and ANCOVA. Additional linear regression analysis was performed to facilitate the statistical control of confounding variables. Mixed models were used to analyze repeated measurements for the entire cohort of patients that underwent TIF2 (after eventual cross-over for the PPI-group). SPSS®-pc, version 20.0 (IBM, Armonk, New York, USA) was used for data analysis. A $p$-value of less than 0.05 is considered to be statistically significant.

Table 4.1 Patient characteristics at baseline. Values represent means (SD), median (range) or counts (\%).

\begin{tabular}{|c|c|c|c|c|}
\hline Variable & TIF2 $(n=40)$ & PPI $(n=20)$ & Total & $p$-value \\
\hline Age (mean) (SD) & $42.4(13.3)$ & $49.3(11.3)$ & 44.7 (12.9) & $p=0.05$ \\
\hline \multicolumn{5}{|l|}{ Gender (no.) (\%) } \\
\hline Male & $24(60)$ & $14(70)$ & $38(63)$ & \\
\hline Female & $16(40)$ & $6(30)$ & $22(37)$ & $p=0.45$ \\
\hline BMI (mean) (SD) & $26(3.7)$ & $26(3.4)$ & $26(3.6)$ & $p=0.95$ \\
\hline \multicolumn{5}{|c|}{ Hernia presence (no.) (\%) } \\
\hline No & $9(23)$ & $9(45)$ & $18(30)$ & \\
\hline Yes & $31(77)$ & $11(55)$ & $42(70)$ & $p=0.08$ \\
\hline \multicolumn{5}{|l|}{ Hill grade (no.) (\%) } \\
\hline I & $2(6)$ & $1(6)$ & $3(6)$ & \\
\hline II & $18(53)$ & $11(69)$ & $29(58)$ & \\
\hline III & $11(32)$ & $4(25)$ & $15(30)$ & \\
\hline IV & $3(9)$ & $0 \quad(0)$ & $3(6)$ & $p=0.40$ \\
\hline \multicolumn{5}{|l|}{ Esophagitis (no.) (\%) } \\
\hline None & $27(68)$ & $14(70)$ & $41(68)$ & \\
\hline$A$ & 7 (17) & $3(15)$ & $10(17)$ & \\
\hline B & $6(15)$ & $3(15)$ & $9 \quad(15)$ & $p=0.97$ \\
\hline $\begin{array}{l}\text { LES resting pressure } \\
\text { (median) (range) }\end{array}$ & $15.2(8-25)$ & $15.5(6-25)$ & $15.3(6-25)$ & $p=0.893$ \\
\hline $\begin{array}{l}\text { Duration of GERD } \\
\text { (median) (range) }\end{array}$ & $4.5(0.05-18.95)$ & $5.4(0.33-20.30)$ & $4.8(0.05-20.3)$ & $p=0.882$ \\
\hline
\end{tabular}

\section{RESULTS}

\section{Randomized controlled trial}

Recruitment was initiated in 2008 and in 2011, 60 consecutive patients were randomized and completed the follow-up in one center. At the time of study comple- 
tion in one center, the recruitment had not been started in the second center, mainly due to financial issues. We performed analysis of the single center data to function as an unplanned interim analysis of the trial and report the results. A Consort flow diagram shows the inclusion and allocation at interim analysis (figure 4.1).

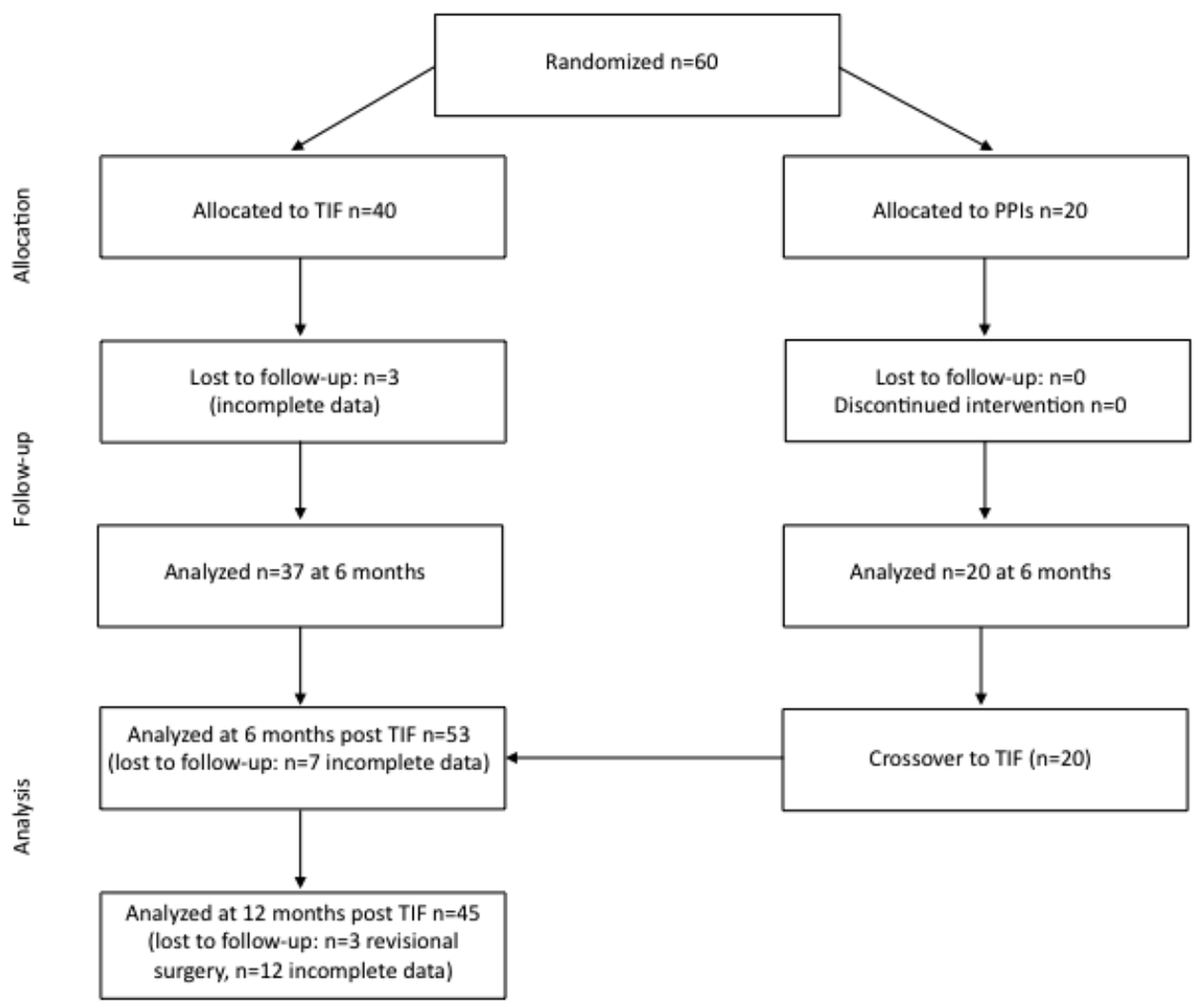

Figure 4.1 Consort flow diagram.

The majority of patients were Caucasian and 63\% was male. Patient characteristics were comparable for the two randomized groups, with similar distribution of demographics and anatomical deterioration of the gastroesophageal junction (table 4.1).

At 6 months follow-up, quality of life evaluation showed a significantly higher improvement of $\geq 50 \%$ after TIF (55\%) compared PPI treatment (5\%), $(p<0.001$, figure 4.2). Satisfaction scores in the TIF-group showed that $50 \%$ were satisfied with their general health condition, $26 \%$ were neutral and 24\% were dissatisfied and for the PPI-group $0 \%$ were satisfied, $15 \%$ were neutral and $85 \%$ were dissatis- 
fied. Esophageal acid exposure time decreased more after PPI-treatment, but no significant difference in decrease was found between randomized groups (total: $p=0.228$, figure 4.3). Normalization of $\mathrm{pH}$ (total proportion of time with a $\mathrm{pH}$ of $<4$ in 24-hour period $\leq 4,2 \%$ ) for TIF-group and PPI-group was $50 \%$ and $63 \%$, respectively. TIF2 induced a significant increase in LES-resting pressure compared to the PPI-group ( $p=0.004$ ) and a higher decrease in number of total reflux episodes at impedance measurement compared to the PPI-group. The difference was near significance in the intention to treat analysis $(p=0.058)$. Per protocol analysis of impedance data were statistically significant in favor of TIF2 ( $p=0.012$, figure 4.4). Both groups had similar outcomes in healing of esophagitis after 6 months compared to baseline endoscopy (TIF2: $33 \%$ to $14 \%$ and PPI: $30 \%$ to $10 \%$ ). In the PPIgroup all patients continued the use of PPIs as instructed, mostly at a single dose per day. Cessation of PPIs occurred in $74 \%$ of patients post TIF2, $17 \%$ used PPIs occasionally and $9 \%$ daily at 6 months follow-up.

Per-operative complications of TIF2 in this trial were limited to one adverse event. During one TIF2-procedure it was difficult to maintain an adequate endoscopic view on the gastro-esophageal junction, which required additional insufflations. The patient appeared to have developed a pneumoperitoneum, which was released with the insertion of a Verres-needle. Post-operative upper gastrointestinal radiography did not show any signs of perforation and the event had no further impact on the patient's recovery.

Post-operative complications at day one were mild and transient in all cases. Among these complications, sore throat, cough, belching, pain, nausea, vomiting, bloating, left shoulder pain, melaena, hematemesis, constipation, asthma exacerbation and tinnitus were recorded.

Serious adverse events included pneumonia in three patients of which one needed readmission and intravenous antibiotics. One patient experienced severe epigastric pain weeks after the TIF-procedure. The patient was readmitted and analyzed with an upper GI-radiography and endoscopy, which showed an intact valve without further abnormalities and the pain resolved spontaneously. We encountered one death, 20 months after inclusion. The patient was male, aged 52 and randomized for PPI-group. He had undergone TIF-procedure after cross-over and died 11 months post TIF-procedure. Death was ascertained by his general practitioner. The cause of death was assumed cardiac or neurological, but the exact cause remains uncertain. Autopsy was not performed upon family request. The event was reported to the ethics committee and within the time frame it was considered probably unrelated to the trail interventions.

Treatment failure based on relapse of symptoms, unresponsive to PPI treatment, in conjunction with anatomical failure at endoscopy and/or pathologic $\mathrm{pH}$ measurements occurred in three patients. Revisional laparoscopic fundoplication was performed in two patients, randomized to the PPI-group (after cross-over to 
TIF) at 6 and 14 months and in one patient, randomized to the TIF-group at 10 months post-procedure.

Fundoplication-related gastrointestinal side effects, such as epigastric pain, flatulence, bloating, diarrhea, dysphagia, the ability to vomit and to belch, assessed with GSRS-questionnaire did not occur. The TIF-group showed even more improvement compared to PPI-group ( $p=0.001)$ at 6 months follow-up.
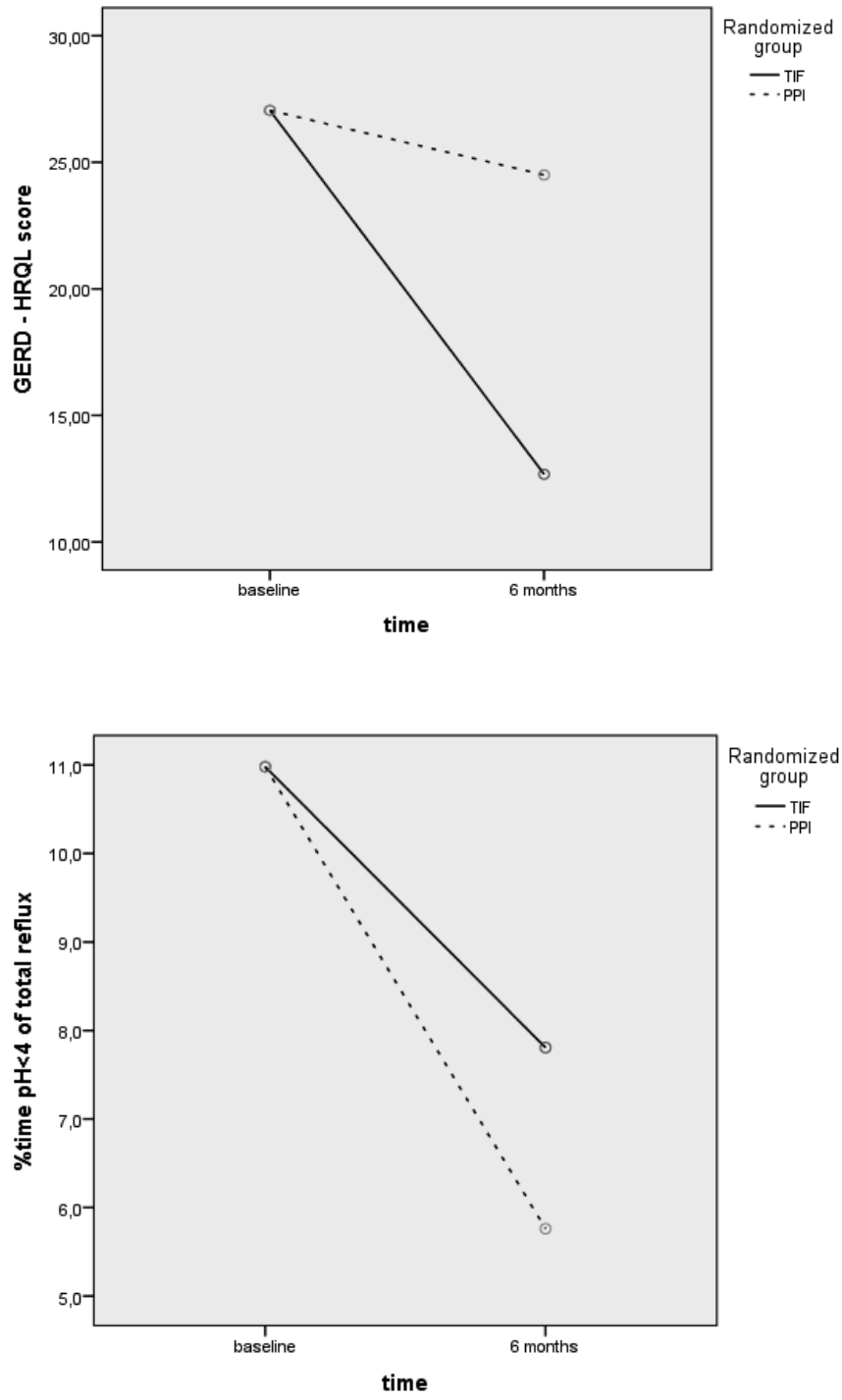

Figure 4.2 GERD-HRQL questionnaire scores of TIF versus PPI-group at baseline and at 6 months presented in absolute scores.

Figure 4.3 Esophageal pHmonitoring TIF versus PPIgroup at 6 months followup, presented in mean $\%$ of time $\mathrm{pH}<4$. 


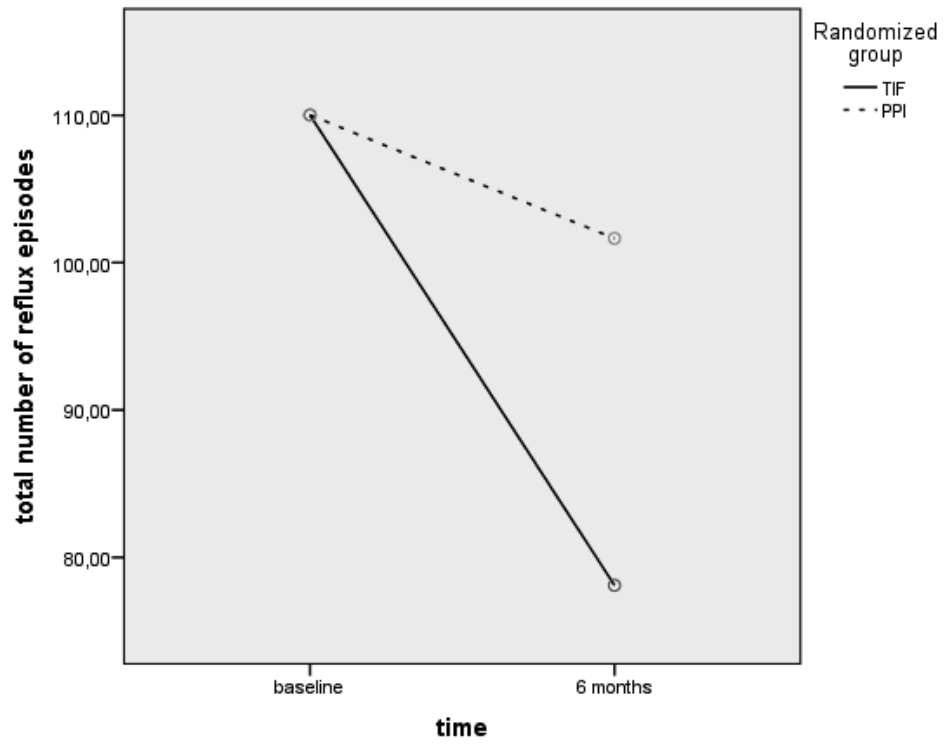

Figure 4.4 Impedance monitoring TIF versus PPIgroup at 6 months follow-up.

\section{TIF2 cohort results}

Further objectives of the study were to evaluate effectiveness of the TIF-procedure in restoring the anatomy, biomechanics, geometry and physiology of the antireflux barrier. TIF2 was feasible in all patients $(n=60)$, mean procedure time was 33.4 minutes (range 17-75) and mean 18 fasteners (range 7-26) were used for the construction of valves of mean $3.8 \mathrm{~cm}$ (range 3-5) in length and mean 229 degree (range 160-300 degree) in circumference. We experienced two device failures with the need for device replacement. In both events the helical retractor broke after 1 and 8 firings, respectively. In the entire group 11 fastener deployments were recorded as failures, clearly visible during TIF-procedure. The appearance of the created valves was evaluated by post-procedure endoscopy. Directly after TIF2, complete reduction of hiatal hernia (if present) was accomplished in all cases. Hill grade I was achieved in $90 \%$, Hill-grade II in $8 \%$, Hill-grade III in $2 \%$ and no patients had a Hill grade IV at the end of the procedure. Adherence to the endoscope was tight, moderate or loose in $83 \%, 15 \%$ and $2 \%$, respectively (table 4.2 ).

At $6(n=53)$ and $12(n=45)$ months after TIF, quality-of-life scores showed a statistically significant improvement compared to baseline measurements $(p<0,05$, figure 4.5). At 6 and 12 months, LES-pressures and impedance measurements were still significantly increased compared to baseline. Distal esophageal acid exposure, however, did not statistically significantly improve compared to baseline at 6 months $(p=0.06)$ and at 12 months after TIF ( $p=0.171$, figure 4.6). Normalization of pH was accomplished after TIF in $44 \%$ at 6 months and in $29 \%$ at 12 months. 
Daily use of antisecretory medication was discontinued by $39 \%$ of patients and $61 \%$ needed occasional or daily PPIs at 12 months follow-up (table 4.3).

Table 4.2 Endoscopy at baseline, 6 and 12 months after TIF2 procedure.

\begin{tabular}{|c|c|c|c|c|}
\hline Endoscopy & Baseline & Post TIF2 & 6 months post TIF2 & 12 months post TIF 2 \\
\hline Number of patients & 60 & 60 & 53 & 45 \\
\hline Hiatal hernia (HHD) & $70 \%$ & $0 \%$ & $37 \%$ & $55 \%$ \\
\hline $\mathrm{HHD} 1 \mathrm{~cm}$ & $38 \%$ & - & $50 \%$ & $43 \%$ \\
\hline $\mathrm{HHD} 2 \mathrm{~cm}$ & $62 \%$ & - & $30 \%$ & $38 \%$ \\
\hline $\mathrm{HHD} 3 \mathrm{~cm}$ & $0 \%$ & - & $20 \%$ & $19 \%$ \\
\hline Esophagitis & $32 \%$ & - & $25 \%$ & $27 \%$ \\
\hline Grade A & $53 \%$ & - & $38 \%$ & $40 \%$ \\
\hline Grade B & $47 \%$ & - & $46 \%$ & $60 \%$ \\
\hline Grade C & $0 \%$ & - & $16 \%$ & $0 \%$ \\
\hline Grade D & $0 \%$ & - & $0 \%$ & $0 \%$ \\
\hline Barrett & $0 \%$ & - & $0 \%$ & $0 \%$ \\
\hline z-line normal & $85 \%$ & - & $89 \%$ & $90 \%$ \\
\hline z-line irregular & $15 \%$ & - & $11 \%$ & $10 \%$ \\
\hline Hill grade I & $6 \%$ & $90 \%$ & $39 \%$ & $35 \%$ \\
\hline Hill grade II & $58 \%$ & $8 \%$ & $42 \%$ & $35 \%$ \\
\hline Hill grade III & $30 \%$ & $2 \%$ & $19 \%$ & $25 \%$ \\
\hline Hill grade IV & $6 \%$ & $0 \%$ & $0 \%$ & $5 \%$ \\
\hline Tight adherence & $12 \%$ & $83 \%$ & $59 \%$ & $42 \%$ \\
\hline Moderate adherence & $50 \%$ & $15 \%$ & $27 \%$ & $29 \%$ \\
\hline Loose adherence & $38 \%$ & $2 \%$ & $14 \%$ & $29 \%$ \\
\hline
\end{tabular}

Table 4.3 PPI usage 6 and 12 months post TIF2 procedure.

\begin{tabular}{lcll}
\hline PPI-usage & Baseline & $\mathbf{6}$ months post TIF2 & $\mathbf{1 2}$ months post TIF2 \\
\hline None & $0 \%$ & $66 \%$ & $39 \%$ \\
Occasional & $0 \%$ & $18 \%$ & $17 \%$ \\
Daily & $100 \%$ & $16 \%$ & $44 \%$ \\
\hline
\end{tabular}



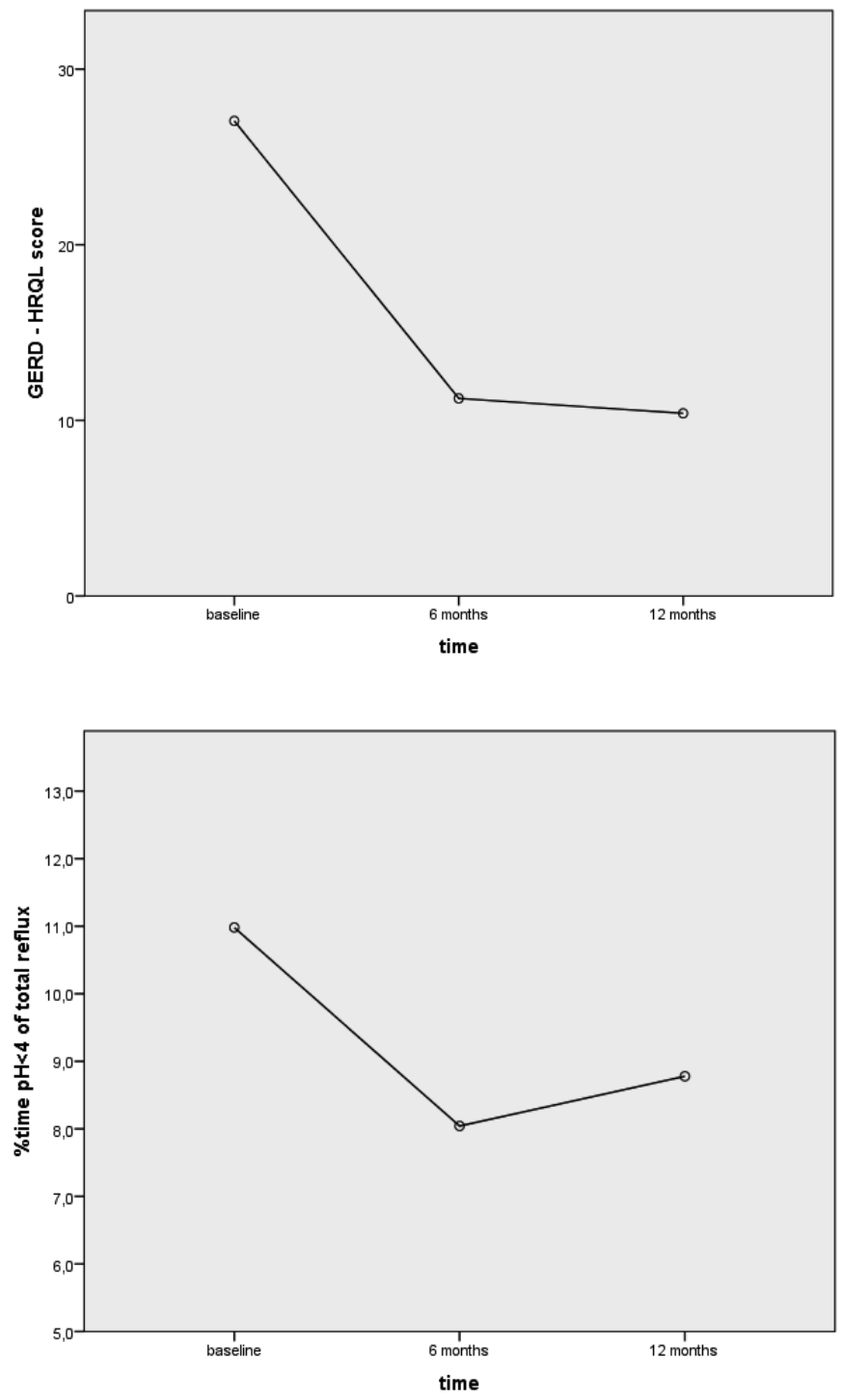

Figure 4.5 GERD-HRQL questionnaire scores at baseline, 6 and 12 months follow-up after TIF2, presented in absolute scores.

Figure 4.6 Esophageal $\mathrm{pH}$ monitoring at baseline, 6 and 12 months follow-up after TIF2, presented in mean $\%$ of time $\mathrm{pH}<4$.

\section{DISCUSSION}

History of endoscopic antireflux treatment modalities has taught us that early studies with encouraging results have been proven wrong by later randomized controlled trials, showing the true efficacy and durability. ${ }^{52}$ Accordingly, a randomized controlled trial was in need to assess the effectiveness and durability of TIF2 compared to standard treatment modalities. In this trial 60 selected GERD patients, responsive to medical treatment, were randomized for either TIF or PPI-treatment. 
After 6 months follow-up, a similar decrease in total distal esophageal acid exposure was accomplished. TIF decreased the number of reflux episodes, increased LES-resting-pressure and resulted in a significantly improved GERD-related quality of life compared to PPI-treatment. Also, this improvement was not compromised by additional fundoplication-related side effects, such as gas-bloating and dysphagia. After cross-over for the PPI-group, the cohort of 60 patients that had undergone TIF2 was evaluated at 6 and 12 months. The initial encouraging results in objective reflux control were not sustained and distal esophageal acid exposure increased in conjunction with deteriorated endoscopy findings. Many patients needed additional PPIs and some needed revisional surgery to control their symptoms. At 12 months normalization of distal esophageal acid exposure was only achieved in $29 \%$ and PPI cessation in 39\%.

The available literature on the TIF-procedure, published between 2008 and 2012, showed a variation of outcomes. The data derived from 18 reports on mostly initial experiences are summarized in table 4.4. These include retro and prospective studies with a non-randomized design and generally a short follow-up duration (mean 12.8 months, range 2-36). Only a few studies included objective parameters, such as pH-measurements and many reported only subjective outcome measures, such as quality of life and PPI-usage. Although results did not compare to those of laparoscopic antireflux surgery, overall, outcomes in 15 studies were in favor of TIF. ${ }^{53}$ Three studies have reported negative results and additionally, two papers have been published on revisional surgery after previous unsuccessful TIFprocedures. ${ }^{33-36,52,62}$ In the 18 studies, with a total of a composite 728 patients, 50 cases (7\%) of revisional laparoscopic fundoplication have been reported.

Although TIF has been considered relatively safe, serious adverse events reported in the literature included esophageal perforations on device insertion, hemorrhage requiring transfusion, permanent numbness of the tongue, pneumonia and pneumothorax. Serious adverse events during the present trial were a pneumoperitoneum during the procedure. The air leakage had probably occurred due to the required high insufflation pressures via the small perforations made with fastener deployment. Serious post-operative adverse events included 3 pneumonias, a readmission for unexplained severe epigastric pain. One patient died 11 months after the TIF2-procedure, most likely, due to an unrelated cause.

Other adverse events and side effects were probably related to the insertion of the $18 \mathrm{~mm}$-diameter device, with subsequently repetitive axial rotations and the "wrapping" of the greater gastric curvature around the esophagus. These side effects were of a transient nature and support the apparent safety of TIF. Most importantly, the feared post surgical fundoplication side effects, such as dysphagia and gas-bloating, resolved within a short period of time. No long-term fundoplication related complications occurred. These outcomes correspond with the results of systematic reviews in which partial fundoplication techniques were associated 
with significantly less fundoplication related side effects compared to total 360 degree fundoplication. ${ }^{54}$

Earlier we reported our experience with TIF1-procedure after a cohort-study in 38 patients, who were referred for antireflux surgery. In contrast with the improved quality of life and decrease in PPI-usage, post-operative pH-measurements did not significantly improve compared to baseline and after prolonged follow-up duration, many patients needed additional PPIs and 37\% of patients had undergone revisional laparoscopic Nissen fundoplication after mean 17 months (range 7-34 months). ${ }^{35}$ Disruption of the polypropylene H-fasteners, leading to failure of the TIF-valve as a barrier to reflux was seen in the majority of these patients. In the present study, TIF2 enabled to create potent valves, scored as a Hill grade I in $90 \%$ at endoscopy directly after the procedure, but after 12 months a Hill grade I was only seen in $35 \%$ of patients. This lack of durability has been an important cause of treatment failure of previous endoscopic procedures for GERD and also appears to be of concern for TIF-valves.33, 52, 55, 56 Literature data have shown feasibility of the TIF-procedure in the creation of a potent gastroesophageal valve and after the procedure most patients experience a relatively symptom free period, allowing initial PPI cessation. This symptom-free period may be induced by initial placebo effects, but considering objective outcomes in GERD control, it is more likely explained by an initially well functioning antireflux barrier. Resumption of symptoms in previous studies has been dedicated to a "suture loss". The "pull-through" of fasteners, verified by endoscopy or laparoscopy (in revisional laparoscopic procedures) has been reported by others. In our series we experienced patients coming back into the clinic, having actually felt the loss of fasteners, after coughing or physical exercise, causing their symptoms to return. ${ }^{33-36}$ It seems that, while extragastric mobilization of the fundus, to release the tension of the fundoplication, can not be achieved with TIF, the continues forces on the repair eventually cause the anatomy of the GEJ to return into its original shape, causing the valve to unravel. ${ }^{33}$ This finding is supported by a study of Testoni and colleagues who found that a higher number of fasteners, used in the procedure, was predictive for positive outcomes. ${ }^{63}$

There are several limitations to this study. First, the trial has not been completed for secondary reasons and at ad hoc interim analysis half of the required participants were included. The study as reported is therefore underpowered and results should be interpreted with some caution. Although TIF seemed successful after short time follow-up, the disappointing outcomes of distal esophageal acid exposure and valve appearance at 12 months follow-up was the main reason for our group not complete the trial and include another 60 patients in our center, before the durability of TIF has been improved. Another limitation is the short follow-up duration of only six months for the comparative part of the study. The cross-over design was chosen to facilitate recruitment and seemed to be valid be- 
cause the outcomes of PPI-treatment with an extensive follow-up duration are widely known. ${ }^{59}$

In conclusion, in this randomized controlled trial, endoscopic fundoplication resulted in a similar decrease in distal esophageal acid exposure compared to PPItherapy at six months follow-up. Additionally, TIF2 resulted in an increased LES resting pressure and a reduction in volume reflux and thereby provided an improved quality of life. These results support the validity of the concept of TIF2 as an alternative to PPI-treatment, because it enables the creation of an effective antireflux barrier, entirely endoscopically. Unfortunately the antireflux barrier deteriorated with elapsing time and therefore, in this form, TIF2 has in our opinion no place in routine GERD treatment. A next generation endoscopic fundoplication technique may benefit from a more solid suturing or stapling mechanism to better withstand intra-abdominal traction forces and warrant durability. 
Table 4.4 Summary of previous clinical studies evaluating TIF.

\begin{tabular}{|c|c|c|c|c|c|c|}
\hline First author & Pub-year & TIF1/2 & $\mathbf{N}$ & $\begin{array}{l}\text { Serious Adverse events/ } \\
\text { Revisional surgery }\end{array}$ & FU & Reported outcomes: \\
\hline Cadiere et al. ${ }^{32}$ & 2008 & TIF1 & 19 & - & 12 & $\begin{array}{l}\text { QoL: } 67 \% \text { improved } \\
\text { (>50\% improved in 53\%) } \\
\text { pH normal in } 63 \% \\
\text { PPI cessation in } 82 \%\end{array}$ \\
\hline Cadiere $^{60}$ & 2009 & TIF1 & 14 & - & 24 & $\begin{array}{l}\text { QoL score }>50 \% \text { in } 64 \% \\
\mathrm{pH}: \mathrm{N} / \mathrm{A} \\
\mathrm{PPI} \text { cessation in } 71 \%\end{array}$ \\
\hline Cadiere et al. ${ }^{32}$ & 2008 & TIF1 & 84 & $\begin{array}{l}2 x \text { esophageal perfora- } \\
\text { tions } / 1 x \text { hemorrhage }\end{array}$ & 12 & $\begin{array}{l}\text { QoL: }>50 \% \text { improved in } \\
73 \% / 37 \% \text { normalization } \\
\text { pH: N/A } \\
\text { PPI: cessation in } 81 \%\end{array}$ \\
\hline Muls et al. ${ }^{61}$ & 2012 & TIF1 & 54 & 12 revisional procedures & 36 & $\begin{array}{l}\text { QoL: significantly im- } \\
\text { proved } \\
\text { pH: } 82 \% \text { normalized } \\
(n=11) \\
\text { PPI: cessation in } 61 \%\end{array}$ \\
\hline $\begin{array}{l}\text { Bergman S et } \\
\text { al. }^{57}\end{array}$ & 2008 & TIF1 & 8 & - & 2 & $\begin{array}{l}\text { QoL: improved } \\
\text { pH: N/A } \\
\text { PPI } 50 \% \text { reduced: } 50 \% \text { \& } \\
\text { cessation in } 25 \%\end{array}$ \\
\hline Repici et al. ${ }^{62}$ & 2010 & TIF1 & 20 & $\begin{array}{l}\text { 2x hemorrhage } \\
4 x \text { revisional LNF }\end{array}$ & 12 & $\begin{array}{l}\text { QoL: significantly im- } \\
\text { proved } \\
\text { pH: improved in } 16,6 \% \text { \& } \\
\text { Worsened in } 66.7 \% \\
\text { PPI: cessation in } 35 \%\end{array}$ \\
\hline Testoni et al. ${ }^{63}$ & 2010 & TIF2 & 20 & - & 6 & $\begin{array}{l}\text { QoL: significantly im- } \\
\text { proved } \\
\text { pH: significantly im- } \\
\text { proved } \\
\text { PPI: cessation in 55\% }\end{array}$ \\
\hline Velanovich $^{64}$ & 2010 & & 26 & $\begin{array}{l}2 x \text { failed device introduc- } \\
\text { tion } \\
1 \times \text { mucosal tear + bleeding }\end{array}$ & 2 & $\begin{array}{l}\text { QoL: significantly im- } \\
\text { proved } \\
\text { pH: N/A } \\
\text { PPI: N/A }\end{array}$ \\
\hline $\begin{array}{l}\text { Demyttenaere et } \\
\text { al }^{65}\end{array}$ & t2010 & TIF2 & 26 & $2 x$ hemorrhage & 10 & $\begin{array}{l}\text { QoL: significantly im- } \\
\text { proved } \\
\text { pH: N/A } \\
\text { PPI: cessation in } 32 \%\end{array}$ \\
\hline Hoppo et $\mathrm{al}^{33}$ & 2010 & TIF2 & 19 & $\begin{array}{l}\text { 1x perforation } \\
1 x \text { Hemorrhage } 1 x \text { Perma- } \\
\text { nent numbness tongue } \\
52 \% \text { revisional LNF }\end{array}$ & 10.8 & $\begin{array}{l}\text { QoL: N/A } \\
\mathrm{pH}: \text { N/A } \\
\text { PPI: cessation in } 26 \%\end{array}$ \\
\hline
\end{tabular}




\begin{tabular}{|c|c|c|c|c|c|c|}
\hline First author & Pub-year & TIF1/2 & $\mathbf{N}$ & $\begin{array}{l}\text { Serious Adverse events/ } \\
\text { Revisional surgery }\end{array}$ & FU & Reported outcomes: \\
\hline Bell et al. ${ }^{60}$ & 2011 & TIF2 & 37 & $\begin{array}{l}\text { 1x Mediastinal abscess } \\
\text { 1x Hemorrhage }\end{array}$ & 6 & $\begin{array}{l}\text { QoL: }>50 \% \text { improved in } \\
70-80 \% \\
\text { pH: normalization in } 61 \% \\
\text { PPI: cessation in } 82 \%\end{array}$ \\
\hline Barnes et al. ${ }^{66}$ & 2011 & TIF2 & 124 & $\begin{array}{l}\text { 1x Pneumonia } \\
5 \times(4 \%) \text { revisional LNF }\end{array}$ & 7 & $\begin{array}{l}\text { QoL: normalization in } \\
75-80 \% \\
\mathrm{pH}: \mathrm{N} / \mathrm{A} \\
\mathrm{PPI} \text { : cessation in } 93 \%\end{array}$ \\
\hline Witteman et al. ${ }^{68}$ & ${ }^{68} 2012$ & TIF1 & 38 & $\begin{array}{l}\text { 1x hemorrhage } \\
14 \times(37 \%) \text { revisional LNF }\end{array}$ & $6 / 36$ & $\begin{array}{l}\text { QoL: significantly im- } \\
\text { proved } \\
\text { PH: not significantly } \\
\text { improved } \\
\text { PPI: cessation } 66 \% 6 \\
\text { months/ } \\
42 \% \text { at } 36 \text { months }\end{array}$ \\
\hline Testoni et al. $^{63}$ & 2012 & TIF2 & $42 / 26$ & $\begin{array}{l}2 \text { pleural perfora- } \\
\text { tion/pneumothorax }\end{array}$ & $6 / 24$ & $\begin{array}{l}\text { QoL: N/A } \\
\mathrm{pH}: \mathrm{N} / \mathrm{A} \\
\mathrm{PPI} \text { : cessation in } \\
60 \% / 42,3 \%\end{array}$ \\
\hline $\operatorname{Trad}^{69}$ & 2012 & TIF2 & 28 & - & 14 & $\begin{array}{l}\text { QoL: N/A } \\
\text { pH: N/A } \\
\text { PPI: cessation in } 64 \% \\
\text { (82\% off daily PPIs) }\end{array}$ \\
\hline Petersen et al. ${ }^{70}$ & 2012 & TIF2 & 23 & 3x revisional LNF & 6 & $\begin{array}{l}\text { QoL: significantly im- } \\
\text { proved ( } n=19) \\
\text { pH: normalized } 43 \% \\
(n=14) \\
\text { PPI: cessation42\% }\end{array}$ \\
\hline Narsule et al. ${ }^{71}$ & 2012 & TIF2 & 46 & $\begin{array}{l}1 \text { pneumonia } \\
2 \text { revisional TIF } \\
1 \text { revisional LNF }\end{array}$ & 4,7 & $\begin{array}{l}\text { QoL: significantly im- } \\
\text { proved } \\
\text { pH: N/A } \\
\text { PPI: N/A }\end{array}$ \\
\hline Bell et al. ${ }^{72}$ & 2012 & TIF2 & 100 & - & 6 & $\begin{array}{l}\text { QoL: normalized in } 73 \% \\
\text { pH: N/A } \\
\text { PPI: cessation in } 80 \%\end{array}$ \\
\hline
\end{tabular}

Abbreviations: Pub-year= year of publication; TIF1/2= Type of TIF-procedure; $\mathrm{N}=$ number of included patients; FU= Follow-up duration (months); QoL= Quality of life; $\mathrm{pH}=$ results of $\mathrm{pH}$ measurements; $\mathrm{PPI}=$ percentage of patients with PPI cessation. 


\section{REFERENCES}

1. Stylopoulos N, Rattner DW. The history of hiatal hernia surgery: from Bowditch to laparoscopy. Ann Surg 2005;241:185-193.

2. Jones MP, Sloan SS, Rabine JC, Ebert CC, Huang CF, Kahrilas PJ. Hiatal hernia size is the dominant determinant of esophagitis presence and severity in gastroesophageal reflux disease. Am J Gastroenterol 2001;96:1711-1717.

3. Mittal RK. Hiatal hernia: myth or reality? Am J Med 1997;103:33S-39S.

4. Mittal RK. Hiatal hernia and gastroesophageal reflux: another attempt to resolve the controversy. Gastroenterol 1993;105:941-943.

5. Moss SF, Kidd M, Modlin IM. The status of the hiatus: the role of hernia in gastroesophageal reflux disease. J Clin Gastroenterol 2007;41:S144-S153.

6. Rydberg L, Ruth M, Lundell L. Mechanism of action of antireflux procedures. Br J Surg 1999;86:405-410.

7. El-Serag HB. Time trends of gastroesophageal reflux disease: a systematic review. Clin Gastroenterol Hepatol 2007;5:17-26.

8. Lundell L. Surgery of gastroesophageal reflux disease: a competitive or complementary procedure? Dig Dis 2004;22:161-170.

9. Metz DC. Managing gastroesophageal reflux disease for the lifetime of the patient: evaluating the long-term options. Am J Med 2004;117 Suppl 5A:49S-55S.

10. Moayyedi P, Talley NJ. Gastro-oesophageal reflux disease. Lancet 2006;367:2086-100.

11. Nandurkar S, Talley NJ. Epidemiology and natural history of reflux disease. Baillieres Best Pract Res Clin Gastroenterol 2000;14:743-57.

12. Smout AJ. The patient with GORD and chronically recurrent problems. Best Pract Res Clin Gastroenterol 2007;21:365-78.

13. Fass R. Proton-pump inhibitor therapy in patients with gastro-oesophageal reflux disease: putative mechanisms of failure. Drugs 2007;67:1521-30.

14. Gerson LB, Boparai V, Ullah N, Triadafilopoulos G. Oesophageal and gastric pH profiles in patients with gastro-oesophageal reflux disease and Barrett's oesophagus treated with proton pump inhibitors. Aliment Pharmacol Ther 2004;20:637-43.

15. Lundell L, Miettinen P, Myrvold HE, Pedersen SA, Liedman B, Hatlebakk JG, Julkonen R, Levander K, Carlsson J, Lamm M, Wiklund I. Continued (5-year) followup of a randomized clinical study comparing antireflux surgery and omeprazole in gastroesophageal reflux disease. J Am Coll Surg 2001;192:172-179; discussion 179-181.

16. Anvari M, Allen C, Marshall J, Armstrong D, Goeree R, Ungar W, Goldsmith C. A randomized controlled trial of laparoscopic Nissen fundoplication versus proton pump inhibitors for treatment of patients with chronic gastroesophageal reflux disease: One-year follow-up. Surg Innov 2006;13:238-49.

17. Spechler SJ. Comparison of medical and surgical therapy for complicated gastroesophageal reflux disease in veterans. The Department of Veterans Affairs Gastroesophageal Reflux Disease Study Group. N Engl J Med 1992;326:786-92.

18. Spechler SJ, Lee E, Ahnen D, Goyal RK, Hirano I, Ramirez F, Raufman JP, Sampliner R, Schnell T, Sontag S, Vlahcevic ZR, Young R, Williford W. Long-term outcome of medical and surgical therapies for gastroesophageal reflux disease: follow-up of a randomized controlled trial. Jama 2001;285:2331-2338.

19. Allgood PC, Bachmann M. Medical or surgical treatment for chronic gastrooesophageal reflux? A systematic review of published evidence of effectiveness. Eur J Surg 2000;166:713-721.

20. Cookson R, Flood C, Koo B, Mahon D, Rhodes M. Short-term cost effectiveness and long-term cost analysis comparing laparoscopic Nissen fundoplication with proton-pump inhibitor maintenance for gastro-oesophageal reflux disease. Br J Surg 2005;92:700-706.

21. Lundell L, Miettinen P, Myrvold HE, Hatlebakk JG, Wallin L, Malm A, Sutherland I, Walan A. Sevenyear follow-up of a randomized clinical trial comparing proton-pump inhibition with surgical therapy for reflux oesophagitis. Br J Surg 2007;94:198-203. 
22. Mahon D, Rhodes M, Decadt B, Hindmarsh A, Lowndes R, Beckingham I, Koo B, Newcombe RG. Randomized clinical trial of laparoscopic Nissen fundoplication compared with proton-pump inhibitors for treatment of chronic gastro-oesophageal reflux. Br J Surg 2005;92:695-699.

23. Dallemagne B, Weerts J, Markiewicz S, Dewandre JM, Wahlen C, Monami B, Jehaes C. Clinical results of laparoscopic fundoplication at ten years after surgery. Surg Endosc 2006;20:159-165.

24. Coelho JC, Wiederkehr JC, Campos AC, Andrigueto PC. Conversions and complications of laparoscopic treatment of gastroesophageal reflux disease. J Am Coll Surg 1999;189:356-361.

25. Kamolz T, Granderath FA, Bammer T, Pasiut M, Pointner R. Dysphagia and quality of life after laparoscopic Nissen fundoplication in patients with and without prosthetic reinforcement of the hiatal crura. Surg Endosc 2002;16:572-577.

26. Lundell L. Complications after anti-reflux surgery. Best Pract Res Clin Gastroenterol 2004;18:935945.

27. Wills VL, Hunt DR. Dysphagia after antireflux surgery. Br J Surg 2001;88:486-499.

28. Bessell JR, Finch R, Gotley DC, Smithers BM, Nathanson L, Menzies B. Chronic dysphagia following laparoscopic fundoplication. Br J Surg 2000;87:1341-1345.

29. Hayden J, Jamieson G. Optimization of outcome after laparoscopic antireflux surgery. ANZ J Surg 2006;76:258-263.

30. Cadiere GB, Rajan A, Rqibate M, Germay O, Dapri G, Himpens J, Gawlicka AK. Endoluminal fundoplication (ELF) - evolution of Esophy $\mathrm{X}^{\mathrm{TM}}$, a new surgical device for transoral surgery. Minim Invasive Ther Allied Technol 2006;15:348-355.

31. Cadiere GB, Rajan A, Germay 0, Himpens J. Endoluminal fundoplication by a transoral device for the treatment of GERD: A feasibility study. Surg Endosc 2008;22:333-42.

32. Cadiere GB, Buset M, Muls V, Rajan A, Rosch T, Eckardt AJ, Weerts J, Bastens B, Costamagna G, Marchese M, Louis H, Mana F, Sermon F, Gawlicka AK, Daniel MA, Deviere J. Antireflux transoral incisionless fundoplication using EsophyX: 12-month results of a prospective multicenter study. World J Surg 2008;32:1676-88.

33. Hoppo T, Immanuel A, Schuchert M, Dubrava Z, Smith A, Nottle P, Watson DI, Jobe BA. Transoral incisionless fundoplication 2.0 procedure using EsophyX for gastroesophageal reflux disease. J Gastrointest Surg 2010;14:1895-901.

34. Furnee EJ, Broeders JA, Draaisma WA, Schwartz MP, Hazebroek EJ, Smout AJ, van Rijn PJ, Broeders IA. Laparoscopic Nissen fundoplication after failed EsophyX fundoplication. $\mathrm{Br} \quad \mathrm{J}$ Surg;2011;97:1051-5.

35. Witteman BP, Strijkers R, de Vries E, Toemen L, Conchillo JM, Hameeteman W, Dagnelie PC, Koek $\mathrm{GH}$, Bouvy ND. Transoral incisionless fundoplication for treatment of gastroesophageal reflux disease in clinical practice. Surg Endosc. 2012; 26(11): 3307-15.

36. Witteman BP, Kessing BF, Snijders G, Koek GH, Conchillo JM, Bouvy ND. Revisional laparoscopic antireflux surgery after unsuccessful endoscopic fundoplication. Surg Endosc 2013; Epub ahead of print.

37. Velanovich V, Vallance SR, Gusz JR, Tapia FV, Harkabus MA. Quality of life scale for gastroesophageal reflux disease. J Am Coll Surg 1996;183:217-24.

38. Kulich KR, Wiklund I, Junghard O. Factor structure of the Quality of Life in Reflux and Dyspepsia (QOLRAD) questionnaire evaluated in patients with heartburn predominant reflux disease. Qual Life Res 2003;12:699-708.

39. Kahrilas PJ, Sifrim D. High-Resolution Manometry and Impedance-pH/Manometry: Valuable Tools in Clinical and Investigational Esophagology. Gastroenterology 2008.

40. Conchillo JM, Schwartz MP, Selimah M, Samsom M, Sifrim D, Smout AJ. Acid and non-acid reflux patterns in patients with erosive esophagitis and non-erosive reflux disease (NERD): a study using intraluminal impedance monitoring. Dig Dis Sci 2008;53:1506-12.

41. Bredenoord AJ. Impedance-pH monitoring: new standard for measuring gastro-oesophageal reflux. Neurogastroenterol Motil 2008;20:434-9.

42. Zerbib F, Roman S, Ropert A, des Varannes SB, Pouderoux P, Chaput U, Mion F, Verin E, Galmiche JP, Sifrim D. Esophageal pH-impedance monitoring and symptom analysis in GERD: a study in patients off and on therapy. Am J Gastroenterol 2006;101:1956-63. 
43. Sifrim D, Dupont L, Blondeau K, Zhang X, Tack J, Janssens J. Weakly acidic reflux in patients with chronic unexplained cough during 24 hour pressure, $\mathrm{pH}$, and impedance monitoring. Gut 2005;54:449-54.

44. Bernhard A, Pohl D, Fried M, Castell DO, Tutuian R. Influence of bolus consistency and position on esophageal high-resolution manometry findings. Dig Dis Sci 2008;53:1198-205.

45. Bredenoord AJ, Smout AJ. High-resolution manometry. Dig Liver Dis 2008;40:174-81.

46. Fox MR, Bredenoord AJ. Oesophageal high-resolution manometry: moving from research into clinical practice. Gut 2008;57:405-23.

47. Jobe BA, Kahrilas PJ, Vernon AH, Sandone C, Gopal DV, Swanstrom LL, Aye RW, Hill LD. Endoscopic appraisal of the gastroesophageal valve after antireflux surgery. Am J Gastroenterol 2004;99:233243.

48. Hill LD, Kozarek RA, Kraemer SJ, Aye RW, Mercer CD, Low DE, Pope CE, 2nd. The gastroesophageal flap valve: in vitro and in vivo observations. Gastrointest Endosc 1996;44:541-547.

49. Jobe BA, O'Rourke RW, McMahon BP, Gravesen F, Lorenzo C, Hunter JG, Bronner M, Kraemer SJ. Transoral endoscopic fundoplication in the treatment of gastroesophageal reflux disease: the anatomic and physiologic basis for reconstruction of the esophagogastric junction using a novel device. Ann Surg 2008;248:69-76.

50. Bell RC, Cadiere GB. Transoral rotational esophagogastric fundoplication: technical, anatomical, and safety considerations. Surg Endosc 2011;25:2387-99.

51. Kulich KR, Madisch A, Pacini F, Pique JM, Regula J, Van Rensburg CJ, Ujszaszy L, Carlsson J, Halling K, Wiklund IK. Reliability and validity of the Gastrointestinal Symptom Rating Scale (GSRS) and Quality of Life in Reflux and Dyspepsia (QOLRAD) questionnaire in dyspepsia: a six-country study. Health Qual Life Outcomes 2008;6:12.

52. Jafri SM, Arora G, Triadafilopoulos G. What is left of the endoscopic antireflux devices? Curr Opin Gastroenterol 2009;25:352-7.

53. Peters MJ, Mukhtar A, Yunus RM, Khan S, Pappalardo J, Memon B, Memon MA. Meta-analysis of randomized clinical trials comparing open and laparoscopic anti-reflux surgery. Am J Gastroenterol 2009;104:1548-61; quiz 1547, 1562.

54. Broeders JA, Mauritz FA, Ahmed Ali U, Draaisma WA, Ruurda JP, Gooszen HG, Smout AJ, Broeders IA, Hazebroek EJ. Systematic review and meta-analysis of laparoscopic Nissen (posterior total) versus Toupet (posterior partial) fundoplication for gastro-oesophageal reflux disease. Br J Surg 2010; 97:1318-30.

55. Schiefke I, Zabel-Langhennig A, Neumann S, Feisthammel J, Moessner J, Caca K. Long term failure of endoscopic gastroplication (EndoCinch). Gut 2005;54:752-8.

56. Pearl JP, Marks JM. Endolumenal therapies for gastroesophageal reflux disease: are they dead? Surg Endosc 2007;21:1-4.

57. Bergman S, Mikami DJ, Hazey JW, Roland JC, Dettorre R, Melvin WS. Endolumenal fundoplication with EsophyX: the initial North American experience. Surg Innov 2008;15:166-70.

58. Testoni PA, Vailati C, Testoni S, Corsetti M. Transoral incisionless fundoplication (TIF 2.0) with EsophyX for gastroesophageal reflux disease: long-term results and findings affecting outcome. Surg Endosc 2010,;26:1425-35.

59. Miner PB, Jr. Review article: physiologic and clinical effects of proton pump inhibitors on nonacidic and acidic gastro-oesophageal reflux. Aliment Pharmacol Ther 2006;23 Suppl 1:25-32.

60. Cadiere GB, Van Sante N, Graves JE, Gawlicka AK, Rajan A. Two-year results of a feasibility study on antireflux transoral incisionless fundoplication using EsophyX. Surg Endosc 2009;23:957-64.

61. Muls V, Eckardt AJ, Marchese M, Bastens B, Buset M, Deviere J, Louis H, Rajan A, Daniel MA, Costamagna G. Three-year Results of a Multicenter Prospective Study of Transoral Incisionless Fundoplication. 2012; Surg Innov.

62. Repici A, Fumagalli U, Malesci A, Barbera R, Gambaro C, Rosati R. Endoluminal fundoplication (ELF) for GERD using EsophyX: a 12-month follow-up in a single-center experience. J Gastrointest Surg 2010;14:1-6. 
63. Testoni PA, Corsetti M, Di Pietro S, Castellaneta AG, Vailati C, Masci E, Passaretti S. Effect of transoral incisionless fundoplication on symptoms, PPI use, and ph-impedance refluxes of GERD patients. World J Surg 2010; 34:750-7.

64. Velanovich V. Endoscopic, endoluminal fundoplication for gastroesophageal reflux disease: initial experience and lessons learned. Surgery; 2010, 148:646-51; discussion 651-3.

65. Demyttenaere SV, Bergman S, Pham T, Anderson J, Dettorre R, Melvin WS, Mikami DJ. Transoral incisionless fundoplication for gastroesophageal reflux disease in an unselected patient population. Surg Endosc 2010;24:854-8.

66. Bell RC, Freeman KD. Clinical and pH-metric outcomes of transoral esophagogastric fundoplication for the treatment of gastroesophageal reflux disease. Surg Endosc 2011; 25:1975-84.

67. Barnes WE, Hoddinott KM, Mundy S, Williams M. Transoral incisionless fundoplication offers high patient satisfaction and relief of therapy-resistant typical and atypical symptoms of GERD in community practice. 2011; Surg Innov;18:119-29.

68. Witteman BP, Strijkers R, de Vries E, Toemen L, Conchillo JM, Hameeteman W, Dagnelie PC, Koek GH, Bouvy ND. Transoral incisionless fundoplication for treatment of gastroesophageal reflux disease in clinical practice. Surg Endosc 2012; 26:3307-15.

69. Trad KS, Turgeon DG, Deljkich E. Long-term outcomes after transoral incisionless fundoplication in patients with GERD and LPR symptoms. Surg Endosc 2012; 26:650-60.

70. Petersen RP, Filippa L, Wassenaar EB, Martin AV, Tatum R, Oelschlager BK. Comprehensive evaluation of endoscopic fundoplication using the EsophyX device. Surg Endosc 2012; 26:1021-7.

71. Narsule CK, Burch MA, Ebright MI, Hess DT, Rivas R, Jr., Daly BD, Fernando HC. Endoscopic fundoplication for the treatment of gastroesophageal reflux disease: initial experience. J Thorac Cardiovasc Surg 2012; 143:228-34.

72. Bell RC, Mavrelis PG, Barnes WE, Dargis D, Carter BJ, Hoddinott KM, Sewell RW, Trad KS, DaCosta Gill B, Ihde GM. A prospective multicenter registry of patients with chronic gastroesophageal reflux disease receiving transoral incisionless fundoplication. J Am Coll Surg 2012; 215:794-809. 



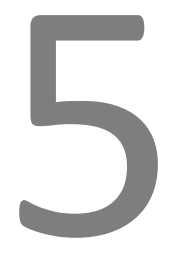

Revisional laparoscopic antireflux surgery after unsuccessful endoscopic fundoplication 


\section{ABSTRACT}

\section{Background}

Transoral incisionless fundoplication (TIF) is a novel endoscopic procedure for treatment of gastroesophageal reflux disease (GERD), which is currently under evaluation. In case of treatment failure, subsequent revisional laparoscopic antireflux surgery (rLARS) may be required. This study aimed to evaluate the feasibility, safety, and outcomes of rLARS after previous endoscopic fundoplication.

Methods

Chronic GERD patients who underwent rLARS after a previous TIF-procedure were included in the study. Pre- and post-operative assessment included GERD-related quality-of-life scores, proton pump inhibitor (PPI) usage, 24-h pH-metry, upper gastrointestinal endoscopy and registration of adverse events.

\section{Results}

Revisional laparoscopic Nissen fundoplication was feasible in all 15 patients included in the study without conversions to open surgery. Acid exposure of the distal esophagus improved significantly after rLARS and esophagitis, PPI usage and hiatal hernia decreased. Quality of life did not improve significantly after rLARS and $33 \%$ of the patients experienced dysphagia.

\section{Conclusion}

Revisional laparoscopic Nissen fundoplication was feasible and safe after unsuccessful endoscopic fundoplication, resulting in objective reflux control at the cost of a relatively high rate of dysphagia.

Published as:

Revisional laparoscopic antireflux surgery after unsuccessful endoscopic fundoplication. Witteman BPL, Kessing BF, Snijders G, Koek GH, Conchillo JM, Bouvy ND. Surg Endosc. 2013 jun;27(6):2231-6. 


\section{INTRODUCTION}

At the beginning of this century, endoscopic procedures for the treatment of gastro-esophageal reflux disease (GERD) were introduced as a less invasive alternative to laparoscopic antireflux surgery (LARS). ${ }^{1}$ Techniques included radiofrequency ablation, injection therapy and suturing or stapling techniques. ${ }^{2-5}$ The outcomes of endoscopic antireflux techniques, however, were disappointing and many techniques have been abandoned. Of these techniques the suturing or stapling techniques are most similar to antireflux surgery because they attempt to reconstruct the anatomic reflux barrier at the gastroesophageal junction.

The transoral incisionless fundoplication (TIF), designed to resemble parts of the surgical fundoplication, is currently under evaluation. Although some early series showed encouraging outcomes, also substantial treatment failure rates have been reported.6-9

In case of failure, subsequent revisional laparoscopic antireflux surgery (rLARS) would be an obvious next step in an attempt to control reflux in these patients. However, this could be technically more challenging due to the altered anatomic situation around the gastroesophageal junction, induced by the endoscopic procedure and could lead to an increased rate of complications or suboptimal outcomes.

The current study aimed to evaluate the feasibility and safety of rLARS after previous TIF and to assess its efficacy in subjective and objective reflux control.

\section{METHODS}

\section{Patient characteristics}

Patients who underwent rLARS after a previous TIF were included in the study. These patients were selected from a group, prospectively followed in the context of clinical trials evaluating the TIF-procedure at our institution between 2006 and 2008. Written informed consent was obtained and protocols were approved by the local medical ethics committee.

The TIF-procedure was offered to GERD patients, referred for surgical management by their gastroenterologists because they were refractory to antisecretory medication or dissatisfied with it. The inclusion criteria for the TIF-procedure were chronic GERD (>6 months), age of 18 to 75 years, body mass index (BMI) lower than $36 \mathrm{~kg} / \mathrm{m}^{2}$ and normal or hypotonic lower esophageal sphincter (LES) resting pressure $(<30 \mathrm{mmHg}$ ). The presence of gastroesophageal reflux was confirmed by pathological 24-h esophageal $\mathrm{pH}$ monitoring. Patients were excluded if they had a large hiatal hernia $(>5 \mathrm{~cm}$ ), Barrett's esophagus, hypertonic LES resting pressure or motility disorders. In case of treatment failure after TIF, antisecretory medication was resumed on demand. The rLARS procedure was offered in case of 
continuing or recurrent typical GERD symptoms while the patient was receiving antisecretory medication in combination with anatomic wrap failure at endoscopy and/or pathologic $\mathrm{pH}$-measurements.

\section{Procedure details}

TIF was performed according to the TIF protocol previously described using the EsophyX-device (EndoGastric Solutions, Inc., Redmond, WA, USA). ${ }^{10}$ With the patient under general anesthesia and endotracheally intubated, a partial fundoplication was established endoscopically by performing sequential retractions of tissue and placement of multiple polypropylene H-fasteners.

The rLARS procedure included the restoration of the pre-TIF anatomy by taking down the endoscopically created fundoplication, via meticulous sharp dissection through the serosal adhesions and fasteners, using endoscopic scissors. Subsequently, after mobilization of the fundus, by dissection of two or three short gastric vessels, a "floppy" laparoscopic 360 degree Nissen fundoplication was performed by two experienced upper gastrointestinal (GI) surgeons. Adverse events during surgery and postoperatively were recorded.

\section{GERD monitoring}

Objective and subjective GERD monitoring was performed at baseline, at 3 and 6 months after each intervention (TIF and rLARS) according to protocol. At baseline (pre-TIF), after TIF, and after rLARS, symptomatic outcome was assessed using a GERD-related quality-of-life questionnaire (Health-Related Quality of Life [HRQL]) developed and validated to measure typical GERD symptoms in response to GERD therapy using a visual analog scale.11, 12 General health condition satisfaction scores were monitored by the responses of patients as "satisfied," "neutral," or "dissatisfied."

All patients were advised to stop PPI usage 2 weeks after TIF or surgery and instructed to resume PPI usage in case of recurrent GERD-related symptoms. Their PPI usage was recorded in a drug diary. Objective assessment was performed by measurements of the distal esophageal acid exposure using the Orion II Ambulatory 24-h pH system (Medical Measurement Systems, Enschede, The Netherlands). A $\mathrm{pH}$ lower than 4 for up to $4.2 \%$ of the monitoring time was considered physiologic esophageal acid exposure. Hiatal hernia, esophagitis (Los Angeles classification scale) and appearance of the fundoplication were evaluated by upper GI endoscopy at baseline and after each intervention. 
Data distribution was evaluated using the Kolmogorov-Smirnov test. The acid exposure time and satisfaction rate were compared using the Wilcoxon signed rank test and a paired Student's $t$-test was used to compare GERD-HRQL scores. Statistical analysis was performed using Prism software version 5 (Graph Pad, San Diego, CA, USA). Throughout this report data are presented as mean \pm standard error of the mean (SEM) or as median (interquartile range [IQR]) depending on data distribution. Differences were considered statistically significant at a $p$-value lower than 0.05 .

\section{RESULTS}

At the time of data-collection, 43 patients had undergone the TIF-procedure in our institution in the context of clinical trials. Of these 43 patients, 38 had undergone the TIF1-procedure and 5 had undergone TIF2-procedure in two different trials. Of the 15 patients who underwent rLARS, 14 patients had undergone a previous TIF1-procedure and one a previous TIF2-procedure.

The median age of the patients was 49 years (range 25-65 years) and seven patients were women. The interval between TIF and rLARS was median 17 months (range 7-34 months), and follow-up period after rLARS was median 14 months (range 3-34 months).

Patients eligible for rLARS had continuing or recurrent GERD symptoms after TIF in combination with disruption of fasteners (found in $76 \%$, with partial disruption in $53 \%$ and complete disruption in $13 \%$ ) and/or pathologic acid exposure (found in $73 \%$ ).

The rLARS procedure was feasible for all the patients without the necessity of conversion to open surgery. The operation time was median 112 min (range 57$206 \mathrm{~min}$ ). The peri-operative adverse events included a gastric perforation in one patient during dissection of the endoscopic fundoplication. The perforation was noted during the surgery and closed by endoscopic suturing. Post-operative upper GI radiography did not show leakage, and the event had no further consequences for the patient. The major post-operative adverse event was dysphagia in $33 \%$ of the patients, with $27 \%$ needing one or more endoscopic pneumodilations. Other adverse events were mild and resolved for the majority of patients within the first week after rLARS.

The GERD-related quality-of-life scores after rLARS (18 \pm 4$)$ were improved significantly compared with baseline scores $(32 \pm 4)(p<0.05)$, although the improvement between post-TIF and rLARS $(23 \pm 5)$ was not statistically significant (figure 5.1). The satisfaction score after surgery was significantly improved compared with baseline score but did not differ from the score after TIF. 
The median acid exposure time after rLARS (1.5; range 0.2-8.6) was significantly decreased compared with post-TIF $(9.0$; range $4.5-16.6)(p<0.05)$ but not compared with baseline (7.1; range 5.9-12.8) and was normalized in $67 \%$ of patients (figure 5.2). After rLARS esophagitis, PPI-usage and hiatal hernia improved (summary outcomes is listed in table 5.1).
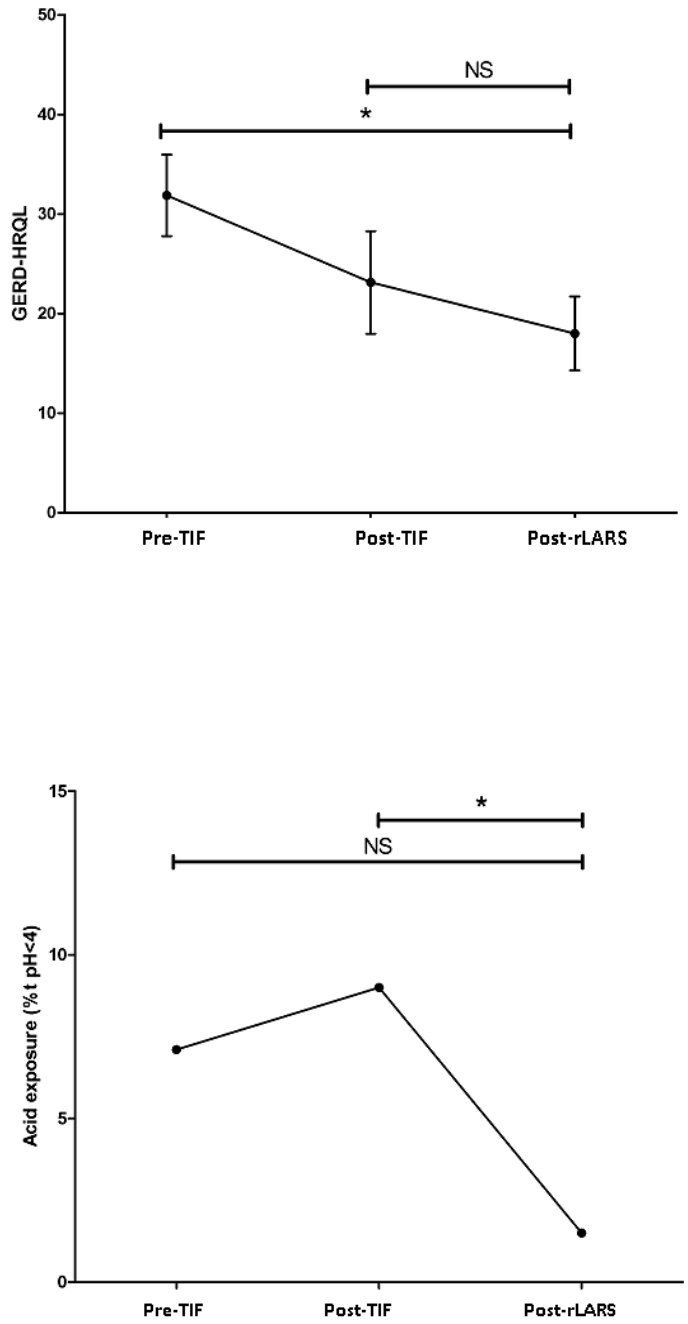

Figure 5.1 GERD-HRQL scores before TIF, after TIF and after rLARS. Data are presented as mean and standard error of the mean. $*=p<0.05, \mathrm{NS}=$ non-significant.

Figure 5.2 Esophageal acid exposure time (\%) measured before TIF, after TIF and after rLARS. Data are presented as medians. $*=p<0.05, \mathrm{NS}=$ non-significant. 
Table 5.1 Summary of outcomes of rLARS following previous TIF-procedure. Values are medians (ranges) or percentages.

\begin{tabular}{llll}
\hline Outcome & Pre-TIF & Post-TIF & Post-rLARS \\
\hline No. patients & 15 & 15 & 15 \\
HRQL-SCORE & $32 \pm 4$ & $23 \pm 5$ & $18 \pm 4$ \\
Satisfaction score: & & & \\
Satisfied: & $0 \%$ & $33 \%$ & $33 \%$ \\
Neutral: & $67 \%$ & $53 \%$ & $53 \%$ \\
Dissatisfied: & $33 \%$ & $13 \%$ & $13 \%$ \\
PPI-usage: & & & \\
Double dose PPIs daily & $67 \%$ & $27 \%$ & $13 \%$ \\
Single dose PPIs daily & $20 \%$ & $20 \%$ & $27 \%$ \\
No PPIs & $13 \%$ & $53 \%$ & $60 \%$ \\
Acid Exposure time & $7.1(5.9-12.8)$ & $9.0(4.5-16.8)$ & $1.5(0.2-8.6)$ \\
(\% of time pH<4) & & & \\
Hernia size: & & & \\
None & $33 \%$ & $47 \%$ & $93 \%$ \\
Small (1-2 cm) & $53 \%$ & $40 \%$ & $7 \%$ \\
Medium (3-5 cm) & $13 \%$ & $13 \%$ & $0 \%$ \\
Esophagitis: & & & \\
None & $47 \%$ & $47 \%$ & $60 \%$ \\
Grade A & $13 \%$ & $20 \%$ & $7 \%$ \\
Grade B & $27 \%$ & $0 \%$ & $0 \%$ \\
Grade C & $0 \%$ & $6 \%$ & $6 \%$ \\
Grade D & $13 \%$ & & \\
\hline & & &
\end{tabular}

\section{DISCUSSION}

When medical therapy fails, surgery has been the only alternative for GERD patients. The laparoscopic Nissen fundoplication has become the gold standard, showing excellent outcomes in terms of GERD control. ${ }^{13}$ Still, clinicians are reluctant to refer patients for surgery due to the invasiveness and complications such as dysphagia. Endoscopic fundoplication, introduced as an attractive minimally invasive alternative, is expected to have fewer side effects. ${ }^{14}$ Unfortunately, in the early experience; endoluminal fundoplication did not control GERD satisfactorily in all patients. In fact, a substantial failure rate has been described.7, 9 Subsequently, rLARS would appear to be the next step for this group of patients. In this study, we report the outcomes of revisional surgery for unsuccessful previous TIF procedures in 15 patients.

In the majority of patients included in this study, failure of the endoscopic fundoplication seemed to be caused by disruption of the polypropylene $\mathrm{H}$ fasteners, which implies concerns about the durability of the endoscopically created fundoplication. Technically, rLARS after TIF was feasible for all the patients without conversions to open surgery. However, previous TIF showed a substantial change in anatomy and with the restoration of the "pre-TIF anatomical situation", operation times were longer compared with primary LARS.15, 16 
We encountered one gastric perforation as the only adverse event during surgery. The post-operative adverse events included a high rate of dysphagia (33\% vs. 13\% after primary Nissen fundoplication). ${ }^{16}$ Dysphagia is difficult to cure and has, as shown in the current study, a serious impact on GERD-related quality of life. The question arises as to why the rate of dysphagia was high in this group.

Tension-free 360 degree Nissen fundoplications were performed by two experienced upper GI surgeons. Besides the restoration of anatomy, the procedure did not differ from our standard primary LARS, after which dysphagia is uncommon. We take due care in creating a tension-free fundoplication by mobilization the fundus along the greater curvature, about 10-15 cm inferior to the angle of His, with dissection of two to three short gastric vessels. After completion of the wrap, it is routinely checked for rotational tension by pulling the fundus through the retro-esophageal window to create a 360 degree wrap, which should stay in place after its release. We do not routinely use a bougie for calibration and no bougies were used during the rLARS procedures. A posterior crural repair was performed until the empty esophagus was just reached. The additional scar tissue at the fundus after the TIF procedure could perhaps be responsible for additional tension and therefore could be the cause for dysphagia. On the other hand it is remarkable that revisional Nissen fundoplication after previous antireflux surgery does not result in a significantly increased rate of postoperative dysphagia (3-17\%) compared to primary LARS and improves GERD related quality of life scores. ${ }^{17-19}$ Perhaps a bougie should have been used in rLARS during wrap construction and crural closure. In a randomized controlled trial, Patterson et al. reported a significant decrease in postoperative dysphagia for patients who had a 56-Fr bougie placed during primary LARS compared with patients who had no bougie placed. ${ }^{20} \mathrm{We}$ speculate that a partial fundoplication such as the Toupet procedure may be a superior option for rLARS. Studies have shown the partial posterior fundoplication to be equally effective in reflux control, with less postoperative dysphagia in primary LARS. ${ }^{16}$

For the 15 selected study patients, the $\mathrm{pH}$ measurements did not improve after TIF compared with baseline, and even a slight increase in acid exposure of the distal esophagus is suggested (figure 5.2). A degradation of the antireflux barrier due to the endoscopic procedure also has been reported by other groups and ascribed to the learning curve for the TIF technique and the prototype device. ${ }^{8}$

Currently, the TIF2 technique with the second-generation Esophy $\mathrm{X}^{\mathrm{TM}}$ device has been introduced and is suggested to improve outcomes. ${ }^{21}$ The major difference between the initial TIF1 technique and TIF2 is the order and location of fastener placement, with the addition of rotational and longitudinal elements to an esophagogastric instead of a gastrogastric fundoplication. ${ }^{22}$ Although acid exposure increased, GERD-related quality of life improved after TIF. This outcome confirms the poor correlation between symptoms and objective GERD testing and may be explained by a placebo effect at the time of data collection. In the experience with 
other early endoscopic GERD therapies, this effect was reported to be as high as 25-50\%. ${ }^{23,24}$

After rLARS, acid exposure of the distal esophagus improved significantly, and esophagitis, PPI usage, and hiatal hernia decreased. Despite improved objective reflux control, the GERD-related quality of life did not improve significantly, nor did the general satisfaction scores, mainly due to the high rate of dysphagia, which is represented in the GERD-HRQL scores.

The single other study on this topic was published by Furnée et al. ${ }^{25}$ In their study, 11 patients underwent laparoscopic Nissen fundoplication after a failed TIF procedure. Gastric perforations occurred in $27 \%$ of the patients, resulting in one conversion to laparotomy and a subphrenic abscess requiring additional surgical exploration in one patient. Reflux control after rLARS was satisfactory, but dysphagia after rLARS was high in their series as well (27\%).

The limitations of the current study were the small group of patients, the short follow-up period, and the selection bias due to enrollment of all the subjects from a group of highly selected patients in the context of clinical trials with the TIF procedure.

We conclude that revisional laparoscopic Nissen fundoplication is, although technically challenging, feasible and safe after failed endoscopic fundoplication. In this study, a significant improvement in objective reflux control was established at the cost of a relatively high rate of dysphagia, which had an impact on quality of life. How to prevent postoperative dysphagia after rLARS remains unclear and needs further research. 


\section{REFERENCES}

1. Nason KS, Schuchert MJ, Witteman BP, Jobe BA. Endoscopic therapies for the treatment of reflux disease. Semin Thorac Cardiovasc Surg 2008;20:320-5.

2. Schwartz MP, Wellink H, Gooszen HG, Conchillo JM, Samsom M, Smout AJ. Endoscopic gastroplication for the treatment of gastro-oesophageal reflux disease: a randomised, sham-controlled trial. Gut 2007;56:20-8.

3. Rothstein R, Filipi C, Caca K, Pruitt R, Mergener K, Torquati A, Haber G, Chen Y, Chang K, Wong D, Deviere J, Pleskow D, Lightdale C, Ades A, Kozarek R, Richards W, Lembo A. Endoscopic fullthickness plication for the treatment of gastroesophageal reflux disease: a randomized, shamcontrolled trial. Gastroenterology 2006;131:704-712.

4. Corley DA, Katz P, Wo JM, Stefan A, Patti M, Rothstein R, Edmundowicz S, Kline M, Mason R, Wolfe MM. Improvement of gastroesophageal reflux symptoms after radiofrequency energy: a randomized, sham-controlled trial. Gastroenterology 2003;125:668-676.

5. Deviere J, Costamagna G, Neuhaus H, Voderholzer W, Louis H, Tringali A, Marchese M, Fiedler T, Darb-Esfahani P, Schumacher B. Nonresorbable copolymer implantation for gastroesophageal reflux disease: a randomized sham-controlled multicenter trial. Gastroenterology 2005;128:532540 .

6. Cadiere GB, Van Sante N, Graves JE, Gawlicka AK, Rajan A. Two-year results of a feasibility study on antireflux transoral incisionless fundoplication using EsophyX. Surg Endosc 2009;23:957-64.

7. Hoppo T, Immanuel A, Schuchert M, Dubrava Z, Smith A, Nottle P, Watson DI, Jobe BA. Transoral incisionless fundoplication 2.0 procedure using EsophyX for gastroesophageal reflux disease. J Gastrointest Surg 2011;14:1895-901.

8. Repici A, Fumagalli U, Malesci A, Barbera R, Gambaro C, Rosati R. Endoluminal fundoplication (ELF) for GERD using EsophyX: a 12-month follow-up in a single-center experience. J Gastrointest Surg 2010;14:1-6.

9. Witteman BP, Strijkers R, de Vries E, Toemen L, Conchillo JM, Hameeteman W, Dagnelie PC, Koek GH, Bouvy ND. Transoral incisionless fundoplication for treatment of gastroesophageal reflux disease in clinical practice. Surg Endosc. 2012; 26(11):3307-3315

10. Cadiere GB, Buset M, Muls V, Rajan A, Rosch T, Eckardt AJ, Weerts J, Bastens B, Costamagna G, Marchese M, Louis H, Mana F, Sermon F, Gawlicka AK, Daniel MA, Deviere J. Antireflux Transoral Incisionless Fundoplication Using EsophyX: 12-Month Results of a Prospective Multicenter Study. World J Surg 2008;32:1676-1688.

11. Velanovich V, Vallance SR, Gusz JR, Tapia FV, Harkabus MA. Quality of life scale for gastroesophageal reflux disease. J Am Coll Surg 1996;183:217-224.

12. Velanovich V. The development of the GERD-HRQL symptom severity instrument. Dis Esophagus 2007;20:130-134.

13. Dallemagne B, Weerts J, Markiewicz S, Dewandre JM, Wahlen C, Monami B, Jehaes C. Clinical results of laparoscopic fundoplication at ten years after surgery. Surg Endosc 2006;20:159-165.

14. Cadiere GB, Buset M, Muls V, Rajan A, Rosch T, Eckardt AJ, Weerts J, Bastens B, Costamagna G, Marchese M, Louis H, Mana F, Sermon F, Gawlicka AK, Daniel MA, Deviere J. Antireflux transoral incisionless fundoplication using EsophyX: 12-month results of a prospective multicenter study. World J Surg 2008;32:1676-88.

15. Nieponice A, Jobe BA. Endoscopic fundoplication: real or fantasy? J Gastrointest Surg 2011; 15:1295-8.

16. Broeders JA, Mauritz FA, Ahmed Ali U. Systematic review and meta-analysis of laparoscopic Nissen (posterior total) versus Toupet (posterior partial) fundoplication for gastroesophageal reflux disease. Br J Surg 2011;97:1318-1330

17. Iqbal A, Awad Z, Simkins J et al. Repair of 104 failed antireflux operations. Ann Surg 2006; 244:42-51

18. Curet MJ, Josloff RK, Schoeb O, Zucker KA. Laparoscopic reoperation for failed antireflux procedures. Arch Surg 1999; 34:559-563 
19. Floch NR, Hinder RA, Klingler PJ et al. Is laparoscopic reoperation for failed antireflux surgery feasible? Arch Surg 1999;134:733-737

20. Patterson EJ, Herron DM, Hansen PD, Ramzi N, Standage BA, Swanström LL. Effect of an esophageal bougie on the incidence of dysphagia following nissen fundoplication: a prospective, blinded, randomized clinical trial. Arch Surg 2000 Sep;135(9):1055-61; discussion 1061-2.

21. Bell RC, Cadiere GB. Transoral rotational esophagogastric fundoplication: technical, anatomical, and safety considerations. Surg Endosc 2011;25:2387-99.

22. Jobe BA, O'Rourke RW, McMahon BP, Gravesen F, Lorenzo C, Hunter JG, Bronner M, Kraemer SJ. Transoral endoscopic fundoplication in the treatment of gastroesophageal reflux disease: the anatomic and physiologic basis for reconstruction of the esophagogastric junction using a novel device. Ann Surg 2008;248:69-76.

23 Hogan WJ Clinical trials evaluating endoscopic GERD treatments: is it time for a moratorium on the clinical use of these procedures? Am J Gastroenterol. 2006; 101:437-439

24 Pearl JP, Marks JM. Endolumenal therapies for gastroesophageal reflux disease: are they dead? Surg Endosc 2007;21:1-4

25. Furnee EJ, Broeders JA, Draaisma WA, Schwartz MP, Hazebroek EJ, Smout AJ, van Rijn PJ, Broeders IA. Laparoscopic Nissen fundoplication after failed EsophyX fundoplication. 2010;Br J Surg;97:1051-5. 



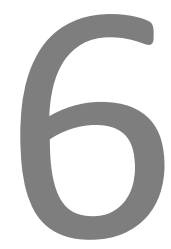

Minimally invasive esophagectomy 


\section{ABSTRACT}

Esophagectomy is the primary therapy for resectable tumors in the distal esophagus. Traditional "open" esophagectomy has been associated with significant morbidity and mortality rates. In an attempt to lower these rates, minimally invasive esophagectomy (MIE) was introduced. Highlights of the present literature comparing the open to the minimally invasive approach are described in this chapter, followed by a detailed report on the technical aspects of two MIE procedures, each indicated for different stages of disease. Laparoscopic transhiatal inversion esophagectomy (LIE) is applied for treatment of end-stage benign disease and early malignancy confined to the mucosa (T1a-stage). While for T1b-stage or advanced stage resectable malignancies, the combined laparoscopic-thoracoscopic (twocavity) approach with en bloc lymphadenectomy can be employed. 


\section{INTRODUCTION}

Malignancies of the esophagus are highly lethal and survival strongly correlates with the disease stage. Approximately $50 \%$ of patients present with incurable advanced or metastatic disease. ${ }^{1}$ Adenocarcinoma is the most common type of esophageal cancer in Western Society and esophagectomy is the primary therapy for resectable tumors. Patients with a T1-T3 lesions (and selected with T4 tumors) are eligible for surgery, when distant dissemination has been ruled out. Esophagectomy can be the first line of therapy in T1-2N0M0 lesions and for more advanced stage disease, induction neo-adjuvant chemo (radiation) therapy is recommended.

The choice of surgical approach in resectable cases depends upon several factors: tumor characteristics, type and extent of lymphadenectomy required and the type of conduit available for restoration of the gastrointestinal continuity. Resection of the esophagus and subsequent gastrointestinal continuity restoration is a technically challenging operation and can have a major impact on the patient's health condition. Traditional "open" esophagectomy (OE) for malignancies has been associated with relatively high postoperative morbidity and mortality. The 5year survival is around $20-40 \%$ and overall morbidity ranges between $20-80 \%{ }^{2}$ Especially transthoracic, compared to transhiatal approaches are at risk for complications. In the early 1990s, minimally invasive esophagectomy (MIE) was introduced in an attempt to lower complication rates and improve outcomes..$^{3-6}$ In this chapter the highlights of the present literature of MIE compared to traditional OE are reviewed and two (thoraco) laparoscopic approaches, each indicated for different stages of disease, are described in detail.

\section{TRADITIONAL VERSUS MINIMALLY INVASIVE ESOPHAGECTOMY}

In the past two decades over 200 papers have been published on MIE. The approach was proven feasible and safe in experienced high volume centers, but the important question is, whether MIE indeed has improved outcomes in treatment of esophageal cancer. Proposed advantages of MIE reside in smaller incisions, less blood loss, better preservation of pulmonary function and fewer other postoperative complications, all leading to a shorter hospital stay. Critics challenge MIE on it technical difficulties, adequacy of surgical margins, extent of lymph node dissection and long-term oncologic outcomes. ${ }^{7}$

Open and minimally invasive procedures were compared in several systematic reviews of selected variations of mainly comparative case-controlled studies. Verhage and colleagues found 10 studies eligible for analysis. ${ }^{8}$ Two studies compared open transhiatal esophagectomy and transhiatal laparoscopic esophagectomy and four studies compared combined transthoracic and transhiatal surgery with thoracolaparoscopic esophagectomy. The other four studies did not fit within these subgroups. Overall comparison in a total of 616 cases of MIE versus open 
surgery showed a slightly increased operation time for MIE, but other parameters showed trends in its favor: a decreased blood loss, a shorter ICU and hospital stay and an increased number of harvested lymph nodes. Mean morbidity/mortality rates for MIE and OE were 43.8\%/1.9\% and 60.4\%/4.5\%, respectively. Pulmonary complications in MIE were $15.1 \%$ versus $22.9 \%$ in $\mathrm{OE}$.

A meta-analysis performed by Nagpal et al. with 672 patients out of 12 studies, also showed significantly less hemorrhage, shorter hospital stay, reduced morbidity and respiratory complications in MIE, but no significant difference in 30-day mortality was found. ${ }^{9}$

Another systematic review by Bierre and colleagues included 11 studies with a composite total of 1061 patients. ${ }^{10}$ They compared total MIE with open and hybrid (thoracoscopy combined with laparotomy) procedures. No significant differences were found in MIE versus OE, however, trends toward improved morbidity, pulmonary complications, anastomotic leakage, hospital stay, operation time, blood loss and also mortality were recognized.

Sgourakis et al. selected eight comparative studies for their meta-analysis and pooled the data of 1008 patients. Two comparisons were made. First open thoracotomy versus VATS-laparoscopy showed equal outcomes in removed lymph nodes and (30-day/three year) survival. Overall morbidity was in favor of MIE, but significantly more anastomotic stricture formation was seen. ${ }^{11}$ Secondly, no differences were found comparing open thoracotomy versus VATS-esophagectomy.

In summary, these systematic reviews suggest similar oncological outcomes and trends, mainly concerning the short-term morbidity in favor of MIE. Although multiple randomized controlled trials have compared the open with the minimally invasive surgical approach for other indications such as in colorectal cancer, these trials are lacking for esophagectomy. ${ }^{12}$ Multicenter, prospective randomized controlled trials are necessary to confirm or refute these trends of benefits after minimally invasive esophagectomy compared to the traditional open approach.

\section{SURGICAL TECHNIQUE FOR MINIMALLY INVASIVE ESOPHAGECTOMY}

Esophageal cancer is known for early and rapid dissemination because of the longitudinally oriented lymphatic plexus within the submucosa with direct transmural lymphatic connections and the lack of a serosal lining. Although lymph node involvement is infrequent in T1a-stage (mucosal) adenocarcinoma of the esophagus, lymph node involvement increases nearly 10-fold in T1b-stage (submucosal) disease. ${ }^{13-15}$ Laparoscopic transhiatal inversion esophagectomy (LIE) with gastric substitution can be employed for treatment of end-stage benign disease (Barrett's high grade dysplasia; achalasia) and early malignancy confined to the mucosa. ${ }^{16,17}$ The combined laparoscopic-thoracoscopic (two-cavity) approach with en-bloc lymphadenectomy is indicated for treatment of resectable advanced locoregional disease. ${ }^{18}$ Depending on the level of the tumor, an intrathoracic (Ivor Lewis ap- 
proach) or cervical anastomosis of the proximal remains of the esophagus and the conduit is applied. We emphasize that the technique for MIE is subject to continuous optimization and that other techniques or modifications may just be as effective as the techniques presented in this chapter.

\section{Pre-operative considerations}

Pre-operative evaluation and staging includes endoscopy, endoscopic ultrasound (EUS) and positron emission tomography combined with computed tomography (PET-CT) scanning. Evaluation of co-morbid conditions should include at least an evaluation of a patient's cardiopulmonary reserve. In selected cases with severe peripheral occlusive arterial disease, a visceral angiogram is obtained. An exercise program, smoking cessation, and optimization of nutritional status should be endeavored. Pre-operative mechanical bowel preparation is performed when colon interposition may be required.

\section{Anesthesia}

Prior to induction, a thoracic epidural is placed for postoperative pain control and antibiotic prophylaxis (second-generation cephalosporin) is administered. Endotracheal intubation is performed with a single lumen tube in LIE. In combined laparoscopic-thoracoscopic (two-cavity)-approach a double lumen endotracheal tube is required for single-lung ventilation. A nasogastric tube and a urinary catheter are placed and an arterial catheter for continuous blood pressure monitoring is instituted.

\section{LAPAROSCOPIC TRANSHIATAL INVERSION ESOPHAGECTOMY}

\section{Patient positioning}

After induction, an intra-operative bronchoscopy and esophagogastroduodenoscopy can be performed for assessment of anatomic relationships and tumor location. Skin preparation and draping of the abdomen, chest and left side of the neck is performed in a single field. For the abdominal portion of laparoscopic esophagectomy, the patient is placed in a supine, split-legged position and secured to the operation table with supportive padding for all pressure zones. A cushion can be placed at scapula level to induce slight neck extension for exposure, if a cervical anastomosis is planned. The surgeon stands between the patient's legs (French position), the first assistant is positioned at the patient's left and the second assistant at the patient's right. 


\section{Port placement}

After pneumoperitoneum is obtained by using Veress needle technique, the primary site of access is approximately $15 \mathrm{~cm}$ below the left costal margin, $3 \mathrm{~cm}$ out of the midline. A 30-45 degree laparoscope is introduced through a 10-mm port and, before secondary port placements, a staging laparoscopy is performed. A six-port approach is used with the remaining ports in the following locations: second port (12-mm, surgeon's right hand) $12 \mathrm{~cm}$ from the xiphoid process, $2 \mathrm{~cm}$ below the left costal margin; third port (5-mm, first assistant) left anterior axillary line along the costal margin; fourth port (5-mm, liver retractor) left of the xiphoid process; fifth port (12-mm, surgeon's left hand, access endoscopic stapling device) inferior to the right costal margin and immediately to the right of the falciform ligament; sixth port (5-mm, second assistant) right mid-abdominal position based on internal anatomy (figure 6.1).

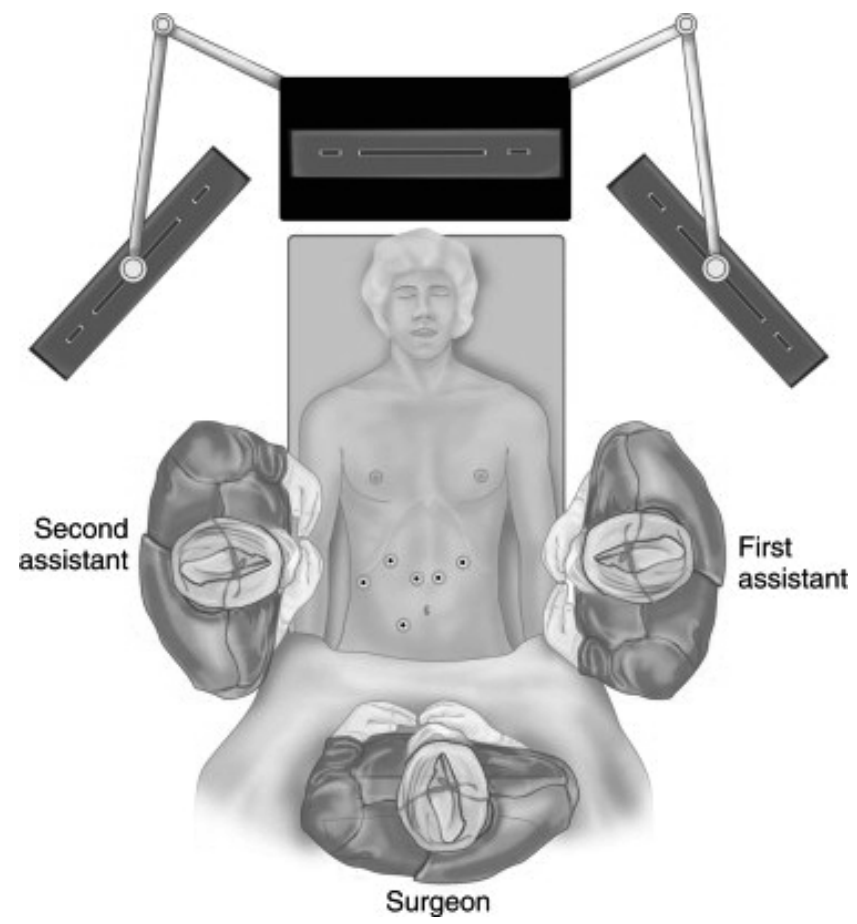

Figure 6.1 Positioning and port placement in minimally invasive esophagectomy.

\section{Hiatal dissection}

Using a liver retractor, the hiatal opening and the gastrohepatic omentum are exposed and divided, along with the hepatic branch of the anterior vagus trunk, using the Harmonic scalpel (figure 6.2). A replaced left hepatic artery in the lesser omentum, which arises from the left gastric artery in about $30 \%$ of population, should be 
spared. The phrenoesophageal membrane is opened around the esophagus until both the crural pillars are dissected and the esophagus can be encompassed. In LIE, indicated for benign disease or early malignancies, the vagal nerves are preserved to maintain gastric physiology.

\section{Gastric mobilization}

The epiphrenic fat is retracted toward the left anterior abdominal wall to provide tension on the left gastric vessels. The overlying peritoneum is opened, using the Harmonic scalpel, and the left gastric vessels are identified and divided using an endoscopic vascular stapler (figure 6.3). The gastric fundus is mobilized with the division of the short vessels (figure 6.4). The gastrocolic omentum is divided along the greater curvature. At Demel's (watershed) point, the union of left and right gastroepiploic vessels is preserved to protect the blood supply to the gastric conduit. The gastrosplenic ligament is divided, including the intervening short gastric vessels, and the gastric fundus is further mobilized along the pancreaticogastric fold, where the posterior gastric artery is identified and divided. The distal stomach is mobilized by the division of the gastrocolic ligament at the greater curvature and then the attachments between the posterior gastric wall and pancreas. When the gastric duodenal artery is identified, Kocher's maneuver is performed. The duodenum and pancreas head are detached from the retroperitoneum and retracted to the patient's left side. Care is taken to protect the gastroduodenal artery, to maintain blood flow to the right gastroepiploic artery to supply the gastric conduit.

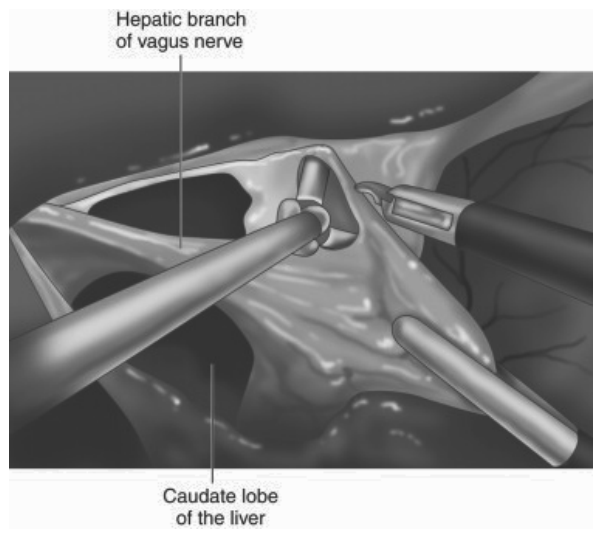

Figure 6.2 Hiatal dissection.

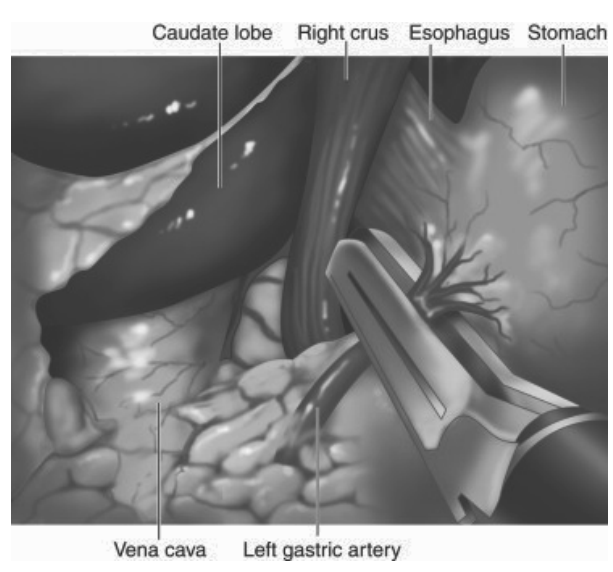

Figure 6.3 Division left gastric vessels.

\section{Gastric conduit creation}

The nasogastric tube is retracted to an intrathoracic position. The gastric conduit is created using a 45-mm endostapler. The first load is fired 5 to $6 \mathrm{~cm}$ proximal to the 
pylorus and, stepwise, the conduit is created at a $5 \mathrm{~cm}$ distance from the lesser curvature. Care is taken to preserve the right gastric vessels (figure 6.5). The distal margin of the lesser curvature, which is maintained in continuity with the esophagus, is resected and is sent for frozen section examination intra-operatively to confirm clear resection margin in case of a distally localized tumor. At this point, a pyloroplasty is performed optionally, to prevent gastric outlet obstruction in the case of vagotomy in en bloc lymph node dissection (see figure 6.10 in the combined laparoscopic-thoracoscopic (two-cavity) approach).

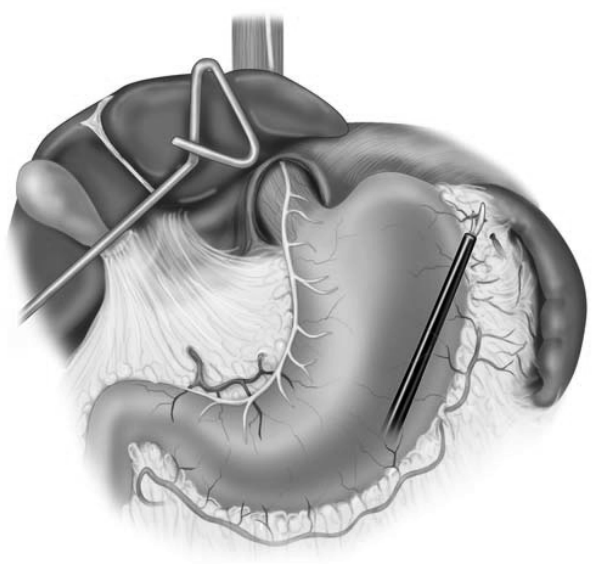

Figure 6.4 The gastrosplenic ligament is divided, including the intervening short gastric vessels.

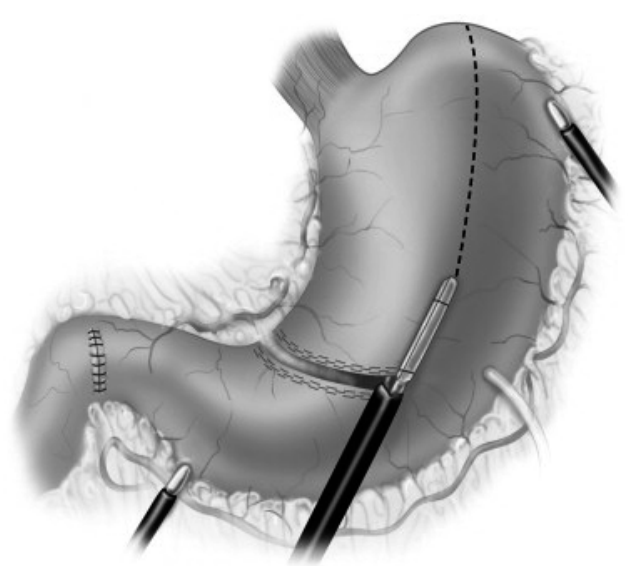

Figure 6.5 Creation of the gastric conduit for esophageal substitution.

\section{Transhiatal mobilization and esophagogastric division}

The distal esophagus is mobilized circumferentially in the mediastinum through the hiatus. The right crus can be divided to improve exposure. The dissection of the mediastinal portion of the esophagus from the surrounding intrathoracic structures is performed as proximally as is safe. Care is taken to prevent damage to the trachea, inferior pulmonary veins, azygos vein and aortic arch. To determine the location of the anatomic esophagogastric junction, an intra-operative endoscopy is performed. The gastric fundus is divided with an endoscopic stapler, distal to the esophagogastric junction, placed in an Endobag and removed at the end of the procedure. A needle jejunostomy is placed for postoperative nutrition. In advanced disease stage, the greater curve side of the conduit tip is secured to the staple line in the distal esophagus to facilitate the gastric pull-up and the procedure is converted to a right-sided thoracoscopy for the laparoscopic-thoracoscopic (twocavity) approach. 


\section{Cervical access}

Access to the cervical esophagus is obtained through a $5-\mathrm{cm}$ incision along the medial border of the sternocleidomastoid muscle. The platysma and omohyoid muscles are divided. Through the avascular plane, the carotid sheath is exposed and retracted laterally. The thyroid gland and the trachea are retracted medially, while attention is paid to preserve the recurrent laryngeal nerve. The deep cervical fascia is opened and blunt fingertip dissection is used to surround the esophagus with fascia and access the upper mediastinum.

\section{Inversion technique}

The cervical esophagus is opened and a vein stripper is introduced retrograde into the esophagus. Through a small gastrotomy at staple-line level, the vein stripper is retrieved and taken out of the abdomen through the right upper abdominal $12-\mathrm{mm}$ port site. A medium-sized anvil and a $60-\mathrm{cm}$ trailing suture are placed on the end of the vein stripper. After retraction into the abdominal cavity, the anvil is secured with a horizontal mattress suture to the gastrotomy and the esophagus is inverted by drawing back the cervical end of the vein stripper (figure 6.6).

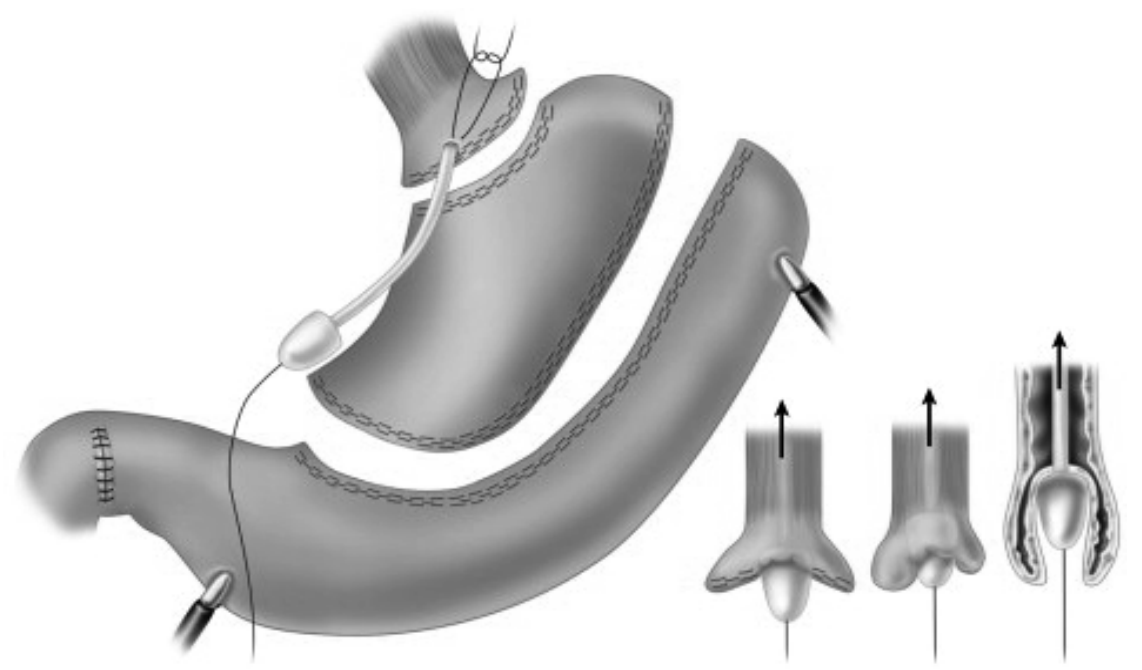

Figure 6.6 The inversion technique in laparoscopic transhiatal inversion esophagectomy (LIE). 
The inverted border of the esophagus is grasped and gentle traction at the cervical end of the vein stripper provides counter-tension to facilitate mobilization during division of mediastinal attachments and blood vessels. The dissection is continued until the esophagus is extracted through the cervical wound and transected at the proximal margin.

\section{Conduit pull-through and esophagogastrostomy}

The $60-\mathrm{cm}$ trailing suture, which was fixed at the anvil site of the vein stripper and pulled through the cervical wound with the specimen, is used to bring a 26 French thoracic drainage tube down into the abdominal cavity from the cervical incision. The proximal gastric conduit is sutured to the tube, carefully pulled through the mediastinum, and brought to the surface in the cervical wound without rotation. A vertical gastrotomy is made in the gastric conduit to allow a $35 \mathrm{~mm}$ endostapler to be inserted in the conduit and the proximal esophagus to create a stapled end-toside anastomosis. The gastrostomy and esophagostomy are closed in two layers (Figure 6.7).

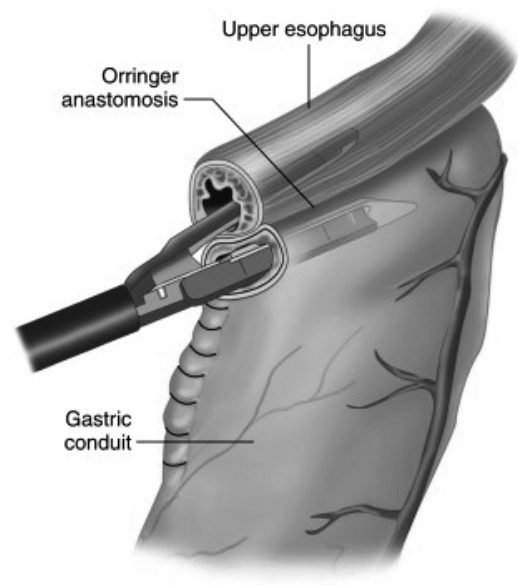

Figure 6.7 Stapled side-to-end anastomosis of the proximal esophagus and the conduit in LIE.

\section{Closing}

A nasogastric tube is introduced into the gastric conduit. In the cervical opening, a closed suction drain is placed alongside the anastomosis and the fascia layers and platysma muscle are closed. Final inspection of the abdominal cavity is performed and the specimen retrieval bag, containing the gastric fundus and all trocars are removed under direct visualization. The fascia is closed using Vicryl sutures and the skin is closed using resorbable sutures. 


\section{COMBINED LAPAROSCOPIC-THORACOSCOPIC (TWO-CAVITY) APPROACH}

\section{Positioning}

In this approach, the patient is intubated with a double-lumen tube for single-lung ventilation during the thoracic part of the procedure. The abdominal portion of the procedure is carried out similar to that described above for the LIE, but inversion technique is not performed; Instead, lymphatic tissue and vagal nerve branches are resected en bloc with the esophagus and esophagogastric junction. For thoracoscopic mobilization of the esophagus (after the abdominal portion of the procedure has been completed), the patient is repositioned into a left lateral decubitus position and supported with a beanbag. The right hemithorax is disinfected, drapes are placed and single left lung ventilation is applied. The surgeon stands on the patient's right, the first assistant positions on the patient's left.

\section{Port placement}

Five ports are introduced: a $10-\mathrm{mm}$ camera port in the $7^{\text {th }}-8^{\text {th }}$ intercostal space, midaxillary line; a $5-\mathrm{mm}$ port in the $8^{\text {th }}-9^{\text {th }}$ intercostal space, posterior axillary line; a $10-\mathrm{mm}$ port in the $4^{\text {th }}$ intercostal space on the anterior axillary line; and a 5 -mm port posterior to the scapula tip (figure 6.8). A single 5-mm port is placed anteriorly for suction. A staging thoracoscopy and laparoscopy is performed to evaluate the presence of gastric extension, liver metastases, peritoneal carcinomatosis or T4 tumor.

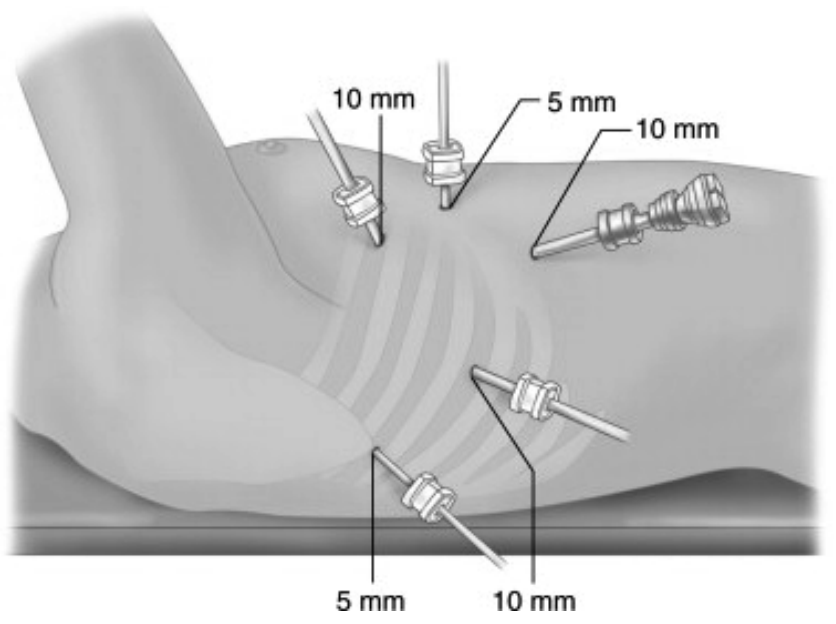

Figure 6.8 Placement of thoracic ports in combined laparoscopic-thoracoscopic (two-cavity) esophagectomy, with positioning in left lateral decubitus and bean-bag support. 


\section{Esophageal mobilization}

The central tendon of the diaphragm is retracted inferio-anteriorly using a percutaneous suture. The inferior pulmonary ligament is divided to the level of the inferior pulmonary vein and artery and the esophagus with attached lymphatic tissues is dissected away from the pericardium and developed towards both cranial and caudal sides. The mediastinal pleura is opened until the azygos arch can be identified and divided using a reticulating endoscopic vascular stapling device. Proximal to the azygos vein, dissection must be in close proximity to the esophagus to avoid recurrent laryngeal nerve injury. The subcarinal space is developed and the esophagus is dissected away from the right and left mainstem bronchi. Division of the aortoesophageal vessels is performed with special attention to the preservation of the contralateral pleura and the thoracic duct.

\section{Conduit pull-through and esophagogastrostomy}

The esophagus is mobilized into the abdominal-thoracic inlet and separated from the hiatus. The conduit that is attached via a suture to the specimen is pulled intramediastinally through the hiatus. The suture is cut and the specimen is retracted in a cranial direction, thereby exposing the most medial aspect of the mediastinal dissection (e.g., contralateral pleura). The upper esophagus is divided $3 \mathrm{~cm}$ cranially to the azygos vein level using endoscopic scissors and the specimen is removed through the extended surgeon right-hand port using a wound protector. The specimen is opened and checked for gross margins.

\section{Intrathoracic anastomosis}

The esophageal-conduit anastomosis is created using a 28-mm endoscopic end-to end-stapler, (Ivor-Lewis approach). The Ivor-Lewis approach in the combined laparoscopic-thoracoscopic (two-cavity) esophagectomy with thoracoscopic intrathoracic anastomosis can be employed only for lesions in the distal third of the esophagus. For more proximal lesions, a cervical anastomosis, as described earlier) is advised. The anvil is sutured into the proximal esophagus and the conduit staple line is opened to allow access of a stapler that is introduced intrathoracically through the extended inferior postero-lateral port (figure 6.9). Rotation must be prevented and the length of conduit necessary to achieve a tensionless anastomosis must be determined. The presence of intact tissue "doughnuts" in the stapler after firing is confirmed, as this indicates a complete circumferential anastomosis. Closure of the gastrotomy is performed by dividing the surplus conduit with a roticulating endoscopic stapling device and removed. This specimen will serve as the final distal margin for histologic examination. A nasogastric tube is placed in the conduit proximal to the hiatal opening and a Jackson-Pratt drain is placed near 
the anastomosis opposite from the staple line. After the thoracic cavity is irrigated with warmed antibiotic saline, hemostasis is achieved and the right lung is reventilated after placement of a 28 French thoracostomy tube.

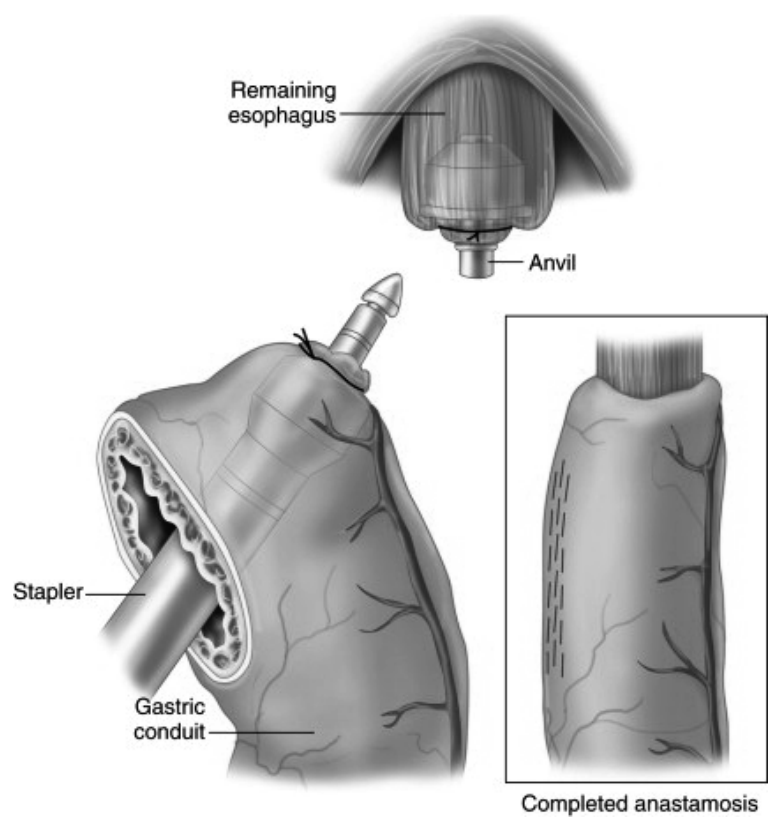

Figure 6.9 End to side esophagealconduit anastomosis (Ivor-Lewis approach) in combined laparoscopicthoracoscopic (two-cavity) esophagectomy.

\section{Closing}

The fascia is closed using Vicryl suture and skin is closed with resorbable suture. The double-lumen tube is exchanged for a single-lumen tube and a bronchoscopy is performed to clear intrapulmonary secretions.

\section{POST-OPERATIVE CARE}

Measures of interest for post-operative care after minimally invasive esophagectomy are stimulation of early ambulation and pulmonary physiotherapy. The nasogastric tube is removed and jejunostomy tube feeding is started around the first to third post-operative day if there are no signs of ileus. Before discharge, an upper gastrointestinal tract contrast radiographic examination is performed (6-7 th $^{\text {th }}$ postoperative day) to verify the integrity of the anastomosis and pyloroplasty. Dietary education is provided and focused on small, frequent meals. The closed suction drain is pulled back by $2 \mathrm{~cm}$ prior to discharge. This drain is removed at the first post-operative clinic visit, eventual after the patient undergoes a second upper GItract contrast radiographic examination. The first evaluation visit is scheduled at 2 
to 3 weeks and the jejunostomy tube is removed at 6 weeks if the patient's oral intake and weight are sufficient.

\section{PEARLS AND PITFALLS}

In addition to the techniques described in this chapter, other successful minimally invasive approaches have been reported. The key to success for minimally invasive esophagectomy is a high patient volume and a well-trained multidisciplinary surgical team.

Neo-adjuvant chemo (radiation) therapy is not seen as a contraindication to the minimally invasive approach.

LIE can be used for lesions across the esophagogastric junction by the use of an antegrade (proximal to distal) inversion technique. The inversion starts in the proximal esophagus and the esophagus is extracted through an abdominal port site.

The Ivor-Lewis approach in the combined laparoscopic-thoracoscopic (two-cavity) esophagectomy with thoracoscopic intrathoracic anastomosis can be employed only for lesions in the distal third of the esophagus. For more proximal lesions, a cervical anastomosis is advised.

If vagotomy is performed, a gastric drainage procedure (pyloroplasty, pyloromyotomy or pyloric finger disruption) is performed at the surgeon's discretion, to prevent delayed gastric emptying and associated complications (e.g. aspiration pneumonia). We routinely perform pyloroplasty following a vagotomy; however, this procedure is controversial because it could induce bile reflux into the conduit and contribute to anastomotic stricture development. Pyloroplasty - Heinecke and Mikulicz technique (figure 6.10). 

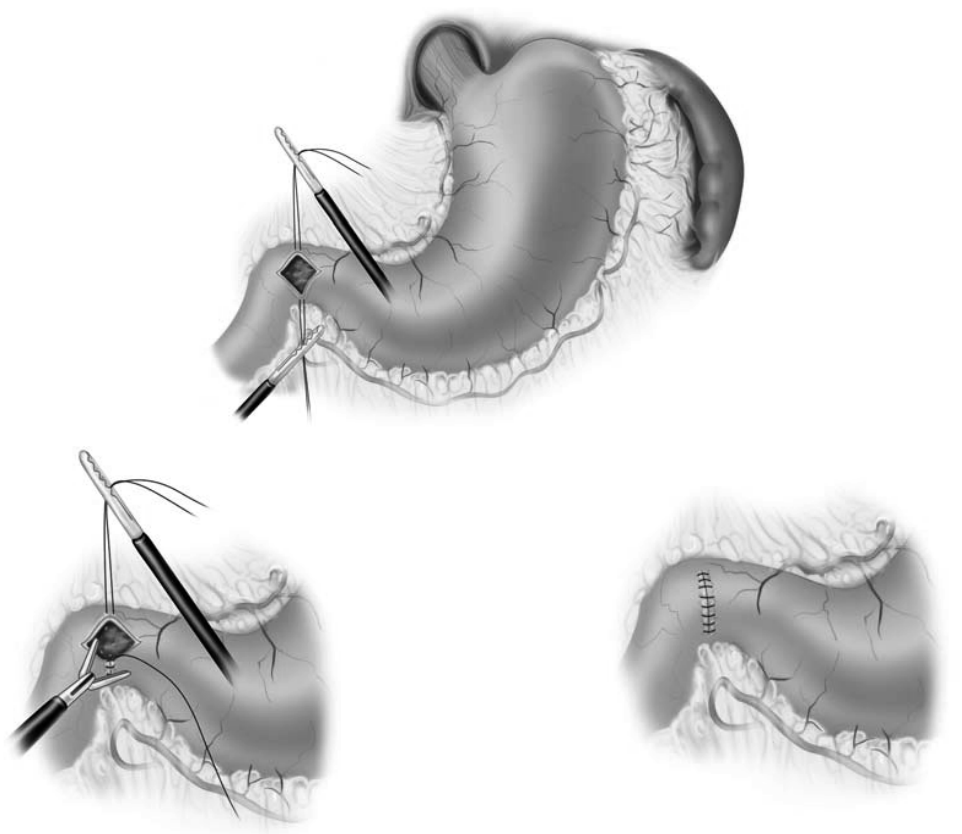

Figure 6.10 Pyloroplasty - Heinecke and Mikulicz technique: Superior and inferior tension sutures are placed. The muscular layer is incised using ultrasonic scissors and subsequently closed transversally with interrupted sutures. 


\section{REFERENCES}

1. Engel LS, Chow WH, Vaughan TL, Gammon MD, Risch HA, Stanford JL, Schoenberg JB, Mayne ST, Dubrow R, Rotterdam H, West AB, Blaser M, Blot WJ, Gail MH, Fraumeni JF, Jr. Population attributable risks of esophageal and gastric cancers. J Natl Cancer Inst 2003;95:1404-13.

2. Sant M, Aareleid T, Berrino F, Bielska Lasota M, Carli PM, Faivre J, Grosclaude P, Hedelin G, Matsuda T, Moller H, Moller T, Verdecchia A, Capocaccia R, Gatta G, Micheli A, Santaquilani M, Roazzi P, Lisi D. EUROCARE-3: survival of cancer patients diagnosed 1990-94--results and commentary. Ann Oncol 2003;14 Suppl 5:v61-118.

3. Collard JM, Lengele B, Otte JB, Kestens PJ. En bloc and standard esophagectomies by thoracoscopy. Ann Thorac Surg 1993;56:675-9.

4. DePaula AL, Hashiba K, Ferreira EA, de Paula RA, Grecco E. Laparoscopic transhiatal esophagectomy with esophagogastroplasty. Surg Laparosc Endosc 1995;5:1-5.

5. Luketich JD, Nguyen NT, Weigel T, Ferson P, Keenan R, Schauer P. Minimally invasive approach to esophagectomy. Jsls 1998;2:243-7.

6. Swanstrom LL, Hansen P. Laparoscopic total esophagectomy. Arch Surg 1997;132:943-7; discussion 947-9.

7. Luketich JD, Alvelo-Rivera M, Buenaventura PO, Christie NA, McCaughan JS, Litle VR, Schauer PR, Close JM, Fernando HC. Minimally invasive esophagectomy: outcomes in 222 patients. Ann Surg 2003;238:486-94; discussion 494-5.

8. Verhage RJ, Hazebroek EJ, Boone J, Van Hillegersberg R. Minimally invasive surgery compared to open procedures in esophagectomy for cancer: a systematic review of the literature. Minerva Chir 2009;64:135-46.

9. Nagpal K, Ahmed K, Vats A, Yakoub D, James D, Ashrafian H, Darzi A, Moorthy K, Athanasiou T. Is minimally invasive surgery beneficial in the management of esophageal cancer? A meta-analysis. Surg Endosc;24:1621-9.

10. Biere SS, Cuesta MA, van der Peet DL. Minimally invasive versus open esophagectomy for cancer: a systematic review and meta-analysis. Minerva Chir 2009;64:121-33.

11. Sgourakis G, Gockel I, Radtke A, Musholt TJ, Timm S, Rink A, Tsiamis A, Karaliotas C, Lang H. Minimally invasive versus open esophagectomy: meta-analysis of outcomes. Dig Dis Sci;55:3031-40.

12. Aziz O, Constantinides V, Tekkis PP, Athanasiou T, Purkayastha S, Paraskeva P, Darzi AW, Heriot AG. Laparoscopic versus open surgery for rectal cancer: a meta-analysis. Ann Surg Oncol 2006;13:413-24.

13. Oh DS, Hagen JA, Chandrasoma PT, Dunst CM, Demeester SR, Alavi M, Bremner CG, Lipham J, Rizzetto C, Cote R, Demeester TR. Clinical biology and surgical therapy of intramucosal adenocarcinoma of the esophagus. J Am Coll Surg 2006;203:152-61.

14. Rice TW, Blackstone EH, Adelstein DJ, Zuccaro G, Jr., Vargo JJ, Goldblum JR, Murthy SC, DeCamp MM, Rybicki LA. Role of clinically determined depth of tumor invasion in the treatment of esophageal carcinoma. J Thorac Cardiovasc Surg 2003;125:1091-102.

15. Rice TW, Zuccaro G, Jr., Adelstein DJ, Rybicki LA, Blackstone EH, Goldblum JR. Esophageal carcinoma: depth of tumor invasion is predictive of regional lymph node status. Ann Thorac Surg 1998;65:787-92.

16. Akiyama H, Tsurumaru M, Ono Y, Udagawa H, Kajiyama Y. Esophagectomy without thoracotomy with vagal preservation. J Am Coll Surg 1994;178:83-5.

17. Jobe BA, Kim CY, Minjarez RC, O'Rourke R, Chang EY, Hunter JG. Simplifying minimally invasive transhiatal esophagectomy with the inversion approach: Lessons learned from the first 20 cases. Arch Surg 2006;141:857-65; discussion 865-6.

18. Orringer MB, Marshall B, Iannettoni MD. Eliminating the cervical esophagogastric anastomotic leak with a side-to-side stapled anastomosis. J Thorac Cardiovasc Surg 2000;119:277-88. 



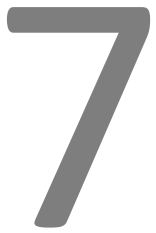

Transoral endoscopic esophagectomy:

Management of esophageal high-grade dysplasia and superficial cancer with organ preservation 


\section{ABSTRACT}

\section{Introduction}

Limitations of endoscopic therapies for Barrett's esophagus and superficial cancer include a compromised histological assessment, the need for surveillance, subsequent procedures and stricture formation. Circumferential en bloc resection of the mucosa-submucosa complex followed by deployment of a biologic scaffold onto the remaining muscularis propria may address these concerns. The objective of this study was to determine technical feasibility of transoral resection of the esophageal lining.

\section{Methods}

Transoral endoscopic inner layer esophagectomy was performed in ten swine. Endpoints included: procedure duration, hemorrhage, number of perforations, and adequacy of resection length and depth.

\section{Results}

Procedures were successfully completed in all animals without peri-operative mortality. Procedure times averaged 179 minutes (range 125-320). No perforations were found and a mean of $1.7(0-4)$ interventions for hemorrhage was required. Complete longitudinal resection was achieved in nine of ten animals. Resection depth included all mucosal layers in $100 \%$ of tissue sections, the submucosal layers, SM1 in $100 \%$ and SM2 in $96 \%$. A portion of SM3 was adherent to the muscularis propria in $70 \%$.

\section{Conclusion}

Transoral endoscopic resection of the inner esophageal layers was feasible and reproducible. This technique may facilitate a single-step definitive treatment and staging tool for early neoplastic lesions, obviating the need for esophagectomy.

Published as:

Transoral endoscopic inner layer esophagectomy: Management of high-grade dysplasia and superficial cancer with organ preservation. Witteman BPL, Foxwell TJ, Monsheimer S, Gelrud A, Eid GM, Nieponice A, O’Rourke RW, Hoppo T, Bouvy ND, Badylak SF, Jobe BA. J Gastrointest Surg. 2009 Dec;13(12):210412

Presented as:

Transoral Endoscopic Esophagectomy. Witteman BPL, Foxwell TJ, Monsheimer S, Gelrud A, Eid GM, Nieponice A, O’Rourke RW, Hoppo T, Bouvy ND, Badylak SF, Jobe BA. Presidential Plenary Session, Society for Surgery of the Alimentary Tract (SSAT) Digestive Disease Week (DDW) 2009, Chicago, IL, USA 


\section{INTRODUCTION}

Esophageal resection is the standard treatment for Barrett's esophagus with high grade dysplasia (HGD) and invasive malignancy. ${ }^{1,2}$ Despite a significant reduction in mortality rate reported by experienced centers, esophagectomy is associated with substantial morbidity rates. ${ }^{3-5}$ As a result, there has been an impetus to move towards esophageal preservation in patients with intramucosal neoplastic lesions in which lymphatic involvement is unlikely. ${ }^{6-8}$

The introduction of endoscopic approaches such as endoscopic mucosal resection and radiofrequency ablation has resulted in a public demand for definitive endoscopic treatments which ultimately preserve the esophagus. The primary limitation of current techniques resides in an incomplete and inconsistent histological assessment of the entire affected luminal surface area. As such, patients require lifelong surveillance and subsequent interventions for undetected synchronous or metachronous lesions. ${ }^{9}, 10$ While endoscopic submucosal dissection provides larger specimens, this technique is highly operator dependent, limited by existing technology and has a high risk of perforation. ${ }^{11-13}$ Finally, with all techniques aimed at esophageal preservation, there is a risk for stricture formation, particularly when resection involves the complete circumference, if ablation depth travels into the submucosal layer or if the defect is over $30 \mathrm{~mm}$ in length. ${ }^{14-16}$

In an attempt to overcome these limitations we started a research project, which is focused on obtaining an intact sleeve of the mucosa-submucosa complex (MSC) over the entire length of the diseased esophagus, while preventing stricture formation with the co-localization of porcine bladder-derived extracellular matrix in the remaining muscularis propria tube. The purpose of this study was to evaluate the technical feasibility of transoral endoscopic inner layer esophagectomy (TEE) and determine adequacy of resection length and depth in an animal model.

\section{MATERIALS AND METHODS}

All experiments were conducted in accordance with the 1996 Guide for the Care and Use of Laboratory Animals after approval by the Institutional Animal Care and Use Committee at the University of Pittsburgh.

\section{Procedure Development and Description}

Under general anesthesia using intramuscular injections of ketamine $(20 \mathrm{mg} / \mathrm{kg})$ and xylazine $(0,1 \mathrm{mg} / \mathrm{kg})$ for induction and $2 \%$ isoflurane with endotracheal intubation for maintenance, ten adult female swine (Yorkshire cross) weighing 40-50 $\mathrm{kg}$ underwent percutaneous endoscopic gastrostomy placement. The distance from the dental arch to the esophagogastric junction was measured and recorded. In order to access the plane between the MSC and muscularis propria, the procedure 
was initiated with circumferential "suck-and-cut" endoscopic mucosal resection starting at $25 \mathrm{~cm}$ from the dental arch (Figure 7.1 ).

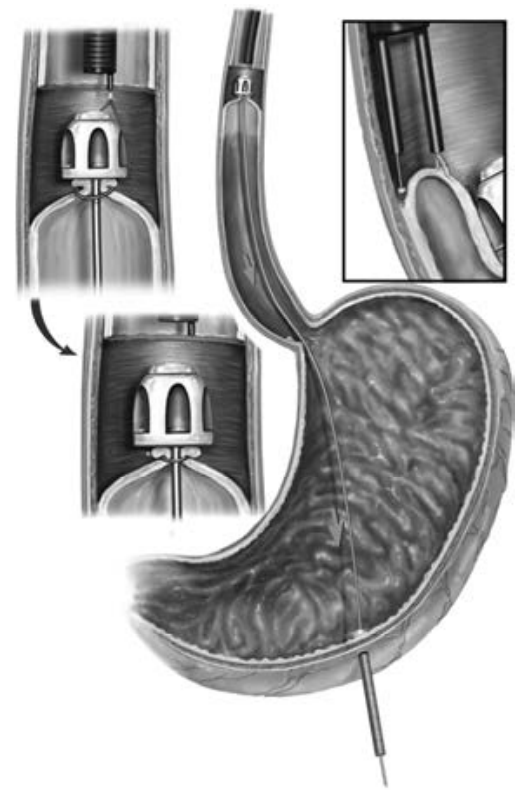

Figure 7.1 After initial circumferential resection of the mucosa-submucosa complex, a vein stripper is secured to a cuff of MSC. By drawing back on the vein stripper, the MSC sleeve is inverted to facilitate submucosal dissection.

Using a flexible double channel therapeutic endoscope (GIF-2T160, Olympus America, Center Valley, PA, USA), a circumferential cuff of MSC was developed over a two centimeter length, with submucosal dissection using cap dissection, cautery dissection (insulated tip electrosurgical knife, Olympus, Japan) or hydrodissection with an irrigation catheter (Olympus America, Center Valley, PA, USA). A vein stripper was then passed retrograde through the gastrostomy tube, retrieved endoscopically and exited orally. A 60-cm trailingsuture was tied to the vein stripper at the oral end and a 9.5-mm olive-shaped cap was attached. Subsequently, the stripper was pulled back into the esophagus and secured to the MSC using an endoloop (Olympus America, Center Valley, PA, USA). Drawing back on the vein stripper at the site of the gastrostomy facilitated inversion of a sleeve of the MSC. With this maneuver, a submucosal dissection plane was acquired and tension was distributed evenly throughout the circumference of the submucosa-muscularis propria interface. By withdrawing the trailing suture orally or pulling the vein stripper caudally, additional exposure and counter traction was facilitated along the dissection plane. The dissection was continued across the anatomic esophagogastric junction until the entire sleeve of MSC was inverted into the stomach (Figure 7.2). 


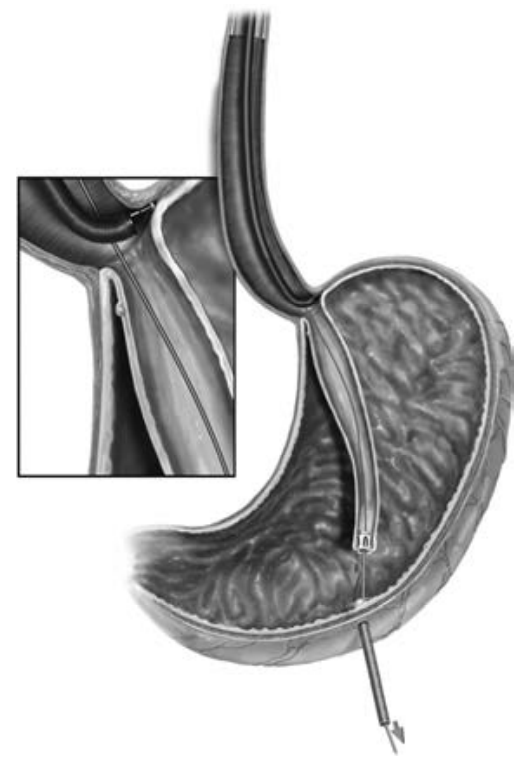

Figure 7.2 The diseased part of mucosa-submucosa complex is dissected away from the muscularis propria and inverted into the stomach.

The sleeve was subsequently penetrated below the level of the esophagogastric junction using an endoscopic needle knife, and the opening was balloon-dilated until it was large enough to facilitate passage of the endoscope into the gastric lumen. Circumferential transection of the MSC was performed with the endoscope on a retroflexed position (Figure 7.3).

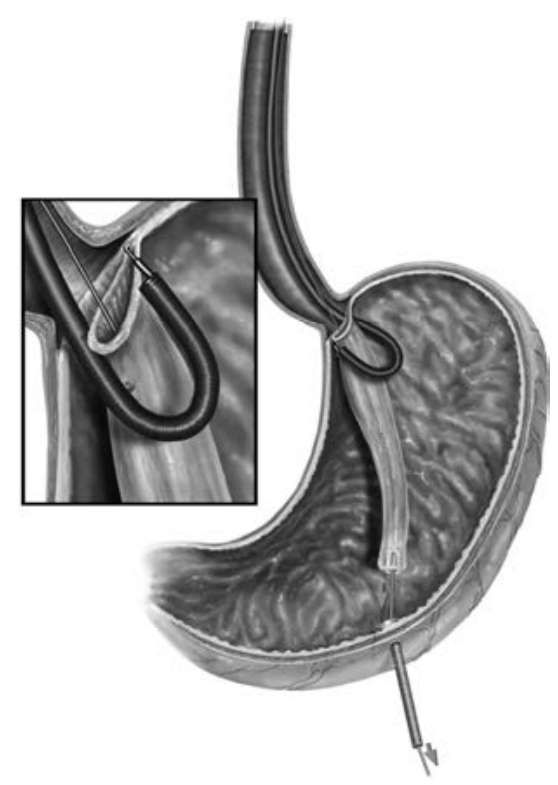

Figure 7.3 Transection of the sleeve of mucosasubmucosa complex was performed from within the gastric lumen in a retroflexed position using electrocautery 
Prior to transoral removal of the MSC, the specimen was turned "outside in" by drawing proximally on the trailing suture; conceptually, the purpose of this maneuver is to eliminate exposure of the muscularis propria to malignant cells within the mucosal surface of the specimen (figure 7.4). Hemorrhage within the muscularis propria tube was controlled and the endoscope was removed. All animals were euthanized and en bloc removal of the remaining esophagus and stomach was performed.

\section{Technical evaluation}

All procedures were recorded and reviewed to establish the following endpoints: procedure duration (minutes), number of endoscopic resections required to achieve circumferential MSC removal at the proximal cuff site, qualitative assessment of techniques used for submucosal dissection during proximal cuff creation, number of hemorrhage episodes requiring suction and intervention, number of perforations within each MSC sleeve and muscularis propria tube.

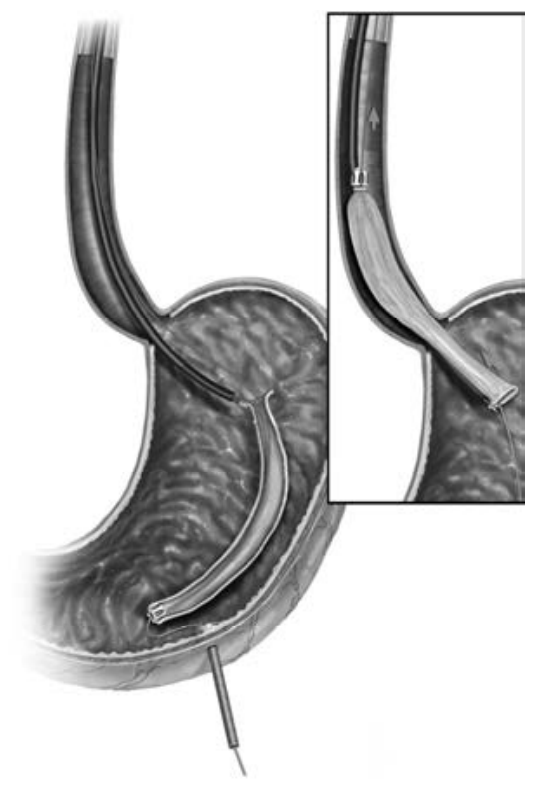

Figure 7.4 Before oral retrieval, spillage of tumor cells on to the muscularis propria is prevented by turning the sleeve of MSC "outside-in" by drawing the trailing suture cranially.

\section{Gross morphology examination}

The entire length of MSC and muscularis propria were examined for perforation using pressurized intraluminal infusion of saline solution (figure 7.5a, b). Adequacy of resection length was evaluated by comparing MSC with the corresponding muscularis propria tube that was opened longitudinally after leak testing was performed (figure $7.5 \mathrm{c}$ ). The specimen length in centimeters from proximal to distal 
resection margin was measured within the length of muscularis propria. Incomplete resection length was defined as any residual MSC adherent to the muscularis propria proximal to the anatomic esophagogastric junction, defined as the point at which the esophagus "flared" into the proximal stomach.

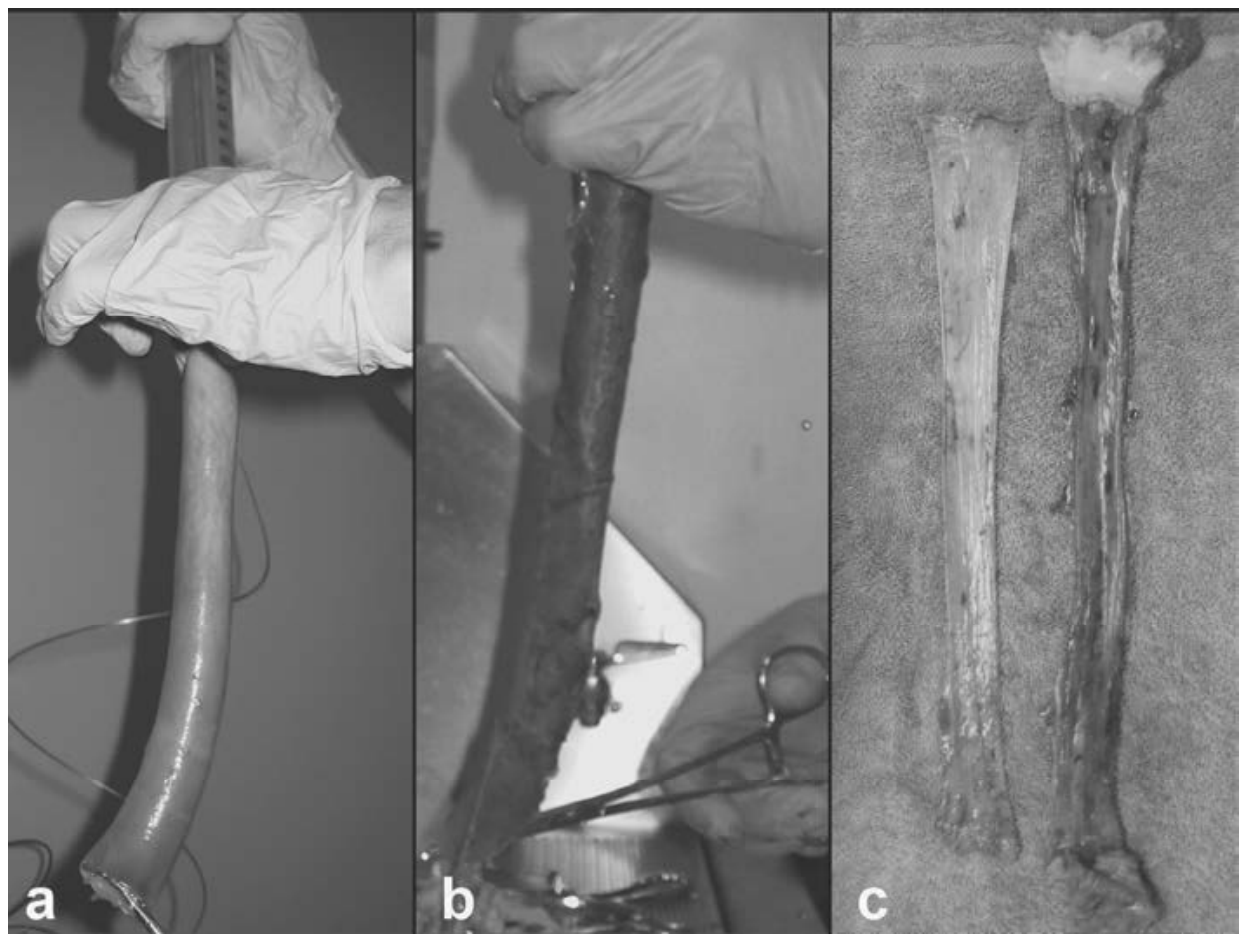

Figure 7.5 Evaluation of integrity of the mucosa-submucosa complex sleeve (a) and muscularis propria tube (b) at necropsy using pressurized intraluminal infusion of saline solution. Resection length was evaluated macroscopically by comparing the specimen with the corresponding muscularis propria tube (c).

\section{Histology analysis}

To determine adequacy of resection depth, MSC and muscularis propria sleeves were cross-sectioned into five tissue samples along the entire length of the esophagus and processed in paired fashion for each animal. Specimens were then placed in buffered formalin solution and subsequently stained with hematoxylin-eosin for histological exanimation. At each level, five sections of each tissue sample were examined. Evaluation of resection depth was categorized based on established histopathological classification of tumor invasion depth in the gastrointestinal tract, wherein the mucosa is subdivided into epithelium, lamina propria and muscularis mucosa (M1-3) and the submucosal layer is subdivided into thirds (SM13). ${ }^{17-19}$ Resection depth was defined adequate as sections contained all mucosal layers and at least the complete SM1 layer. 

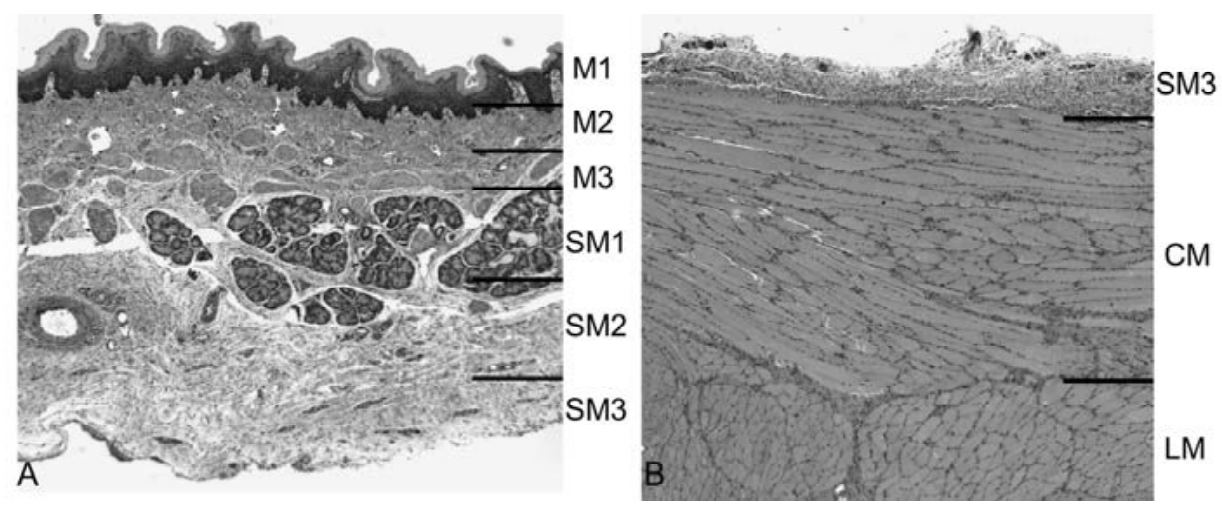

Figure 7.6 Histological image showing the resection depth of TEE was mainly through the SM3 layer in $96 \%$ of specimens. A small portion of the SM3 layer was found attached to the muscularis propria after resection in 70\% of specimens; M1-3 mucosal layers (epithelium, lamina propria, muscularis mucosae), SM1-3 submucosal layers, CM circular muscle layer, LM longitudinal muscle layer.

\section{RESULTS}

\section{Technical evaluation}

In an acute survival model, TEE was successfully completed without perioperative mortality in all animals over a mean length of $32.2 \mathrm{~cm}$ (range 20-55). Procedure time averaged 179 minutes (range 125-320). The mean number of cap resections required to reach a circumferential plane to initiate proximal cuff submucosal dissection was 2.6 (range 1-6); in six animals, a single 360 degree circumferential endoscopic resection of the MSC was accomplished by applying suction within the center of the esophageal lumen.

For creation of the $2 \mathrm{~cm}$ proximal cuff of MSC, we relied primarily on established techniques for submucosal dissection, which included tapered cap dissection between the MSC and muscularis propria aided with needle knife cautery dissection after saline submucosal "lift." The use of sodium hyaluronate solution, which is isotonic and provides long-lasting submucosal elevation away from the muscularis propria, was not employed in this study secondary to cost. Hydrodissection was difficult to control with precision and was abandoned.

Once secured to the proximal cuff, dissection of the MSC away from the muscularis propria was accomplished by drawing back on the vein stripper at the site of the gastrostomy thereby leading to inversion of the MSC. Electrocautery aided the dissection by dividing fibrous attachments and controlling bleeding as the stripping was stepwise carried distally. It was essential to carry the MSC inversion on to the proximal stomach to ensure there was no remaining tissue within the esophagus after distal transection of the MSC sleeve. Hemorrhage events were 
encountered in a mean of 1.7 (range 0-4) animals and were best controlled with endoscopic coagulation forceps. No perforations were identified during the procedure and no other complications occurred.

\section{Gross morphology examination}

There were no perforations identified along the length of the MSC or muscularis propria. In nine of ten animals, the entire length of MSC was completely resected leaving an intact muscularis propria tube in situ. Adequate resection length was not achieved in one animal in which a 3-cm-long and 0.5-cm-wide segment of MSC remained adherent to the muscularis propria at the level of the esophagogastric junction.

\section{Histology analysis}

Histological assessment demonstrated that resection depth included all mucosal layers and the SM1 layer in 100\% of sections. The entire SM2 layer was included in $96 \%$ of sections, and a complete SM3 layer was present in only $30 \%$ of sections, as in $70 \%$ of sections, the lower half of SM3 was found to be adhered to the muscularis propria (figure 7.6).

\section{DISCUSSION}

The incidence of Barrett's esophagus and esophageal adenocarcinoma is dramatically rising and esophageal cancer has become the world's sixth leading cause of cancer death. ${ }^{20,21}$ Overall morbidity and mortality rates associated with esophagectomy are substantial and esophageal resection has been challenged as a treatment for HGD and intramucosal cancer since lymph node involvement is unlikely $(<5 \%) .^{6-8}$ However, early lesions have the potential to be lethal and are only curable if completely removed. Since surveillance programs have increased the number of patients detected within early stage disease, interest in less invasive endoscopic treatments has grown. ${ }^{22,23}$

Currently available endoscopic techniques, however, have significant limitations. Photodynamic therapy initially demonstrated promising results, but has been abandoned by many centers due to photosensitivity-related side effects, recurrent disease, uncontrolled depth of ablation and stricture formation. ${ }^{24,25}$. Early results of radiofrequency ablation in the treatment of dysplasia have been encouraging, but as in photodynamic therapy, there is no specimen available for histopathological examination and the depth of ablation is limited to 500 microns, thereby preventing its use in the treatment of invasive cancer. In addition, although recent data suggest that radiofrequency ablation may reduce the occurrence of subsquamous intestinal metaplasia when compared to prevalent pretreatment 
cases, patients are committed to a lifetime of surveillance endoscopy and the need for subsequent interventions. ${ }^{2,25,26}$ The use of endoscopic mucosal resection has generated excellent results in treatment of high-grade dysplasia and early adenocarcinoma with an extrapolated 5-year survival rate of $98 \%$ in highly selected patients. ${ }^{4}$ However, it is important to note that disease recurrence secondary to synchronous or metachronous cancers is common and requires frequent surveillance endoscopies with the need for subsequent endoscopic resection and combination therapy with radiofrequency ablation. ${ }^{27,} 28$ Furthermore, currently used cap or snare endoscopic resection techniques limit the lesion resection size to $20 \mathrm{~mm}$, requiring piecemeal resections of larger lesions with a compromised histological assessment of radial resection margins. In addition, the thermal destruction of lateral edges makes this even more challenging. Finally, long lesions will require a stepwise approach to prevent stricture formation with the need for multiple procedures and an exhaustive follow-up.

Recent reports describe successful endoscopic en bloc dissection of larger esophageal MSC specimens in patients using endoscopic submucosal dissection. This technique was shown to be superior to endoscopic mucosal resection as an effective staging procedure as well as a curative treatment in a small series of patients with superficial adenocarcinoma at the esophagogastric junction. However, this technique is highly operator dependent and limited by existing technology resulting in a risk of perforation and stricture formation. ${ }^{11-13,} 29$ To overcome these limitations, we designed transoral endoscopic inner layer esophagectomy for resection of a sleeve of the mucosa-submucosa complex, leaving the intact muscularis propria in situ.

Submucosal dissection was demonstrated to be feasible in the swine model in earlier studies. ${ }^{30,} 31$ These findings in combination with the inversion concept, which was first described for the entire esophagus by Akiyama et al., formed the basis for the TEE concept. ${ }^{32}$ In the present study, inversion provided equally distributed circumferential counter traction that facilitated separation along the plane between the submucosal and muscular layer. As opposed to endoscopic submucosal dissection, which is known to have a high risk of perforation and the potential for intra- and perioperative hemorrhage, with TEE there was minimal blood loss and an unobstructed plane of dissection without perforation. Hemorrhage was easily controlled by following the groove between the MSC and muscle during the stripping process and coagulating with forceps or needle knife.

The resection length and depth were found to be both accurate and reproducible. It appears as if the path of least resistance during stripping is located within the outermost aspect of SM3 as 70\% of animals had a small portion adherent to the muscularis propria. Assuming reproducibility in humans, TEE could be a reliable staging tool and/or treatment for patients with long segment multifocal dysplasia and intramucosal cancer, thereby providing the pathologist a complete specimen that can be assessed for tumor invasion depth (T-status), grade of differentia- 
tion (G-status), involvement of lymphatic vessels and veins and the presence of metachroneous lesions, and completeness of resection (R-status). This robust information will better guide clinicians in their efforts to balance procedural risk (i.e., esophagectomy) with the risk for lymphatic involvement in the face of esophageal preservation. While lymph node involvement is infrequent in T1a-stage adenocarcinoma of the esophagus, it is increased by nearly 10 -fold when there is submucosal involvement (T1b-stage).6, 8, 33 Therefore TEE will not be suitable as definitive treatment in patients with T1b-lesions and surgical candidates should undergo esophagectomy.

Limitations of the present study are the swine model and the swine's healthy esophagus. It can be anticipated that the "stripping" with inversion technique will be more difficult and require the assistance of submucosal electrocautery dissection in the diseased human esophagus in the presence of inflammation or fibrous attachments caused by many years of progressing disease. Another concern for clinical application in patients with esophageal cancer is the potential risk of seeding the gastrostomy side with shed malignant mucosal cells. This risk could be minimized by using percutaneous fluoroscopic placement instead of an endoscopic approach and also by initiating the resection $2-3 \mathrm{~cm}$ above the lesion to prevent contact of the gastrostomy tube with diseased esophageal tissue after inversion.

Circumferential endoscopic mucosal resection has resulted in significant stricture formation if performed in a single setting and therefore is expected to be a major concern related to TEE. ${ }^{14}$ The use of extracellular matrix scaffolds, derived from porcine urinary bladder, are known to promote site-specific tissue remodeling. Recently, this technique has been demonstrated to prevent stricture formation in the canine esophagus after short segment $(5 \mathrm{~cm})$ circumferential endoscopic mucosal resection. ${ }^{34,35}$ In further experiments, we plan to evaluate prevention of stricture formation after TEE with extracellular matrix scaffold deployment over the entire length of the esophagus in a survival model (figure 7.7). 


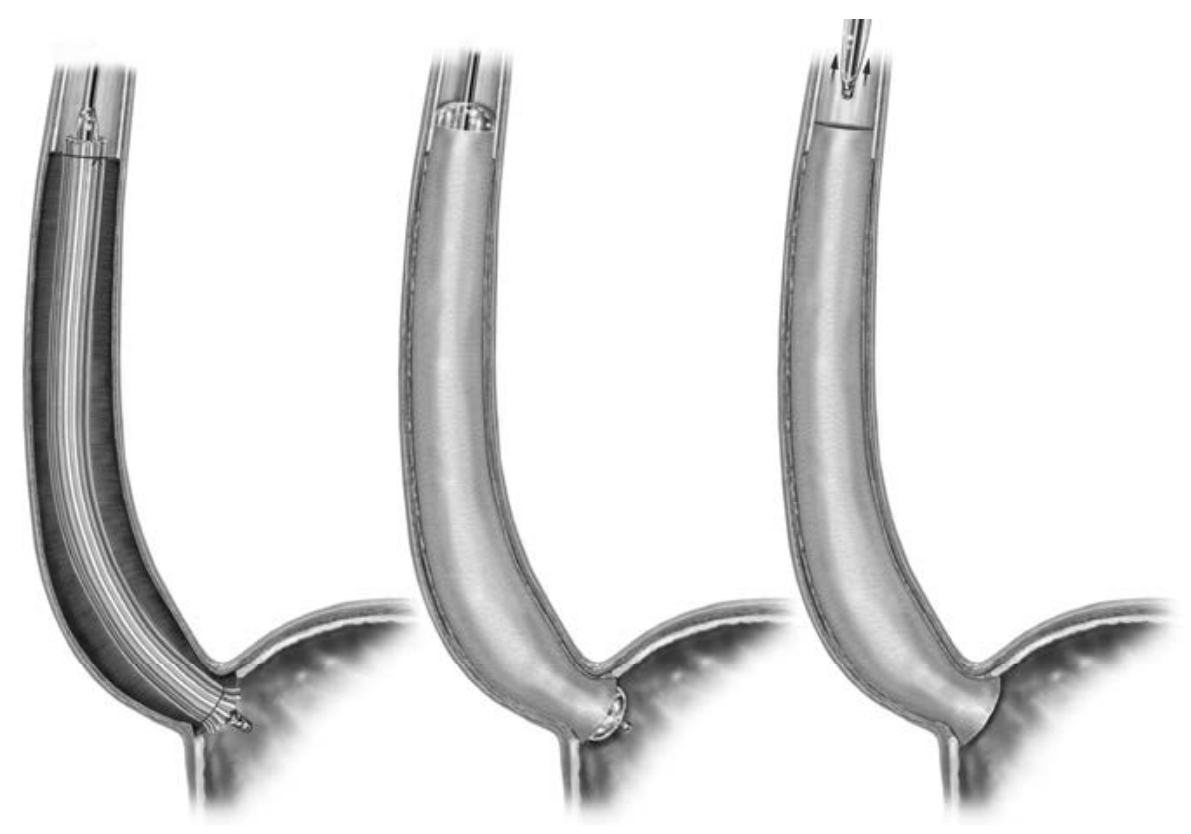

Figure 7.7 TEE with extracellular matrix scaffold deployment over the entire length of the esophagus.

\section{CONCLUSION}

Transoral endoscopic inner layer esophagectomy was feasible and reproducible and resulted in intact, en bloc specimens over the entire esophageal length. The inversion technique provided a blunt dissection with an equally distributed circumferential counter traction and this prevented perforation. This technique may lead to a single step staging and/or therapeutic approach with esophageal preservation for Barrett's esophagus and early stage malignancy that avoids the morbidity of traditional esophagectomy. Future work will need to focus on stricture prevention after TEE with the use of a xenograft biologic scaffold. 


\section{REFERENCES}

1. DeMeester SR. New options for the therapy of Barrett's high-grade dysplasia and intramucosal adenocarcinoma: endoscopic mucosal resection and ablation versus vagal-sparing esophagectomy. Ann Thorac Surg 2008;85:S747-50.

2. Shaheen NJ, Sharma P, Overholt BF, Wolfsen HC, Sampliner RE, Wang KK, Galanko JA, Bronner MP, Goldblum JR, Bennett AE, Jobe BA, Eisen GM, Fennerty MB, Hunter JG, Fleischer DE, Sharma VK, Hawes RH, Hoffman BJ, Rothstein RI, Gordon SR, Mashimo H, Chang KJ, Muthusamy VR, Edmundowicz SA, Spechler SJ, Siddiqui AA, Souza RF, Infantolino A, Falk GW, Kimmey MB, Madanick RD, Chak A, Lightdale CJ. Radiofrequency Ablation in Barrett's Esophagus with Dysplasia. N Engl J Med 2009;360:2277-88.

3. Thomas P, Doddoli C, Neville P, Pons J, Lienne P, Giudicelli R, Giovannini M, Seitz JF, Fuentes P. Esophageal cancer resection in the elderly. Eur J Cardiothorac Surg 1996;10:941-6.

4. Ell C, May A, Pech O, Gossner L, Guenter E, Behrens A, Nachbar L, Huijsmans J, Vieth M, Stolte M. Curative endoscopic resection of early esophageal adenocarcinomas (Barrett's cancer). Gastrointest Endosc 2007;65:3-10.

5. Holscher AH, Bollschweiler E, Schneider PM, Siewert JR. Early adenocarcinoma in Barrett's oesophagus. Br J Surg 1997;84:1470-3.

6. Oh DS, Hagen JA, Chandrasoma PT, Dunst CM, Demeester SR, Alavi M, Bremner CG, Lipham J, Rizzetto C, Cote R, Demeester TR. Clinical biology and surgical therapy of intramucosal adenocarcinoma of the esophagus. J Am Coll Surg 2006;203:152-61.

7. Rice TW, Blackstone EH, Adelstein DJ, Zuccaro G, Jr., Vargo JJ, Goldblum JR, Murthy SC, DeCamp MM, Rybicki LA. Role of clinically determined depth of tumor invasion in the treatment of esophageal carcinoma. J Thorac Cardiovasc Surg 2003;125:1091-102.

8. Rice TW, Zuccaro G, Jr., Adelstein DJ, Rybicki LA, Blackstone EH, Goldblum JR. Esophageal carcinoma: depth of tumor invasion is predictive of regional lymph node status. Ann Thorac Surg 1998;65:787-92.

9. Farrell JJ, Lauwers GY, Brugge WR. Endoscopic mucosal resection using a cap-fitted endoscope improves tissue resection and pathology interpretation: an animal study. Gastric Cancer 2006;9:38.

10. Ahmadi A, Draganov P. Endoscopic mucosal resection in the upper gastrointestinal tract. World J Gastroenterol 2008;14:1984-9.

11. Kakushima N, Yahagi N, Fujishiro M, Kodashima S, Nakamura M, Omata M. Efficacy and safety of endoscopic submucosal dissection for tumors of the esophagogastric junction. Endoscopy 2006;38:170-4.

12. Yoshinaga S, Gotoda T, Kusano C, Oda I, Nakamura K, Takayanagi R. Clinical impact of endoscopic submucosal dissection for superficial adenocarcinoma located at the esophagogastric junction. Gastrointest Endosc 2008;67:202-9.

13. Oyama T, Tomori A, Hotta K, Morita S, Kominato K, Tanaka M, Miyata Y. Endoscopic submucosal dissection of early esophageal cancer. Clin Gastroenterol Hepatol 2005;3:S67-70.

14. Kamler JP, Borsatto R, Binmoeller KF. Circumferential endoscopic mucosal resection in the swine esophagus assisted by a cap attachment. Gastrointest Endosc 2002;55:923-8.

15. Katada C, Muto M, Manabe T, Boku N, Ohtsu A, Yoshida S. Esophageal stenosis after endoscopic mucosal resection of superficial esophageal lesions. Gastrointest Endosc 2003;57:165-9.

16. Conio M, Sorbi D, Batts KP, Gostout CJ. Endoscopic circumferential esophageal mucosectomy in a porcine model: an assessment of technical feasibility, safety, and outcome. Endoscopy 2001;33:791-4.

17. Kudo S. Endoscopic mucosal resection of flat and depressed types of early colorectal cancer. Endoscopy 1993;25:455-61.

18. Ono H, Kondo H, Gotoda T, Shirao K, Yamaguchi H, Saito D, Hosokawa K, Shimoda T, Yoshida S. Endoscopic mucosal resection for treatment of early gastric cancer. Gut 2001;48:225-9. 
19. Endo M, Yoshino K, Kawano T, Nagai K, Inoue H. Clinicopathologic analysis of lymph node metastasis in surgically resected superficial cancer of the thoracic esophagus. Dis Esophagus 2000;13:1259.

20. Ries LA, Wingo PA, Miller DS, Howe HL, Weir HK, Rosenberg HM, Vernon SW, Cronin K, Edwards BK. The annual report to the nation on the status of cancer, 1973-1997, with a special section on colorectal cancer. Cancer 2000;88:2398-424.

21. Enzinger PC, Mayer RJ. Esophageal cancer. N Engl J Med 2003;349:2241-52.

22. Fitzgerald RC, Saeed IT, Khoo D, Farthing MJ, Burnham WR. Rigorous surveillance protocol increases detection of curable cancers associated with Barrett's esophagus. Dig Dis Sci 2001;46:1892-8.

23. van Sandick JW, van Lanschot JJ, Kuiken BW, Tytgat GN, Offerhaus GJ, Obertop H. Impact of endoscopic biopsy surveillance of Barrett's oesophagus on pathological stage and clinical outcome of Barrett's carcinoma. Gut 1998;43:216-22.

24. Overholt BF, Panjehpour M, Halberg DL. Photodynamic therapy for Barrett's esophagus with dysplasia and/or early stage carcinoma: long-term results. Gastrointest Endosc 2003;58:183-8.

25. Prasad GA, Wang KK, Buttar NS, Wongkeesong LM, Krishnadath KK, Nichols FC, 3rd, Lutzke LS, Borkenhagen LS. Long-term survival following endoscopic and surgical treatment of high-grade dysplasia in Barrett's esophagus. Gastroenterology 2007;132:1226-33.

26. Ganz RA, Overholt BF, Sharma VK, Fleischer DE, Shaheen NJ, Lightdale CJ, Freeman SR, Pruitt RE, Urayama SM, Gress F, Pavey DA, Branch MS, Savides TJ, Chang KJ, Muthusamy VR, Bohorfoush AG, Pace SC, DeMeester SR, Eysselein VE, Panjehpour M, Triadafilopoulos G. Circumferential ablation of Barrett's esophagus that contains high-grade dysplasia: a U.S. Multicenter Registry. Gastrointest Endosc 2008;68:35-40.

27. Giovannini M, Bories E, Pesenti C, Moutardier V, Monges G, Danisi C, Lelong B, Delpero JR. Circumferential endoscopic mucosal resection in Barrett's esophagus with high-grade intraepithelial neoplasia or mucosal cancer. Preliminary results in 21 patients. Endoscopy 2004;36:782-7.

28. Lopes CV, Hela M, Pesenti C, Bories E, Caillol F, Monges G, Giovannini M. Circumferential endoscopic resection of Barrett's esophagus with high-grade dysplasia or early adenocarcinoma. Surg Endosc 2007;21:820-4.

29. Ishihara R, Iishi H, Uedo N, Takeuchi Y, Yamamoto S, Yamada T, Masuda E, Higashino K, Kato M, Narahara H, Tatsuta M. Comparison of EMR and endoscopic submucosal dissection for en bloc resection of early esophageal cancers in Japan. Gastrointest Endosc 2008;68:1066-72.

30. von Delius S, Feussner H, Henke J, Schneider A, Hollweck R, Rosch T, Prinz C, Schmid RM, Frimberger E. Submucosal endoscopy: a novel approach to en bloc endoscopic mucosal resection (with videos). Gastrointest Endosc 2007;66:753-6.

31. Willingham FF, Gee DW, Sylla P, Lauwers GY, Rattner DW, Brugge WR. En bloc esophageal mucosectomy for concentric circumferential mucosal resection (with video). Gastrointest Endosc 2009;69:147-51.

32. Akiyama H, Tsurumaru M, Ono Y, Udagawa H, Kajiyama Y. Esophagectomy without thoracotomy with vagal preservation. J Am Coll Surg 1994;178:83-5.

33. Nigro JJ, Hagen JA, DeMeester TR, DeMeester SR, Peters JH, Oberg S, Theisen J, Kiyabu M, Crookes PF, Bremner CG. Prevalence and location of nodal metastases in distal esophageal adenocarcinoma confined to the wall: implications for therapy. J Thorac Cardiovasc Surg 1999;117:16-23; discussion 23-5.

34. Nieponice A, Gilbert TW, Badylak SF. Reinforcement of esophageal anastomoses with an extracellular matrix scaffold in a canine model. Ann Thorac Surg 2006;82:2050-8.

35. Nieponice A, McGrath K, Qureshi I, Beckman EJ, Luketich JD, Gilbert TW, Badylak SF. An extracellular matrix scaffold for esophageal stricture prevention after circumferential EMR. Gastrointest Endosc 2008. 


\section{PLENARY DISCUSSION DIGESTIVE DISEASE WEEK, CHICAGO, 2009}

Discussant Dr. Lee Swanstrom (Portland, OR): Thank you for inviting me to discuss this very interesting paper and congratulations to Dr. Witteman, Jobe, and their team for doing this very innovative and I think thought-provoking study. Also thank you for sending the very nicely written manuscript.

I think we are looking at the future of GI surgery here; it certainly represents a developing trend toward local treatment of early cancers. This is a porcine model of en bloc esophageal mucosal resection, not quite esophagectomy yet. Your title is a little challenging in this regard but I think, as you point out, this is just step one in an ongoing study.

As you also mention, it is not a totally new concept. It has obviously always been desirable to not excise the whole en bloc esophagus for early cancer or for benign disease; Akiyama and DeMeester described this over 20 years ago, as you mentioned, as a treatment in humans for benign disease: stripping the mucosa out with a vein stripper and for diseases like end-stage achalasia to do a subsequent pull-up through the muscularis tube. So it has been around for a while. But obviously, what is novel here is that you are applying it to cancer and I think that is a very important stage because it really goes hand in hand with some of the things like Barrett's ablation that are increasingly popular.

I just want to point out to the audience some of the points that need to be emphasized. The first is that this is an extension; a surgical extension of those technologies like Barrett's ablation of early cancers that I think is probably going to eliminate traditional esophagectomy for premalignant mucosa and early stage malignancies. This approach is superior to ablation in that it provides us with a pathology specimen, so margin determination and better staging are possible. There is no doubt in my mind that this is the way things are obviously going to go.

I think the other thing to stress is that this was totally an endoscopic procedure. Unlike traditional mucosal stripping techniques, which require open or laparoscopic access, this is essentially done with no incisions other than a PEG-tube. So it is an important and "NOTES"-like development in patient friendly care. I would also emphasize the fact that this is a bunch of surgeons doing a very complex interventional endoscopic procedure and use this as a chance to soapbox that surgeons need to be involved in flexible endoscopy and especially interventional endoscopy.

Then, as you mentioned with your teaser at the end of the presentation and in your previous publications, this is a platform for future development in tissue engineering for stricture prevention and maybe someday for esophageal replacement and that has a very exciting future. So my questions to you are: Please enlarge a little bit more on what you see are the differences between doing this in the porcine model and in humans who have a very different esophageal physiology. If you work with pigs, you are aware that the mucosa is pretty slippery on the submucosa, but is it the same in humans, and what do you forecast the difficulties being along that line? Will 
there be more bleeding? And will the split on the same plain that nice deep submuscularis in a human or will it split in a more superficial plain? You mentioned the possibility of fibrosis. These experiments were done in a normal esophagus. How are you going to investigate looking at a diseased esophagus whether it is ulcerated, fibrotic, or with Barrett's? What impact will that have? How are you going to investigate that before this technique goes into widespread human use? A couple of technical questions: The procedure took 3 hours, even though the video made it look like 10 minutes. What steps actually used up most of that time? It sounds like the early experience with getting that proximal mucosectomy is a little bit difficult, and I see that one of your video clips shows a very elegant one-stage technique. Maybe you can enlarge on that just briefly. How much of this was really dissection versus stripping? Or maybe this is a more relevant question in a human; how much do you think is actually going to be dissection under direct vision to get a good clean layer versus just tying a strip to it by yanking real hard, which makes the endoscope only needed for mopping up the bleeding? Bleeding control in humans is a real problem with endoscopic submucosal dissection (ESD) kind of techniques. How do you control bleeding? Did you use clips? Finally, the last question: I think you tease us a bit with this tissue regeneration thing. I think we all know that that is probably a way out there before it is widely available. Do you see an intermediate use of this technique of massive en bloc lengths of Barrett's being stripped out, i.e., could you do a pull-up through muscular tube potentially to combine this with maybe a minimally invasive tubularization of the stomach and a pull-up? Can you perhaps comment on that?

Closing Discussant Dr. Bart P. Witteman (Pittsburgh, PA): Thank you Dr. Swanstrom for your very interesting remarks and questions.

The first question was on the expected difference in performing this technique in humans instead of in the swine model. We expect that this dissection will be more challenging in the human esophagus. In the patient I showed, we used submucosal dissection techniques, which were spearheaded by the Japanese. I expect that these techniques will be very useful not only to access the initial submucosal plain but also to assist the inversion process, once the vein stripper is secured. I think during a stepwise procedure in which the assistant carefully draws back on the vein stripper and strips portions of the submucosal complex down the esophagus, the surgeon can use submucosal dissection tools endoluminally to control hemorrhage and dissect adhesions between the submucosa and muscular layer.

That brings me to the second question, which was on how to perform TEE in a diseased esophagus. I think the submucosal dissection techniques will also be very helpful in this area, as many years of progressing disease can cause more adherence of the submucosal layer to the muscularis propria. In our procedures, the creation of an initial 2-3 cm cuff was most time-consuming as for this step we tried different techniques. We used hydrodissection techniques to lift the submucosa from the muscularis propria and also blunt dissection, using the transparent cap of the EMR-kit at 
the tip of the endoscope for dissection, but these were time-consuming and insufficient for tight adhesions. Therefore, we relayed on the mentioned submucosal dissection techniques.

The third question was how to control bleeding. We used an endoscopic forceps with cautery in the swine model, which will probably be very useful in humans too. With the inversion technique, vessels become nicely visible and are easily grabbed with an endoscopic forceps during a stepwise dissection.

The final question was on how we think about the use of a biologic scaffold for controlling stricture formation and if there is a role for gastric pull-up in the resected area instead. The use of an extracellular matrix scaffold has been very promising in the canine model after circumferential EMR and showed site-specific tissue remodeling. We now perform a study to explore the effects of a bioscaffold on stricture formation after TEE in the swine model. We also have future plans to perform a study in patients with en bloc resection and bioscaffold substitution for treatment of Barrett's esophagus with high-grade dysplasia. I think the technique of a gastric pull-up in the muscularis tube will be a less attractive option, as the laparoscopic part will add invasiveness to the procedure. Especially after the experience in our first patient, we would like to explore the use of TEE technique, the endoscopic circumferential stripping of the mucosa-submucosa complex, followed by placement of the extracellular matrix scaffold to control post-operative stricture formation. 



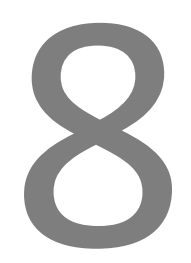

General discussion and future perspectives 
Chapter 8

"Discoveries are often made by not following instructions, by going off the main road and by trying the untried." (Frank Tyger, 1929-2011, New York) 
Now that the benefits of laparoscopic surgery have been broadly acknowledged and confirmed in well-designed clinical trials, the focus is on even less invasive techniques. Natural Orifice Surgery (NOS) is an emerging technology that allows diagnostic and therapeutic procedures to be performed through a natural orifice. ${ }^{1-4}$

NOS refers to the entire field of surgical procedures performed through natural orifices and includes Natural Orifice Transluminal Endoscopic Surgery (NOTES). Because of its minimally invasive nature, it is thought to have potential benefits for patients, such as the avoidance of all incision-related complications, less pain, less immunosuppression, better cosmesis, a faster recovery and shorter hospital stays.

At the contrary, NOS may induce suboptimal outcomes in efficacy and new risks related to a learning curve. Although successful NOTES for cholecystectomy and appendectomy in patients has been described in case reports, the technique has generally been evaluated in a research setting in animal models. ${ }^{5,} 6$

In 2006, the American Society for Gastrointestinal Endoscopy (ASGE) and the Society of American Gastrointestinal and Endoscopic Surgeons (SAGES) organized a working group called Natural Orifice Surgery Consortium for Assessment and Research (NOSCAR) to develop standards for the practice of this emerging technology. A White Paper on NOTES was released to emphasize the need for an interdisciplinary approach, to identify major areas of research and technical barriers. ${ }^{7}$ Parallel in Europe, the New European Surgical Academy (NESA) founded a NOSworking group with members of internationally renowned scientists and clinicians from various disciplines, with the goal to optimize existing surgical procedures and to introduce new procedures and ideas.

Current barriers to successful NOS include spatial orientation and accurate visualization with flexible endoscopy, adequate hemostasis, infection prevention after contamination of the operation field with luminal organisms and the limited availability of advanced instrumentation, e.g. multitask platforms. Ideal platform features include a small diameter device, capability of triangulation and stability to allow retraction with steerable and exchangeable instruments. Additional barriers are safe access to the peritoneal cavity and a reliable closure technique in case of internal visceral incisions. Furthermore, training and education programs will be important to safely translate these new high-tech procedures into clinical practice.

Just like the initiation of the laparoscopic approach, NOS is greeted with skepticism and critics challenge the safety and advantages. This skepticism stands out well, because it will prevent the technique from being introduced clinically, without the confirmation of its safety and efficacy in well-designed clinical trials.

The general aims of this thesis were to review, describe, develop and research the natural orifice approach in foregut surgery for treatment of gastroesophageal reflux disease and related esophageal complications, such as highgrade dysplasia and superficial adenocarcinoma. In order to warrant safe and responsible implementation of NOS, we began with the evaluation of endoluminal 
procedures, as opposed to transluminal procedures, to avoid the complex closure of visceral incisions. Our research team was comprised with surgeons and gastroenterologists, with the complementary skills of both advanced laparoscopy and therapeutic endoscopy.

For treatment of GERD, several endoscopic devices and techniques have been developed. Techniques based on different mechanisms of action have been tested; tissue remodeling by radiofrequency delivery, injection of bulking agents, creation of mucosal tissue pleats by suturing and full-thickness endoscopic fundoplication. ${ }^{8-}$ 9 Thus far, these techniques were unable to replicate the substantial improvement in objective measures of GERD, achievable by laparoscopic fundoplication and many have been withdrawn from the market.

The ideal endoscopic antireflux procedure would be minimally invasive, safe, easy, effective, durable and have the ability to be performed under conscious sedation. ${ }^{10}$ Full-thickness suture plication has been recently developed and is most similar to surgery, because it reconstructs the geometric abnormalities of the gastroesophageal valve. ${ }^{11,12}$

The merits of early surgery in GERD patients have been demonstrated in several randomized controlled trials. ${ }^{13-16}$ Antireflux surgery was shown more effective than pharmacological antisecretory therapies in terms of patient satisfaction, clinical outcome and healthcare cost reduction. ${ }^{17-20}$ Hence, operative restoration of gastroesophageal junction competence at the anatomic, mechanic and physiologic levels is critical in GERD treatment. This is by all means true for patients with volume-reflux-related symptoms, such as regurgitation, asthma, laryngitis and dental erosions. Furthermore, while during the last few decades GERD was mainly treated with medication, the incidence of GERD-induced adenocarcinoma has a 6-fold increase. ${ }^{21}$ It had been suggested that acid suppressive drugs do not seem to prevent the development of adenocarcinoma in Barrett's esophagus and therefore, the acidic component is not likely the sole carcinogenic agent within the gastric juice. ${ }^{22}$ Broadly applied restoration of the reflux barrier may therefore, theoretically, contribute to a lower incidence of GERD-related esophageal cancer.

Disadvantages of surgery are the invasiveness and fundoplication-related side effects that frequently compromise the otherwise excellent post-surgical results. ${ }^{19,} 23$ Persistent dysphagia, inability to belch and vomit, as well as increased bloating and flatulence are common side effects that may occur after surgery. ${ }^{17,24-}$ 27

In 2006, we pioneered transoral incisionless fundoplication (TIF) with the Esophy $\mathrm{X}^{\mathrm{TM}}$-device and successfully performed one of the first human cases. TIF was designed to offer a minimally invasive anatomic repair for GERD that rivals lifelong medications and laparoscopic surgery. Safety and feasibility of the TIF-procedure was shown in our cohort study in 38 chronic GERD patients, who were referred for antireflux surgery. Adverse events and side effects of TIF were mild and related to 
the insertion of the relatively large diameter device with subsequently repetitive axial rotations in order to create the fundoplication. More importantly, the feared post-surgical fundoplication side effects, such as dysphagia and gas-bloating did not occur. ${ }^{28}$

Post-procedure endoscopy showed reduction of hiatal hernia and well defined gastroesophageal valves, estimated Hill grade I in $75 \%$ of patients. Complete reduction was higher for small hiatal hernia than for larger hiatal hernia size and for this reason we excluded a hernia size of $>2 \mathrm{~cm}$ for further procedures. After a short follow-up duration, outcomes were encouraging and patients reported symptom-control and the ability to stop daily PPI usage. Post-procedure pHmeasurements improved, but did not show a statistically significant reduction of distal esophageal acid exposure. With increased follow-up duration, symptoms returned and $37 \%$ had requested revisional surgery after three years follow-up. The fact that symptoms got worse over time, after a relatively symptom-free period, could be due to a placebo-effect, but may also be the result of a lack of durability of the fundoplication. ${ }^{29,} 30$ The "pull-through" of the H-fasteners through the esophageal wall has been reported as the primary mechanism of failure after TIF. ${ }^{31}$

All beginnings are difficult and several questions were raised in the early stage of the evaluation of the new technique; was a learning curve responsible for the suboptimal outcomes? Would TIF be more beneficial to a different selection of GERD patients? Can we improve the technique, in order to improve outcomes?

A learning curve is integral with the introduction of a new surgical technique and may influence early outcomes. However, the procedures in our studies were all performed by a fixed group of physicians who were experienced in minimally invasive techniques and underwent initial in-vivo-training in an animal model. Before the studies, they had performed several clinical cases, proctored on site by the device manufacturer's staff.

Criteria for eligibility were chosen to select patients who would probably benefit from TIF and were based on experiences with surgical fundoplication. ${ }^{32}$ In early studies, TIF was applied as a substitute, in patients who were referred for surgical GERD management. While substantial components of antireflux surgery, such as extragastric dissection allowing hernia reduction and cruraplasty can not be achieved with TIF, it might not be legitimate to compare TIF to surgery. The severity of GERD increases with the severity of anatomical change and dysfunction of the gastroesophageal junction. ${ }^{33-38}$ It is therefore understandable that patients with progressed GERD, due to a severely defective reflux barrier, will still need the rigorous restoration of laparoscopic surgery. Accordingly, patients with less progressed anatomical defects may more likely benefit from minimally invasive endoluminal approaches. Available studies with TIF were non-randomized and all included patients who were referred for surgical GERD treatment. Most studies, of which some were company sponsored, reported feasibility and safety of the TIFprocedure with short-term efficacy, represented in subjective outcome measures 
including quality of life and cessation of PPI-therapy. Some studies also included objective parameters, such as $\mathrm{pH}$-measurements. A decrease, as well as an increase of distal esophageal acid exposure after TIF, has been reported. ${ }^{34-36}$ Although the minimally invasive endoluminal technique seemed attractive in most early studies and side-effects were mild, the efficacy of TIF did not compare to the excellent results of laparoscopic antireflux surgery. ${ }^{39}$

In an attempt to improve GERD control, the TIF-procedure was technically modified into TIF2, based on a study in animals that showed superior results in lower esophageal sphincter pressure and length, compared to the TIF1-technique and tridimensional vector volume measurements resembled the Nissen fundoplication. ${ }^{40}$ The major difference between the initial TIF1 and TIF2 technique was the order and location of fastener placement, with the addition of rotational and longitudinal elements to an esophagogastric instead of a gastrogastric fundoplication. The EsophyX $\mathrm{X}^{\mathrm{TM}}$-device had also been improved and the second generation became less flexible and enabled to apply more torque to the fundoplication in order to wrap the gastric fundus around the esophagus. TIF2-technique with the new device was theoretically more consistent with surgery and these modifications prompted the need for additional studies in a randomized design.

With this background we prepared a randomized controlled trial in which the TIF2-technique was compared to PPI-treatment in GERD patients who were responsive to PPIs, but who opted for more definitive therapy. The trial was intended to be a two-centre study and power-analysis determined a sample size requirement of 120 patients. At the time of study completion in one center, the recruitment had not been started in the second center, mainly due to financial issues. After completion of the trial in one center an interim analysis showed an equal decrease in total distal esophageal acid exposure for TIF and PPI-treatment after a 6 months follow-up. Furthermore, TIF2 resulted in an increased LES resting pressure and a decreased number of reflux episodes. While PPIs enabled reduction of acid-related symptoms (heartburn), by reducing the acidic component in the ongoing reflux of the gastric contents, TIF2 enabled to "cure" GERD by controlling "volume reflux" and thereby improving not only the acid-related symptoms, but also the volume reflux-related symptoms (regurgitation), which was represented in significantly improved quality of life scores.

These results support the validity of the concept of TIF2 as an alternative to PPIs. TIF2 created an effective antireflux barrier entirely endoscopically. Unfortunately, in our randomized trial the initial effects of TIF2 were not sustained. Some impact of placebo effects is suggested, because symptom-improvement remained at 12 months, while the objective measures had deteriorated. As also seen in our first study, with elapsing time the need for PPIs increased and some patients needed revisional laparoscopic surgery.

With every endoluminal procedure reported to date, durability has been of permanent concern. ${ }^{41}$ Literature data and our own experience indicate that after a 
relatively symptom free period, with objective reflux control, TIF appears to fail with elapsing time. ${ }^{29}$ On completion of the procedures, well defined omega shaped partial fundoplications were established, but in many patients, the corrected anatomy was not maintained. This "suture loss" was verified by endoscopy or laparoscopy (in revisional laparoscopic procedures). Some patients had actually felt the "popping" of fasteners, after coughing or physical exercise, followed by resumption of GERD-symptoms. ${ }^{42,} 43$ While extra-gastric dissection around the fundus releases the tension of the "floppy" laparoscopic fundoplication, this cannot be achieved with endoscopic fundoplication. The polypropelene fasteners and the subsequent tissue fusion may not have been able to withstand the continues downward forces of the adherent structures on the repair, causing the anatomy to return in its original shape.

This thesis was also focused on outcomes of subsequent revisional laparoscopic antireflux surgery (rLARS) as a next step in the attempt to control GERD in case of TIF failure. rLARS could theoretically be challenging due to the altered anatomical situation around the gastroesophageal junction. Technical difficulties could emerge and lead to complications and/or suboptimal outcomes. Technically, rLARS was feasible in all patients without the need to convert to open surgery. However, previous TIF had caused a substantial change in anatomy and with the additionally required dissection, operation time was prolonged. We encountered a gastric perforation during dissection, which was also seen during revisional surgery in other centers. ${ }^{44}$ rLARS resulted in objective reflux control at the cost of a relatively high rate of post-operative dysphagia, which negatively impacted the quality of life. We speculate that a partial fundoplication, such as the Toupet procedure, may be a superior option for revisional surgery, because systematic reviews of primary LARS have shown that the partial posterior fundoplication is equally effective in reflux control with less significant post-operative dysphagia. ${ }^{31}$

Limitations to our studies on TIF were the non-randomized design in our first study and the limited follow-up duration. Furthermore, in both studies there was a selection bias, with the strict criteria for eligibility at inclusion. The randomized trial, described in chapter 4, was obviously underpowered at interim analysis. Another limitation was the loss of the comparative part after six months. This cross-over design was chosen to facilitate recruitment and because the outcomes of long-term PPI-treatment with an extensive follow-up are widely known. ${ }^{46}$

In our opinion, endoscopic fundoplication, in its present form, has no place in routine GERD treatment. The mechanism of TIF-failure had its basis in the lack of durability of the created fundoplication. A next generation endoscopic fundoplication technique may improve outcomes, if equipped with a more solid suturing or stapling mechanism to better withstand intra-abdominal traction forces. Recently a new device, capable of creating a totally endoscopic fundoplication, has been developed, consisting of an endoscope, endoscopic ultrasound and a surgical stapler. The SRS ${ }^{\mathrm{TM}}$ Endoscopic Stapling System (Medigus, Tel Aviv, Israel) is a modi- 
fied reusable endoscope, that fires 3 rows of titanium staples, plicating the fundus onto the esophagus while using ultrasonic sights for accurate positioning. ${ }^{47}$ This technique is currently under evaluation and is hoped to provide a more durable repair. Further ideas for NOS in GERD treatment include the implementation of transluminal access into the procedure, for instance to provide extragastric dissection tot release tension of the gastric fundus, by division of the gastrophrenic and gastrosplenic ligaments. Further development of instrumentation and stable multitask-platforms may even result in the ability to perform the entire "surgical fundoplication", including cruraplasty and hiatal hernia reduction, by means of NOTES. A transvaginal or transrectal access to the peritoneal cavity would provide the best angle for surgical maneuvers in the upper abdomen. The approach for transrectal antireflux surgery has already been tested in an animal model and was feasible despite some complications, including bleeding and infection. ${ }^{48}$ With the presently available endoscopes, percutaneous assistance was required, which made it a so-called hybrid-NOTES-procedure. Although it has been demonstrated that careful abdominal access through a natural orifice and visceral wound closure may be possible without clinical infections, the transrectal approach in GERD surgery would still seem to be hazardous. It violates many established surgical precepts by deliberate perforation of the colon, with risk of fecal contamination of the peritoneum and changes a "clean" procedure into a "clean-contaminated" procedure. ${ }^{49}$

When GERD has already damaged the inner lining of the distal esophagus and induced metaplasia, management involves three components: treatment of the associated GERD, endoscopic surveillance to detect dysplasia and treatment of the dysplasia. Esophageal resection is the standard treatment for Barrett's esophagus with high-grade dysplasia and resectable invasive malignancies.50, 51 Often a surgeon is confronted with the need for esophagectomy in elderly patients, with medical comorbidities, including pulmonary and cardiovascular disease. Patients who develop a pulmonary infection after surgery have a $20 \%$ mortality rate. ${ }^{52}$

Traditional "open" esophagectomy has been associated with significant morbidity and mortality rates and to lower these rates, minimally invasive esophagectomy (MIE) was introduced. ${ }^{53-55}$ Bierre et al. reported the results of the first multicenter randomized controlled trial of MIE versus the open approach and showed benefits of MIE in terms of a reduced rate of pulmonary infections, hospital stay and quality of life, without compromising the quality of the resected specimen. Other open label multicenter randomized controlled trials comparing MIE to open surgery are underway and soon, additional reports are expected. ${ }^{56-58}$

Despite the advantages of the minimally invasive approach, esophagectomy is still associated with substantial morbidity rates. ${ }^{59-61}$ As a result, there has been an impetus to move towards esophageal preservation in patients with intramucosal neoplastic lesions in which lymphatic involvement is unlikely.62-64 However, 
these early lesions have the potential to be lethal and are only curable if completely removed. Since surveillance programs have increased the number of patients detected within early-stage disease, the interest in less invasive endoscopic treatments has grown. ${ }^{65,} 66$ Endoscopic approaches, such as endoscopic mucosal resection (EMR) and radiofrequency ablation have been introduced to remove the damaged parts of the esophageal inner lining. Limitations of these endoscopic therapies include a compromised histological assessment, the need for lifelong surveillance, subsequent procedures and stricture formation. While endoscopic submucosal dissection (ESD) provides larger specimens, this technique is highly operator dependent, limited by existing technology and has a high risk of perforation and therefore, becomes a surgical procedure with the possible need for conversion and should take place in the operation room. Circumferential en bloc resection of the mucosa-submucosa-complex followed by deployment of a biologic scaffold onto the remaining muscularis propria may address these concerns.

In this thesis feasibility of transoral endoscopic esophagectomy (TEE) was shown in an animal model and provided a resection length and depth that was found to be both accurate and reproducible. Assuming reproducibility in humans, TEE could be a reliable staging tool and/or treatment for patients with long segment multifocal dysplasia and intramucosal cancer, while providing the pathologist with a complete specimen that can be assessed on T, G and R-status. This information will better guide clinicians in their efforts to balance procedural morbidity, with the risk for lymphatic involvement in the face of esophageal preservation.

While lymph node involvement is infrequent in T1a-stage adenocarcinoma of the esophagus, it is increased by nearly 10 -fold when there is submucosal involvement (T1b-stage).62, 64, 67 Therefore, TEE will not be suitable as a definitive treatment in patients with T1b-, or advanced stage lesions and these patients should undergo MIE.

Limitations of our TEE study were the swine model and the animal's healthy esophagus. It can be anticipated that the "stripping" with inversion technique will be more difficult in the diseased human esophagus, in the presence of inflammation or fibrous attachments caused by many years of progressing GERD. Circumferential endoscopic mucosal resection has resulted in significant stricture formation if performed in a single setting and therefore is expected to be a major concern related to TEE. ${ }^{68}$ The use of extracellular-matrix-scaffolds, derived from porcine urinary bladders, are known to promote site-specific tissue remodeling. Recently, this technique has been demonstrated to prevent stricture formation in the canine esophagus after circumferential endoscopic mucosal resection. ${ }^{69-70}$

Meanwhile the TEE-technique in conjunction with biologic scaffold placement has been brought into clinical care at the University of Pittsburgh Medical Center (UPMC) in collaboration with the McGowan Institute for Regenerative Medicine. Currently, eight human case reports have been described. Five patients suf- 
fered from chronic GERD with hiatal hernia and had long-segment Barrett with high-grade dysplasia and superficial adenocarcinoma. These patients were not eligible for standard esophagectomy due to their co-morbidities. TEE with extracellular matrix deployment was feasible in all patients and at 4-24 months followup the normal mature squamous epithelium was restored and patients could return to normal diets without significant dysphagia. ${ }^{71}$

In three additional case reports previous endoscopic ablation and resection had failed. Patients underwent subsequent TEE, combined with extracellular matrix placement, which provided regenerated (neo)epithelium and avoided stricture formation. ${ }^{72}$ After the esophagus had healed, these patients underwent laparoscopic fundoplication to prevent the ongoing reflux, damaging the esophagus. Ideally, the fundoplication to cure GERD would of course have been performed by means of NOS, which may be a future option when endoscopic fundoplication techniques have been further developed and are able to create a durable repair.

I conclude that endoscopic fundoplication was feasible and safe in our trails. The concept of the TIF-technique proved to be an effective minimally invasive antirefluxprocedure and, for a limited period, an alternative to PPIs. Unfortunately, durability of the currently available technique proved to be insufficient. Before endoscopic fundoplication techniques will have a place in the treatment algorithm for GERD, it should be improved and efficacy should be demonstrated in well-designed trials with a lengthy follow-up.

Transoral endoscopic esophagectomy was feasible and reproducible and resulted in intact, en bloc specimens. This technique may lead to a single-step staging and/or therapeutic approach with esophageal preservation for Barrett's esophagus and early stage malignancy that avoids the morbidity of esophagectomy. Xenograft biologic scaffold deployment appeared to be effective in stricture prevention after TEE in early case reports, but further clinical studies are necessary to confirm these encouraging results.

At this stage, Natural Orifice Surgery is best performed and evaluated in a research environment by a team that has the complementary skills of advanced therapeutic endoscopy and laparoscopic surgery. There are many fundamental issues in terms of safety, efficacy and durability that need to be optimized prior to its routine application. However, after the major impact of minimally invasive techniques, such as laparoscopy, on our daily clinical practice, it would be conceivable that NOS or a derivative of this new technology will have bright future as the newest frontier in minimally invasive surgery. 


\section{REFERENCES}

1. Willingham FF, Brugge WR. Taking NOTES: translumenal flexible endoscopy and endoscopic surgery. Curr Opin Gastroenterol 2007;23:550-5.

2. Halim I, Tavakkolizadeh A. NOTES: The next surgical revolution? Int J Surg 2008;6:273-6.

3. Baron TH. Natural orifice transluminal endoscopic surgery. Br J Surg 2007;94:1-2.

4. Kalloo AN, Singh VK, Jagannath SB, Niiyama H, Hill SL, Vaughn CA, Magee CA, Kantsevoy SV. Flexible transgastric peritoneoscopy: a novel approach to diagnostic and therapeutic interventions in the peritoneal cavity. Gastrointest Endosc 2004;60:114-7.

5. Fong DG, Pai RD, Thompson CC. Transcolonic endoscopic abdominal exploration: a NOTES survival study in a porcine model. Gastrointest Endosc 2007;65:312-8.

6. Pai RD, Fong DG, Bundga ME, Odze RD, Rattner DW, Thompson CC. Transcolonic endoscopic cholecystectomy: a NOTES survival study in a porcine model (with video). Gastrointest Endosc 2006;64:428-34.

7. Rattner D, Kalloo A. ASGE/SAGES Working Group on Natural Orifice Translumenal Endoscopic Surgery. October 2005. Surg Endosc 2006;20:329-33.

8. Corley DA, Katz P, Wo JM, Stefan A, Patti M, Rothstein R, Edmundowicz S, Kline M, Mason R, Wolfe MM. Improvement of gastroesophageal reflux symptoms after radiofrequency energy: a randomized, sham-controlled trial. Gastroenterology 2003;125:668-676.

9. Rothstein R, Filipi C, Caca K, Pruitt R, Mergener K, Torquati A, Haber G, Chen Y, Chang K, Wong D, Deviere J, Pleskow D, Lightdale C, Ades A, Kozarek R, Richards W, Lembo A. Endoscopic fullthickness plication for the treatment of gastroesophageal reflux disease: a randomized, shamcontrolled trial. Gastroenterology 2006;131:704-712.

10. Falk GW, Fennerty MB, Rothstein RI. AGA Institute Technical Review on the Use of Endoscopic Therapy for Gastroesophageal Reflux Disease. Gastroenterology 2006;131:1315-36.

11. Cadiere GB, Rajan A, Rqibate M, Germay O, Dapri G, Himpens J, Gawlicka AK. Endoluminal fundoplication (ELF)--evolution of EsophyX, a new surgical device for transoral surgery. Minim Invasive Ther Allied Technol 2006;15:348-55.

12. Pleskow D, Rothstein R, Kozarek R, Haber G, Gostout C, Lembo A. Endoscopic full-thickness plication for the treatment of GERD: long-term multicenter results. Surg Endosc 2007;21:439-44.

13. Anvari M, Allen C, Marshall J, Armstrong D, Goeree R, Ungar W, Goldsmith C. A randomized controlled trial of laparoscopic Nissen fundoplication versus proton pump inhibitors for treatment of patients with chronic gastroesophageal reflux disease: One-year follow-up. Surg Innov 2006;13:238-49.

14. Lundell L, Miettinen P, Myrvold HE, Pedersen SA, Liedman B, Hatlebakk JG, Julkonen R, Levander K, Carlsson J, Lamm M, Wiklund I. Continued (5-year) followup of a randomized clinical study comparing antireflux surgery and omeprazole in gastroesophageal reflux disease. J Am Coll Surg 2001;192:172-179; discussion 179-181.

15. Spechler SJ. Comparison of medical and surgical therapy for complicated gastroesophageal reflux disease in veterans. The Department of Veterans Affairs Gastroesophageal Reflux Disease Study Group. N Engl J Med 1992;326:786-92.

16. Spechler SJ, Lee E, Ahnen D, Goyal RK, Hirano I, Ramirez F, Raufman JP, Sampliner R, Schnell T, Sontag S, Vlahcevic ZR, Young R, Williford W. Long-term outcome of medical and surgical therapies for gastroesophageal reflux disease: follow-up of a randomized controlled trial. Jama 2001;285:2331-2338.

17. Allgood PC, Bachmann M. Medical or surgical treatment for chronic gastrooesophageal reflux? A systematic review of published evidence of effectiveness. Eur J Surg 2000;166:713-721.

18. Cookson R, Flood C, Koo B, Mahon D, Rhodes M. Short-term cost effectiveness and long-term cost analysis comparing laparoscopic Nissen fundoplication with proton-pump inhibitor maintenance for gastro-oesophageal reflux disease. Br J Surg 2005;92:700-706.

19. Lundell L, Miettinen P, Myrvold HE, Hatlebakk JG, Wallin L, Malm A, Sutherland I, Walan A. Sevenyear follow-up of a randomized clinical trial comparing proton-pump inhibition with surgical therapy for reflux oesophagitis. Br J Surg 2007;94:198-203. 
20. Mahon D, Rhodes M, Decadt B, Hindmarsh A, Lowndes R, Beckingham I, Koo B, Newcombe RG. Randomized clinical trial of laparoscopic Nissen fundoplication compared with proton-pump inhibitors for treatment of chronic gastro-oesophageal reflux. Br J Surg 2005;92:695-699.

21. Pohl H, Welch HG. The role of overdiagnosis and reclassification in the marked increase of esophageal adenocarcinoma incidence. J Natl Cancer Inst 2005;97:142-6.

22. Tamhankar AP, Peters JH, Portale G, Hsieh CC, Hagen JA, Bremner CG, DeMeester TR. Omeprazole does not reduce gastroesophageal reflux: new insights using multichannel intraluminal impedance technology. J Gastrointest Surg 2004;8:890-7; discussion 897-8.

23. Dallemagne B, Weerts J, Markiewicz S, Dewandre JM, Wahlen C, Monami B, Jehaes C. Clinical results of laparoscopic fundoplication at ten years after surgery. Surg Endosc 2006;20:159-165.

24. Coelho JC, Wiederkehr JC, Campos AC, Andrigueto PC. Conversions and complications of laparoscopic treatment of gastroesophageal reflux disease. J Am Coll Surg 1999;189:356-361.

25. Kamolz T, Granderath FA, Bammer T, Pasiut M, Pointner R. Dysphagia and quality of life after laparoscopic Nissen fundoplication in patients with and without prosthetic reinforcement of the hiatal crura. Surg Endosc 2002;16:572-577.

26. Lundell L. Complications after anti-reflux surgery. Best Pract Res Clin Gastroenterol 2004;18:935945.

27. Wills VL, Hunt DR. Dysphagia after antireflux surgery. Br J Surg 2001;88:486-499.

28 Broeders JA, Mauritz FA, Ahmed Ali U, Draaisma WA, Ruurda JP, Gooszen HG, Smout AJ, Broeders IA, Hazebroek EJ. Systematic review and meta-analysis of laparoscopic Nissen (posterior total) versus Toupet (posterior partial) fundoplication for gastro-oesophageal reflux disease. $\mathrm{Br} \mathrm{J}$ Surg;97:1318-30.

29. Hogan WJ. Clinical trials evaluating endoscopic GERD treatments. Is it time for a moratorium on the clinical use of these procedures? Am J Gastroenterol 2006;101:437-439.

30. Pearl JP, Marks JM. Endolumenal therapies for gastroesophageal reflux disease: are they dead? Surg Endosc 2007;21:1-4.

31. Nieponice A, Jobe BA. Endoscopic fundoplication: real or fantasy? J Gastrointest Surg;15:1295-8.

32. Kahrilas PJ, Shaheen NJ, Vaezi MF. American Gastroenterological Association Institute technical review on the management of gastroesophageal reflux disease. Gastroenterology 2008;135:13921413,1413 e1-5.

33. Stylopoulos N, Rattner DW. The history of hiatal hernia surgery: from Bowditch to laparoscopy. Ann Surg 2005;241:185-193.

34. Jones MP, Sloan SS, Rabine JC, Ebert CC, Huang CF, Kahrilas PJ. Hiatal hernia size is the dominant determinant of esophagitis presence and severity in gastroesophageal reflux disease. Am J Gastroenterol 2001;96:1711-1717.

35. Mittal RK. Hiatal hernia: myth or reality? Am J Med 1997;103:33S-39S.

36. Mittal RK. Hiatal hernia and gastroesophageal reflux: another attempt to resolve the controversy. Gastroenterol 1993;105:941-943.

37. Moss SF, Kidd M, Modlin IM. The status of the hiatus: the role of hernia in gastroesophageal reflux disease. J Clin Gastroenterol 2007;41:S144-S153.

38. Rydberg L, Ruth M, Lundell L. Mechanism of action of antireflux procedures. Br J Surg 1999;86:405-410.

39. Peters MJ, Mukhtar A, Yunus RM, Khan S, Pappalardo J, Memon B, Memon MA. Meta-analysis of randomized clinical trials comparing open and laparoscopic anti-reflux surgery. Am J Gastroenterol 2009;104:1548-61; quiz 1547, 1562.

40. Jobe BA, O'Rourke RW, McMahon BP, Gravesen F, Lorenzo C, Hunter JG, Bronner M, Kraemer SJ. Transoral endoscopic fundoplication in the treatment of gastroesophageal reflux disease: the anatomic and physiologic basis for reconstruction of the esophagogastric junction using a novel device. Ann Surg 2008;248:69-76.

41. Furnee EJ, Broeders JA, Draaisma WA, Schwartz MP, Hazebroek EJ, Smout AJ, van Rijn PJ, Broeders IA. Laparoscopic Nissen fundoplication after failed EsophyX fundoplication. Br J Surg;97:1051-5. 
42. Hoppo T, Immanuel A, Schuchert M, Dubrava Z, Smith A, Nottle P, Watson DI, Jobe BA. Transoral incisionless fundoplication 2.0 procedure using EsophyX for gastroesophageal reflux disease. J Gastrointest Surg;14:1895-901.

43. Witteman BP, Strijkers R, de Vries E, Toemen L, Conchillo JM, Hameeteman W, Dagnelie PC, Koek GH, Bouvy ND. Transoral incisionless fundoplication for treatment of gastroesophageal reflux disease in clinical practice. Surg Endosc.

44. Bergman S, Mikami DJ, Hazey JW, Roland JC, Dettorre R, Melvin WS. Endolumenal fundoplication with EsophyX: the initial North American experience. Surg Innov 2008;15:166-70.

45. Thijssen AS, Broeders IA, de Wit GA, Draaisma WA. Cost-effectiveness of proton pump inhibitors versus laparoscopic Nissen fundoplication for patients with gastroesophageal reflux disease: a systematic review of the literature. Surg Endosc; 25:3127-34.

46. Miner PB, Jr. Review article: physiologic and clinical effects of proton pump inhibitors on nonacidic and acidic gastro-oesophageal reflux. Aliment Pharmacol Ther 2006;23 Suppl 1:25-32.

47. Ufuk Topuz, Tarik Umutoglu, Mefkur Bakan and Erdogan Ozturk.Anesthetic management of the SRS endoscopic stapling system for gastro-esophageal reflux diseaseWorld J Gastroenterol. 2013 January 14; 19(2): 319-320

48 Wilhelm D, Meining A, Schneider A, von Delius S, Preissel A, Sager J, Fiolka A, Friess H, Feussner H. NOTES for the cardia: antireflux therapy via transluminal access.Endoscopy. 2010 Dec;42(12):1085-91.

49 Swantrom LL. Transrectal GERD treatment-just what we need? Endoscopy 2010 Dec;42(12):11067.

50. DeMeester SR. New options for the therapy of Barrett's high-grade dysplasia and intramucosal adenocarcinoma: endoscopic mucosal resection and ablation versus vagal-sparing esophagectomy. Ann Thorac Surg 2008;85:S747-50.

51. Shaheen NJ, Sharma P, Overholt BF, Wolfsen HC, Sampliner RE, Wang KK, Galanko JA, Bronner MP, Goldblum JR, Bennett AE, Jobe BA, Eisen GM, Fennerty MB, Hunter JG, Fleischer DE, Sharma VK, Hawes RH, Hoffman BJ, Rothstein RI, Gordon SR, Mashimo H, Chang KJ, Muthusamy VR, Edmundowicz SA, Spechler SJ, Siddiqui AA, Souza RF, Infantolino A, Falk GW, Kimmey MB, Madanick RD, Chak A, Lightdale CJ. Radiofrequency Ablation in Barrett's Esophagus with Dysplasia. N Engl J Med 2009;360:2277-88.

52. Atkins BZ, Shah AS, Hutcheson KA, Mangum JH, Pappas TN, Harpole DH, Jr., D'Amico TA. Reducing hospital morbidity and mortality following esophagectomy. Ann Thorac Surg 2004;78:1170-6; discussion 1170-6.

53. Luketich JD, Schauer PR, Christie NA, Weigel TL, Raja S, Fernando HC, Keenan RJ, Nguyen NT. Minimally invasive esophagectomy. Ann Thorac Surg 2000;70:906-11; discussion 911-2.

54. Luketich JD, Alvelo-Rivera M, Buenaventura PO, Christie NA, McCaughan JS, Litle VR, Schauer PR, Close JM, Fernando HC. Minimally invasive esophagectomy: outcomes in 222 patients. Ann Surg 2003;238:486-94; discussion 494-5.

55. Cuesta MA, van den Broek WT, van der Peet DL, Meijer S. Minimally invasive esophageal resection. Semin Laparosc Surg 2004;11:147-60.

56. Biere SS, van Berge Henegouwen MI, Maas KW, Bonavina L, Rosman C, Garcia JR, Gisbertz SS, Klinkenbijl JH, Hollmann MW, de Lange ES, Bonjer HJ, van der Peet DL, Cuesta MA. Minimally invasive versus open oesophagectomy for patients with oesophageal cancer: a multicentre, open-label, randomised controlled trial. Lancet;379:1887-92.

57. Khan O, Nizar S, Vasilikostas G, Wan A. Minimally invasive versus open oesophagectomy for patients with oesophageal cancer: a multicentre, open-label, randomised controlled trial. J Thorac Dis; 4:465-6.

58. Dantoc MM, Cox MR, Eslick GD. The first randomised controlled trial on minimally invasive esophagectomy (MIE) and the ongoing quest for greater evidence. J Thorac Dis;4:459-61.

59. Thomas P, Doddoli C, Neville P, Pons J, Lienne P, Giudicelli R, Giovannini M, Seitz JF, Fuentes P. Esophageal cancer resection in the elderly. Eur J Cardiothorac Surg 1996;10:941-6. 
60. Ell C, May A, Pech O, Gossner L, Guenter E, Behrens A, Nachbar L, Huijsmans J, Vieth M, Stolte M. Curative endoscopic resection of early esophageal adenocarcinomas (Barrett's cancer). Gastrointest Endosc 2007;65:3-10.

61. Holscher AH, Bollschweiler E, Schneider PM, Siewert JR. Early adenocarcinoma in Barrett's oesophagus. Br J Surg 1997;84:1470-3.

62. Oh DS, Hagen JA, Chandrasoma PT, Dunst CM, Demeester SR, Alavi M, Bremner CG, Lipham J, Rizzetto C, Cote R, Demeester TR. Clinical biology and surgical therapy of intramucosal adenocarcinoma of the esophagus. J Am Coll Surg 2006;203:152-61.

63. Rice TW, Blackstone EH, Adelstein DJ, Zuccaro G, Jr., Vargo JJ, Goldblum JR, Murthy SC, DeCamp MM, Rybicki LA. Role of clinically determined depth of tumor invasion in the treatment of esophageal carcinoma. J Thorac Cardiovasc Surg 2003;125:1091-102.

64. Rice TW, Zuccaro G, Jr., Adelstein DJ, Rybicki LA, Blackstone EH, Goldblum JR. Esophageal carcinoma: depth of tumor invasion is predictive of regional lymph node status. Ann Thorac Surg 1998;65:787-92.

65. Fitzgerald RC, Saeed IT, Khoo D, Farthing MJ, Burnham WR. Rigorous surveillance protocol increases detection of curable cancers associated with Barrett's esophagus. Dig Dis Sci 2001;46:1892-8.

66. van Sandick JW, van Lanschot JJ, Kuiken BW, Tytgat GN, Offerhaus GJ, Obertop H. Impact of endoscopic biopsy surveillance of Barrett's oesophagus on pathological stage and clinical outcome of Barrett's carcinoma. Gut 1998;43:216-22.

67. Nigro JJ, Hagen JA, DeMeester TR, DeMeester SR, Peters JH, Oberg S, Theisen J, Kiyabu M, Crookes PF, Bremner CG. Prevalence and location of nodal metastases in distal esophageal adenocarcinoma confined to the wall: implications for therapy. J Thorac Cardiovasc Surg 1999;117:16-23; discussion 23-5.

68. Kamler JP, Borsatto R, Binmoeller KF. Circumferential endoscopic mucosal resection in the swine esophagus assisted by a cap attachment. Gastrointest Endosc 2002;55:923-8.

69. Nieponice A, Gilbert TW, Badylak SF. Reinforcement of esophageal anastomoses with an extracellular matrix scaffold in a canine model. Ann Thorac Surg 2006;82:2050-8.

70. Nieponice A, McGrath K, Qureshi I, Beckman EJ, Luketich JD, Gilbert TW, Badylak SF. An extracellular matrix scaffold for esophageal stricture prevention after circumferential EMR. Gastrointest Endosc 2008.

71. Badylak SF, Hoppo T, Nieponice A, Gilbert TW, Davison JM, Jobe BA. Esophageal preservation in five male patients after endoscopic inner-layer circumferential resection in the setting of superficial cancer: a regenerative medicine approach with a biologic scaffold. Tissue Eng Part A;17:164350.

72. Hoppo T, Badylak SF, Jobe BA. A novel esophageal-preserving approach to treat high-grade dysplasia and superficial adenocarcinoma in the presence of chronic gastroesophageal reflux disease. World J Surg;36:2390-3. 

APPENDICES

List of abbreviations

Summary

Samenvatting

Dankwoord

List of publications and presentations

Curriculum Vitae auctoris 


\section{LIST OF ABBREVIATIONS}

\begin{tabular}{|c|c|}
\hline ARS & Antireflux Surgery \\
\hline ASA & American Society of Anesthesiologists physical status classification \\
\hline $\mathrm{BE}$ & Barrett's Esophagus \\
\hline BMI & Body Mass Index \\
\hline $\mathrm{CM}$ & Circular Muscle layer \\
\hline $\mathrm{CRF}$ & Case Report Form \\
\hline Epub & Electronic publication \\
\hline FDA & Food and Drug Administration (United States of America) \\
\hline GERD & Gastroesophageal Reflux Disease \\
\hline GEJ & Gastroesophageal Junction \\
\hline GEV & Gastroesophageal Valve \\
\hline GIA & Gastrointestinal Anastomosis \\
\hline GSRS & Gastrointestinal Symptom Rating Scale \\
\hline HGD & High Grade Dysplasia \\
\hline HHD & Hiatal Hernia Diaphragmatic \\
\hline HRQL & Health Related Quality of Life \\
\hline IQM & Interquartile Range \\
\hline LARS & Laparoscopic Antireflux Surgery \\
\hline LES & Lower Esophageal Sphincter \\
\hline LIE & Laparoscopic transhiatal Inversion Esophagectomy \\
\hline LNF & Laparoscopic Nissen Fundoplication \\
\hline LM & Longitudinal Muscle layer \\
\hline MSC & Mucosa Submucosa Complex \\
\hline MIE & Minimally Invasive Esophagectomy \\
\hline $\mathrm{N}$ & Number of subjects \\
\hline $\mathrm{N} / \mathrm{A}$ & Not Available \\
\hline PET-CT & Positron Emission Tomography \& Computed Tomography \\
\hline $\mathrm{pH}$ & potentia Hydrogenii \\
\hline PPI & Proton Pump Inhibitor \\
\hline RCT & Randomized Controlled Trial \\
\hline rLARS & revisional Laparoscopic Antireflux Surgery \\
\hline TEE & Transoral Endoscopic Esophagectomy \\
\hline TIF & Transoral Incisionless Fundoplication \\
\hline QoL & Quality of Life \\
\hline SEM & Standard Error of the Mean \\
\hline SD & Standard Deviation \\
\hline SM1-3 & Submucosal layer 1-3 \\
\hline $\begin{array}{l}\text { SAGES } \\
\text { tLESR }\end{array}$ & $\begin{array}{l}\text { Society of American Gastrointestinal Endoscopic Surgeons } \\
\text { transient Lower Esophageal Sphincter Relaxations }\end{array}$ \\
\hline
\end{tabular}




\section{SUMMARY}

Minimally invasive surgery continues to evolve. Now that the benefits of laparoscopic surgery have been acknowledged and confirmed in well-designed trials, a new and exiting minimally invasive technique has been introduced. Natural orifice surgery (NOS) is a technique whereby diagnostic and therapeutic procedures can be performed through a natural orifice. Potential benefits to patients include the avoidance of all incision-related complications, less immunosuppression, less pain, a faster recovery and better cosmesis.

The aim of this thesis was to review, describe, develop and research the natural orifice approach in foregut surgery for treatment of gastroesophageal reflux disease and related esophageal complications, such as high-grade dysplasia and superficial adenocarcinoma.

Gastroesophageal reflux disease (GERD) is described in chapter 2 and represents a condition that develops when the reflux of the stomach contents causes troublesome symptoms and/or complications. Reflux can damage the inner lining of the distal esophagus and lead to esophagitis, Barrett's esophagus and finally even to cancer.

When initial medical treatment with proton pump inhibitors (PPIs) fails, laparoscopic fundoplication has been the gold standard for surgical GERD management. Downsides of surgery are the invasiveness and fundoplication-related side effects, including dysphagia and gas-bloating.

Endoluminal techniques have been introduced as a less invasive alternative to surgery. Transoral incisionless fundoplication (TIF) was designed to mimic parts of the surgical technique and enables to create a full-thickness partial fundoplication. Our initial experiences with this technique were described in chapter 3. In a cohort of 38 chronic GERD patients, who were referred for surgical GERD management, TIF1 was evaluated and the feasibility and safety of the procedure was shown. At six months, quality of life and PPI-cessation results were encouraging. Post-procedure esophageal acid exposure however, did not significantly improve and after three years, 37\% had requested revisional laparoscopic surgery as their GERD was not satisfactory managed. In the remaining cohort, quality of life was still significantly improved after three years and the daily use of PPIs was discontinued by $74 \%$. We concluded that TIF1 improved quality of life and reduced the need for PPIs in only a subgroup of patients and that an unacceptably high number of patients required additional medication and revisional surgery.

In our randomized controlled trial, described in chapter 4, the second generation TIF was compared to PPI-treatment in GERD patients, who were satisfactory managed with PPIs, but opted for more definitive treatment. At six months follow-up, TIF2 resulted in an equal control of acid exposure compared to PPIs. Additionally, it increased LES-pressures and decreased volume-reflux, which resulted in an improved quality of life. These results supported the validity of the concept of 
TIF2 as an effective alternative to PPIs. Unfortunately the antireflux barrier deteriorated with increased follow-up duration. A next generation endoscopic fundoplication technique may improve outcomes, if equipped with a more solid suturing or stapling mechanism to better withstand intra-abdominal traction forces and warrant durability.

As said, in the early experience with TIF, reflux control was not always accomplished. In case of treatment failure, subsequent revisional laparoscopic antireflux surgery (rLARS) would be an obvious next step in an attempt to control GERD. In chapter 5, outcomes of rLARS after previous TIF were reported. Fifteen patients were included in the study that showed feasibility without the need for conversion to open surgery. Acid exposure of the distal esophagus improved significantly post rLARS and esophagitis, PPI-usage and hiatal hernia decreased. Quality of life however, did not improve because 33\% suffered from dysphagia. We concluded that rLARS was technically challenging, but feasible following failed TIF and resulted in objective reflux control at the cost of a relatively high rate of dysphagia, which had a negative impact on quality of life.

In case GERD has already resulted in Barrett's metaplasia, management involves three components: treatment of the associated GERD to prevent further damage, endoscopic surveillance to detect dysplasia and subsequently treatment of the dysplasia. In high-grade dysplasia (HGD) or cancer, esophageal resection has been the standard treatment. Despite encouraging reports on the minimally invasive approach, described in chapter 6, esophagectomy still is associated with substantial morbidity rates. As a result, there has been a driving force to move towards organ preservation in HGD and intramucosal cancer, in which lymph node involvement is uncommon. Limitations of available endoscopic therapies include a compromised histological assessment, the need for lifelong surveillance, subsequent procedures and stricture formation. Circumferential en bloc resection of the mucosa-submucosa complex by means of NOS, followed by deployment of a biologic scaffold onto the remaining muscularis propria, may address these concerns.

In chapter 7 the evaluation of transoral resection of the esophageal inner lining in an animal model was reported. Transoral endoscopic esophagectomy (TEE) was feasible, reproducible and resulted in intact, en bloc specimens over the entire esophageal length. The inversion technique provided a blunt dissection with equally distributed circumferential counter traction and this prevented perforation. We concluded that TEE of the inner esophageal layers was feasible and reproducible, with the potential to result in a single-step definitive treatment and/or staging tool for early neoplastic lesions, obviating the need for esophagectomy. Future work will need to focus on stricture prevention with the use of a xenograft biologic scaffolds.

At this stage, Natural Orifice Surgery is best performed and evaluated in a research environment by a team that has the complementary skills of advanced therapeutic endoscopy and laparoscopic surgery. There are many fundamental 
issues in terms of safety, efficacy and durability that need to be optimized prior to its routine application. However, after the major impact of minimally invasive techniques, such as laparoscopy, on our daily clinical practice, it would be conceivable that NOS or a derivative of this new technology will have bright future as the newest frontier in minimally invasive surgery. 



\section{SAMENVATTING}

De minimaal invasieve chirurgie blijft zich ontwikkelen en nu de voordelen van de laparoscopische benadering (kijkoperatie) zijn erkend en bevestigd in goede wetenschappelijke studies, is er een nieuwe, nog minder invasieve techniek geïntroduceerd. Natural Orifice Surgery (afgekort NOS) is een techniek waarbij diagnostische en therapeutische procedures kunnen worden uitgevoerd via een natuurlijke lichaamsopening. Voordelen voor patiënten zijn het voorkomen van schade aan de weke delen (huid, spieren en buikwand) en de incisiegerelateerde complicaties zoals wondinfecties en littekenbreuken. Andere potentiële voordelen zijn een betere cosmetiek, minder pijn, minder immunosuppressie, een sneller herstel en een kortere opnameduur.

Het doel van dit proefschrift was het beschrijven, ontwikkelen en onderzoeken van NOS-technieken in de bovenbuikchirurgie voor de behandeling van gastro-oesofageale refluxziekte (GORZ) en gerelateerde complicaties zoals hooggradige dysplasie in de slokdarm en slokdarmkanker.

De pathofysiologie van GORZ en de huidige behandelingsmodaliteiten worden beschreven in hoofdstuk 2. GORZ is een aandoening die ontstaat wanneer reflux (het terugvloeien van maaginhoud naar de slokdarm) klachten en/of complicaties veroorzaakt. Refluxziekte kan de binnenbekleding van het onderste deel van de slokdarm beschadigen en leiden tot oesofagitis (slokdarmontsteking), Barrett's slokdarm (voorstadium slokdarmkanker) en uiteindelijk zelfs tot oesofaguscarcinoom (slokdarmkanker).

Wanneer medicamenteuze behandeling van GORZ met proton-pompremmers (PPIs) onvoldoende effectief is, zijn GORZ patiënten aangewezen op chirurgische behandeling met de laparoscopische fundoplicatie (kijkoperatie waarbij de maagklep wordt hersteld). Nadelen van deze operatie zijn echter het invasieve karakter en fundoplicatie-gerelateerde bijwerkingen, zoals dysfagie (slikklachten) en gas-bloating (opgeblazen gevoel) die lastig te behandelen zijn.

NOS-technieken werden geïntroduceerd als een minder invasief alternatief voor de laparoscopische operatie. Transoral incisionless fundoplication (TIF) werd ontwikkeld om een deel van de standaard antireflux operatie na te bootsen en uit te voeren via de mond. Onze eerste ervaringen met deze techniek worden beschreven in hoofdstuk 3. TIF1 werd geëvalueerd in een cohort van 38 chronische GORZ-patiënten, die werden verwezen voor chirurgische behandeling. De uitvoerbaarheid en veiligheid van de TIF1-procedure werd in deze studie aangetoond. $\mathrm{Na}$ zes maanden waren de resultaten in kwaliteit van leven en het vermogen van patienten de PPIs te stoppen zeer veelbelovend. Echter, de objectieve metingen van oesofageale zuurexpositie verbeterden niet significant. Na drie jaar had 37\% van de patiënten, bij recidiverende symptomen, alsnog de laparoscopische operatie ondergaan. In het resterende cohort was de kwaliteit van leven na drie jaar nog steeds aanzienlijk verbeterd en het dagelijks gebruik van PPIs werd door $74 \%$ 
gestaakt. Concluderend resulteerde de TIF1-procedure slechts bij een subgroep van de patiënten tot een betere kwaliteit van leven en verminderde de noodzaak tot medicatie gebruik na drie jaar follow-up. De groep die alsnog de standaard laparoscopische operatie moest ondergaan of aanvullende medicatie nodig had was onaanvaardbaar groot.

In een gerandomiseerde studie, beschreven in hoofdstuk 4, werd de doorontwikkelde tweede generatie TIF-techniek en de medicamenteuze behandeling van GORZ vergeleken. Patiënten die goed reageerden op de behandeling met PPIs, maar een meer definitieve oplossing zochten voor hun refluxziekte, werden geïncludeerd. TIF2 resulteerde na zes maanden follow-up in een vergelijkbare vermindering van zuurexpositie in de distale slokdarm als de PPI-behandeling. Bovendien steeg na de TIF2-procedure de druk van de lage slokdarmsfincter en verminderde de "volume-reflux", waarbij er een significant verbeterde kwaliteit van leven werd gemeten. Deze resultaten ondersteunen de validiteit van het TIF-concept als een effectief alternatief voor medicamenteuze GORZ behandeling. Helaas verslechterde de refluxbarrière na verloop van tijd door een gebrek aan duurzaamheid van de TIF2. Een volgende generatie NOS-fundoplicatietechniek zou wellicht met een meer solide hechtsyteem of staplemechanisme, dat beter bestand is tegen intraabdominale tractiekrachten, tot betere resultaten kunnen leiden.

Zoals beschreven was de TIF-procedure niet altijd succesvol in het creëren van een adequate refluxbarrière. Bij falen van de TIF-behandeling was revisie laparoscopische antireflux chirurgie (rLARS) een logische volgende stap voor patiënten die onvoldoende reageerden op het herstarten van medicamenteuze behandeling. In hoofdstuk 5 worden de resultaten van rLARS na een eerder gefaalde TIFprocedure gerapporteerd. Vijftien patiënten werden geïncludeerd in een studie die de uitvoerbaarheid en veiligheid van rLARS aantoonde, zonder de noodzaak tot conversie naar open chirurgie. Na rLARS nam de zuurexpositie van de distale slokdarm af, almede oesofagitis, hiatus hernia en het PPI-gebruik. Echter, de gemiddelde kwaliteit van leven verbeterde in deze groep niet, omdat 33\% last kreeg van dysfagie. We geconcludeerd dat rLARS technisch haalbaar was na een voorafgaande TIF-procedure en resulteerde in objectieve reflux controle ten koste van een relatief hoog percentage van dysfagie, die de kwaliteit van leven negatief beïnvloedde.

In het geval dat GORZ al premaligne Barrett's metaplasie in de distale oesofagus heeft veroorzaakt, zijn drie componenten van belang: de behandeling van GORZ om verdere schade te voorkomen, endoscopische surveillance en de behandeling van eventuele dysplasie. In geval van hooggradige dysplasie (HGD) of resectabel oesofaguscarcinoom, is een oesofagusresectie de standaard behandeling. Ondanks bemoedigende literatuur over de minimaal invasieve benadering, beschreven in hoofdstuk 6, gaat oesofagusresectie nog steeds gepaard met een substantiële morbiditeit (complicaties). Dien ten gevolge is er een drijvende kracht om te streven naar orgaanbehoud door middel van endoscopische technieken bij pati- 
enten met HGD en oppervlakkig oesofaguscarcinoom (stadium T1a), omdat lymfekliermetastasering in deze stadia zeldzaam is. De beperkingen van de huidige endoscopische technieken zijn de gecompromitteerde histologische beoordeling, de noodzaak van levenslange surveillance, vervolgprocedures en strictuurvorming. Een circumferentiële, en bloc resectie van het mucosa-submucosa complex door middel van NOS, gevolgd door de plaatsing van een "xenograft biologic scaffold" (bio-mesh) op de muscularis propria zou een oplossing kunnen zijn voor deze beperkingen.

In hoofdstuk 7 wordt een studie naar de uitvoerbaarheid van transorale endoscopische oesofagusresectie (TEE) in een diermodel beschreven. TEE resulteerde in intacte, en bloc resecties van het mucosa-submucosa complex over de gehele lengte van de oesofagus. Met inversietechniek werd met een gelijk verdeelde tegentractie, een stompe dissectie verkregen waardoor perforatie van de slokdarm werd voorkomen. We concludeerden dat TEE in een diermodel uitvoerbaar en reproduceerbaar was. TEE heeft het potentieel om uiteindelijk te resulteren in een "single-step" definitieve behandeling en/of stadiëring van vroeg stadium neoplasie in de oesofagus met orgaanbehoud. Vervolgonderzoek zal zich moeten richten op de preventie van strictuurvorming in het resectiegebied door middel van de plaatsing van een bio-mesh.

Natural Orifice Surgery bevindt zich op dit moment voornamelijk in een onderzoekssetting. De implementatie in de chirurgische praktijk mag pas plaatsvinden wanneer de veiligheid en effectiviteit, met voordelen ten opzichte van de huidige behandelingsmethoden in wetenschappelijk onderzoek zijn aangetoond. Er is meer onderzoek nodig, maar met de opkomst van de minimaal invasieve chirurgie is het niet ondenkbaar dat NOS een steeds grotere rol gaat spelen in de chirurgische praktijk en naast laparoscopische chirurgie een bijdrage kan leveren aan een snel en voorspoedig post-operatief herstel. 



\section{LIST OF PUBLICATIONS AND PRESENTATIONS}

\section{Publications}

Witteman BPL, Conchillo JM, Rinsma NF, Betzel B, Peeters A, Koek GH, Stassen LPS, Bouvy ND. Randomized controlled trial of transoral incisionless fundoplication versus proton pump inhibitors for treatment of gastroesophageal reflux disease. Submitted.

Witteman BPL, Jobe BA. Laparoscopic antireflux procedures. Submitted on invitation of UpToDate, Waltham, MA, 2013.

Sanz AF, Hoppo T, Witteman BPL, Brown BN, Gilbert TW, Badylak SF, Jobe BA, Nieponice A. In-vivo assessment of a biologic occluder for NOTES gastrotomy closure. Accepted Surg Laparosc Endosc \& Percutan Tech, 2013.

Witteman BPL, Kessing B, Snijders G, Dagnelie PC, Koek GH, Conchillo JM, Bouvy ND. Revisional laparoscopic antireflux surgery after unsuccessful endoscopic fundoplication. Surg Endosc. 2013 jun;27(6):2231-6, Epub jan 52013.

Witteman BPL, Jobe BA. Minimally invasive esophagectomy. Vernon-Ashley Atlas of Minimally Invasive Surgical Techniques, Elsevier 2012.

Witteman BPL, Strijkers R, De Vries E, Toemen L, Conchillo JM, Hameeteman W, Dagnelie PC, Koek GH, Bouvy ND. Transoral incisionless fundoplication for the treatment of gastroesophageal reflux disease in clinical practice. Surg Endosc. 2012 Nov;26(11):3307-15. Epub 2012 May 31.

Nason KS, Levy R, Witteman BPL, Luketich JD. The laparoscopic approach to paraesophageal hernia repair. J Gastrointest Surg. 2012 Feb;16(2):417-26. Epub 2011 Dec 9.

Hoppo T, McMahon BP, Witteman BPL, Kreamer SJ, O’Rourke RW, Gravesen F, Bouvy ND, Jobe BA. Functional lumen imaging probe to assess geometric changes in the esophagogastric junction following endoluminal fundoplication. J gastrointest Surg. 2011 Jul;15(7):1112-20, Epub 2011 May 20. 
Witteman BPL, Foxwell TJ, Monsheimer S, Gelrud A, Eid GM, Nieponice A, O’Rourke RW, Hoppo T, Bouvy ND, Badylak SF, Jobe BA. Transoral endoscopic inner layer esophagectomy: management of high-grade dysplasia and superficial cancer with organ preservation. J Gastrointest Surg. 2009 Dec;13(12):2104-12. Epub 2009 Oct 14.

Witteman BPL, Bouvy ND, Koek GH. Will skepticism stop the evolution of endoscopic GERD treatment? Eur J Gastroenterol Hepatol. 2009 Oct;21(10):1222-4.

Nason KS, Schuchert MJ, Witteman BPL, Jobe BA. Endoscopic therapies for the treatment of reflux disease. Semin Thorac Cardiovasc Surg. 2008; 20(4):320-5.

Presentations on this topic

National

Witteman BPL, Conchillo JM, Rinsma NF, Betzel B, Peeters A, Koek GH, Stassen LPS, Bouvy ND. Randomized controlled trial of transoral incisionless fundoplication versus proton pump inhibitors for treatment of GERD. Nederlandse Vereniging voor Gastroenterologie en Gastrointestinale Chirurgie, Veldhoven 2013

Witteman BPL, Franken JM, Polat F, Van den Wildenberg FJH, Rosman C. Thoracolaparoscopische oesofagus-cardiaresectie met buismaagreconstructie en intrathoracale anastomose zonder selectieve longventilatie. Nederlandse Vereniging voor Heelkunde, Veldhoven, 2012

Witteman BPL, Strijkers R, De Vries EE, Toemen L, Conchillo JM, Hameeteman W, Dagnelie PC, Koek GH, Bouvy ND. Transoral incisionless fundoplication for treatment of gastroesophageal reflux disease in clinical practice. Three years follow-up in 38 chronic GERD patients. Nederlandse Vereniging voor Gastroenterologie en Gastrointestinale Chirurgie, Veldhoven, 2010

Witteman BPL, Conchillo JM, Hameeteman W, Dagnelie PC, Koek GH, Bouvy ND. Endoluminale fundoplicatie voor gastro-oesofageale refluxziekte met de Esophyx $^{\mathrm{TM}}$; Een modificatie van de techniek: TIF2. Nederlandse Vereniging voor Heelkunde, Veldhoven, 2008

Witteman BPL, De Vries EE, Van Dam RM, Hameeteman W, Masclee AAM, Greve JW, Koek GH, Bouvy ND. Endoluminal fundoplicatie met de Esophyx ${ }^{\mathrm{TM}}$; een nieuwe techniek in de behandeling van gastro-oesofageale refluxziekte. Pelerin Wetenschapssymposium, Maastricht, 2007 
Witteman BPL, De Vries EE, Van Dam RM, Hameeteman W, Masclee AAM, Greve JW, Koek GH, Bouvy ND. Esophyx ${ }^{\mathrm{TM}}$; Endoluminal fundoplication for gastroesophageal reflux disease (GERD). Nederlandse Vereniging voor Heelkunde, Ede, 2006

\section{International}

Witteman BPL, Conchillo JM, Rinsma NF, Betzel B, Peeters A, Koek GH, Stassen LPS, Bouvy ND. Randomized controlled trial of transoral incisionless fundoplication versus proton pump inhibitors for treatment of gastroesophageal reflux disease. Digestive Disease Week (poster), Orlando, Florida, USA, 2013

Witteman BPL, Foxwell TJ, Monsheimer S, Gelrud A, Eid GM, Nieponice A, O’Rourke RW, Hoppo T, Bouvy ND, Badylak SF, Jobe BA. Natural orifice surgery for early stage esophageal malignancy: proof of concept. Society for Surgery of the Alimentary Tract, Digestive Disease Week, Chicago, IL, USA, 2009

Witteman BPL, Foxwell TJ, Monsheimer S, Gelrud A, Eid GM, Nieponice A, O’Rourke RW, Hoppo T, Bouvy ND, Badylak SF, Jobe BA. Transoral endoscopic esophagectomy. Presidential Plenary Session, Society for Surgery of the Alimentary Tract, Digestive Disease Week, Chicago, IL, USA, 2009

Witteman BPL, Jobe BA. Natural orifice transluminal endoscopic surgery (NOTES): Challenges. Surgical Innovations Center, Pittsburgh, PA, USA, 2009

Witteman BPL, De Vries E, Nieman FHM, Hameeteman W, Masclee A, Van Dam RM, Greve JW, Koek GH, Bouvy ND. EsophyX ${ }^{\mathrm{TM}}$-Device, a new technique for flexible endoscopic intraluminal fundoplication for the treatment of gastroesophageal reflux disease. European Society of Esophagology, Dublin, Ireland, 2007 



\section{DANKWOORD}

Aan de totstandkoming van dit proefschrift hebben velen een bijdrage geleverd. Graag wil ik naast de patiënten die geparticipeerd hebben in de verschillende studies een aantal mensen in het bijzonder bedanken voor hun inzet en betrokkenheid bij mijn promotieonderzoek.

Dr. N.D. Bouvy, co-promotor, beste Nicole, als initiator van vele innovatieve onderzoeksprojecten in Maastricht, waaronder de endoluminale antireflux chirurgie, heb je me geïnspireerd en meegesleept in je enthousiasme deze technieken te gaan onderzoeken. Ik waardeer je scherpe visie, je optimisme, je vertrouwen en bovenal je buitengewone betrokkenheid bij mijn promotieonderzoek. Mijn dank is groot!

Prof. dr. L.P.S. Stassen, promotor, beste Laurents, het is voor mij een grote eer om je eerste promovendus te mogen zijn en na mij zullen er ongetwijfeld nog velen volgen. Ik denk met genoegen terug aan mijn opleiding in Maastricht onder jouw supervisie en aan de gezamenlijke organisatie van de Chirurgencup 2010, maar mijn dank gaat vooral uit naar je steun bij de voorbereidingen van mijn promotie!

Dr. J.M. Conchillo, co-promotor, dr. G.H. Koek, MDL-arts, beste José en Ger, dit onderzoek was slechts mogelijk met de "complementary skills of advanced therapeutic endoscopy and laparoscopic surgery" en was dus nooit gelukt zonder de betrokkenheid van de afdeling maag, darm en leverziekten en van jullie in het bijzonder. Dank voor jullie inzet en de fijne samenwerking!

Leden van de beoordelingcommissie, Prof. dr. C.G.M.J. Baeten, Prof. dr. M.A. Cuesta, Prof. dr. A.A.M. Masclee, dr. C. Rosman en dr. E.J. Spillenaar Bilgen. Hartelijk dank voor uw belangstelling en kritische beoordeling van mijn proefschrift.

Prof. dr. ir. P.C. Dagnelie, dr. A. Peeters en drs. B. Betzel. Dank voor de epidemiologische en statistische ondersteuning van dit proefschrift. Andrea en Bark, jullie bijdrage is van essentieel belang geweest bij de analyse van de gerandomiseerde studie.

Boudewijn en Fedde, bedankt voor de prettige samenwerking en jullie bijdrage aan de manuscripten. Veel succes met jullie veelbelovende onderzoekscarrières in de upper GI!

Studiecoördinatoren Eva, Rob, Liza, Gitte en Ralf, dank voor jullie geweldige inzet bij de follow-up van de patiënten en het datamanagement van de TIF-studies. 
Medewerkers van de endoscopie-, MDL functie-, en operatieafdeling van het Academisch Ziekenhuis Maastricht. Veel dank voor de flexibiliteit en medewerking aan het mogelijk maken van de verschillende studies.

Dana Hamers, dank voor de prachtige illustraties op de cover en in hoofdstuk 2. Randy Mc Kenzie, thanks for your great artwork on Transoral Endoscopic Esophagectomy in chapter 7 .

Dr. B.A. Jobe and prof. J.D. Luketich. Thank you very much for the fellowship at the University of Pittsburgh Medical Center. Blair and Elizabeth, thanks for your hospitality, the year has been very educational, a valuable contribution to this thesis and above all an experience for life!

Katie, Toshi and Alex, it has been a pleasure doing research with you in Pittsburgh. Andreas, George and Sudhir, it was great to work with you guys in the NOTES-lab at CSI Pittsburgh (Center of Surgical Innovations). I wish you all the best!

Opleiders dr. A.G.M. Hoofwijk, prof. dr. J.W.M. Greve, prof. dr. C.H.C. Dejong, prof. dr. L.P.S. Stassen, dr. C. Rosman en drs. I.M.C. Janssen, veel dank voor de chirurgische (vervolg) opleiding.

Collegae chirurgen, A(N)IOS, PA's, NP's, operatieassistenten, verpleegkundigen, doktersassistenten en secretaresses uit Maastricht, Nijmegen en Arnhem. Dank voor de steun en prettige samenwerking.

Maatschap chirurgie en orthopedie Rijnstate Ziekenhuis, Arnhem. Ik dank de maatschap voor de ondersteuning en de mogelijkheid tot het onderzoeksverlof in de laatste fase van mijn promotietraject. Mijn speciale dank gaat uit naar Ernst-Jan, Frits, Ignace en Theo: Wat is het fijn te werken in een team dat voorop loopt op het gebied van minimaal invasive en innovatieve chirurgie!

Paranimfen, Spencer en Christian, dank voor jullie steun tijdens de verdediging van mijn proefschrift. Met heel veel plezier kijk ik terug naar de geweldige tijd in Maastricht. Al zien we elkaar niet meer elke dag, onze vriendschap gaat nooit verloren. Bedankt mannen!

Lieve familie, schoonfamilie, vrienden en dispuutsgenoten, fijn dat jullie er zijn en bedankt voor jullie interesse in mijn promotieonderzoek.

Jasper, broer(tje), we delen op verschillende gebieden een passie voor de gezondheidszorg en jij zorgt waar nodig altijd voor een steuntje in de rug. Ik ben trots op je en je mooie gezin met de meisjes Patricia, Daphne en Myrthe. 
Lieve mam en pa, graag draag ik dit boek aan jullie op, als dank voor alle mogelijkheden die jullie me hebben geboden en voor de onvoorwaardelijke liefde en steun.

En mijn grootste dank gaat uit naar mijn vrouw Sandy. Lieve schat, ik ben je heel dankbaar, niet alleen voor je hulp bij de totstandkoming van dit proefschrift, maar vooral voor je liefde, je geduld, je puurheid, je schoonheid, je lach... ik hou intens van je en heb zin in onze toekomst samen! 



\section{CURRICULUM VITAE AUCTORIS}

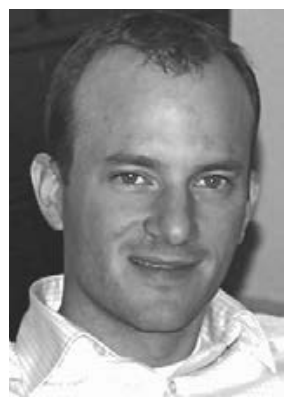

Bart Pieter Laurens Witteman was born on New Year's Eve, 1975 in Halsteren, Noord-Brabant, The Netherlands. At the age of twelve, he moved with his parents and brother to Borne, Overijssel where he in 1994 graduated from highschool (VWO, Twickel College, Hengelo). He studied medicine at the Maastricht University and after his final internship at The Prince of Wales Hospital, Sydney, Australia he obtained his medical degree in 2001. He acquired his first clinical experience as a resident in general surgery and intensive care at the Meander Medical Center, Amersfoort (supervision prof. dr. Th.J.M.V. van Vroonhoven). In July 2003 he started his surgical training at the Orbis Medical Center (supervision dr. A.G.M. Hoofwijk) and subsequently at the Maastricht University Medical Center (supervision prof. dr. J.W.M. Greve, prof. dr. C.H.C. Dejong and prof. dr. L.P.S. Stassen). In Maastricht he began his scientific career, focused on innovative minimally invasive techniques in upper gastrointestinal surgery (supervision dr. N.D. Bouvy and prof. dr. L.P.S. Stassen). His research was continued during the fellowship "Minimally Invasive Foregut Surgery" at the University of Pittsburgh Medical Center, Pittsburgh, Pennsylvania, United States (supervision B.A. Jobe M.D. and prof. J.D. Luketich M.D.) and has resulted in this thesis. After he obtained his title in general surgery in 2010, he started his training in gastrointestinal surgery at the Canisius Wilhelmina Hospital, Nijmegen (CHIVO-GIC, supervision dr. C. Rosman) and was certified in 2011. Currently he works as a gastrointestinal-oncological surgeon and fellow bariatric surgery (supervision drs. I.M.C. Janssen) at the Rijnstate Hospital, Arnhem. 